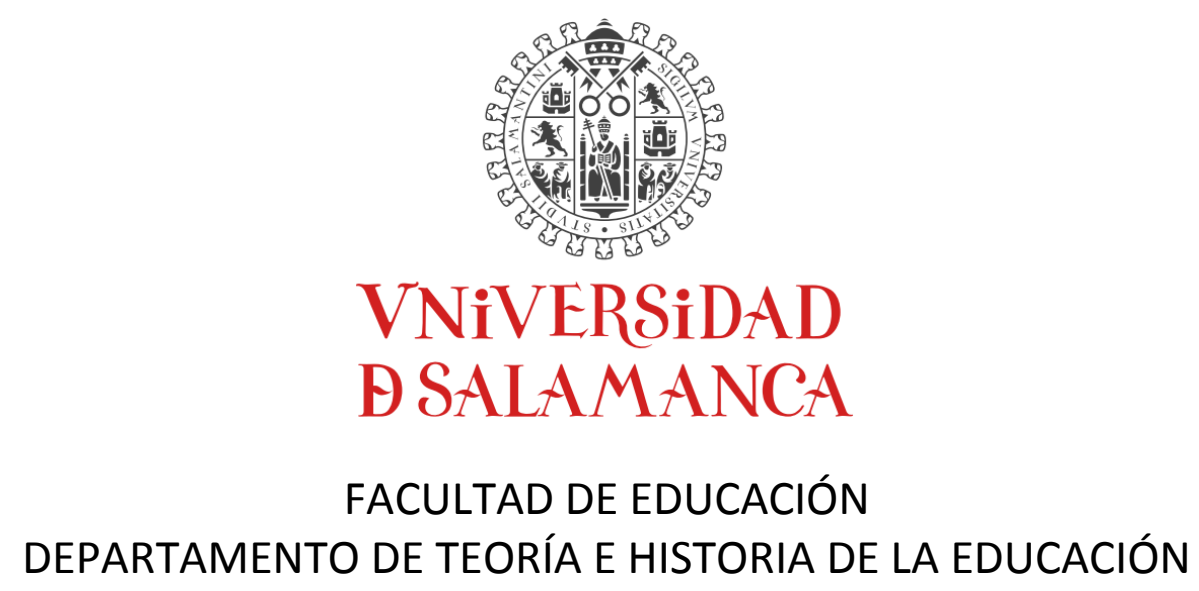

TESIS DOCTORAL

\title{
Modelos blended learning en Educación Superior: análisis crítico-pedagógico
}

Mario Vásquez Astudillo

\author{
DIRECTORES \\ Dr. Joaquín García Carrasco \\ Dr. Antonio Víctor Martín García
}





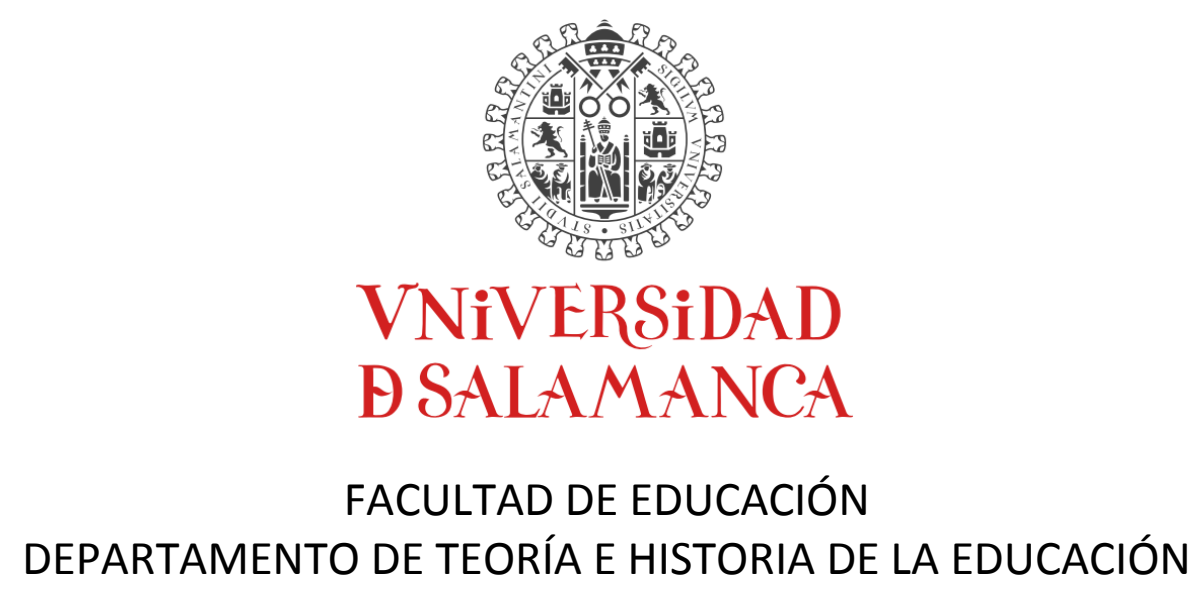

\title{
TESIS DOCTORAL
}

\section{Modelos blended learning en Educación Superior: análisis crítico-pedagógico}

\author{
DOCTORANDO \\ Mario Vásquez Astudillo \\ El director de la tesis \\ El director de la tesis \\ Dr. Joaquín García Carrasco \\ Dr. Antonio Víctor Martín García
}





\section{Agradecimientos}

Ciertos hitos en la vida nos dan la oportunidad de contemplar el camino recorrido y agradecer a tantos compañeros de ruta de diversas latitudes, que aportan a ensanchar nuestro territorio con la creación de nuevos mapas, nuevas visiones y nuevas experiencias.

Tal ha sido mi experiencia vital e intelectual durante el doctorado (la separación cartesiana es sólo para poner el énfasis en ambos componentes), que arriesgo ser injusto por no poder nombrar a todos en esta oportunidad.

A Vicente Vásquez, mi amado hijo, mi principal motor, a quien admiro por su vitalidad, compromiso social y deseos de aprender.

A Joaquín García Carrasco y María José Rodríguez Conde, sus oportunos consejos y la rememoración de sus enseñanzas, me proporcionaron luz en más de un momento.

A Antonio Víctor Martín García, por su generosidad y profesionalismo, en el instante preciso me dio el impulso necesario para la finalización de esta tesis.

A Rosanara Urbanetto, mi namorada y compañera de este hermoso periplo iniciado un frío día de invierno salmantino, mi gratitud por su confianza y apoyo.

A mis amigos y a mis compañeros del doctorado, venidos de diversos confines, con quienes compartimos tantos momentos y tantos diálogos abundantes en ideas y sueños.

A mis amigos de la Pastoral Universitaria de Salamanca, verdadero centro de hermandad, solidaridad, acogida e interculturalidad, espacio pletórico de vivencias.

A Miguel Ángel García, párroco de Salamanca, por tantas conversaciones y momentos llenos de amistad.

A Sergio Gahona, ex Vicerrector de INACAP La Serena, su apoyo me permitió soñar y realizar el doctorado.

A Eugenio Covarrubias, ex Vicerrector de INACAP La Serena, importante puntal en medio del camino para dar un avance significativo y poder concluir exitosamente este proyecto.

A Cristian Toro, Claudia Tello, Félix Alcayaga, profesores de INACAP, quienes desinteresadamente hicieron posible realizar mi investigación. Infinitos agradecimientos.

A mis amigos del Centro de Enseñanza Aprendizaje, INACAP La Serena, quienes me dieron la oportunidad de dialogar y creer en los sueños de los jóvenes que formamos. 



\section{ÍNDICE}

\section{CAPÍTULO 1}

INTRODUCCIÓN

\section{CAPÍTULO 2}

ENTORNO DE LA EDUCACIÓN SUPERIOR 21

2.1. Tecnologías y educación 23

2.1.1 Desarrollo de las tecnologías 23

2.1.2 Segundo entorno, el aula de clases $\quad 27$

2.1.3 Tercer entorno, espacios virtuales de aprendizaje 33

2.2 La educación superior desde la perspectiva internacional 36

2.2.1 Espacio Europeo de Educación Superior (EEES) 36

2.2.2 Proyecto Tunning para América Latina 38

2.2.3 Sistema de Créditos Transferibles de Chile 39

\section{CAPÍTULO 3}

CONCEPTO Y TIPOLOGÍA DE MODELOS BLENDED LEARNING

3.1. Uso del concepto blended learning 42

3.2 Modelos b-learning en educación superior 44

3.2.1 Modelos con énfasis en lo tecnológico 46

3.2.2 Modelos con énfasis en lo pedagógico 54

3.2.3 Perfil y rol del docente en la modalidad b-learning 69

3.2.4 Perfil y rol del estudiante en la modalidad b-learning 74

$\begin{array}{lll}3.3 & \text { Resultados acerca de la efectividad del b-learning } & 77\end{array}$

\section{CAPÍTULO 4}

LA TEORÍA DE LA ACTIVIDAD COMO FUNDAMENTO PEDAGÓGICO 87 DE LOS MODELOS BLENDED LEARNING

4.1. Evolución de la teoría de la actividad 91

4.1.1 La mediación cultural de Vigotsky 92

4.1.2 La estructura jerárquica de la actividad definida por Leontiev 96

4.1.3 Expansión del modelo de Vigotsky hacia el sistema de actividad 101

4.1.4 Interacción de los sistemas de actividad 106

$\begin{array}{ll}\text { 4.1.5 Los ciclos expansivos de la actividad } & 110\end{array}$

4.1.6. La actividad como base de la formación b-learning 113 


\section{CAPÍTULO 5}

METODOLOGÍA DE LA INVESTIGACIÓN

$\begin{array}{lll}5.1 & 117\end{array}$

$\begin{array}{lll}5.1 .1 & \text { Variables } & 118\end{array}$

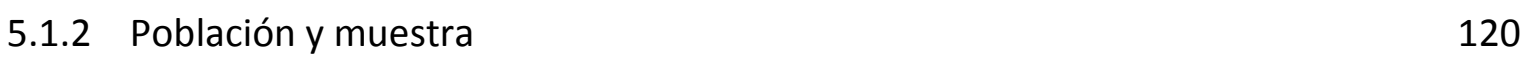

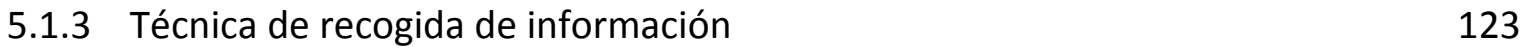

$\begin{array}{lll}\text { 5.1.4 Procedimiento de análisis } & 144\end{array}$

$\begin{array}{lll}5.2 & \text { Estudio cualitativo } & 146\end{array}$

$\begin{array}{ll}\text { 5.2.1 Apartados y categorías } & 146\end{array}$

5.2.2 Población y muestra 146

$\begin{array}{ll}\text { 5.2.3 Técnicas de recogida de información } & 147\end{array}$

5.2.4 Procedimiento de análisis 155

\section{CAPÍTULO 6}

PRESENTACIÓN DE LOS RESULTADOS, ANÁLISIS E INTERPRETACIÓN 157

$\begin{array}{lll}6.1 & \text { Estudio cuantitativo } & 158\end{array}$

6.1.1 Cuestionario 1 conocimientos y actitudes hacia las tecnologías 158

6.1.2 Cuestionario 2 conocimientos y satisfacción hacia las tecnologías 169

$\begin{array}{lll}6.2 & \text { Estudio cualitativo } & 184\end{array}$

6.2.1 Análisis documental 184

6.2.2 Entrevistas a profesores y grupos focales de estudiantes 199

\section{CAPÍTULO 7}

CONCLUSIONES

REFERENCIAS

\section{APÉNDICES}

Apéndice A. Validación de cuestionario $\quad 283$

$\begin{array}{ll}\text { Apéndice B. Cuestionario } 1 & 288\end{array}$

Apéndice C. Cuestionario $2 \quad 293$

Apéndice D. Protocolo de focus group de estudiantes $\quad 297$

Apéndice E. Protocolo de entrevista a profesores $\quad 299$

Apéndice F. Pauta para guiar el análisis documental 301

Apéndice G. Planificación sugerida de las e-actividades 302

$\begin{array}{ll}\text { Apéndice } H \text {. Tablas prueba t por campus } & 317\end{array}$ 


\section{Índice de Figuras}

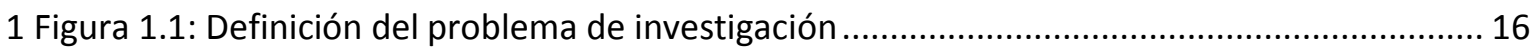

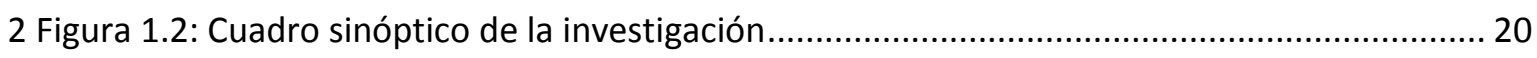

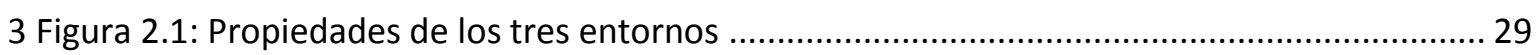

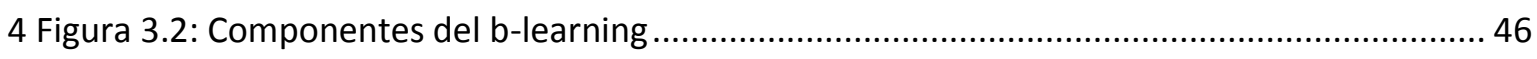

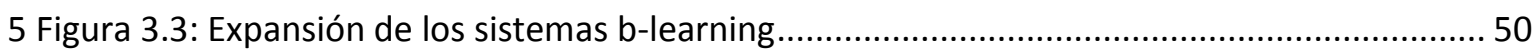

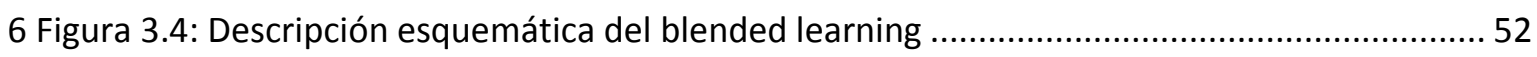

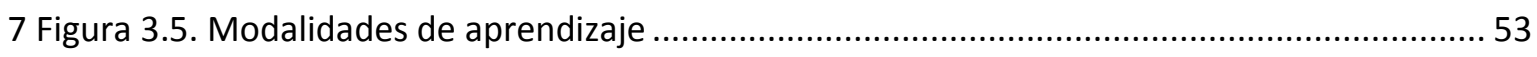

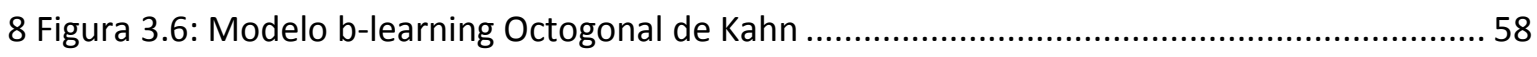

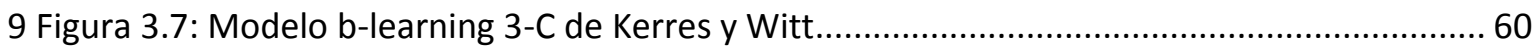

10 Figura 3.8: Dimensiones del modelo de comunicación educativa en b-learning.......................... 62

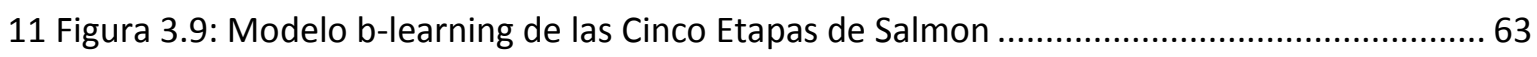

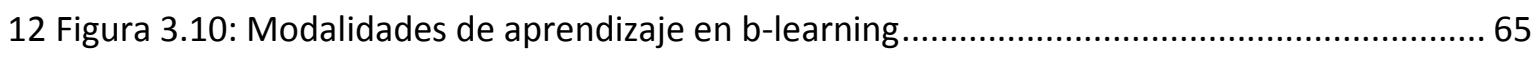

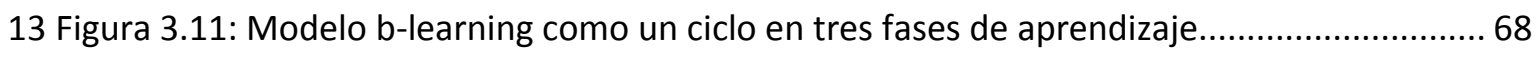

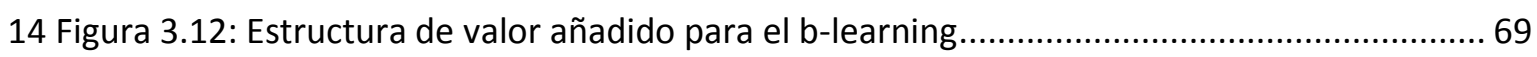

15 Figura 4.1 Modelo de mediación (A) y su reformulación (B) .................................................... 93

16 Figura 4.2: Modelo de la primera generación de la teoría de la actividad ................................. 95

17 Figura 4.3. Estructura jerárquica de la actividad según Leontiev ............................................ 98

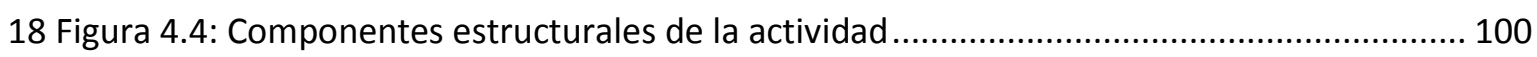

19 Figura 4.5. Modelo de la segunda generación de la teoría de la actividad............................... 102

20 Figura 4.7: Mediación en Modelo de la segunda generación de la teoría de la actividad......... 103

21 Figura 4.7: Modelo de la tercera generación de la teoría de la actividad..................................... 108

22 Figura 4.8: Aprendizaje expansivo en la tercera generación de la teoría de la actividad.......... 112

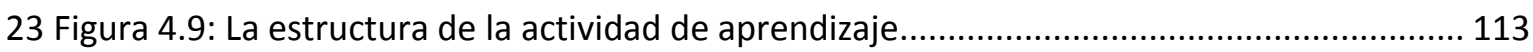

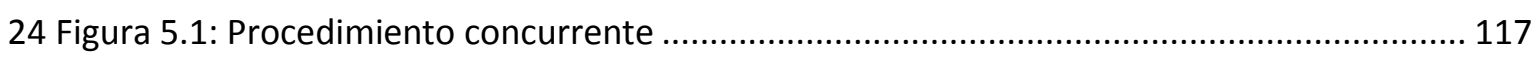

25 Tabla 5.1: Variables dependientes e independientes ............................................................. 119

26 Figura 5.2: Ubicación geográfica de los Campus de la UTC de Chile INACAP .......................... 120

27 Figura 5.3: Ubicación geográfica de los Campus seleccionados de la UTC de Chile INACAP.... 123 


\section{Índice de Tablas}

1 Tabla 3.1: Autores según los énfasis de enfoque del blended learning ....................................... 45

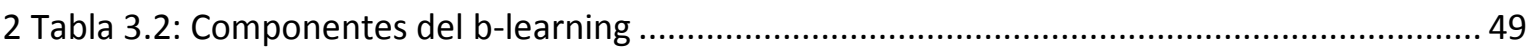

3 Tabla 3.3: Competencias requeridas al docente en los modelos b-learning ............................... 73

4 Tabla 3.4: Competencias requeridas al estudiante en los modelos b-learning ............................. 76

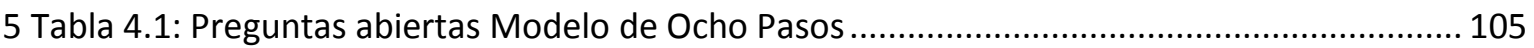

6 Tabla 5.2: Distribución de la población alumnos de primer año de la carrera de Ingeniería ..... 121

7 Tabla 5.3: Distribución de la muestra de alumnos de primer año de la carrera de Ingeniería en

Prevención de Riesgos, Calidad y Ambiente de la Universidad Tecnológica de Chile INACAP ...... 122

8 Tabla 5.4: Técnicas de recogida de información según las variables ......................................... 124

9 Tabla 5.5: Variables, dimensiones, indicadores e ítems en el Cuestionario CAEEST ................... 129

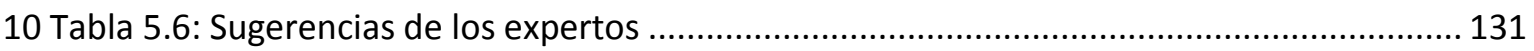

11 Tabla 5.7: Validación de la pertinencia y claridad de jueces expertos del Cuestionario 1 ........132

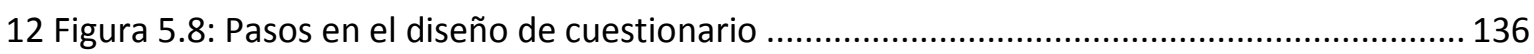

13 Tabla 5.9: Variables dependientes, dimensiones, indicadores e ítems en el cuestionario....... 138

14 Tabla 5.10: Variables independientes primarias, dimensiones, indicadores e .......................... 139

15 Tabla 5.11: Sugerencias de los expertos validadores........................................................... 140

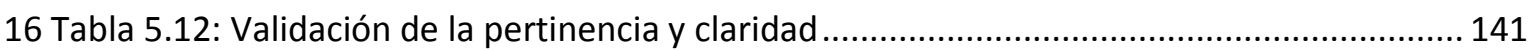

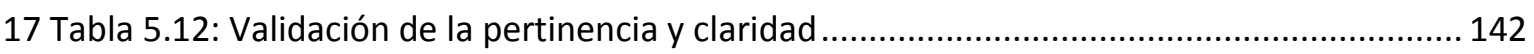

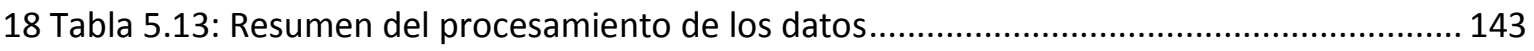

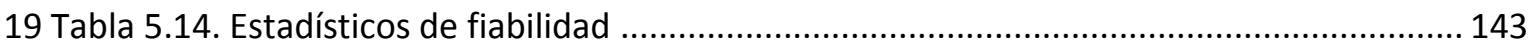

20 Tabla 5.16: Distribución de la muestra de alumnos y docentes de la carrera de Ingeniería en

Prevención de Riesgos, Calidad y Medio Ambiente .................................................................. 147

21 Tabla 5.17: Técnicas, procedimientos e instrumentos del estudio cualitativo .......................... 148

22 Tabla 5.18: Inventario de documentos existentes y disponibles ............................................. 150

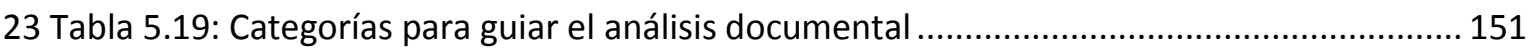

24 Tabla 5.20: Categorías para guiar los grupos focales de alumnos ......................................... 153

25 Tabla 5.21: Apartados y categorías para guiar las entrevistas semiestructuradas a docentes 154

26 Tabla 6.1: Distribución de la muestra global de alumnos por sexo y edad según en Campus . 158

27 Tabla 6.2: Distribución de la muestra global de alumnos por sexo y edad ............................... 159

28 Tabla 6.3: Disponibilidad de equipos y acceso a Internet ....................................................... 160

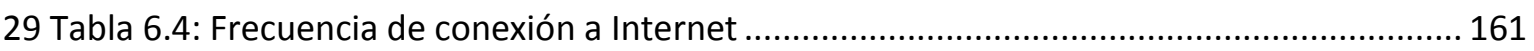

30 Tabla 6.5: Formación sobre cómo utilizar recursos de Internet para tareas académicas ......... 162

31 Tabla 6.6: Conocimiento y frecuencia de uso de recursos tecnológicos .................................... 165

32 Tabla 6.7: Actitudes hacia Internet al inicio y final de la asignatura ........................................... 167

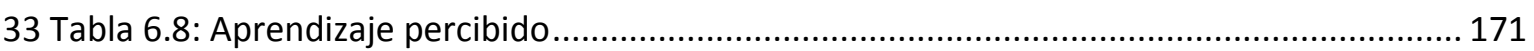

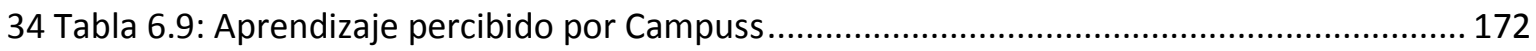

35 Tabla 6.10: Satisfacción hacia las tecnologías por modalidad: piloto y control........................ 173

36 Tabla 6.11: Satisfacción hacia las tecnologías por Campus................................................... 175 
37 Tabla 6.12: Variables altamente significativas según Prueba t 176

38 Tabla 6.13: Correlación entre competencias instrumentales y variables independientes ........ 179

39 Tabla 6.14: Correlación entre competencias tecnológicas y variables independientes ............ 180

40 Tabla 6.15: Correlación entre competencias interpersonales y variables independientes ....... 181

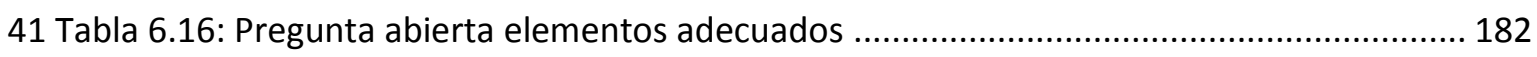

42 Tabla 6.17: Pregunta abierta elementos inadecuados en la formación a través de Internet... 183

43 Tabla 6.18: Unidades de aprendizaje y horas de la asignatura TCOE ..................................... 185

44 Tabla 6.19: Programación de las Evaluaciones Grupos Piloto TCOE ........................................... 188

45 Tabla 6.20: Programación de las Evaluaciones Grupos Control TCOE ..................................... 189

46 Tabla 6.21: Actividades en línea programadas y ejecutadas por Campus ................................ 190

47 Tabla 6.22: Producción de mensajes y conversaciones por Campus y cursos piloto.................. 192

48 Tabla 6.23: Participación en las actividades en línea ............................................................ 195 



\section{CAPÍTULO 1 INTRODUCCIÓN}

La presente investigación tiene como foco la realización de un análisis crítico-pedagógico de modelos blended learning implementados en educación superior, en un contexto que está cambiando para la educación superior, debido al advenimiento de la economía del conocimiento y el rápido y permanente desarrollo de las tecnologías de la comunicación. Entonces cabe la pregunta cómo consiguen las instituciones de educación superior comprender y utilizar los enfoques pedagógicos y curriculares más adecuados y relevantes, para no quedar ajenas a las tendencias de desarrollo social, cultural, tecnológico y económico del mundo. Estos requerimientos y demandas formativas que responden a la internacionalización y el cumplimiento de ciertos estándares metodológicos y del logro de competencias acreditables están dando visibilidad al diseño del aprendizaje que el profesorado realiza.

Con todo el amplio desarrollo tecnológico de las últimas décadas, que pretendió en algunos casos con mucho optimismo reemplazar al profesor, el aula ha resultado ser un sistema duradero para la comunicación. Es una piedra angular de la sociedad en la transmisión de la cultura y la preparación de las personas para su adecuado desempeño en la sociedad. La presencialidad tiene virtudes características difíciles de equiparar en un entorno tecnológico. En este sentido, las tecnologías de la información y comunicaciones (TIC) no amenazan la función de la universidad, lo que se discute es la necesidad de una nueva pedagogía, basada en la interactividad, la personalización y el desarrollo de la capacidad de aprender y pensar de manera autónoma. En este trabajo asumimos que las TIC se constituyen en una oportunidad, que pueden ser integradas desde lo presencia tendiendo hacia una modalidad blended learning, como recurso y medio que permite, por un lado, flexibilizar la oferta educativa atendiendo de ese modo a las diversas necesidades 
formativas de la población, y por otro, innovar y diversificar las metodologías de enseñanza-aprendizaje y modalidades de comunicación.

Ante esta irrupción de las nuevas tecnologías del conocimiento y la información (TIC) la educación es una de las disciplinas más beneficiadas. Sin embargo, las herramientas informáticas por sí solas no cambiarán automáticamente las metodologías de enseñanza, de ahí que se visualiza una potente combinación de la calidad de la tradicional cultura analógica presencial (personalizada e individualizada) con la potencia creativa y de valor selectivo y de filtrado (colectivo) de la nueva cultura digital virtual, en síntesis, blended learning, esto es una combinación de clases presenciales y actividades en línea a través de plataformas tecnológicas institucionales y/o de código abierto o aplicaciones Web 2.0 de uso personal y grupal por parte de docentes y alumnos. Las plataformas tecnológicas ayudan a la organización de actividades no presenciales complementarias al desarrollo de asignaturas o cursos presenciales. Se puede ofrecer información y seguimiento de forma restringida al grupo de alumnos, así como evaluar el trabajo realizado por estos (pruebas de autoevaluación, coevaluación, evaluación continua, seguimiento individualizado, acreditación de saberes).

En este sentido, una de las principales oportunidades de las nuevas herramientas y aplicaciones Web responde al principio de no requerir del usuario una alfabetización tecnológica avanzada. Estas herramientas estimulan la experimentación, reflexión y la generación de conocimientos individuales y colectivos, favoreciendo la conformación de un ciberespacio de intercreatividad que contribuye a crear un entorno de aprendizaje colaborativo. El desafío está en que los profesores aprovechen esta oportunidad para crear un entorno de aprendizaje apoyado en la Web 2.0 y orientado a la generación de experiencias de aprendizaje, a la reflexión y el análisis, así como a la cooperación entre los estudiantes, en las que el profesor adopta el papel de orientador del alumno, y transforma a éste último en el verdadero protagonista del aprendizaje.

Si bien reconocemos el potencial de las nuevas tecnologías, las primeras experiencias de aprendizaje, con uso de las nuevas aplicaciones Web, en cursos e-learning han tenido un alto número de alumnos que abandonan los estudios. La incapacidad de éstos para llevar a la práctica lo aprendido, se debe en gran parte a que los esfuerzos se han centrado en 
plasmar en la pantalla los contenidos que antes estaban en los libros o en las aulas. Así se ha ganado en libertad y rapidez de acceso, en flexibilidad de horarios y lugares de acceso, en actualización de contenidos, pero se ha generado un sistema de aprendizaje pasivo que no respeta las premisas básicas del aprendizaje, y que desaprovecha muchas de las virtudes del sistema tradicional. El blended learning es coherente con los valores tradicionales de las instituciones de educación superior y ha demostrado el potencial para mejorar tanto la eficacia y la eficiencia de las experiencias significativas de aprendizaje

Tanto el e-learning como el b-learning son modelos de aprendizaje en los que el estudiante tiene que desarrollar habilidades tan importantes para su vida futura en esta sociedad como, que implican el dominio de estas mismas tecnologías que pueden estar al servicio del proceso de enseñanza aprendizaje, tales como la capacidad de buscar y encontrar información relevante en la red; desarrollar criterios para valorar esa información, poseer indicadores de calidad; aplicar información a la elaboración de nueva información y a situaciones reales; trabajar en equipo compartiendo y elaborando información; tomar decisiones sobre la base a informaciones contrastadas; tomar decisiones en grupo.

En esta tesis doctoral damos cuenta, a través de la revisión crítico-pedagógica de modelos blended learning y el estudio de un caso, cómo se han ido integrando paulatinamente los ámbitos presenciales y en línea en modelos con énfasis ya sea en lo tecnológico o en lo pedagógico para el logro de competencias acorde marcos formativos de referencia nacionales e internacionales para las instituciones de educación superior. Esquemáticamente, el problema de investigación que abordamos se presenta en la Figura 1.1.

En la investigación constataremos si las tecnologías por sí solas producen los cambios, o si se requieren nuevos métodos pedagógicos que integren y potencien lo mejor del sistema presencial y el sistema virtual en modalidades blended learning o combinada. Por otro lado, estudiaremos como los diseños blended learning están provocando un cambio en los roles del profesor y del alumno. Surgen nuevas tareas tales como la de organizar los contenidos acorde a las posibilidades que brinda el soporte tecnológico o espacio virtual, el que demanda varias tareas, entre otras: una gestión diaria del flujo de información, la elaboración de nuevos materiales adaptados a las TIC, la realización de tutorías virtuales, 
la revisión y evaluación de trabajos, la gestión de grupos de trabajo, el acompañamiento y asesoramiento individual y colectivo.

1 Figura 1.1: Definición del problema de investigación

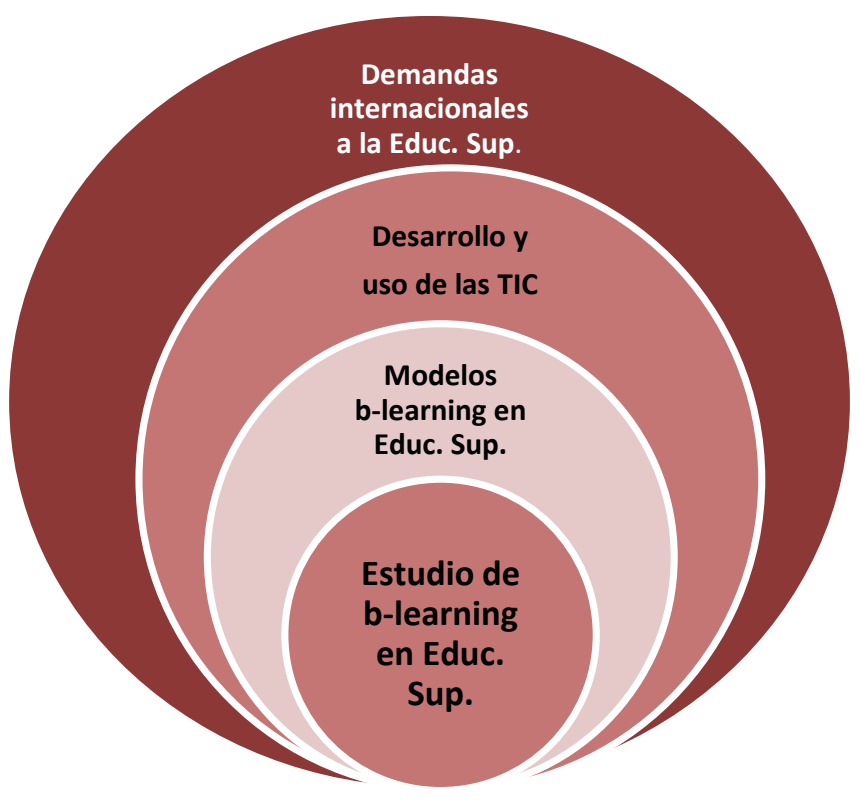

Fuente: elaboración propia

A fin de acotar el ámbito de la investigación de los modelos blended learning, nos plantemos las siguientes preguntas de investigación:

- ¿Es la modalidad blended learning más efectiva que la modalidades presencial en el desarrollo de competencias instrumentales, tecnológicas e interpersonales en educación superior?

- ¿El diseño pedagógico de la modalidad blended learning orientado a la interacción y desarrollo de actividades virtuales favorece el aprendizaje percibido de competencias instrumentales, tecnológicas e interpersonales?

- ¿Los profesores y estudiantes valoran las tecnologías asociadas a la modalidad blended learning como herramientas eficientes para el logro de competencias instrumentales, tecnológicas e interpersonales de los estudiantes?

Atendiendo a la búsqueda de respuesta a estas preguntas de investigación es que nos hemos planteado los siguientes objetivos de investigación, uno general que orienta la 
investigación y definimos varios específicos que dirigen la definición de variables con sus respectivos indicadores así como las estrategias de recopilación y procesamiento de la información para su posterior análisis.

\section{Objetivo general}

Evaluar la efectividad de un modelo blended learning aplicado en educación superior en el logro de aprendizajes percibidos y la satisfacción hacia las tecnologías como herramientas de aprendizaje en educación superior.

\section{Objetivos específicos}

- Revisar y analizar críticamente los modelos blended learning aplicados en educación superior con el fin de contribuir a una mayor justificación pedagógica de uso de los mismos.

- Determinar si existen diferencias de aprendizaje percibido en competencias instrumentales, tecnológicas e interpersonales, entre distintos grupos estudiantes de educación superior que cursan una asignatura en la modalidad blended learning y en la modalidad presencial tradicional.

- Establecer si existe relación entre el diseño pedagógico con el nivel de satisfacción en el uso de tecnologías como herramientas de aprendizaje en educación superior de estudiantes cursan una asignatura en la modalidad blended learning y en la modalidad presencial tradicional.

Para dar cuenta del logro de los objetivos planteados, el informe de esta tesis de doctorado lo hemos estructurado en siete capítulos, siendo el primero de ellos esta introducción y cuyo cuadro sinóptico de las fases de la investigación se exponen en la Figura 1.2. 
El segundo capítulo abordamos el entorno de la educación superior desde una doble perspectiva. Por un lado la del contexto de los avances tecnológicos que genera posibilidades a la educación, tanto a la potenciación del aula de clases presencial como a la conformación de los nuevos entornos o espacios virtuales de aprendizaje. En segundo término, revisamos el contexto internacional y nacional de la Educación Superior para lo cual se aborda los retos y oportunidades que ha supuesto el Espacio Europeo de Educación Superior (EEES) y el Proyecto Tunning para el caso de América Latina, así como, a nivel específico de Chile los avances y compromisos que está provocando el Sistema de Créditos Transferibles.

En el tercer capítulo nos ocuparemos del conjunto de elementos que caracterizan los modelos blended learning aplicados en Educación Superior. Corresponde iniciar ese capítulo con la distinción de los variados uso del concepto blended learning dando cuenta con ello de lo multifacético del fenómeno en estudio. Además, sistematizaremos y contrastaremos modelos blended learning con énfasis en lo tecnológico y modelos cuyo énfasis se encuentra en lo pedagógico. Una parte importante está dedicada a caracterizar los roles que les cabe al profesor y a los estudiantes en estos modelos blended learnig. Cerramos el capítulo con la revisión de un conjunto significativo de investigaciones respecto a los resultados acerca de la efectividad del blended learning.

Por su parte, el cuarto capítulo lo dedicamos a la teoría de la actividad como marco conceptual en el que podemos situar los elementos sociales y tecnológicos de un modelo blended learning, en una misma unidad de análisis, llamada actividad. Revisaremos la evolución de la teoría de la actividad desde sus orígenes con los aportes de la noción de mediación cultural de Vigotsky y la posterior propuesta de la estructura jerárquica de la actividad aportada por Leontiev, la que Engeström denomina como la segunda generación de la teoría de la actividad. En la tercera generación de la teoría de la actividad, Engeström desarrolla las herramientas conceptuales para entender el diálogo, la multiplicidad de perspectivas y las redes de interacción de los sistemas de actividad. El objetivo del modelo de Engeström es trascender el carácter individual de la actividad, hacia un carácter colectivo, que represente de una mejor manera los elementos sociales e históricoculturales que están presentes en toda actividad humana. En nuestra investigación lo relevante es que la teoría de la actividad se muestra como un referente teórico adecuado 
cuando se plantean situaciones que involucran a grupos de personas que realizan actividades mediadas o facilitadas por un soporte tecnológico, como lo es un proceso de enseñanza-aprendizaje usando la modalidad blended learning.

Una vez definido el marco de referencia teórico en los capítulos anteriores, en el quinto capítulo nos ocupamos de los aspectos metodológicos del diseño de la investigación, el que considera la complejidad y singularidad de los fenómenos sociales y educativos. La naturaleza del objeto educativo de investigación nos impone un enfoque que considere varias dimensiones, una complementariedad entre paradigmas que combinan datos, métodos y técnicas de investigación, sin seguir una sola tendencia metodológica. En síntesis, describimos y fundamentamos el diseño metodológico mixto y transversal abordando los criterios para determinar las variables, población y muestra, las técnicas e instrumentos de recogida de información cualitativa y cuantitativa, válida y confiable, con sus correspondientes procedimientos de análisis.

Los resultados, el análisis e interpretación de cada estudio, cualitativo y cuantitativo se exponen por separado en el sexto capítulo. El estudio cuantitativo aborda los resultados de los dos cuestionarios que forman parte de la investigación. El primero de ellos acerca de los conocimientos y actitudes hacia las tecnologías y el segundo, referido a los conocimientos y satisfacción hacia las tecnologías. En el análisis utilizamos técnicas estadísticas descriptivas e inferenciales, adaptadas a la naturaleza de las variables incluidas en los cuestionarios. Por su parte el estudio cualitativo se basa en el análisis documental y las entrevistas a profesores y grupos focales de estudiantes para lo cual se aplican los procesos de procesamiento y reducción de datos.

Finalmente, el capítulo siete lo dedicamos a las conclusiones en las que se integran el estudio cuantitativo y cualitativo. El estudio cuantitativo nos aporta una descripción estadística del caso de estudio y las inferencias, generalizaciones posibles a partir de una muestra de cierta amplitud. En cambio, el estudio cualitativo, aporta a profundizar, explicar los resultados cuantitativos. Además en la ejecución del estudio cualitativo se van obteniendo resultados parciales que tributan a una mejor compresión del objeto de estudios, así como a la realización de ajustes a algunas de las variables y los instrumentos del estudio cuantitativo. 


\section{Figura 1.2: Cuadro sinóptico de la investigación}

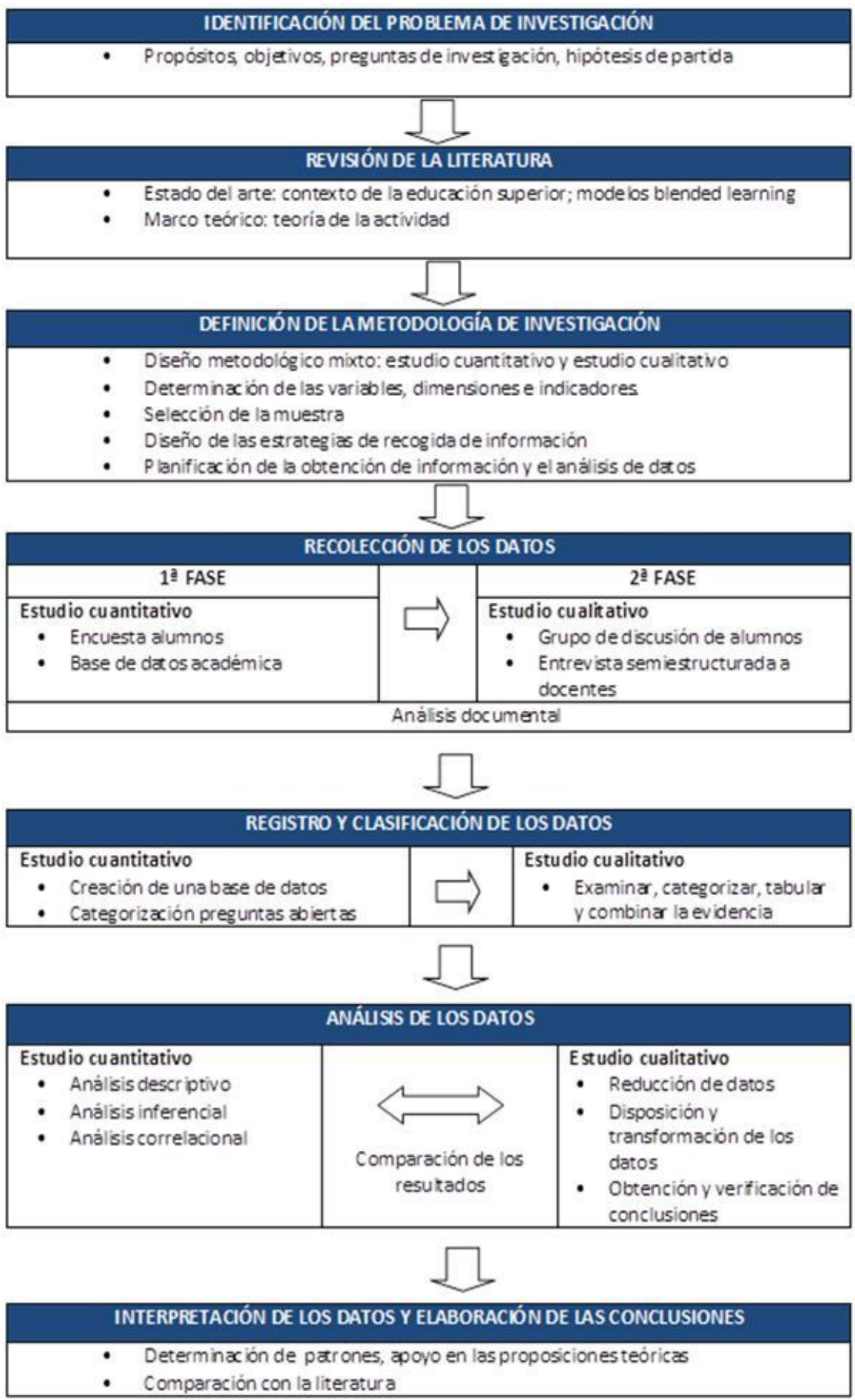

Fuente: elaboración propia 


\section{CAPÍTULO 2 \\ ENTORNO DE LA EDUCACIÓN SUPERIOR}

2.1. Tecnologías y educación

2.1.1 Desarrollo de las tecnologías

2.1.2 Segundo entorno, el aula de clases

2.1.3 Tercer entorno, espacios virtuales de aprendizaje

2.1 La educación superior desde la perspectiva internacional

2.2.1 Espacio Europeo de Educación Superior (EEES)

2.2.2 Proyecto Tunning para América Latina

2.2.3 Sistema de Créditos Transferibles de Chile 


\section{CAPÍTULO 2}

\section{ENTORNO DE LA EDUCACIÓN SUPERIOR}

El contexto en el que se desenvuelve la educación superior está experimentando cambios permanentes que representan oportunidades y desafíos en cuanto a las estrategias para cumplir su rol formativo, de investigación y extensión. Algunos de los elementos que conforman el actual y cambiante contexto están dados por: la economía del conocimiento; el nuevo perfil del estudiante que demanda formación desde diversas latitudes, modos de acceso diversos y con rasgos etarios nuevos; el rápido y permanente desarrollo de las tecnologías de la comunicación y el interés de las empresas en la universidad. Este entorno de globalización e internacionalización en que está inserta la universidad ha ido configurando nuevas oportunidades para la educación superior en Europa y América Latina.

En este capítulo veremos dos elementos centrales del entorno de la educación superior. Por un lado como han impactado históricamente las tecnologías en el campo educativo, hasta el estado actual en el que las nuevas tecnologías han generado un escenario nuevo; y por otro lado, revisaremos cómo se están organizando internacionalmente las instituciones de educación, y particularmente en Chile, para establecer estándares asociados al curriculum en cuanto a las titulaciones y las metodologías, destacando el rol que cumplen las tecnologías de la información y las comunicaciones para el logro de estos propósitos. 


\subsection{Tecnologías y educación}

\subsubsection{Desarrollo de las tecnologías}

El antiguo matemático hindú Pingala presentó la primera descripción que se conoce de un sistema de numeración binario en el siglo tercero antes de nuestra era, lo cual coincidió con su descubrimiento del concepto del número cero. Una serie completa de 8 trigramas y 64 hexagramas, análogos a 3 bit y números binarios de 6 bit, eran conocidos en la antigua China en el texto clásico del I Ching. En 1605 Francis Bacon ideó un sistema por el cual las letras del alfabeto podrían reducirse a secuencias de dígitos binarios, la cuales podrían ser codificados como variaciones apenas visibles en la fuente de cualquier texto arbitrario. El sistema binario moderno fue documentado en su totalidad por Leibniz, en el siglo dieciocho, en su artículo "Explication de l'Arithmétique Binaire". En él se mencionan los símbolos binarios usados por matemáticos chinos. Leibniz usó el 0 y el 1 , al igual que el sistema de numeración binario actual. En 1854, el matemático británico George Boole, publicó un artículo que marcó un antes y un después, detallando un sistema de lógica que terminaría denominándose Álgebra de Boole. Dicho sistema jugaría un papel fundamental en el desarrollo del sistema binario actual, particularmente en el desarrollo de circuitos electrónicos. Es así como durante más de dos mil años se ha venido creando el sistema binario que es la base de la electrónica y las tecnologías de la información y las comunicaciones. Desde esta perspectiva histórica, las actuales tecnologías informáticas les deben un tributo a estos matemáticos.

Al revisar la incorporación de tecnologías asociadas a las comunicaciones en los procesos de enseñanza y aprendizaje desde inicios del siglo pasado, encontramos que varias tecnologías han generado grandes promesas y a la vez grades decepciones en el campo educativo. En 1922 la Universidad Estatal de Pennsylvania transmite cursos a través de la radio. Ese mismo año, Thomas Edison predijo que las películas, primera tecnología moderna para el aprendizaje, reemplazarían a los textos de estudio y quizás a los profesores en las aulas de clases. Durante la segunda guerra mundial se creó la necesidad de despliegue masivo de filmes para el entrenamiento de millones de personas de servicios alrededor del mundo en diversos temas, desde higiene personal hasta mantenimiento de armas. Este éxito devino en filmes instructivos más creativos y cubrieron temas más 
apropiados para los niños en las escuelas. Un floreciente comercio de películas educativas proporcionó material fílmico acerca de cualquier tema imaginable (Rosenberg, 2001).

Pero fue la televisión la que logró emocionar a los educadores. Ya el año 1934 la Universidad Estatal de lowa comienza cursos televisados de asignaturas como higiene bucal e identificación de constelaciones de estrellas. La televisión podía traer cualquier forma de aprendizaje a la sala de clases. La cinta de vídeo podía capturar la mejor instrucción para el uso continuo, así la televisión podía asegurar acceso al aprendizaje hasta las más remotas áreas geográficas. Nuevamente se vio la posibilidad de reemplazar al profesor. A pesar de algunos éxitos extraordinarios, la televisión educativa no proporcionó una utopía de aprendizaje. Primero que todo, la tecnología fue más fácil de justificar que la programación. Muchas instituciones de educación superior y universidades invirtieron millones de dólares en equipamiento, sólo para darse cuenta que no tenían dinero para programas o personal para crearlos. Segundo, la mayoría de los programas carecieron de alguna forma diseño instructivo y los profesores no sabían cómo integrar el aprendizaje en el salón de clases. Pero la principal razón por la cual la televisión no llegó a ser el profesor fue porque faltaba la mayor cualidad de la enseñanza: la capacidad para interactuar con el aprendiz, proporcionar retroalimentación y alterar la presentación para suplir la necesidad del estudiante. La televisión fue un proveedor información de una sola vía, realmente no fue educación.

Esta necesidad de interacción renovó el esfuerzo en el área de entrenamiento basada en computadores (Computer Based Training, CBT). Si bien en 1946, con la introducción de los primeros mainframes como ENIAC y UNIVAC (computadoras grandes, poderosas y costosas utilizada principalmente en empresas que necesitan procesar gran cantidad de datos o soportan gran cantidad de usuarios), nacen los primeros programas educacionales basados en computadoras, con el propósito de entrenar al personal a ingresar datos en ellas, es sólo hasta en los años setenta y ochenta se les dedicó tremenda cantidad de esfuerzo a este campo. Los primeros resultados fueron marginales. El advenimiento del computador personal se convirtió en un punto crucial. Al desplegar más computadores personales en las casas y en las oficinas, los desarrolladores de CBT empezaron a visualizar una base común de hardware para correr los programas. Pero esta señal esperanzadora tuvo corta vida, pues las diferencias en hardware, software (Tabla 2.1), lenguajes de programación y 
otras barreras técnicas hicieron la disponibilidad universal más un deseo que una realidad. Los programas tuvieron que ser desarrollados en diferentes formatos lo que configuró una propuesta costosa. $\mathrm{Y}$ justo cuando un programa salió al mercado, los cambios en la plataforma tecnológica lo hicieron obsoleto. En 1969 se funda Internet y en 1976 se abre la Universidad de Phoenix, la primera Universidad en Estados Unidos en ofrecer cursos online.

Las empresas de tecnologías de aprendizaje llegaron a los años noventa con cuatro condiciones en contra. Primero, los cambios tecnológicos hicieron casi imposible servir a todas las plataformas en uso. Segundo, las limitaciones de hardware y software volvieron los programas aburridos y faltos de autenticidad. Tercero, la creciente inestabilidad del contenido tanto como los costos de desarrollo y el tiempo, hicieron a la gente temerosa de gastar para construir y desplegar un sistema efectivo. Cuarto, las limitaciones y problemas asociados con la tecnología de computadores, tanto como la falta de conciencia de unos enfoques de diseño instruccional actualizado, disminuyeron la contribución del más avanzado procedimiento de aprendizaje.

Según señala Israelite (citado por Rosenberg, 2001) las tecnologías de aprendizaje se han movido por repetidos ciclos de fracasos. Una tecnología se desarrolla y aplica para resolver problemas educativos. Esto hace que surjan expectativas que no pueden satisfacerse. Muchos de los programas de aprendizaje son de pobre diseño y efectividad. Se establece que el uso de la tecnología ha sido inadecuado e improductivo. En un periodo relativamente corto, la frustración y la desilusión se manifiestan con el abandono de la tecnología. La gente retorna a lo que ya sabe: a técnicas tradicionales de enseñanza ya probadas. Es decir, hasta que llega la próxima gran tecnología y el ciclo se repite. ¿Ha cambiado Internet esto? ¿Romperá el ciclo? Israelite dice que podría, pero solamente si somos cuidadosos de cómo vemos y usamos la Web.

La incorporación de la tecnología en los usos cotidianos del hombre es una tendencia que en las últimas décadas ha ido in crescendo. Prácticamente toda innovación en materia de tecnología de la información y comunicación ha sido adaptada a usos educativos. Desde el dictado de cursos por radio, hasta la actualidad en que la proliferación de dispositivos 
móviles hace que podamos aprender en la palma de nuestras manos (Prendes, Gutiérrez, Martínez, 2010).

1 Tabla 2.1: Razones del fracaso del entrenamiento CBT

\begin{tabular}{|c|c|c|}
\hline & Razones & Descripción \\
\hline 1 & El contenido no era bueno. & Desactualizado, dirigido a audiencias múltiples \\
\hline 2 & $\begin{array}{l}\text { El aprendizaje no era } \\
\text { auténtico }\end{array}$ & La información no está asociada al mundo real \\
\hline 3 & $\begin{array}{l}\text { La forma prima sobre la } \\
\text { sustancia }\end{array}$ & $\begin{array}{l}\text { Se abusa en el uso de las nuevos artefactos ignorando los } \\
\text { principios de diseño instruccional y la información }\end{array}$ \\
\hline 4 & $\begin{array}{l}\text { Diferentes ritmos de } \\
\text { aprendizaje }\end{array}$ & $\begin{array}{l}\text { Aprendices con distintas bases de conocimiento. El diseño } \\
\text { de opciones múltiples eleva los costos }\end{array}$ \\
\hline 5 & $\begin{array}{l}\text { La tecnología fue una } \\
\text { barrera }\end{array}$ & $\begin{array}{l}\text { Rápidos cambios de la tecnología: plataformas, sistemas } \\
\text { operativos, formatos de almacenamiento }\end{array}$ \\
\hline 6 & $\begin{array}{l}\text { Fue inútil después del uso } \\
\text { inicial }\end{array}$ & $\begin{array}{l}\text { Luego de un pasado un tiempo del primer uso, es muy } \\
\text { difícil encontrar una información específica el programa } \\
\text { CBT }\end{array}$ \\
\hline 7 & $\begin{array}{l}\text { El aprendizaje no fue } \\
\text { reforzado }\end{array}$ & No era un substituto del salón de clases \\
\hline 8 & No había apoyo para él & $\begin{array}{l}\text { Tenían una posición secundaria respecto a las actividades } \\
\text { presenciales de la sala de clases }\end{array}$ \\
\hline 9 & Aburridos & $\begin{array}{l}\text { El material no era muy interesante o el diseño de la página } \\
\text { no era estimulante }\end{array}$ \\
\hline 10 & Falta de cambio de enfoque & $\begin{array}{l}\text { Usar el enfoque de la vieja tecnología en el uso de la nueva. } \\
\text { Enfocarse en cómo rediseñar el episodio de aprendizaje en } \\
\text { sí mismo }\end{array}$ \\
\hline
\end{tabular}

Fuente: Elaboración propia basada Rosenberg, 2001

Este crescendo tuvo un vertiginoso ascenso en la década del 90 y de entrada al nuevo milenio. El e-learning generó un boom en este período; hasta el punto que se creyó que el aprendizaje electrónico desplazaría al tradicional. Pasado el auge, la tendencia fue menguando, combinando elementos tecnológicos con tradicionales. Hoy en día, ante la reciente proliferación de herramientas Web 2.0, la educación mediada por tecnologías recibe nuevos aportes, y renueva sus métodos. Por otro lado, la multiplicación de sistemas de administración/gestión de aprendizaje (LMS) de código abierto, en cierta forma democratizan las herramientas, poniéndolas disponibles a una mayor cantidad de usuarios. Vale aclarar, que si bien hubo momentos de auge de diferentes tecnologías ninguna terminó por desplazar a otras, sino que actualmente se integran entre ellas, y se aplican según las necesidades educativas de cada proyecto. Así, el e-learning 1.0 convive con el elearning 2.0. Los usuarios integran encuentros presenciales, con herramientas móviles, 
foros en línea, etc. Existe todavía en algunos sectores de la educación una decepción respecto de la tan anunciada revolución de la educación superior gracias a las TIC (OCDE en Roco, 2005).

Es interesante destacar el rol que ha tenido la universidad en el desarrollo tecnológico, ya que todos los avances tecnológicos clave que derivaron en la creación de Internet son fruto del trabajo de instituciones gubernamentales, grandes universidades y centros de investigación. Internet no se originó en el mundo empresarial (Castells, 2001).

\subsubsection{Segundo entorno, el aula de clases}

Para caracterizar el primer, segundo y tercer entorno nos basamos en los aportes de Echeverría (2004). El primer entorno corresponde al medio natural que rodea al ser humano y a su propio cuerpo con los sentidos que pueden dar cuenta de ese medio (olfato, vista, oído). El segundo entorno es cultural y social el que puede ser denominado entorno urbano, construido. El entorno es aquello que está alrededor de nuestro cuerpo, de nuestra vista, o, en general de las diversas implementaciones que se hayan creado para expandir nuestro espacio inmediato. En este sentido, las TIC posibilitan la construcción de un tercer entorno estructuralmente distinto al primer y segundo entornos.

El tercer entorno es un nuevo espacio social en fase de construcción el que depende de una serie de innovaciones tecnológicas, que conforme surjan nuevos avances tecnológicos, las propiedades del tercer entorno se irán modificando, por ser un espacio básicamente artificial. Este tercer entorno sólo ha sido posible tras numerosos avances técnicos y científicos, es un resultado de la tecnología (Echeverría, 2004). La descripción de los tres entornos que identifica Echeverría, la agrupa en una veintena de propiedades o variables. Cada una de ellas tiene grados entre las categorías de una propiedad y otra (Figura 2.1).

Las aulas forman parte del segundo entorno y han existido probablemente durante al menos 4.000 años. El aula ha resultado ser un sistema sorprendentemente duradero para la comunicación, ya fuera en las escuelas o en las iglesias. Los lugares destinados a la instrucción adoptan formas diversas, pero para la mayoría de las personas en todos los países, un aula es una habitación rectangular con mesas rectangulares y una pizarra 
rectangular (Tiffin, 1997). Esa forma para la facilitación del aprendizaje se ha extendido por todo el mundo. Podemos llamarla aula convencional constituyendo un sistema de comunicación para la instrucción que ha perdurado con el tiempo y ha tenido un gran éxito en la educación superior, desde el principio de la existencia de las instituciones universitarias (Bartolomé, 2002).

Si bien las nuevas tecnologías han creado un nuevo entorno el que la educación formal presencial sólo ha visitado y usado marginalmente, sin la masividad y los éxitos que se le han asignado a las herramientas tecnológicas. ¿A qué se debe este éxito del aula del segundo entorno? El aula funciona como un sistema de comunicación. El aula físicamente se encuentra aislada de estímulos externos para permitir la concentración de los aprendices en las tareas de aprendizaje que diseña el docente. La pizarra es un importante foco de la atención y un medio para presentar la información a través de palabras, números, imágenes, diagramas de varios tipos. Cuando un profesor desarrolla un problema o un ejercicio en la pizarra, está guiando el aprendizaje de los alumnos, la preguntas que hace un alumno sirve para la reflexión de los demás y las respuestas del profesor sirven a todos los alumnos (Diez, 1989). Las relaciones que se producen entre los aprendices y el profesor, entre los aprendices, entre estos y el objeto de conocimiento configuran una trama rica que construye el conocimiento la que difícilmente puede ser reproducida por un texto de estudio u otros medios sin la presencia del profesor. El aula genera una economía de escala que procede de la interacción del grupo con apoyo de la pizarra. 
3 Figura 2.1: Propiedades de los tres entornos

\begin{tabular}{|c|c|}
\hline PRIMER Y SEGUNDO ENTORNO & TERCER ENTORNO \\
\hline Proximal & Distal \\
\hline Recintual & Reticular \\
\hline Presencial & Representacional \\
\hline Sincrónico & Multicrónico \\
\hline Registro análogo & Registro digital rastreable \\
\hline Material & Informacional \\
\hline Natural & Artificial \\
\hline Extensión & Compresión \\
\hline Movilidad física & Fluencia electrónica \\
\hline Circulación lenta & Circulación rápida \\
\hline Asentamiento en la tierra & Asentamiento en el aire \\
\hline Estabilidad & Inestabilidad \\
\hline Localidad & Globalidad \\
\hline Pentasensorialidad & Bisensorial \\
\hline Memoria natural interna & Memoria natural externa \\
\hline Analógico & Digital \\
\hline Diversificación semiótica & Integración semiótica \\
\hline Homogeneidad & Heterogeneidad \\
\hline Nacionalidad & Transnacionalidad \\
\hline Autosuficiencia & Interdependencia \\
\hline Producción & Consumo \\
\hline \begin{tabular}{l|l|l|l|l|l}
$\leftarrow$ & & & & & \\
\end{tabular} & \begin{tabular}{|l|l|l|l|l|l|l|l} 
& & & & & & & \\
\end{tabular} \\
\hline REUNIÓN & INTERCONEXIÓN \\
\hline $\begin{array}{c}\text { Sala de clases } \\
\text { Presencial }\end{array}$ & $\begin{array}{c}\text { Web 2.0, } \\
\text { Espacio virtual de aprendizaje (EVA) }\end{array}$ \\
\hline $\begin{array}{ll}- & \text { Contenidos } \\
- & \text { Habilidades } \\
- & \text { Actitudes, valores }\end{array}$ & $\begin{array}{ll}- & \text { Nuevos contenidos } \\
- & \text { Nuevas actividades } \\
-\quad & \text { Nuevas formas de interacción y } \\
& \text { colaboración }\end{array}$ \\
\hline - Inmigrantes digitales & Nativos digitales \\
\hline
\end{tabular}

Fuente: elaboración propia basada en Echevería (2004); Prensky (2001); Sáez Vacas, en Fumero (2007)

El referente más cercano a las nuevas tecnologías y en contraste con el aula presencial es la educación a distancia, la que, como examina Bartolomé (2002) presenta varios indicadores de éxito, homologables al modelo presencial, el que ha sido más ampliamente utilizado:

- Aprueban más alumnos que en la enseñanza a distancia: se han analizado varios factores. El grupo es el primero a señalar. Fundamentalmente ese grupo "vital" que anima, que proporciona un estímulo para trabajar (a veces en términos afectivos), que proporciona razones para seguir, que en ocasiones acoge al individuo y lo hace continuar en épocas bajas hasta que consigue recuperarse, pero también el grupo 
grande, el sentimiento de pertenencia a un grupo. Se han dado explicaciones basadas en el carácter gregario del ser humano y explicaciones más prácticas.

- El ritmo proporcionado por la asistencia a clases es otro factor a destacar. La exigencia de una actividad periódica favorece cualquier modalidad de enseñanza (presencial, a distancia, virtual).

- El profesor es un elemento clave, refiriéndonos aquí a una persona física y real con quien el alumno establece una relación no mediada (referido a los medios).

Como vemos, la figura del profesor, el sistema de comunicación e interacción para generar sentido de pertenencia, ritmo de trabajo y un andamiaje de apoyo siguen teniendo su valor intrínseco que no ha sido socavado por las tecnologías. En el caso de la educación superior un docente domina un área del conocimiento y posee las estrategias, criterios y procedimientos propios de la disciplina para actualizarlos conforme se generen nuevos conocimientos, se reformulen teorías, se den a conocer resultados de nuevas investigaciones. Este dinamismo de la relación con el conocimiento el profesor la puede transmitir a los estudiantes en el aula presencial, puede diseñar y guiar actividades para que los alumnos adquieran el nuevo conocimiento. El alumno puede desarrollar las actividades de forma individual o grupal, con apoyo o sin apoyo de la tecnología, con instancias de retroalimentación del profesor en reuniones o tutorías individuales o grupales. En este proceso el estudiante está aprendiendo acerca de la disciplina particular y cómo se actualiza un profesional de la misma.

Las nuevas tecnologías han producido una inflexión reciente que no amenazan la figura y rol del profesor ni la instancia presencial, cara a cara, sino que se está revitalizando, como constataremos en el tercer capítulo de esta investigación a partir de los resultados de un considerable número de estudios de uso de tecnologías en la educación superior en la última década. Veremos cómo facilitan el acceso a la información y la interacción con el profesor, con los demás estudiantes y con los recursos en los espacios virtuales. El aula sigue siendo una piedra angular de la sociedad en la transmisión de la cultura y la preparación de las personas para su adecuado desempeño. Hemos crecido con el salón de clases, no hay nadie que, en momento u otro, no haya deseado estar a solas con el maestro, para atraer toda su atención, para aprender lo máximo. En los espacios virtuales usamos la metáfora de aula virtual, otra "aula" que se puede integrar con el aula presencial, por tanto 
con la tecnología podemos dar continuidad al aula presencial. Varios investigadores (Cubides y Martín García, 2014; George-Palilonis, 2009; Ling, 2010; Morán, 2012; Poon, 2013; Turpo y Hernández, 2014), están comprobando el valor de la presencialidad ya como una instancia superior de encuentro, como plenaria y a su vez, los espacios virtuales un lugar y tiempo de interacción, de colaboración y preparación para el encuentro cara a cara con el profesor y los demás estudiantes.

Es así como el sistema tradicional del aula presencial, la del segundo entorno, da la posibilidad al alumno para discutir y compartir con otros sus experiencias en grupo. En la relación alumno-realidad las personas conforman el contexto de aplicación. Esta relación, en la que se basa un entorno de aprendizaje realmente efectivo, dista mucho de la asociación alumno-pantalla con la que se identifican la mayoría de las primeras soluciones e-learning, las que han adolecido de la interacción entre los participantes y del apoyo presencial, ya que falta el contacto con la figura de un tutor cercano que guíe al alumno, que supervise su progreso, que motive para el aprendizaje, que no se limite a resolver sus dudas e incidencias técnicas, sino que le enseñe a aprender y que favorezca el compromiso, se aleja bastante de la figura del "tutor virtual" cuya labor queda, en muchas ocasiones, reducida a la resolución de incidencias. Hasta ahora nos hemos formado esencialmente en modalidades presenciales, pero hoy en día, "los seres humanos somos seres analógicos atrapados en un mundo digital" (Sáez, 2004: 183).

Desde que aparecieron las primeras universidades europeas en los siglos XI y XII, los principios básicos de la universidad han cambiado bien poco mientras que las nuevas tecnologías han aparecido y desaparecido, la forma y función de la universidad persisten (Pittinsky, 2006). Las nuevas tecnologías no amenazan la función de la universidad, lo que se discute es la necesidad de una nueva pedagogía, basada en la interactividad, la personalización y el desarrollo de la capacidad de aprender y pensar de manera autónoma (Castells, 2001). Un ejemplo de la contradicción aparente entre lo virtual y lo presencial tradicional es la Universidad de Salamanca, la que su sitio Web hace un lustro declara que va a integrarse en la era digital, con el objetivo de ocupar un lugar destacado en la Sociedad de la Información y del Conocimiento. Prosigue indicando que este objetivo es estratégico para una "universidad de claro carácter presencial, lo cual no significa renunciar ni un ápice a esta condición, sino abrirse a los modelos formativos, de investigación y gestión que las 
tecnologías informáticas y de las comunicaciones están posibilitando" (USAL, 2009). La Universidad de Salamanca reafirma el claro carácter presencial (segundo entorno) y a su vez se abre a los modelos que posibilitan las tecnologías informáticas y de las comunicaciones (tercer entorno), visión estratégica planteada desde los directivos.

En estos primeros acercamientos sistemáticos de las universidades en la incorporación de los espacios virtuales de aprendizaje, García-Valcárcel (2007) ha constatado que la valoración dada a las tecnologías por los docentes es desde el paradigma tradicional de la clase presencial. La valoración positiva de la formación presencial y el contacto directo entre profesores y alumnos, según Pérez Lorido $(2007,2010)$ llega hasta el punto de vincular tácitamente la identidad característica del docente a la presencialidad. Más que la presencialidad en sí misma, se está valorando la posibilidad de comunicación e interacción con el profesor, la cual las actuales tecnologías de la información y las comunicaciones la están haciendo posible, sin igualar al encuentro cara a cara, pero se pueden enriquecer y potenciar mutuamente el segundo y tercer entornos, combinando lo mejor de ambos mundos o ambientes y ninguno de los puntos débiles (George-Palilonis, 2009; Ling, 2010; Morán, 2012; Poon, 2013).

En aquellas universidades que vienen usando tecnologías desde hace una década constatan que la figura del profesor se fortalece, en nuevos roles con nuevas competencias ya que los estudiantes plantean nuevas necesidades propias de las nuevas herramientas y estrategias metodológicas. Dahlstrom, Walker, Dziuban y Morgan (2013) en el estudio longitudinal aplicado desde el año 2004, en cuya edición del año 2013 participaron sobre 250 instituciones de educación superior de catorce países, representativas de una población estudiantil sobre 1.600 .000 estudiantes, entre los principales hallazgos destaca que los estudiantes reconocen el valor de la tecnología, pero todavía necesitan orientación en lo que respecta a un mejor uso para fines académicos, y en esta perspectiva, señalan que prefieren ambientes de aprendizaje b-learning. 


\subsubsection{Tercer entorno, espacios virtuales de aprendizaje}

En los últimas tres décadas hemos sufrido una aceleración tecnológica que se manifiesta en la aparición constante en el mercado de nuevos equipos cada vez más potentes. Las conversaciones sobre la comunicación digital y las ciberculturas parecen seguir el mismo patrón: todavía no se había terminado de definir al "hipertexto" cuando ya se pasó a "hipermedia", y apenas se estaban descubriendo los secretos del "multimedia" cuando llegó la "convergencia", y también las "interfaces", "tecnología push", "on-demand", etc. Ahora llegó el turno de la "Web 2.0" y la "Web 3.0". Podría decirse que existe una ley semántica que presiona a los enunciadores a abandonar los viejos conceptos y reemplazarlos por otros más frescos (Cobo, 2007), generando una obsolescencia tecnológica planificada.

Las demandas que vive la educación superior se enmarca en un nuevo espacio social: el espacio electrónico o telemático denominado por Echeverría (2004) "tercer entorno". Existen otros conceptos para denominar esta idea de tercer entorno tales como aldea global, tercera ola, ciberespacio, espacio virtual, sociedad de la información, sociedad del conocimiento, frontera electrónica, realidad virtual, mente interconectada. Conforman este tercer entorno las nuevas tecnologías de la información y las comunicaciones (TIC) tales como el teléfono, la televisión, las tarjetas de crédito, las redes telemáticas como Internet, las tecnologías multimedia, los soportes de archivos digitales y electrónicos, o las enciclopedias multimedia, los videojuegos y la realidad virtual.

Semana a semana nos estamos acostumbrando a recibir noticias de los avances tecnológicos asociados a las TIC, en cambio en educación superior recién estamos estudiando cómo están siendo utilizadas y el impacto que tienen en aquellas experiencias, todavía marginales en cuanto al número, respecto a formación presencial sin uso o apoyo de tecnologías. Además las investigaciones sobre los métodos de enseñanza y aprendizaje en la universidad son relativamente recientes en comparación con este mismo tipo de estudios en otros niveles educativos (Gros, 2007; 2011). Sin embargo, actualmente "las principales actividades económicas, sociales, políticas y culturales de todo el planeta se están estructurando por medio de Internet. De hecho, quedar al margen de dichas redes 
es la forma de exclusión más grave que se puede sufrir en nuestra economía y en nuestra cultura" (Castells, 2001: 17).

La interrelación con el mundo exterior, la distancia que podemos cubrir con nuestros propios órganos sensoriales es limitada respecto a lo que podemos lograr con las TIC. Desde las señales de humo, el uso de los tambores para transmitir señales a grandes distancias, todavía visibles y audibles, hasta el uso del telégrafo y el teléfono, el espacio se amplió. Con Internet se han modificado la visión y vivencia del espacio y tiempo de los dos primeros entornos. El acceso a la información a través de Internet sigue creciendo. Es así como documentos culturales únicos de bibliotecas y archivos del mundo entero, tales como manuscritos, mapas, libros raros, películas, grabaciones sonoras, publicaciones y fotografías se pueden consultar con acceso ilimitado y gratuito en el sitio Web de la Biblioteca Digital Mundial creado por la UNESCO y treinta y dos instituciones asociadas.

El sitio Web ha sido concebido y preparado por un equipo de la Biblioteca del Congreso de Estados Unidos. La Bibliotheca Alexandrina de Egipto ha prestado su asistencia técnica a la realización del proyecto. También han contribuido con sus conocimientos especializados y han aportado contenidos al sitio Web las bibliotecas nacionales y algunas instituciones culturales y educativas de Arabia Saudita, Brasil, Egipto, China, Eslovaquia, Estados Unidos, la Federación de Rusia, Francia, Iraq, Israel, Japón, Malí, Marruecos, México, los Países Bajos, Qatar, el Reino Unido, Serbia, Sudáfrica, Suecia y Uganda.

El nuevo entorno digital nos permite conocer, en esta Biblioteca Digital Mundial, algunos tesoros culturales tales como: estelas y huesos para oráculos aportados por la Biblioteca Nacional de China; manuscritos científicos arábigos procedentes de la Biblioteca y Archivos Nacionales de Egipto; fotografías antiguas de América Latina conservadas en la Biblioteca Nacional de Brasil; el Hyakumanto darani, una publicación del año 764 custodiada en la Biblioteca Nacional de la Dieta de Japón; la famosa Biblia del Diablo del siglo XIII, perteneciente a los fondos de la Biblioteca Nacional de Suecia; y obras caligráficas en árabe, persa y turco de las colecciones conservadas en la Biblioteca del Congreso de los Estados Unidos (BDM, 2009).

Este es uno de los miles de ejemplos que podemos encontrar en Internet de cómo nuestro segundo entorno se ve ampliado y permite el trabajo conjunto de tantas instituciones y en 
un corto tiempo desde que en junio de 2005 James H. Billington, bibliotecario del Congreso de los Estados Unidos, propuso el establecimiento de una Biblioteca Digital Mundial a la UNESCO, hasta abril de 2009 en que la Biblioteca Digital Mundial se lanza a un público internacional. Hasta hace unos pocos años atrás la única posibilidad de acceder a ciertos manuscritos era trasladándose al lugar físico, segundo entorno, donde estaba conservado.

Otros ejemplos notables son la disposición gratuita de cursos y programas de pregrado ofertados por las universidades. En primer caso a destacar es el nacimiento de la primera universidad gratuita el año 2009, la University of the People. Actualmente ha matriculado a más de 1.600 estudiantes de 141 países. La edad de los alumnos va desde los 18 a los 72 años, con un promedio de 32 años. Este año 2014 obtuvo la acreditación del Distance and Education Training Council, de EE.UU. El segundo caso a destacar son los MOOC, acrónimo en inglés de Massive Open Online Course y traducido al español como Cursos en Línea Masivos y Abiertos. Es una modalidad de educación abierta, la cual se observa en cientos de cursos de pregrado ofrecidos gratuitamente a través de plataformas educativas en Internet; cuya filosofía es la liberación del conocimiento para que este llegue a un público más amplio, con la participación de miles de alumnos. El término MOOC fue acuñado en el año 2008 por Dave Cormier cuando el número de inscritos a su curso Connectivism and Connective Knowledge aumentó a casi dos mil trescientos estudiantes (Ruiz, 2013).

El poder de las TIC reside, no en el "poderío asombroso de sus circuitos, si no en el espacio virtual de nuevas posibilidades humanas que crea. La innovación tecnológica consiste en inventar y construir las realidades que la tecnología hace posibles" (Sáez, 2004: 53). La proliferación de información y tecnología en la educación superior induce una ciertos cambios radicales de una enseñanza local y frontal, centrada en el profesor, hacia otra en línea y centrada en el estudiante (Martínez, 2012). El tercer entorno está cambiando la sala de clase la que no será más el sistema de suministro de información por defecto. Las sinergias entre el e-learning y las clases presenciales serán cada vez más refinadas, se encontrarán nuevos usos para el aula, cada uno contribuirá con su valor esencial, habrá menos enseñanza y más facilitación. Se tenderá a asociar el aprendizaje en el aula con las aplicaciones y los equipos de trabajo, y el e-learning con el contenido y las herramientas, la utilización de materiales existentes. Ya estamos asistiendo al uso de la sala de sala de clases como una extensión de la comunidad de aprendizaje en línea y viceversa. Sin 
embargo, nos advierte Cabero (2012:2), “estamos haciendo en las aulas virtuales, acciones muy similares a lo que hacíamos en las aulas presenciales". Se está cambiando la tecnología, sin cambiar la pedagogía.

\subsection{La educación superior desde la perspectiva internacional}

Las universidades junto a los gobiernos de un gran número de países han ido formalizado acuerdos internacionales y programas de trabajo para avanzar en la integración de los sistemas de educación superior, los que se han generado a partir de los requerimientos formativos que demanda la nueva economía sustentada en los cambios tecnológicos de las redes telemáticas que influyen en nuestra forma de comunicarnos, de trabajar, de producir, de aprender y enseñar. Cabe destacar los acuerdos internacionales tales como el Espacio Europeo de Educación Superior; el Espacio Común de Canadá, Estados Unidos y México; el Espacio Iberoamericano de Educación Superior; el Espacio Común de Asia Pacífico (Australia, Nueva Zelanda, India, Singapur, China). Además, varios organismos internacionales ofrecen anualmente sus estudios y recomendaciones para la educación superior, en los que convocan a especialistas de los cinco continentes.

\subsubsection{Espacio Europeo de Educación Superior (EEES)}

Las universidades presenciales tradicionales europeas se encuentran en un momento cambio y de singular trascendencia debido a la puesta en marcha del Espacio Europeo de Educación Superior (EEES). El desarrollo tecnológico y las nuevas formas de comunicación obligan a la institución universitaria a replantearse la práctica educativa (De Pablos, 2012; García-Valcárcel, 2007; Martínez, 2013). En la situación actual, caracterizada por los crecientes esfuerzos institucionales dedicados a consolidar los objetivos propuestos siendo una de las principales preocupaciones de los gestores responsables de las universidades en ubicar el papel que las tecnologías de la información y de la comunicación (TIC) y el blearning van a tener dentro de este nuevo escenario que define el EEES (Bosco, 2008; Pérez Lorido, 2007). 
El avance tecnológico y la construcción del EEES generan las necesidades de adaptación a las nuevas exigencias de trabajo didáctico, de estrategias propiciadas por el propio sistema ECTS (European Transfer Credits System). Es decir, estamos ante un cambio de paradigma educativo, pasándose de centrar la atención en la enseñanza (profesor) a centrarse, ahora, en el aprendizaje (alumno), el cambio estructural de los ciclos, grados y créditos y los relacionados con los objetivos de aprendizaje, ahora referidos y definidos en términos de competencias, son algunas de las razones que obligan a un nuevo planteamiento metodológico (De Pablos, 2012; Ruiz, 2008).

La carga de trabajo necesaria del estudiante para la consecución de los objetivos de un programa está constituida por el tiempo que asiste a clases y el tiempo de trabajo personal y/o grupal fuera del aula el cual debe estar programado y tener un seguimiento mediante tutorías por parte de los profesores. Este escenario es propicio para el uso de la modalidad b-learning o aprendizaje combinado o modalidad mixta en la que desde la clase presencial se incorporan herramientas o recursos virtuales o telemáticos para que el alumno interactúe con otros alumnos, con el objeto de aprendizaje y con sus profesores pudiendo queda, como señala Echeverría (2004) una cualidad propia del tercer entorno, evidencia y registro automático de todas las acciones realizadas. La combinación de la formación tradicional, segundo entorno, y el e-learning (formación online) usando todas las modalidades de uso de las tecnologías, configuran, en palabras de Cubides y Martín García (2014) un ecosistema b-learning.

Las universidades han reaccionado rápidamente a este nuevo entorno tecnológico o ecosistema b-learning propiciado por el rápido avance de Internet a través de la implementación de campus virtuales y diversos individuales que conjuntamente apuestan por la incorporación de las TIC a la docencia como uno de los elementos clave para mejorar el proceso de enseñanza-aprendizaje (Tejada, 2007). En este sentido, la docencia virtual se ha convertido en una herramienta habitual en las universidades tradicionalmente presenciales, sobre la base de las nuevas metodologías de aprendizaje para los estudiantes y las nuevas técnicas pedagógicas que requiere el nuevo EEES (Bosco, 2008; De Pablos, 2012; Mondéjar et al, 2007). Es por ello que las nuevas tecnologías de la información desempeñan un rol básico en este proceso. Sin su utilización no podría realizarse la renovación de las metodologías pedagógicas. 
Algunos autores usan la expresión "brick and click university" para hacer referencia al sistema de enseñanza semipresencial con apoyo de las TIC, como por ejemplo, Ardizzone y Rivoltella (2005), la universidad tradicional está pensada a partir del ladrillo (brick): con ello se hace referencia al fuerte apego al lugar físico (el aula, despacho del profesor, las salas de estudio, los laboratorios) y, desde el punto de vista de la enseñanza, a un modelo del saber encomendado en gran medida a la clase presencial con ayuda de la pizarra (chalk and talk, tiza y charla). La nueva universidad, sin desligarse del ladrillo, se ve potenciada por los nuevos servicios que ofrecen las TIC (brick and click university) (Ruipérez, 2006).

\subsubsection{Proyecto Tunning para América Latina}

A su vez, en América Latina se está desarrollando el Proyecto Tunning, cuya estructura organizativa del proyecto tiene una cobertura 190 Universidades, provenientes de 19 países América Latina. Se han creado 18 Centros Nacionales Tuning y un Comité de Gestión. Además han levantado un diagnóstico general de la educación superior en América Latina de las áreas previstas en el proyecto en cuanto a: competencias genéricas y específicas; duración de las titulaciones; sistema de créditos; tipo de créditos; métodos de enseñanza y aprendizaje.

Si bien el marco político para la aplicación del Tuning América Latina no tiene el mismo nivel de involucramiento de los diferentes países como sí lo es en el caso europeo, sí de la perspectiva académica a partir de las redes continentales e intercontinentales, queda explicitada la necesidad de consensuar un perfil de competencias en un sistema de equivalencia para lo cual se propondrán una variedad de enfoques y variadas modalidades acceso a diferentes contextos de aprendizaje por parte de los estudiantes. En este contexto, sin duda la modalidad b-learning es una alternativa pertinente para el desarrollo de las competencias y particularmente la referida al logro de habilidades en el uso de las tecnologías de la información y de la comunicación.

En relación a los enfoques de enseñanza, aprendizaje y evaluación proyectan realizar una traducción de las competencias tanto genéricas como específicas en actividades dentro del proceso de enseñanza, aprendizaje y evaluación. Para ello se propone preparar una serie de materiales que permitan visualizar cuales serán los métodos de enseñanza, aprendizaje 
y evaluación más eficaces para el logro de los resultados del aprendizaje y las competencias identificadas. Cada estudiante debe experimentar una variedad de enfoques y tener acceso a diferentes contextos de aprendizaje, cualquiera que sea su área de estudio.

\subsubsection{Sistema de Créditos Transferibles de Chile}

La iniciativa de generar un Sistema de Créditos Transferibles (STC) nace en abril de 2003, en virtud del acuerdo suscrito por los Rectores de las universidades del Consejo Rectores de las Universidades Chilenas (CRUCH) (organismo que agrupa a las veinticinco universidades públicas tradicionales del país), con la finalidad de impulsar la adopción de un sistema de créditos compatible de las Universidades Chilenas entre sí y con el sistema ECTS y delimitar los requerimientos curriculares reales que se hacen a los estudiantes de acuerdo a la real disponibilidad de tiempo de éstos (STC-CHILE, 2013).

El año 2006 el CRUCH tomó la decisión de establecer un sistema único de créditos académicos para todos sus miembros, que busca fundamentalmente mejorar la calidad de la educación superior. Este sistema está basado en tres componentes. En primer término, el sistema se debe basar en la carga de trabajo total de los estudiantes, esto significa que se debe considerar el tiempo dedicado a cada una de las actividades curriculares que debe realizar el estudiante para el logro de los objetivos de aprendizaje de cada asignatura, clases teóricas o de cátedra, actividades prácticas, de laboratorio o taller, actividades clínicas o de terreno, prácticas profesionales o de carrera, ayudantías de cátedra, tareas solicitadas, estudio personal, entre otras. El segundo componente dice relación con los tiempos que el estudiante dedica a su carrera: se ha convenido que a la carga de trabajo anual total, correspondiente al rango 1.440 -1.900 horas, se le asocian 60 créditos SCT. A partir de este supuesto, un crédito representa entre 24 y 31 horas de trabajo real de un estudiante (STC-CHILE, 2013).

Un grupo de 18 universidades chilenas están utilizando como parte de la construcción de un itinerario para incorporar a las TIC en el mejoramiento de la Formación Inicial de Docentes (FID). Han planteado el desarrollo de propuestas de innovación que permitan el rediseño curricular y/o formativo para una efectiva integración curricular de estas tecnologías, han explicitado el interés por desarrollar competencias en docentes y 
estudiantes para el uso adecuado de Entornos Virtuales de Aprendizaje (EVA), lo cual resulta un aspecto importante considerando el progresivo aumento de este tipo de espacios, ya sea como complemento a la docencia presencial o como modalidad alternativa de formación. Su eje de atención abarca el desarrollo de habilidades para desenvolverse en estos ambientes y para mediar procesos formativos, en modalidad e-learning o blearning, a fin facilitar la gestión de conocimiento por parte de los estudiantes, utilizando herramientas y ambientes sustentados en TIC, mediante procesos formativos centrados en la colaboración entre pares.

Concluimos en este capítulo que las diversas tecnologías usadas integradas como apoyo en educación, no poseen en sí mismas cualidades educativas o pedagógicas. Por sí solas no propician la interacción con el aprendiz, aunque con el advenimiento de Internet y el despliegue constante de tecnologías web 2.0 y web 3.0, se ha facilitado la interacción con los materiales de estudio, con los demás estudiantes y con el profesor, los que ha generado una positiva inflexión en el devenir del uso de tecnologías en educación, lo que facilita la renovación metodológica de las prácticas educativas.

Junto a la renovación metodológica, las nuevas tecnologías han conformado un nuevo contexto para la educación superior que facilita la interconexión, el intercambio por lo cual, las universidades se han ido organizado a nivel internacional para establecer sistemas de créditos transferibles, facilitando la movilidad de los estudiantes entre universidades de diferentes países. En el capítulo siguiente estudiamos en vínculo entre la tecnología y la pedagogía en la modalidad blended learning, los roles de los profesores y estudiantes. Además, exponemos los resultados de algunos estudios acerca de la efectividad del blearning. 


\section{CAPÍTULO 3 \\ CONCEPTO Y TIPOLOGÍA DE MODELOS BLENDED LEARNING}

3.1. Uso del concepto blended learning

3.2 Modelos b-learning en educación superior

3.2.1 Modelos con énfasis en lo tecnológico

3.2.2 Modelos con énfasis en lo pedagógico

3.2.3 Perfil y rol del docente en la modalidad $b$-learning

3.2.4 Perfil y rol del estudiante en la modalidad $b$-learning

3.3 Resultados acerca de la efectividad del $b$-learning 


\section{CAPÍTULO 3 \\ CONCEPTO Y TIPOLOGÍA DE MODELOS BLENDED LEARNING}

\subsection{Uso del concepto blended learning}

La literatura en distintas latitudes ofrece una serie de usos y acepciones de blended learning con énfasis en diferentes focos y aglutina muchas iniciativas formativas, como la combinación de los tradicionales métodos de enseñanza presencial cara a cara y la enseñanza en línea o a distancia (Bartolomé, 2008; Monteiro, Leite y Lima, 2013; Picciano y Dziuban, 2007). Otras acepciones resaltan las actividades de aprendizaje que implican una combinación sistemática de interacciones cara a cara e interacciones tecnológicamente mediadas entre estudiantes, profesores y recursos de aprendizaje (Bersin, 2004; Bliuc, 2007; Graham, 2006; Jones, 2007); optimizando los recursos tanto del aula como de los entornos virtuales (Cubides, Martín García, 2014; la confluencia de la mediación pedagógica y tecnológica, con actividades de aprendizaje que le dan continuidad a la presencialidad a través de lo virtual (Turpo y Hernández, 2014); o el simple uso de espacios virtuales para que los alumnos realicen actividades individuales y/o grupales como apoyo a la clase presencial, desde la cual se administran todas ellas (Barberà, 2008; Duart, 2008; Osorio y Duart, 2012). La mezcla de diferentes enfoques de aprendizaje no es una idea nueva, por ejemplo, conferencias, seminarios, tutorías, estudios de casos, juegos de rol, grupos de aprendizaje (constituyen procedimientos y técnicas heterogéneas, las cuales se emplearon simultáneamente, en un mismo escenario educativo). La diferencia del blended learning con aquella situación estriba en que, en este caso, se simultanea la clase presencial con aplicaciones variables de tecnología digital, incluso tan complejas como las "plataformas digitales de aprendizaje".

En síntesis, concordando con Mart (2012) y Picciano, Dziuban, y Graham (2014), si bien no existe una clara definición concordada para blended learning, sin embargo en todos los 
casos de uso, el hilo conductor, tal como ya lo señalaba Vaughan (2010), es la combinación o integración de la modalidad de educación presencial y no presencial sustentada en las Tecnologías de la Información y Comunicaciones (TIC) cuyos denominadores comunes son la clase o interacción presencial y el apoyo en línea mediante el uso de diversas tecnologías (Figura 3.1). Los objetivos y los aspectos pedagógicos en la integración de ambos componente marcan la diferencia entre una u otra concepción, lo que refleja lo multiforme que es la modalidad blended learning según el uso que le den los usuarios, profesores y estudiantes. Si bien con el tiempo el término ha ido logrando cada vez mayor notoriedad, sin embargo según Morán (2012) falta una representación precisa de la particularidad de esta modalidad de enseñanza que integra y articula los mejores elementos de lo presencial y en línea.

La expresión blended learning, abreviada como b-learning, diversos autores la usan simultánea e indistintamente, en un mismo reporte de sus investigaciones, con distintos vocablos de manera sinónima para referirse a la experiencia b-learning en español, y llegado a este punto el diccionario pierde utilidad ante tal variedad de denominaciones esta forma de aprendizaje, tales como bimodal, combinado, flexible, híbrido, integrado, mezclado, mixto hasta semipresencial, entre otras, hace referencia al uso de recursos tecnológicos tanto presenciales como no presenciales en orden a optimizar el resultado de la formación (Bartolomé, 2002, 2004, 2008; Bartolomé y Aiello, 2006; Graham, 2006; Macdonald, 2008), mediante la combinación de lo mejor de ambos mundos o ambientes y ninguno de los puntos débiles (George-Palilonis, 2009; Ling, 2010; Morán, 2012; Poon, 2013).

4 Figura 3.1: Componentes del blended learning

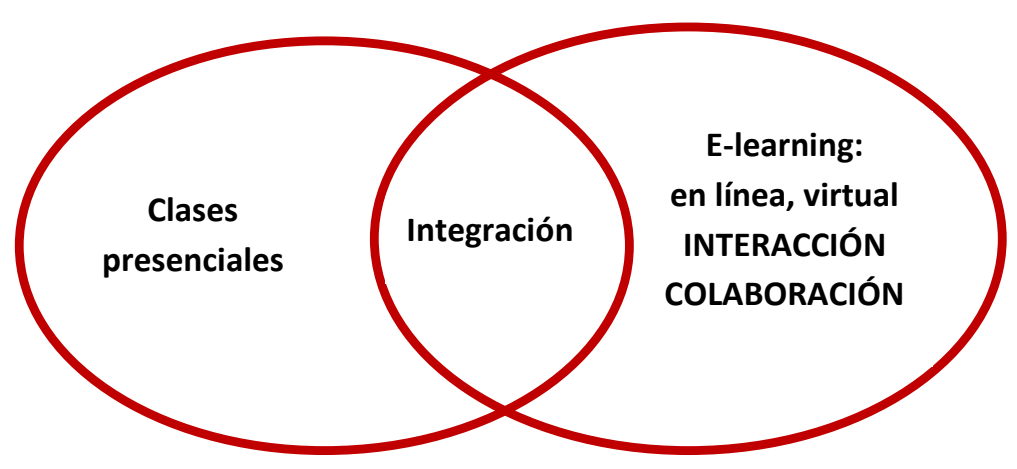

Fuente: elaboración propia basada en Vaughan, 2010 
No obstante, esta combinación de dos categorías de procedimientos en el proceso de aprendizaje, que históricamente estuvieron separadas, el término b-learning hace hincapié en el papel central de las tecnologías informáticas con la finalidad de lograr aprendizajes (sistemas de e-learning). El término se centra en el acceso y la flexibilidad, en la mejora de la enseñanza en el aula y actividades de aprendizaje y transformar la manera cómo las personas aprenden. Desde la perspectiva de su concepción y desarrollo como herramienta formativa, Imbernón (2008) la denomina como una dualidad pedagógica y tecnológica, que combina la enseñanza tradicional y la enseñanza de base tecnológica con una gran variedad de los métodos pedagógicos y las diferentes formas de la tecnología. Si bien persiste la dualidad tecnológica y pedagógico, coincidimos con Martínez (2012) en cuanto que al momento de diseñar un curso b-learning, el énfasis es la pedagogía, no la tecnología.

Esto refleja que el advenimiento del $b$-learning dado los avances tecnológicos y los cambios que se le está demandando a la universidad, es muy reciente. Se constata un cambio en la preocupación en la temática de los investigadores que abordan el b-learning desde el estudio de la instalación de plataformas tecnológicas por parte de las instituciones, su funcionamiento técnico, hacia a las adaptaciones y percepciones de los profesores y alumnos. Hoy ya forman parte de la estructura de las instituciones de educación superior con lo cual los temas de investigación están transitando, se están moviendo hacia los aspectos metodológicos y pedagógicos y cómo impactan en el logro de los aprendizajes comprometidos, hacia una confluencia tecnopedagógica (Turpo y Hernández, 2014). Frente a estos desafíos en a educación superior, El-Mowafy, Kuhn y Snow (2013) proponen que el $b$-learning puede mitigar algunos de esos retos.

\subsection{Modelos b-learning en educación superior}

Como hemos constatado, es inherente a la modalidad b-learning considerar las dimensiones tecnológica y pedagógica. Los enfoques en el uso del b-learning que revisaremos a continuación, se han agrupado según su respectivo énfasis, ya sea en lo tecnológico o en lo pedagógico, siendo una división no taxativa (Tabla 3.1). 
1 Tabla 3.1: Autores según los énfasis de enfoque del blended learning

\begin{tabular}{ll}
\multicolumn{1}{c}{ Tecnológico } & \multicolumn{1}{c}{ Pedagógico } \\
\hline Allen, Seaman, Garrett, 2007 & Graham, 2006, 2014 \\
Area, 2006 & Kerres y Witt, 2003 \\
Bartolomé, 2008 & Khan, 2007 \\
Clark, 2003 & Peñalosa et al, 2010 \\
Duart, 2008 & Roberts, 2003 \\
Graham, 2006, 2014 & Salmon, 2004 \\
Jones, 2007 & Valiathan, 2002 \\
Khan, 2007 & Vaughan, 2010 \\
Mason y Rennie, 2006 & Wenger y Ferguson, 2006 \\
\hline
\end{tabular}

Fuente: elaboración propia

Se ha ido consolidando en la universidad el uso de las nuevas tecnologías en las actividades de aprendizaje, como lo señalaba Jones (2007), por lo cual es relevante facilitar la práctica y adopción de tecnología por parte de los profesores y sistematizar modelos pedagógicos para su uso. Es así, que en esta sección revisaremos los modelos que ponen el énfasis en los aspectos tecnológicos y los que lo hacen en lo pedagógico del b-learning. Para orientar nuestra revisión, usaremos como guía temática las cuatro áreas principales que plantea Gülbahar (2009) que deben ser consideradas al desarrollar un ambiente de aprendizaje combinado, estas son: las tecnologías seleccionadas y su modo de uso, los aspectos pedagógicos del diseño, el perfil y el rol de los docentes y de los estudiantes. Los factores comunes para estas áreas son la comunicación, la colaboración e interacción (Figura 3.2). 
4 Figura 3.2: Componentes del b-learning

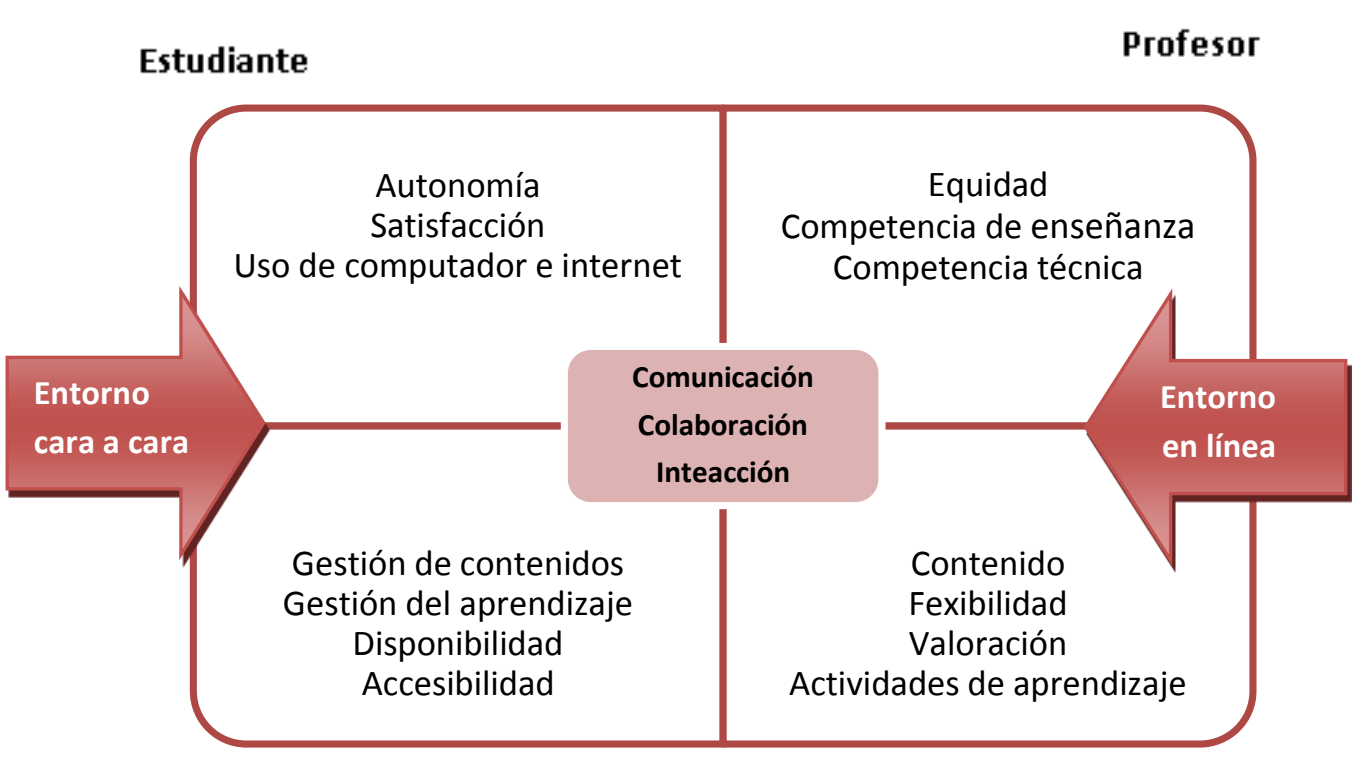

Pedagógica

Tecnológica

Fuente: Gülbahar, 2009

\subsubsection{Modelos con énfasis en lo tecnológico}

La educación presencial tradicional ha ido incorporando las TIC a los procesos de enseñanza aprendizaje. Las universidades desarrollan o contratan plataformas tecnológicas para uso de los docentes y los estudiantes, inicialmente con un marcado uso administrativo, lo que ha posibilitado la familiarización de los profesores y alumnos con estas tecnologías. Fuera de la institución escolar las tecnologías siguen avanzando a un ritmo vertiginoso y cobrando cada vez más usuarios. El uso del correo electrónico en los ambientes universitarios es masivo, es una herramienta de comunicación entre el profesor y los alumnos. Las universidades hoy en día prácticamente no deben enseñar a sus alumnos el uso de las TIC a nivel de usuario. Las tecnologías web 2.0, que permiten la interacción entre los usuarios y el desarrollo de sus aplicaciones e interfaces cada vez más amistosas e intuitivas, han facilitado el uso con finalidades formativas en el ámbito universitario.

Internet es una de las tecnologías más potentes de comunicación e interacción que posee también otras funciones como son de información, memorización, producción, ocio y 
entretenimiento. La colaboración es un proceso por el cual diferentes personas pueden trabajar juntas en una actividad intelectual, social, cultural o empresarial. Antes de la aparición de Internet, la colaboración entre personas de un grupo de trabajo se concretaba fundamentalmente en la realización de actividades presenciales de una forma más o menos estructurada, en la cual se establecían pautas de trabajo de cada uno de los miembros (Puente, 2002).

Actualmente la colaboración electrónica conecta a todos los miembros de un grupo a través de Internet utilizando herramientas tales como el correo electrónico y las diferentes herramientas web 2.0. La colaboración electrónica puede llevarse a cabo de diferentes formas: grupos de discusión o foros; bases de datos para organizar y recuperar información relevante; sistemas de archivos/documentos compartidos para permitir que un grupo trabaje sobre estos simultáneamente; sistemas de comunicación en tiempo real como chats, videoconferencias posibilitan la comunicación síncrona.

La capacidad potencial de las TIC es más que meros artefactos o instrumentos, son capaces de generar nuevos, contextos, escenarios diferentes (García del Dujo y Martín, 2002), entornos de aprendizaje, adaptados a las características y niveles de las personas en formación aporta su carácter como mediadores en los procesos de aprendizaje e incluso sus posibilidades para modificar la interactividad generada (De Pablos, 2007). De tal manera que, en el campo educativo, la calidad vinculada al uso de las tecnologías en realidad se relaciona en buena medida con la calidad de la interactividad, como factor clave en los procesos de enseñanza-aprendizaje (García Del Dujo y Martín García, 2002).

El entorno virtual está disponible gratuitamente, los jóvenes que ingresan a la universidad en su gran mayoría se relacionan e interactúan con sus pares en los entorno virtuales, por ello no deja de llamar la atención los resultados de la investigación que obtiene Marzo (2003) hace ya varios años quien señala que el instrumento mejor valorado por parte de los encuestados para comunicarse con el profesor es el teléfono, a pesar de que a priori se podría pensar en las clases o tutorías como medio más óptimo. La priorización de los estudiantes de una herramienta TIC antes que la tutoría presencial, la podemos comprender considerando el fenómeno que anticipa Barker (2007) en cuanto a que 
estamos experimentando con el advenimiento de las redes inalámbricas celulares, nos estamos en una era de interconectividad electrónica omnipresente.

Junto a las facilidades de acceso a los entornos virtuales, las posibilidades de las plataformas on-line son muy variadas y su utilización no entraña grandes dificultades (Castañeda, 2006; Castillo, 2008; Mondéjar, 2007; Poon, 2013). Los alumnos tienen una imagen positiva y tienden a mejorarla debido a que les facilita el trabajo grupal, el registro de la información y el refuerzo los contenidos (Rodrigues, Pavan y Casales, 2012; Ruiz, 2008; So, 2013). En los resultados de su investigación de una experiencia b-learning, Pérez Navío (2008) y Poon (2013) concluyen que los estudiantes resaltan la sencillez de su aprendizaje y uso, así como la versatilidad en el manejo de tiempos y espacios de aprendizaje, la facilidad para acceder a contenidos, tareas, exámenes desde cualquier lugar y en cualquier momento. Así mismo, mencionan que permite la integración y recuperación rápida de la información, facilita la planeación y organización de los cursos y la administración eficiente de la información, optimiza tiempos, facilita la comunicación entre maestros y alumnos.

La expansión del b-learning se ha debido, según Graham (2006), a las innovaciones tecnológicas. En el pasado, los dos entornos de aprendizaje arquetípicos, presencial y en línea (Tabla 3.2), cada uno con sus métodos, han permanecido muy separados abordando las necesidades de los diferentes públicos (Figura 3.3). Por ejemplo, en el cara a cara tradicional el aprendizaje generalmente se produjo en una actividad dirigida por el profesor en una interacción de persona a persona, en un entorno vivo síncrono, de alta fidelidad. Por otra parte, la formación a distancia hizo hincapié en los sistemas de aprendizaje a su propio ritmo de aprendizaje y el aprendizaje de los materiales de estudio, con interacciones normalmente asincrónicas, de baja fidelidad. 


\section{Tabla 3.2: Componentes del b-learning}

\begin{tabular}{|c|c|c|c|}
\hline \multicolumn{2}{|c|}{ Componente offline } & \multicolumn{2}{|c|}{ Componente online } \\
\hline $\begin{array}{l}\text { Lugar físico de } \\
\text { aprendizaje }\end{array}$ & $\begin{array}{l}\text { Aprendizaje en el } \\
\text { lugar de trabajo } \\
\text { Sala de clases } \\
\text { Visitas a lugares } \\
\text { físicos }\end{array}$ & $\begin{array}{l}\text { Contenido de aprendizaje } \\
\text { online }\end{array}$ & $\begin{array}{l}\text { Recursos básicos para el } \\
\text { aprendizaje. } \\
\text { Contenidos generales } \\
\text { interactivos. } \\
\text { Representaciones y } \\
\text { simulaciones. }\end{array}$ \\
\hline $\begin{array}{l}\text { Tutoría online y } \\
\text { presencial }\end{array}$ & $\begin{array}{l}\text { Tutorización } \\
\text { Seguimiento }\end{array}$ & Tutoría online & $\begin{array}{l}\text { Tutorización online } \\
\text { Seguimiento }\end{array}$ \\
\hline Trabajo de clase & $\begin{array}{l}\text { Lecturas } \\
\text { Seminarios } \\
\text { Juegos de rol } \\
\text { Conferencias }\end{array}$ & $\begin{array}{l}\text { Aprendizaje colaborativo } \\
\text { online }\end{array}$ & $\begin{array}{l}\text { Correo electrónico } \\
\text { Foro de discusión } \\
\text { Trabajo en chat } \\
\text { Videoconferencias }\end{array}$ \\
\hline Medios impresos & $\begin{array}{l}\text { Libros } \\
\text { Revistas } \\
\text { Periódicos }\end{array}$ & $\begin{array}{l}\text { Gestión del aprendizaje } \\
\text { online }\end{array}$ & $\begin{array}{l}\text { Orientaciones sobre las } \\
\text { búsquedas } \\
\text { Recuperación de } \\
\text { documentos y archivos }\end{array}$ \\
\hline Medios electrónicos & Audio / CD / CD7DVD & Internet & $\begin{array}{l}\text { Sitios web } \\
\text { blogs }\end{array}$ \\
\hline $\begin{array}{l}\text { Medios de } \\
\text { comunicación }\end{array}$ & $\begin{array}{l}\text { TV } \\
\text { Radio } \\
\text { TV interactiva }\end{array}$ & Medios móviles & $\begin{array}{l}\text { Portátiles } \\
\text { PDAs } \\
\text { Teléfono móvil }\end{array}$ \\
\hline
\end{tabular}

Fuente: basado en Clark, 2003

La rápida aparición de innovaciones tecnológicas en el último medio siglo (en particular las tecnologías digitales) ha tenido un enorme impacto en las posibilidades de aprendizaje presencial y en línea, acercando a ambos entornos. Las tecnologías de la comunicación ahora nos permiten tener interacciones sincrónicas que ocurren en tiempo real con casi los mismos niveles de fidelidad como en el entorno presencial. En la dimensión de lo humano, hay un creciente interés en facilitar la interacción humana en forma de equipo apoyada por la colaboración, las comunidades virtuales, la mensajería instantánea, los blogs, etc. Tal como lo señala Graham (2006), si bien es imposible ver todo lo que depara el futuro, podemos con bastante certeza visualizar la tendencia que la mezcla de sistemas de aprendizaje irá en aumento. Incluso serán tan omnipresentes que, finalmente, quizás dejaremos de usar la palabra "combinado". Pero independientemente de lo que se decida denominar b-learning en el futuro, es evidente que el fenómeno de la mezcla de aprendizaje está aquí para quedarse. 


\section{Figura 3.3: Expansión de los sistemas b-learning}

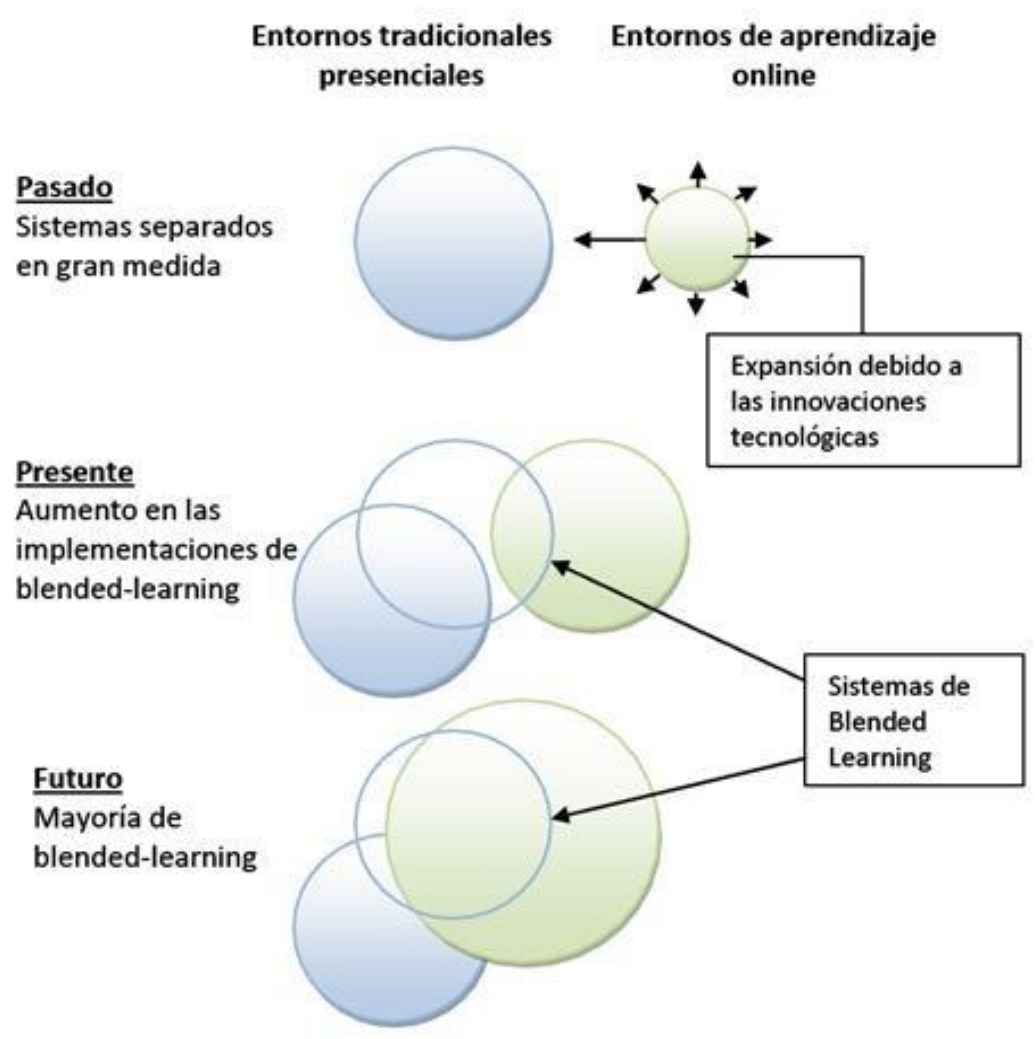

Fuente: Graham, 2006

Como hemos examinado, las nuevas tecnologías han posibilitado la configuración del $b$ learning como una nueva modalidad de aprendizaje. Es así como el modelo de Area (2006) ubica el b-learning en uno de cuatro niveles de integración y uso de Internet en la enseñanza universitaria, en un continuum que va de lo simple a lo complejo. Las formas de uso e integración de Internet pueden oscilar entre la elaboración de pequeñas experiencias docentes (por ejemplo, publicar una página web con el programa de la asignatura) hasta la creación y puesta en funcionamiento de todo un sistema de formación a distancia online, desarrollado institucionalmente por una universidad (Area, 2006:17):

- Nivel I: Edición de documentos convencionales en html. Este nivel es el más básico. Consiste en hacer accesible al alumnado el programa de la asignatura (los objetivos, el temario, la metodología, la evaluación y bibliografía recomendada) y/o los "apuntes" o temas de la materia través de la web. 
- Nivel II: Elaboración de materiales didácticos para la web. Este segundo nivel consiste en elaborar un material didáctico electrónico dirigido al alumnado para estudien la asignatura de modo autónomo en su hogar o fuera del aula convencional y/o realicen diversas actividades en el contexto de la clase bajo la supervisión del profesor. Este material didáctico, a diferencia del nivel anterior, requiere la utilización de los distintos elementos o recursos multimedia e hipertextuales propios de los sitios web.

- Nivel III: Diseño y desarrollo de cursos online semipresenciales (b-learning). En este nivel, el objetivo es desarrollar una modalidad de enseñanza que combine la actividad docente presencial en las aulas, con el desarrollo de un aprendizaje autónomo y a distancia por parte del alumnado. Se suelen utilizar aulas virtuales tipo Moodle, WebCT, etc.

- Nivel IV: Educación virtual, teleformación (e-learning). Similar al anterior, pero consistente en la puesta en práctica de una modalidad de educación a distancia que requiere una actividad docente desarrollada, casi de modo exclusivo, a través de plataformas o aulas virtuales. Apenas se produce encuentro físico o presencial entre docente y alumnado.

En la misma línea de la intensidad del uso de la tecnología, Duart et al (2008), Osorio y Duart, (2011b) y Mason y Rennie (2006) ubican su modelo b-learning en una escala de incremento de uso de la tecnología y de los componentes online, al definir un espectro de los usos de internet como herramienta docente en el contexto universitario, desde la formación presencial o aprendizaje offline y la formación virtual o aprendizaje online. Coinciden con el criterio de los niveles que define Area (2006). El esquema de Mason y Rennie (2006) (Figura 3.4) lo complementamos con la precisión que realiza Duart et al (2008) en cuanto al uso de Internet en la modalidad b-learning, como complemento, como parte lectiva hasta alcanzar en algunos casos, un uso intensivo.

Por su parte, en su modelo Allen, Seaman y Garrett (2007) establecen cuatro tipos de formaciones según la proporción del contenido entregado en línea, entre los que ubican el b-learning, llegando a precisar un porcentaje de referencia amplio: 
- Tradicional: sin utilizar la tecnología en línea, el contenido se entrega por escrito u oralmente.

- Web facilitado: 1 a 29\% del contenido es entregado en línea. Utiliza la tecnología basada en web para facilitar lo que es esencialmente cara a cara, publicando el plan de estudios y asignaciones de tareas.

- B-learning: 30 a 79\% del contenido es entregado en línea. Se combina la entrega en línea y cara a cara. Una proporción sustancial de los contenidos se entregan en línea y tiene un cierto número de reuniones cara a cara.

- En línea: $80 \%$ o la totalidad del contenido es entregado en línea. Por lo general no tienen reuniones cara a cara.

\section{Figura 3.4: Descripción esquemática del blended learning}

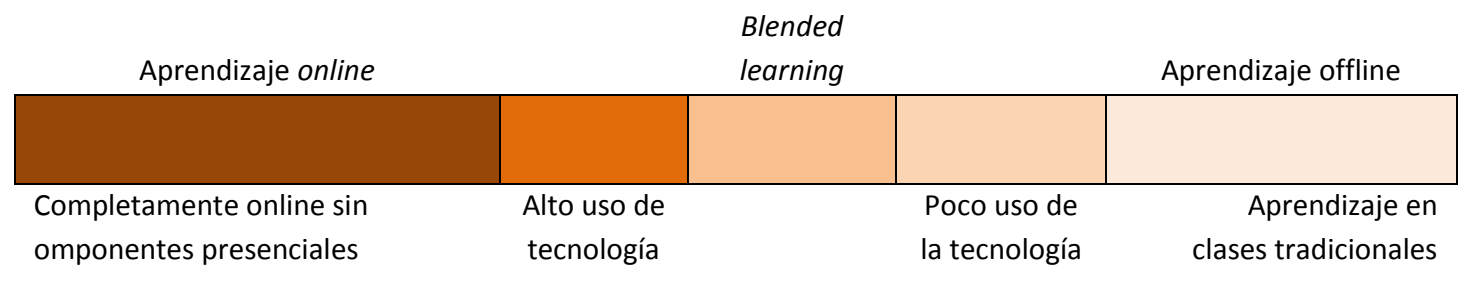

Incremento del uso de la tecnología y de los componentes online

Fuente: Mason y Rennie, 2006; Duart et al, 2008

Si bien las cuatro categorías de modalidades de aprendizaje que aporta Jones (2007) se pueden homologar con las de Area (2006) y a las de Allen et al (2007), sin embargo la diferencia está en que no ubica el b-learning como un punto intermedio entre el uso básico de las TICs y un uso intensivo de las tecnologías en línea, sino como un continuum del $b$ learning que facilita la práctica y adopción de tecnología por parte de los profesores, coincidiendo con Graham (2006) en la omnipresencia de las tecnologías, sin importar en qué grado se usan. Por ello, Jones (2007) inicia su modelo b-learning con la categoría de "Uso básico de TIC", desde el uso de Power Point, Excel, Word, e-mail y bases de datos. El acceso a recursos de aprendizaje facilitados a través de la web corresponde a la categoría "E-reforzado". La siguiente categoría la denomina "E-centrado", corresponde al uso del 
debate, pruebas de evaluación en línea y materiales interactivos. "E-intensiva" es la última categoría en el continuo, donde la enseñanza y el aprendizaje se entregan en conjunto en línea con las inducciones cara a cara (Figura 3.5).

7 Figura 3.5. Modalidades de aprendizaje

\begin{tabular}{|c|c|c|c|}
\hline Uso básico de TIC & E-reforzado & E-centrado & E-intensivo \\
\hline & 1 & 1 & \\
\hline $\begin{array}{l}\text { Presentaciones en } \\
\text { PowerPoint, Excel, } \\
\text { Word, e-mail, bases } \\
\text { de datos }\end{array}$ & $\begin{array}{l}\text { Acceso a recursos en } \\
\text { línea, anuncios, notas } \\
\text { de conferencias, comunic } \\
\text { ación entre estudiantes }\end{array}$ & $\begin{array}{l}\text { Debates, pruebas de } \\
\text { evaluación en línea y } \\
\text { materiales interactivos }\end{array}$ & $\begin{array}{c}\text { Módulos integrales } \\
\text { inducciones cara a cara } \\
\text { y moderado } \\
\text { en línea }\end{array}$ \\
\hline
\end{tabular}

Fuente: Jones, 2007

El modelo semipresencial que ha configurado Bartolomé $(2002,2004,2008,2011)$ centra su preocupación en caracterizar las condiciones de los procesos de formación que ocurren en el entorno de en línea. Sobre la base de sus propias investigaciones de experiencias $b$ learning, especifica ciertas condiciones que debe reunir el entorno virtual o tecnológico para el desarrollo de la modalidad b-learning, da un paso, en relación al incremento del uso y omnipresencia de la tecnología que plantea Graham (2006) y las diversas intensidades de uso que aporta Jones (2007), en el acercamiento a un enfoque pedagógico:

- El entorno que incluye actividades, recursos con los que interactúan las personas, además posibilita la interacción de las personas entre sí. Evitar el colocar los materiales en la red, como si la función fuese sustituir o complementar una clase magistral por una reproducción de sus contenidos en forma escrita.

- El entorno es un espacio en el que el sujeto desarrolla competencias básicas como la capacidad de autorregular el aprendizaje.

- El entorno debe ser rico en recursos de modo que pueda determinar sus necesidades de formación, encontrar los recursos que pueden ayudarle a solucionarlas y aplicarlos de modo efectivo. 
- Proporcionar al entorno de herramientas comunicativas e informativas, dotándolo de un carácter "tutorial".

- Dotar el entorno de flexibilidad, de modo que profesores y estudiantes se encuentren cómodos en él, que puedan utilizarlo adaptándolo a sus necesidades y características.

- Considerar la importancia de los aspectos emocionales en la comunicación humana. Y valorar especialmente lo que en este aspecto nos aportan ciertas acciones presenciales.

- Mucha de la información ya está en Internet o en libros y revistas. Centrarse en las actividades que permitirán a los alumnos desarrollar las competencias requeridas. No limitar el desarrollo de su capacidad de buscar, valorar, seleccionar, estructurar la información.

- No descuidar la potencialidad del lenguaje audiovisual.

Todas estas condiciones del entorno tecnológico aportadas por Bartolomé (2002, 2004, 2008) son compatibles con modelos didácticos muy diferentes. Por ejemplo, es posible crear un entorno b-learning con este modelo tanto si trabajamos por proyectos, centrados en problemas o a partir de temas o actividades. Igualmente podemos utilizarlo si nos planteamos objetivos como si nos orientamos a competencias específicas. Aunque sí Bartolomé parte de una concepción del currículum flexible y centrado en el sujeto.

Entonces, más que buscar puntos intermedios o intersecciones entre los modelos presenciales y en línea, García Aretio (2004) y Burgos (2007) coinciden en señalar que se trata de integrar, armonizar, complementar y conjugar los medios, recursos, tecnologías, metodologías, actividades, estrategias y técnicas más apropiadas para satisfacer cada necesidad concreta de aprendizaje, tratando de encontrar el mejor equilibrio posible. Lejos de atender a una y otra por separado, el b-learning las entrelaza y ofrece, así mayor proximidad y continuidad al alumno, disfrutando de la ventaja de los dos espacios de formación.

\subsubsection{Modelos $b$-learning con énfasis en lo pedagógico}

Las tecnologías resultan rápidamente obsoletas. No se trata de ganar una carrera tecnológica sino de pensar cuáles son los marcos pedagógicos más adecuados para que las 
tecnologías tengan sentido (Castells, 2001; George-Palilonis, 2009; Lion, 2006; Poon, 2013), dado que el desarrollo de las TIC y las nuevas formas de acceder al conocimiento, plantean la necesidad de diseñar nuevas propuestas formativas (Morán, 2013). La web 2.0 es una tecnología centrada en el usuario, en la producción, en la interacción que contribuye a crear un entorno de aprendizaje colaborativo. Estas herramientas estimulan la experimentación, reflexión y la generación de conocimientos individuales y colectivos, favoreciendo la conformación de un entorno virtual de interactividad. Reyero et al (2008) nos advierte sí de los peligros de las nuevas tecnologías, al concebirlas como la panacea docente, estos instrumentos no son la panacea de la educación como tampoco lo fue en su momento la pizarra o más recientemente el proyector de trasparencias. Además el exceso de optimismo tecnológico y pedagógico de algunos docentes al considerar que introduciendo más recursos y posibilidades técnicas en la instrucción, puede generar la ilusión que van a ayudar conseguir automáticamente mejores resultados.

La formación a través de entornos virtuales como catalizadora de procesos de renovación pedagógica favorece y promueve también la búsqueda de nuevas estrategias didácticas que impliquen en una mayor medida al alumnado en el proceso educativo (Pérez Lorido, 2007, 2010), por ello, posiblemente no sirva de nada contar con herramientas de Internet sin que exista una adecuada planificación de la enseñanza, con su correspondiente evaluación, una óptima utilización de medios tecnológicos y por supuesto el acompañamiento de los profesores (Imbernón, 2008). Las preocupaciones que plantean Pérez Lorido (2007) e Imbernón (2008) se pueden comprender mejor si establecemos un paralelismo entre la evolución de la tecnología con los modelos de elearning. Apoyándonos en Gros (2011), se pueden hasta el momento establecer tres generaciones de e-learning. La primera generación el modelo está centrado en los materiales; la segunda, centrada en el aula virtual; la tercera, centrada en la flexibilidad y la participación a través de las comunidades de aprendizaje. Para adoptar el b-learning en la universidad, Martín y García del Dujo (2014) nos plantean que concurren diferentes elementos tales como los aspectos técnicos, los contenidos, el nivel de desempeño de los estudiantes, la filosofía corporativa de cada universidad, entre otros.

Tal como ha ido evolucionando la tecnología, el b-learning es una tendencia cada vez mayor entre instituciones de educación superior y probablemente se convierta en la norma en la 
educación en los próximos años, según lo que afirman El-Mowafy et al (2013). Se ha comenzado a cambiar la naturaleza de la enseñanza y el aprendizaje a través de una adecuada mezcla de aprendizaje cara a cara y tecnologías de la información, que han afectado el aprendizaje al proporcionar un medio de acceso a recursos en línea. Sin embargo, sólo mezclar tecnologías de la información teniendo como referencia el aprendizaje presencial no es suficiente para explotar las potencialidades de la modalidad mixta. Para tener éxito, el $b$-learning necesita un modelo pedagógico basado en las teorías del aprendizaje y estrategias pedagógicas. Un buen ejemplo de diseño de estrategias de aprendizaje es el trabajo que realiza Marcelo et al (2011) en torno a la sistematización de patrones de actividades en la universidad, los que están disponibles en un repositorio.

Sin embargo, los nuevos escenarios mixtos no son contemplados del todo en la teoría educativa existente (Burgos, 2007). Si su diseño deja pasar por alto la teoría de la educación, entonces estamos en peligro de dejar el aprendizaje al azar (Jones, 2007), en otras palabras, el valor del b-learning hay que demostrarlo por motivos pedagógicos, ya que la tecnología no debe estar en primer plano, sino que su objetivo debe ser apoyar el diálogo en el aprendizaje, cuidando la mezcla de los avances tecnológicos y pedagógicos (Jones, 2007, Morán, 2012; Poon, 2013), por tanto, los diseños representan procesos dinámicos, en lugar de productos estáticos (Falconer, 2007), con una gran variedad de posibles formas de combinar las actividades presenciales y en línea que afecta a la sinergia entre los dos componentes (Dettori, 2007). El uso pedagógico va a venir dado por la finalidad, intencionalidad que tenga el docente. Esta preocupación se constata que está siendo abordada por las universidades, ejemplo de ello es el estudio de Tirado, Pérez y Aguaded (2011) que abarca cuatro universidades andaluzas en el que concluyen que la necesidad de una reconceptualización del modelo pedagógico universitario, que requiere una reestructuración del modelo didáctico tradicional hacia estrategias de innovación, cooperación y construcción compartida del conocimiento.

Uno de los elementos pedagógicos clave a considerar en un modelo b-learning, según Rosas (2005) y Bartolomé (2008), es el eje dado por el entorno-alumno, no se trata solo de agregar tecnología a la clase, sino de reemplazar algunas actividades de aprendizaje con otras apoyadas con tecnología. El alumno es un ser diferenciado a nivel cognitivo, metacognitivo y emocionalmente, es decir que posee características, potencialidades y 
necesidades diferentes en sus tres ámbitos. Es el entorno el que se debe adaptar al alumno, respondiendo a sus necesidades de formación mediante recursos y soluciones diferentes. Fainholc (2008) plantea que se requiere una "vigilancia epistemológica" para no reiterar en la educación virtual o en combinación con las TIC, los errores que ha cometido y aún comete la educación presencial convencional pura. Como por ejemplo, caer en el engaño de tratar de reproducir en la red y con las TIC, el perfil de una clase tradicional, sin aprovechar las opciones que brindan estos entornos virtuales en sí mismos al utilizar sus herramientas y características típicas en modalidades que favorezcan el aprendizaje y que son difíciles de hallar para utilizar en la clase tradicional.

En otras palabras, como considera Graham (2006), el modelo b-learning da la posibilidad de evolucionar, ya que la mayoría de enseñanza y el aprendizaje en la práctica actual en la educación superior, todavía se centra en lo transmisivo en lugar de usar estrategias interactivas. Un valioso aporte realizan Osorio y Duart (2011b) en esta línea en su investigación en la que proponen un conjunto de criterios de análisis de las interacciones y su relación con el rendimiento académico. Vemos como el foco del b-learning se ha ido desplazando de los contenidos del curso, a diseñar eficaces estrategias metodológicas de enseñanza y a los procesos de aprendizaje (Novell, 2009).

\subsubsection{Modelo b-learning Octogonal de Khan}

El modelo b-learning Octogonal de Khan (2007) nos sirve como buen punto de partida general para revisar los modelos b-learning que ponen un énfasis explícito en la dimensión pedagógica. Khan expone ocho dimensiones que deben ser consideradas en el diseño de una experiencia formativa b-learning, estas son: la institucional, la pedagógica, la tecnológica, la de diseño de la interfaz, la de evaluación, gestión, recursos de apoyo y la dimensión ética (Figura 3.6). Cada dimensión en el modelo representa una categoría de cuestiones que deben abordarse. Estas ayudan a organizar el pensamiento y a asegurar el programa de aprendizaje resultante y crear una experiencia de aprendizaje significativo. 


\section{Figura 3.6: Modelo b-learning Octogonal de Kahn}

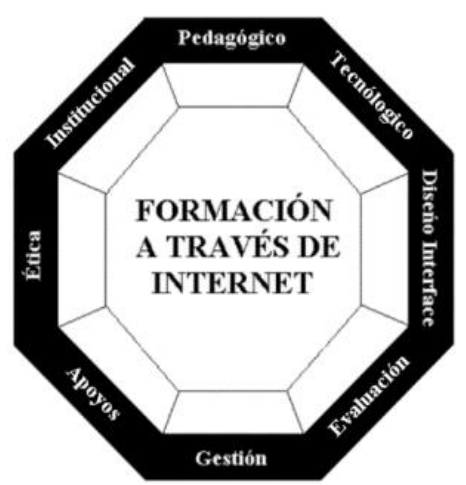

Fuente: Kahn, 2007

Cada una de las dimensiones de Kahn las describimos, brevemente:

- Institucional: se ocupa de cuestiones relativas a la organización, asuntos administrativos, académicos, y servicios para los estudiantes.

- Pedagógica: se refiere a la combinación de contenido que tiene que ser entregado (análisis de contenido), necesidades del alumno (análisis de la audiencia), y los objetivos de aprendizaje (análisis de la meta). La dimensión pedagógica abarca también el aspecto del diseño y la estrategia del b-learning.

- Tecnológico: una vez que se han identificado los métodos de entrega, se define la tecnología que debe abordarse. Los temas incluyen la creación de un ambiente aprendizaje y las herramientas para ejecutar el programa de aprendizaje. Requisitos técnicos, tales como el servidor que soporta el programa de aprendizaje, el acceso al servidor, ancho de banda y accesibilidad, seguridad, hardware, software y problemas de infraestructura.

- Diseño de Interfaces: la interfaz tiene que ser lo suficientemente sofisticada como para integrar diferentes elementos de la combinación. Temas que se pueden abordar como la estructura de contenidos, la navegación, gráficos y ayuda.

- Evaluación: se refiere a la usabilidad de un programa de aprendizaje mixto, así como la evaluación del rendimiento de cada alumno.

- Gestión: abarca cuestiones tales como infraestructura y logística para administrar el desarrollo del programa b-learning. 
- Recursos de apoyo: se ocupa de la preparación de distintos tipos de recursos (en línea y presenciales) disponibles para los estudiantes, así como la organización de ellos. Recursos de apoyo también podría ser un asesoro tutor siempre disponible en persona, a través del correo electrónico, o en un sistema de chat.

- Ética: identifica los problemas éticos que es necesario abordar en el desarrollo de un programa b-learning. Cuestiones que deben ser tratadas tales como la igualdad de oportunidades y la diversidad cultural, entre otras.

Los modelos que revisaremos en adelante, coinciden parcialmente con algunas de las ocho dimensiones de Khan (2007), lo cual permite valorar a este como un modelo integrador de la perspectiva de la gestión institucional, la provisión de los recursos, el modelo pedagógico, el uso de tecnologías y la dimensión ética. La multiplicidad de modelos refleja la riqueza y la plena etapa de desarrollo de la modalidad b-learning, así como las multiplicidades de perspectivas y aportes que se nos presenta para configurar modelos $b$ learning pertinentes a las experiencias formativas a implementar. Además, se explica por lo que señalamos con Graham (2006), al inicio de este capítulo, como la importante expansión del b-learning se ha debido a las innovaciones tecnológicas efectuadas por las universidades, sobre la base del avance de las tecnologías y la experiencia y uso de los alumnos y profesores de éstas, cuyas investigaciones están en pleno proceso de exploración del evaluar el impacto del uso pedagógico.

\subsubsection{Modelo b-learning 3-C de Kerres y Witt}

El modelo $b$-learning de Kerres y Witt (2003), denominado por el autor como modelo $b$ learning 3-C, parte de la premisa de que cualquier ambiente de aprendizaje consta de tres componentes:

1) Un componente de contenido que hace que el material de aprendizaje esté a disposición del alumno;

2) Un componente de comunicación que ofrece el intercambio interpersonal entre los alumnos o los alumnos y los tutores; 
3) Un componente constructivo que facilite y ofrezca guías individuales, así como actividades de cooperación de forma activa en el aprendizaje de tareas o trabajos con diferentes grados de complejidad (Figura 3.7).

9 Figura 3.7: Modelo b-learning 3-C de Kerres y Witt

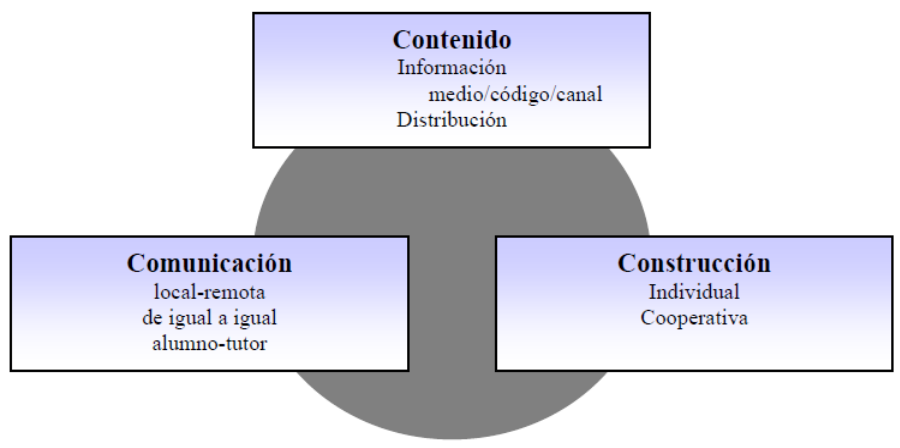

Fuente: Kerres y Witt, 2003

Estos componentes se pueden entregar en diversos formatos: en un escenario presencial, basado en el intercambio de los medios de comunicación, con transmisión de información analógica por aire o por cable o en forma de paquetes digitales a través de Internet en un entorno sincrónico o asincrónico con el texto, multimedia audiovisual o de otro tipo elementos.

Los programas b-learning difieren en el peso relativo de los tres componentes. El esquema didáctico puede ser descrito mediante la especificación de la cantidad de tiempo que un alumno dedica a actividades relacionadas con estos tres componentes. La especificación de los objetivos de aprendizaje ayuda a definir el peso relativo de los tres componentes mezclados en los programas de aprendizaje. Por ejemplo, si los objetivos de aprendizaje consisten principalmente en la adquisición de información básica y conocimiento, entonces el componente de comunicación y de la construcción puede ser limitado. La comunicación y la construcción no son ingredientes necesarios en todos los ambientes de aprendizaje y los alumnos no los aceptan si no son percibidos como elementos facilitadores de su proceso de aprendizaje. 


\subsubsection{Modelo Estratégico de Comunicación Educativa de Peñalosa}

La comunicación es un elemento que debe estar presente en un modelo b-learning. Como vimos anteriormente, para Kerres y Witt (2003) tiene una función relativa a los objetivos de aprendizaje, sin embargo Peñalosa et al (2010) eleva su importancia en su modelo pedagógico centrado en la comunicación, la que considera un eje transversal en la enseñanza en ambientes $b$-learning, que permea todas las dimensiones del $b$-learning.

Las dimensiones que considera fundamentales Peñalosa et al (2010) en un modelo de enseñanza aprendizaje en entornos mixtos, pueden observarse (Figura 3.8) en el plano vertical, las dimensiones: 1) la estructura de los ambientes presencial y tecnológico; 2) contenidos y materiales; 3) diseño de las experiencias educativas, y 4) fomento de las estrategias de aprendizaje y de la autonomía; en el plano horizontal, como dimensiones que atraviesan transversalmente a toda la actividad de aprendizaje, se encuentran: 5) la comunicación, y 6) la cognición.

A partir de la participación en actividades que implican la comunicación de ideas, conocimientos, creencias, experiencias en relación con contextos determinados, los participantes ponen en juego procesos cognitivos, que les permiten realizar tareas complejas de aprendizaje, que implican el desarrollo gradual de pericia, la conformación de modelos mentales cada vez más completos, el enlace entre el conocimiento previo y el nuevo conocimiento, el desarrollo de funciones de pensamiento crítico, y de estrategias de aprendizaje. El estudiante inicia el camino hacia la competencia cuando puede dar sentido e integrar los recursos necesarios en los momentos en que las situaciones o actividades lo demandan. Es imprescindible que los estudiantes tengan conocimientos integrales y los apliquen para interpretar y resolver situaciones. Para esto, dos elementos fundamentales son la comunicación y los procesos cognitivos, que impliquen generar un andamiaje cognitivo a los estudiantes. 
10 Figura 3.8: Dimensiones del modelo de comunicación educativa en b-learning

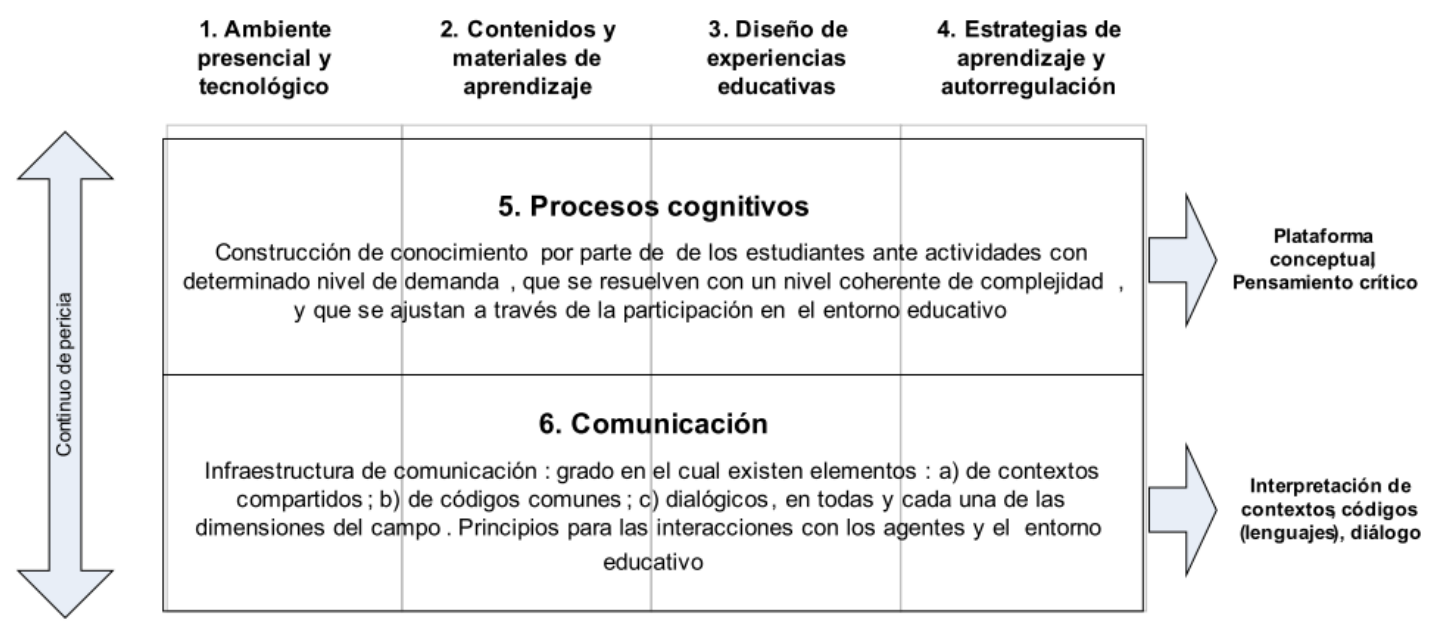

Fuente: Peñalosa et al, 2010

\subsubsection{Modelo b-learning de las Cinco Etapas de Salmon}

Si bien el modelo de Salmon responde en su origen a la modalidad e-learning, el uso que le hemos dado en el contexto de esta investigación, tanto en el diseño de las actividades pedagógicas, como en el diseño de los estudios cuantitativo y cualitativo. Salmon (2004; 2011) responde a la necesidad de crear un andamiaje cognitivo en procesos de formación b-learning. El modelo de Salmon tiene cinco etapas las que amplían gradualmente la experiencia de los estudiantes. Según Salmon (2004: 27) “montar un andamio se refiere a ampliar gradualmente la experiencia de los participantes. Un andamio estructurado de aprendizaje ofrece ayuda y desarrollo esencial a los participantes en cada etapa mientras van ampliando su formación técnica en línea" (Figura 3.9). 
11 Figura 3.9: Modelo b-learning de las Cinco Etapas de Salmon

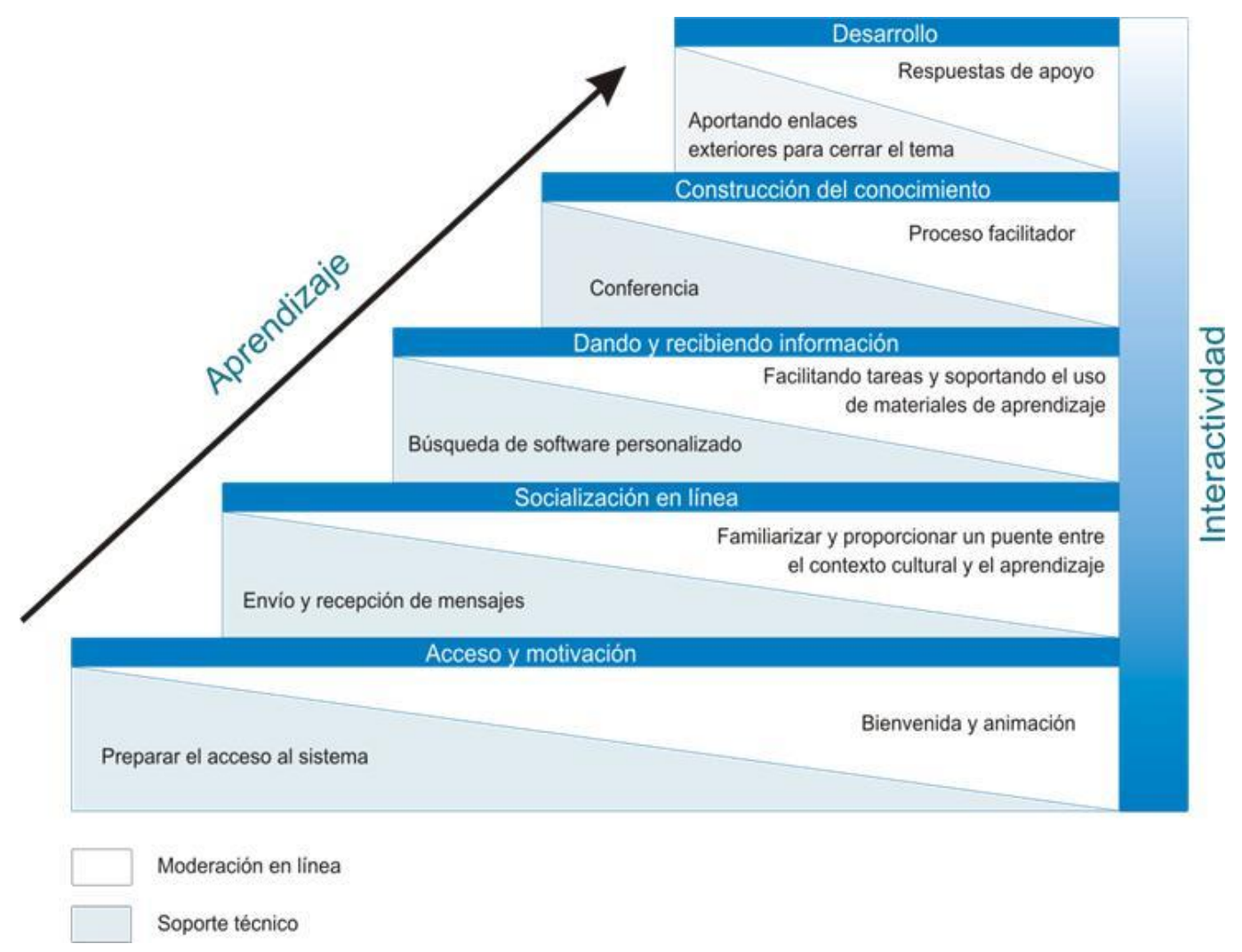

Fuente: Salmon, 2004, 2011

En cada etapa se desarrollan actividades que están compuestas de estrategias de aprendizaje que permiten al estudiante realizar tareas y a su vez, generar nuevos conocimientos que le propicien "construir conocimiento" y desarrollar su propio conocimiento:

- La primera etapa busca el acceso individual y la inducción de los participantes a la formación en línea. En el modelo b-learning las orientaciones para el acceso al entorno en línea así como la motivación para trabajar en estos espacios virtuales, se inician y monitorean en la instancia presencial.

- La segunda, que los participantes establezcan sus identidades en línea y luego busquen a otros con quien interactuar. La síntesis de esta etapa se realiza presencialmente y se explicita cómo los espacios virtuales, fuera de la sala de clases les posibilita conocerse en corto tiempo en aspectos que en el tiempo y espacio presencial normalmente no se logra. 
- La tercera, el intercambio mutuo de información y la cooperación para apoyar el logro de los objetivos de otros participantes. Desde lo presencial se ofrecen estrategias para la búsqueda, procesamiento y aplicación de información.

- La cuarta, debatir en grupo sobre aspectos relacionados con el curso, e interactuar de manera más cooperativa. El profesor ayuda a los estudiantes a organizarse presencialmente para trabajar posteriormente en línea y luego nuevamente reportar los avances en la clase presencial, transformando paulatinamente la clase tradicional en una plenaria.

- La quinta, buscar los mayores beneficios del sistema para ayudarles a alcanzar los objetivos personales y reflexionar sobre los procesos de aprendizaje. Los estudiantes, de manera individual reportan sus hallazgos, conclusiones y los cambios que se han generado en él, en los planos cognitivos y afectivos.

\subsubsection{Modelo b-learning de Wenger y Ferguson}

El modelo Salmon $(2004,2011)$ operacionaliza mediante etapas bien definidas un andamiaje cognitivo el que Peñalosa et al (2010) señala como una variable central en un modelo b-learning. Por su parte, Wenger y Ferguson (2006) para avanzar en el desarrollo de su modelo adoptan un modelo de andamiaje flexible y cíclico que dé respuesta a las actuales necesidades formativas y a las posibilidades tecnológicas; así como a nuevas posibilidades de diseño de la tecnología y el aprendizaje para la formación en el futuro. La mayor fortaleza de este modelo es que contiene una visión más amplia y estable de la totalidad de un programa de formación, y al mismo tiempo tiene la capacidad de constante cambio de los componentes (Figura 3.10).

El modelo se desenvuelve en espiral ascendente cubriendo modalidades de aprendizaje definidas (estudiando, practicando, enseñando, entrenando), cuyo marco de aplicación es suficientemente flexible para adaptarlo a las necesidades de los educandos y educadores. El aprendizaje es dinámico, vivo y en estado de evolución y los estudiantes siempre aprenden de la evolución del proceso más que del contenido estático. En este sentido, se podría argumentar que las modalidades de aprendizaje proporcionan un entorno dinámico y en evolución. No hay elemento específico de aprendizaje que sea claramente distinguible 
de los elementos vecinos en la otra columna. Por ejemplo, estudios de casos se puede aprender "estudiando" o "enseñando" en lugar de "practicando". En determinadas circunstancias los ejercicios pueden ser llevados a cabo en forma de iniciativas auto-guiadas sin entrenar. La línea entre estudio y la práctica, la enseñanza y entrenamiento, es imprecisa. No hay una clara distinción entre la autonavegación en comparación con la navegación guiada. El aprendizaje puede llevarse a cabo en una superposición de las circunstancias en que el alumno construye el conocimiento (auto-aprendizaje) con la ayuda de un docente facilitador (aprendizaje guiado).

12 Figura 3.10: Modalidades de aprendizaje en b-learning

\begin{tabular}{|c|c|c|c|}
\hline \multirow[t]{2}{*}{ Estudiando } & \multicolumn{2}{|c|}{ Autonavegación } & Practicando \\
\hline & $\begin{array}{l}\text { - Libros, artículos, guías } \\
\text { - Referencias } \\
\text { - Contenido aśncrono } \\
\text { - Ayudas de trabajo } \\
\text { - Glosarios } \\
\text { - Preguntas frecuentes }\end{array}$ & $\begin{array}{l}\text { - Tareas auténticas } \\
\text { - Juegos de rol } \\
\text { - Proyectos } \\
\text { - Estudios de caso } \\
\text { - Intercambioy } \\
\text { discusión }\end{array}$ & \\
\hline Enfoque en & & - Foros de debate & Enfoque en \\
\hline Entrega & & & Experiencia \\
\hline & - Aula conferencias & - Ejercicios & \\
\hline Contenido & $\begin{array}{l}\text { - Contenido síncrono } \\
\text { - Demostraciones } \\
\text { - Comentarios / } \\
\text { Discusiones } \\
\text { - Video } \\
\text { - Videoconferencia }\end{array}$ & $\begin{array}{l}\text { - Diagnóstico de } \\
\text { laboratorios } \\
\text { - Práctica en } \\
\text { laboratorios } \\
\text { - Mentoría/ tutoría } \\
\text { - Experimentos }\end{array}$ & y Práctica \\
\hline Enseñando & \multicolumn{2}{|c|}{ Navegación guiada } & Entrenando \\
\hline
\end{tabular}

Fuente: Wenger y Ferguson, 2006 


\subsubsection{Modelo $b$-learning de tres fases de aprendizaje de Roberts}

Roberts (2003), al igual que Wenger y Ferguson (2006), concibe su modelo b-learning como un ciclo en tres etapas de aprendizaje, en las que se identifican tres tipos de aprendizaje. La característica esencial es que describe el ciclo continuo de la retroalimentación y perfeccionamiento gradual de la comprensión. En consecuencia, el aprendizaje se desarrolla en tres fases, comenzando con la conceptualización, progresando a través de la construcción para llegar al diálogo.

La fase de conceptualización se caracteriza por el proceso de interacción entre el marco conceptual pre-existente de los alumnos y los conocimientos del profesor. La fase de construcción se refiere al proceso de construcción y la combinación de conceptos a través de su uso en el desempeño de tareas significativas. La fase de diálogo refiere a la prueba de las conceptualizaciones y la creación de nuevos conceptos durante la conversación con los compañeros y profesores. El diálogo surge a través del aprendizaje colaborativo.

Las tres etapas del ciclo de aprendizaje incluyen elementos que están estrechamente relacionados con las teorías del aprendizaje. La conceptualización se asocia con el desarrollo cognitivo de la teoría del aprendizaje ya que se centra en los conceptos y sus relaciones. La fase de construcción está relacionada con la teoría del aprendizaje constructivista, ya que tiene por objeto la construcción de nuevos conocimientos y su utilización en la realización de actividades basadas en tareas. La fase de diálogo se basa en la teoría social del aprendizaje situado, ya que tiene que ver con el diálogo, la colaboración en grupo y la discusión.

El modelo puede ser adaptado para clasificar tres usos del $b$-learning. Se realiza un mapeo del aprendizaje en un ciclo de los resultados del modelo de aprendizaje combinado en tres niveles diferentes (Figura 3.11):

a) La mezcla en la fase de conceptualización. La mezcla de este nivel se produce cuando el modelo combina aprendizaje presencial con recursos primarios. En esta fase el alumno adquiere los conocimientos conceptuales.

b) La mezcla en la fase de construcción. La mezcla de este nivel se produce cuando el modelo combina actividades de aprendizaje cara a cara con recursos secundarios, 
por ejemplo, actividades en línea basadas en tareas. En esta fase, el alumno está involucrado en la construcción de nuevos conocimientos y la adquisición de habilidades.

c) La mezcla en la fase de diálogo. La mezcla de este nivel se produce cuando el modelo de aprendizaje combina un diálogo cara a cara con recursos terciarios, por ejemplo, discusión en línea y la colaboración en grupo.

Las tres etapas del ciclo de aprendizaje de Roberts (2003) se pueden vincular, integrar y enriquecer con la perspectiva del modelo de Vaughan (2010), quien propone como estrategia para los modelos b-learning, la generación de comunidades de investigación, ya que considera que históricamente, este ha sido el ideal de todos los ambientes de aprendizaje en la educación superior. Las comunidades de investigación son los lugares donde todos los participantes con sus visiones se pueden expresar al mismo tiempo. Vaughan (2010) concibe el aprendizaje como un problema de investigación que impulsa la necesidad de aprender, a través de la participación en la generación de un discurso crítico, con la auto-dirección de estrategias, el desarrollo de métodos de investigación y la reflexión a lo largo de la experiencia de aprendizaje.

En el proceso de investigación de una comunidad, como estrategia de aprendizaje en la modalidad b-learning, Vaughan (2010) propone desarrollarlo en cuatro fases. En la primera fase se define el hecho que da lugar a la investigación, a fin de incitar a la curiosidad y la definición de preguntas clave o problemas de investigación. En la segunda fase se realiza el intercambio y la exploración de perspectivas objetivas e información con otros alumnos. La tercera fase tiene los propósitos de integrar y conectar las ideas través de la reflexión. Finalmente, la cuarta fase corresponde a la aplicación de nuevas ideas y/o la defensa de soluciones. A su vez, el modelo de Roberts (2003) propende a la construcción de nuevos conocimientos y a su utilización a través del diálogo, la colaboración en grupo y la discusión. 
13 Figura 3.11: Modelo b-learning como un ciclo en tres fases de aprendizaje

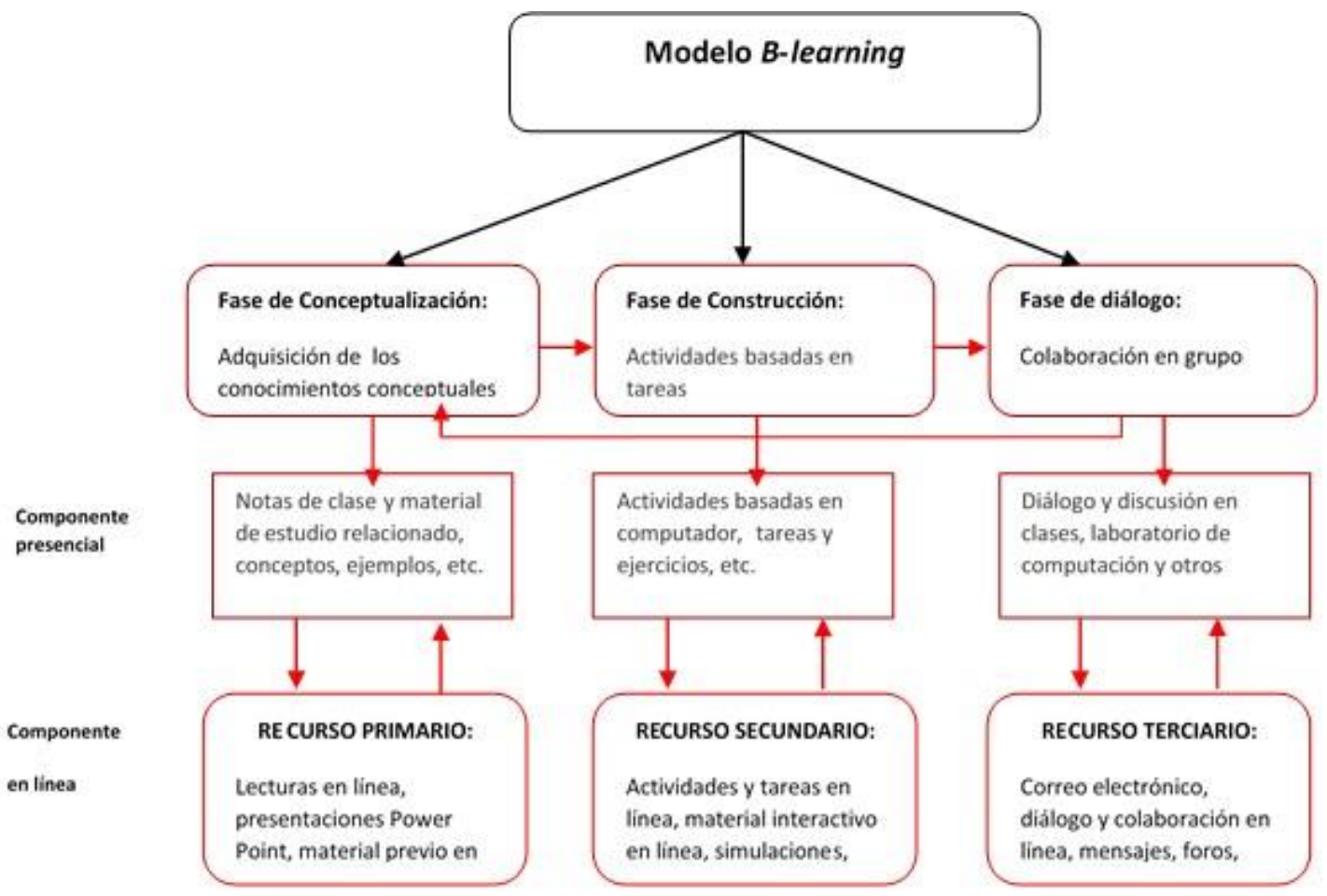

Fuente: Hadjerrouit, 2008, basado en Roberts, 2003

\subsubsection{Modelo b-learning de incremento de la pedagogía de Graham}

El modelo de Graham (2006) sirve de síntesis a la tendencia de los modelos b-learning en el incremento del rol de la pedagogía. Advierte el autor que rara vez se reconoce que un entorno de aprendizaje combinado también puede mezclar los elementos menos eficaces de ambos mundos, si no está bien diseñado. Él ha identificado seis razones por las cuales utilizar un diseño b-learning, estas son: 1) la riqueza pedagógica, 2) acceso al conocimiento, 3) interacción social, 4) disponibilidad de personal, 5) la rentabilidad, y 6) la facilidad de revisión.

La estructura de valor añadido de Graham (2006), con incremento de la pedagogía en las diferentes combinaciones para el b-learning, consta de tres etapas (Figura 3.12). La primera etapa de habilitación de las mezclas, se centra principalmente en abordar las cuestiones de acceso y conveniencia, por ejemplo, las mezclas tienen como objetivo proporcionar una mayor flexibilidad a los alumnos o las mezclas intentan proporcionar las mismas oportunidades de aprendizaje o experiencia. 
La segunda etapa de mejora de las mezclas, posibilita cambios incrementales en la pedagogía, sin cambiar radicalmente la forma de enseñanza y aprendizaje. Esto puede ocurrir en ambos extremos del espectro b-learning. Por ejemplo, en un entorno de aprendizaje tradicional cara cara, recursos adicionales y tal vez algunos materiales complementarios se pueden incluir en línea.

La tercera etapa de transformación de las mezclas, permite una transformación radical de la pedagogía, un cambio de paradigma, por ejemplo, un cambio de un modelo en el que los alumnos son sólo receptores de información a un modelo donde los alumnos construyen activamente el conocimiento a través de interacciones dinámicas. Estos tipos de mezclas permiten la actividad intelectual que no era posible en la práctica sin la tecnología.

14 Figura 3.12: Estructura de valor añadido para el b-learning

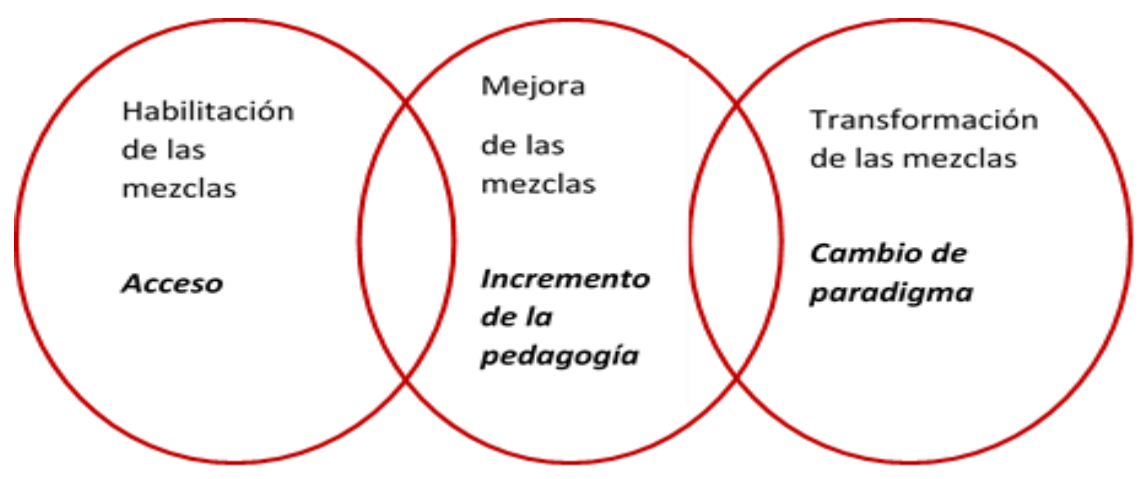

Fuente: Graham, 2006

\subsubsection{Perfil y rol del docente en la modalidad b-learning}

El b-learning es un desafío para los docentes porque aumenta el compromiso pedagógico: al utilizar b-learning los profesores deben resaltar su perfil académico como profesionales innovadores, asumiendo riesgos y desafíos para el beneficio de sus alumnos, centrado en el usuario y el refuerzo sistemático de las actividades de aprendizaje, comunicación, apoyo y evaluación (Gros, 2011; Monteiro et al 2013; Poon, 2013; Stubbs, 2006). Obliga a una mayor planificación de las asignaturas, permitiendo una enseñanza más ordenada y un posible mejor logro de objetivos. Los docentes inmersos en un proyecto $b$-learning podrán adquirir niveles de competencias informáticas de excepción y con metodologías de 
enseñanza y aprendizaje innovadoras (Poon, 2013; Saavedra, 2007). El rol del docente es fundamental para el éxito de este nuevo sistema y si lo asumimos como una innovación, su adopción dependerá fundamentalmente de variables relativas a los profesores (Martín García, 2014). Éste debe resignar parte del control que ejerce en una clase presencial y darle más autonomía al alumno para que trabaje en forma colaborativa, interactiva y participativa. A García Cué (2009) le preocupa que los estilos de enseñar empleados por los profesores no tengan en cuenta los estilos de aprender de los alumnos, ya que los estilos de aprendizaje influyen en las respuestas dadas por los profesores y por los alumnos en el uso de la tecnológica e Internet. Recogiendo los aportes de varios autores (Ardizzone, 2004; Cabero, 2007; Cebrián, 2007; ECDL, 2002; García Nieto, 2005; García-Valcárcel 2007; González, 2007; Gros, 2011; Guitert, 2007; Imbernón, Silva y Guzmán, 2011; Irigoin, 2002; Marcelo, 2004; Miguel, 2006; Monereo, 2005; Morán, 2012; Rodríguez Conde, 2002; Salmon, 2004; Vásquez, 2007) hemos configurado un perfil de competencias requeridas al docente en los modelos b-learning, el cual se expone sintéticamente en la Tabla 3.3.

La implantación de los entornos virtuales provocan un cambio en el rol del profesor y del alumno: hay nueva organización de los contenidos, corresponde realizar una gestión diaria del espacio virtual, la elaboración de nuevos materiales adaptados a las TIC, la realización de tutorías virtuales, revisión, evaluación de trabajos, gestión de grupos de trabajo, acompañamiento y asesoramiento individual y colectivo (Ruiz, 2008; Imbernón et al, 2011; Osorio y Duart, 2011b).

Lo anterior requiere una adecuada preparación del profesor, la disponibilidad de recursos y diseño del material en red son factores de éxito para la implementación de cursos apoyado en TIC, lo que ha traído aparejado las siguientes condiciones en opinión de los docentes participantes:

- Excesivo volumen de trabajo y esfuerzo adicional del docente para hacer frente a la reelaboración, reestructuración, organización de las asignaturas y diseño de materiales (Mondéjar, 2007; Pérez Lorido, 2007; Puentes y Cruz, 2012). La colocación de una parte del contenido en línea no alivia la carga de trabajo del profesor (Singleton, 2013). Poon (2013) sugiere que las instituciones sean realistas respecto a los esfuerzos y tiempo dedicado, 
- Esta alternativa didáctica no dispone, al menos hasta la fecha, de un reconocimiento académico suficiente, que considere una reducción significativa de la docencia presencial para aquellos profesores que trabajan a través del Campus virtual (Pérez Lorido, 2007; Singleton, 2013).

- Estas experiencias son más difíciles que las que se imparten en presencial, tanto para los profesores (elaboración de respuestas a los alumnos, seguimiento, elaboración de materiales) y para los alumnos (disciplina, autonomía, etc.) (Castañeda, 2006).

- Los docentes se han visto "desbordados" en mayor o menor medida para dar retroalimentación (Castañeda, 2006) y en la elaboración de los materiales (Singleton, 2013). Sin embargo, en la tercera o cuarta edición de la acción formativa, según Puentes y Cruz (2012), se puede disminuir el tiempo de dedicación a determinadas demandas de los alumnos adelantándose con las denominadas preguntas frecuentes o FAQ (Frecuently Asked Questions), las que normalmente se realizan en la clase presencial.

- Los docentes deben realizar una cuidadosa selección de herramientas de colaboración y la preparación técnica se deben considerar en el diseño de y la aplicación de aprendizaje mixto (De Jong et al, 2014).

En una investigación realizada por García-Valcárcel (2007), se les solicitó a los docentes que ordenaran las competencias de uso de las TIC por orden de importancia, según la opinión de los profesores universitarios, el listado quedó en el siguiente orden:

1. Saber utilizar Internet para buscar información y recursos en la preparación de las clases.

2. Conocer sitios de Internet (portales, páginas Web, revistas electrónicas, diccionarios, buscadores...) sobre su especialidad.

3. Saber utilizar las principales herramientas de Internet para comunicarse (correo electrónico, listas de distribución, foros...).

4. Saber utilizar programas informáticos específicos de su campo profesional.

5. Elaborar y utilizar presentaciones (PowerPoint...) para explicar temas en clase.

6. Orientar a los alumnos para el uso de las TIC.

7. Conocer estrategias de trabajo colaborativo mediado por TIC.

8. Diseñar una Web docente personal de apoyo a sus clases presenciales.

9. Saber utiliza una plataforma virtual para diseñar actividades complementarias a las presenciales.

10. Diseñar material multimedia (integrando texto, imagen, audio...) para su utilización didáctica. 
11. Colaborar con otros docentes de su especialidad a través de las TIC con fines docentes.

12. Diseñar tutorías online para seguimiento del aprendizaje.

De momento, las primeras preocupaciones están enfocadas desde la clase presencial tradicional. El diseño de actividades complementarias a las presenciales, es decir para generar la modalidad b-learning, aparece en noveno lugar. La última competencia señalada es la de diseñar tutorías online para seguimiento del aprendizaje, siendo esta última la competencia considerada menos importante, mostrando así las reticencias que muchos docentes tienen para el trabajo on-line, entendiendo que nos encontramos en instituciones de enseñanza presencial, donde se brinda a los alumnos un horario de tutorías presenciales que son escasamente aprovechadas por los alumnos y raramente diseñadas por los profesores como tiempos y espacios de seguimiento del aprendizaje.

Sigue persistiendo la preocupación y motivaciones de los docentes en los aspectos tecnológicos ante el b-learning y paulatinamente comienzan a aparecer los aspectos pedagógicos. En su estudio, Monteiro et al (2013) constataron que las motivaciones de los profesores para usar el $b$-learning son la facilidad de disponer recursos para los estudiantes, responder a las demandas metodológicas del acuerdo de Bolonia, por lo cual aparece la necesidad de actualización pedagógica y metodológica. Para los estudiantes su motivación es acceder a materiales con facilidad, rapidez y en cualquier momento, además poder interactuar con compañeros de la clase. La importancia de los recursos Poon (2013) también lo verifica en su estudio, para los estudiantes la disponibilidad de recursos como el factor más importante de éxito de la modalidad b-learning. El $b$-learning posibilita la incorporación de una amplia gama de recursos en el componente en línea, tal como lo demuestra De Jong et al (2014) en su estudio en que compara tres experiencias en las que integran Second Life, foros, blogs y wikis para lograr de manera efectiva aprendizaje activo y colaborativo. 


\section{Tabla 3.3: Competencias requeridas al docente en los modelos b-learning}

\section{COMPETENCIAS}

\section{TECNOLÓGICAS, DIDÁCTICAS Y TUTORIALES:}

- Usar: procesador de texto, base de datos, hojas de cálculo, correo electrónico, chat, foro, videoconferencia, Internet, plataformas, software en uso de la especialidad.

- Utilizar Internet para seleccionar, organizar y valorar información y recursos, realizar seguimiento a los alumnos.

- Marcar el ritmo y el uso del tiempo.

- Diseñar una Web docente personal de apoyo a sus clases presenciales.

- Diseñar tutorías online

- Utilizar una plataforma virtual para diseñar actividades complementarias a las presenciales.

- Diseñar material multimedia (integrando texto, imagen, audio...) para su utilización didáctica.

\section{SISTÉMICAS:}

- Investigar, aplicar, transferir, extrapolar el conocimiento en la práctica y situaciones nuevas.

- Aprender a aprender.

- Organizar y planificar planes y actividades de manera realista que faciliten el aprendizaje.

\section{INTERPERSONALES:}

- Colaborar con otros docentes de su especialidad a través de las TIC con fines docentes.

- Conocer estrategias de trabajo colaborativo mediado por TIC.

- Mantener estilo de comunicación no autoritario, motivador y amistoso.

- Usar y trabajar con las emociones en línea.

- Facilitar técnicas de trabajo intelectual para el estudio en red.

- Usar el humor en línea.

- Plantear observaciones, dudas, cuestiones.

- Promover debates con cuestiones sugerentes.

- Dar feedback a los estudiantes

- Analizar las necesidades y expectativas de los participantes.

- Apoyar y orientar a los alumnos.

- Adaptarse a nuevas situaciones.

- Trabajar autónomamente.

- Diseñar y gestionar proyectos.

\section{CONOCIMIENTOS}

- Conocer sitios de Internet (portales, páginas Web, revistas electrónicas, diccionarios, buscadores...) sobre su especialidad.

- Conocimientos, procedimientos y metodologías específicos de la especialidad.

- Dominio científico, tecnológico y práctico del curso.

- Perfil de egreso y plan de estudios del programa del académico

- Alternativas curriculares y posibilidades de especialización del programa de estudios del estudiante.

- Teorías y didáctica del aprendizaje.

- Teoría y práctica de la comunicación Recursos de ayuda y asesoramiento a los cuales puede acudir el estudiante.

- Conocimientos de los aspectos funcionales de las tecnologías didácticas.

- Conocimiento de las líneas didácticas de los cursos.

- Técnicas de trabajo intelectual para el estudio en red.

- Información objetiva y actualizada de las principales salidas profesionales al finalizar el programa formativo, condiciones del mercado y entorno laboral.

\begin{tabular}{|c|c|}
\hline \multicolumn{2}{|l|}{ ACTITUDES } \\
\hline $\begin{array}{l}\text { - } \text { Motivación y resolución para cumplir rol de tutor } \\
\text { virtual. } \\
\text { - } \quad \text { Comprensión de las dificultades de convertirse en } \\
\text { - } \quad \text { Compromiso con la institución y los estudiantes. } \\
\text { - } \quad \text { Iniciativa y espíritu emprendedor. } \\
\text { - } \quad \text { Ofrecer y recibir críticas constructivas. } \\
\text { - } \\
\text { delicadeza cultural. } \\
\text { Sugerente para promover el debate. }\end{array}$ & $\begin{array}{l}\text { - } \quad \text { Respeto, asertividad, diálogo, escucha. } \\
\text { - } \quad \text { Apertura y accesibilidad a los estudiantes. } \\
\text { - } \quad \text { Mostrar sensibilidad en las relaciones. } \\
\text { - } \quad \text { Responsabilidad, puntualidad. } \\
\text { - } \quad \text { Diálogo, escucha, empatía. } \\
\text { - } \quad \text { Respeto a las ideas de los otros. } \\
\text { - } \quad \text { Sentido positivo ante los problemas técnicos. } \\
\text { - } \quad \text { Amabilidad, Cortesía. } \\
\text { - } \quad \text { Flexibilidad. } \\
\text { - } \quad \text { Trampromiso, entusiasmo por el aprendizaje. } \\
\text { - } \quad \text { Apertura para aceptar sugerencias. }\end{array}$ \\
\hline
\end{tabular}

Fuente: elaboración propia basa en: Ardizzone, 2004; Cabero, 2007; Cebrián, 2007; ECDL, 2002; García Nieto, 2005; García-Valcárcel 2007; González, 2007; Gros, 2011; Guitert, 2007; Imbernón, Silva y Guzmán, 2011; Irigoin, 2002; Marcelo, 2004; Miguel, 2006; Monereo, 2005; Morán, 2012; Rodríguez Conde, 2002; Salmon, 2004; Vásquez, 2007 


\subsubsection{Perfil y rol del estudiante en la modalidad $b$-learning}

El concepto de estudiante ha cambiado de forma notable en la educación superior. No son sólo los jóvenes de entre 18 y 24 años los principales destinatarios de la oferta universitaria, sino que otros segmentos de la población demandan un tipo de formación específica que les sirva para actualizar y mejorar sus conocimientos. En muchos casos, los estudiantes combinan su formación con el trabajo. También son cada vez más los adultos que acceden a las universidades como parte de su formación continua, minorías indígenas, especialmente en América Latina. En definitiva, las necesidades del alumnado son muy variadas y no es fácil pensar en un perfil único de estudiante (Castillo, 2008, Gros, 2007; Levine, 2006; Pittinsky, 2006). Se requieren modalidades flexibles que se adapten a las características y necesidades de los estudiantes con el fin de prolongar el proceso de aprendizaje sin perder el enfoque y los intereses de los estudiantes (Lim, 2009). Además los estudiantes aprenden de diferentes maneras, a su propio ritmo, con diversos estilos de aprendizaje por lo que debemos ofrecer múltiples actividades de aprendizaje de las que el alumno puede elegir (Ardizzone, 2004; Baiton, 2001; Bartolomé, 2004; Beneitone, 2007; Cabero, 2007; ECDL, 2002; García Nieto, 2005; González, 2007; Guitert, 2007; Irigoin, 2002; Marcelo, 2004; Miguel, 2006; Monereo, 2005; OCDE, 2010; Salmon, 2004.) hemos configurado un perfil de competencias requeridas al estudiante en los modelos b-learning, el cual se expone sintéticamente en la Tabla 3.4.

Un elemento más a considerar es que dentro de los espacios virtuales de enseñanza y aprendizaje el rol del estudiante resulta más autónomo, reflexivo y crítico (Imbernón, 2008). El protagonista del proceso es el estudiante, puede preguntar al profesor diez veces más en línea que en la modalidad presencial. El autoaprendizaje adquiere un papel relevante, sin embargo, "nadie les ha enseñado a buscar y seleccionar información de manera crítica, parafraseando y filtrando lo que leen, y recelando de determinadas fuentes, medios o autores" (Monereo, 2005:34).

Los alumnos que han finalizado la enseñanza secundaria, según nos señala Moreno (2003) tienen poca habilidad para "navegar" por los contenidos y estructura, carencia de criterio para distinguir la información importante de la accesoria, deficientes o nulas capacidades de comunicación con el tutor y los compañeros, falta de experiencia en aprendizaje a 
distancia, falta de correspondencia entre las expectativas motivacionales y la realidad y los objetivos del programa formativo, desconocimiento de las propias capacidades y habilidades personales para aprender a distancia.

Lo anterior, nos obliga a considerar las diferencias de los alumnos desde el punto de vista de la motivación (extrínseca e intrínseca), desde canales de percepción (visual, auditivo o cinestésico); desde los estilos cognitivos (activo, reflexivo, teórico) (Moreno, 2003). Además un grupo de habilidades y actitudes básicas personales para aprender en la distancia: autodisciplina, la capacidad de trabajar solo, la gestión del tiempo, cierto grado de independencia en el aprendizaje; capacidad de realizar una programación personal, compaginando vida personal, profesional y estudios. Estas se pueden ver desglosadas en la Tabla 3.4 Competencias de los estudiantes en espacios virtuales.

A finales de la década de los sesenta se consideraba al aula como el único medio para la transmisión de conocimientos, en la actualidad, aunque todavía infrautilizadas, son las TIC las que ofrecen un mayor abanico de posibilidades para la enseñanza. Los alumnos han elegido las asignaturas en red por tres razones principales: curiosidad, posibilidad de flexibilidad en el horario e interés en las TIC (Castañeda, 2006), sin embargo, el volumen de trabajo que les supuso atender esta asignatura online les parece excesivo, superando sobradamente todas sus expectativas iniciales (Mondéjar, 2007; Pérez Lorido, 2007) 2010; Por ello, se requiere predisposición y preparación del alumno (Ruiz, 2008).

Si bien en principio los entornos virtuales posibilitan el desarrollo del aprendizaje significativo, la experimentación de una formación que prepare al alumno para el mundo real, el autoaprendizaje, la productividad, el desarrollo del pensamiento crítico y creativo, el empleo de tecnología (Pérez Navío, 2008), se requiere un esfuerzo adicional por parte de los profesores en el diseño de materiales (Mondéjar, 2007) y en algunos casos los alumnos perciben los cursos demasiado cargados de actividades a las que no les ven la finalidad (Castillo, 2008). Cuando las actividades están bien diseñadas, los alumnos realizaran un esfuerzo mayor, implicándose más en el desarrollo del curso de lo que solían hacerlo presencialmente (Pérez Lorido, 2007). La calidad de las experiencias de aprendizaje de los estudiantes fue influenciado por tres factores, según los resultados de la investigación de Hannah (2010): pertinencia del contenido del curso, autenticidad de los 


\section{Tabla 3.4: Competencias requeridas al estudiante en los modelos b-learning}

\section{COMPETENCIAS

INSTRUMENTALES Y TECNOLÓGICAS:

- Expresarse por escrito con claridad.

- Usar estilo de comunicación virtual.

- Emplear simultáneamente distintos medios.

- Manejar y contrastar fuentes de información.

- Dominar la lectura y comprensión de la lectura textual, audiovisual y multimedia.

- Buscar, seleccionar, organizar y valorar información en Internet.

- Usar criterios para valorar esa información, poseer indicadores de calidad y fiabilidad

- Analizar y sintetizar.

- Diseñar y controlar un esquema de horario - Tomar decisiones, solucionar problemas

\section{SISTÉMICAS:}

- Aplicar, transferir, extrapolar el conocimiento en la práctica y situaciones nuevas.

- Abstracción, análisis y síntesis

- Percibir el conjunto de la estructura global del itinerario formativo y de su significado.

- Ejercer control metacognitivo sobre los acontecimientos.

- Aprender a aprender.

- Aprender de manera autónoma.

\section{INTERPERSONALES:}

- Trabajar con los demás por un objetivo común y saber trabajar en red o entornos virtuales.

- Participar activamente en los procesos.

- Negociar con empatía.

- Aceptar los sistemas de reglas de comportamiento.

- Reflexionar y evaluar su propio trabajo.

- Plantear observaciones, dudas, cuestiones.

- Aceptar y plantear críticas.

- Expresarse, comunicar y crear.

- Ver perspectivas culturales diferentes.

- Participar en la vida pública

- Organizar y planificar planes, actividades y el aprendizaje de manera realista.

- Establecer prioridades.

- Adaptarse a nuevas situaciones.

- Generar nuevas ideas.

- Trabajar autónomamente.

- Diseñar y gestionar proyectos.

- Usar los mecanismos de los ambientes tecnológicos.

- Manejar ordenadores.

\section{CONOCIMIENTOS}

- Conocimiento general básico.

- Conocimiento sobre el área de estudio.

- Rudimentos en conocimiento básico de la profesión.

- Conocimientos, procedimientos y metodologías específicos de la especialidad.

- $\quad$ Estilos de aprendizaje.

- Técnicas de estudio.

\begin{tabular}{|c|c|}
\hline \multicolumn{2}{|l|}{ ACTITUDES } \\
\hline 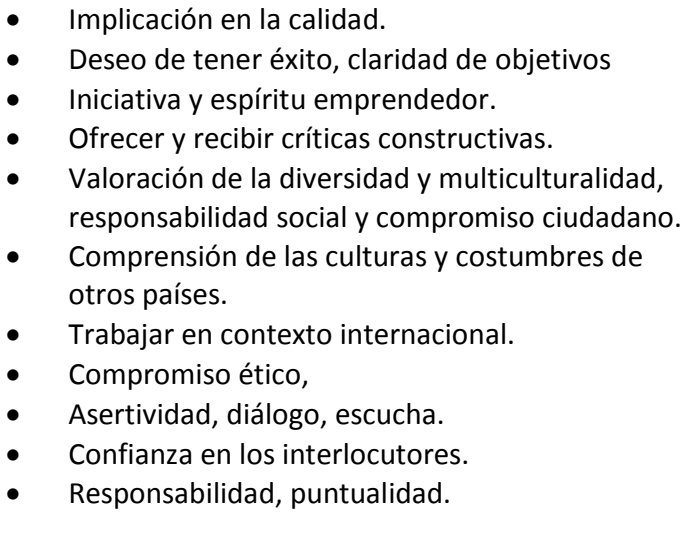 & 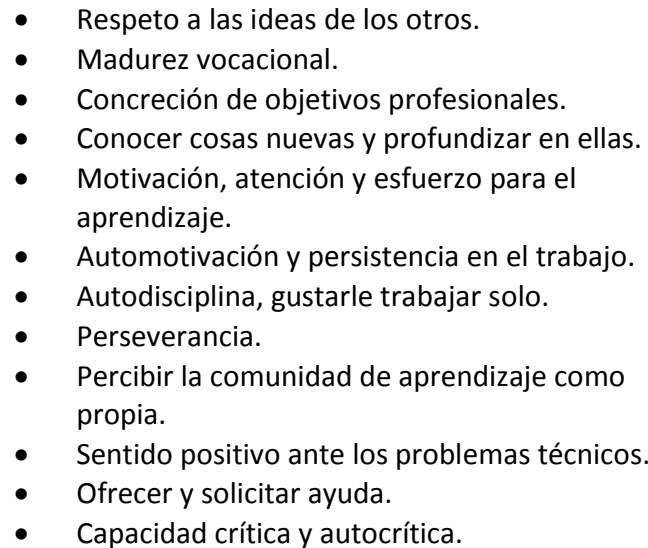 \\
\hline
\end{tabular}

Fuente: elaboración propia basa en: Ardizzone, 2004; Cabero, 2007; Cebrián, 2007; ECDL, 2002; García Nieto, 2005; García-Valcárcel 2007; González, 2007; Gros, 2011; Guitert, 2007; Imbernón, Silva y Guzmán, 2011; Irigoin, 2002; Marcelo, 2004; Miguel, 2006; Monereo, 2005; Morán, 2012; 2002; Salmon, 2004; Vásquez, 2007 
ejercicios de clase y actividades y contexto físico del curso. Por su parte, González Rogado et al $(2010,2013)$ concluyen que la modalidad b-learning metodología permiten al estudiante una mayor responsabilidad hacia el proceso de aprendizaje, una mayor motivación y un resultado final más satisfactorio.

\subsection{Resultados acerca de la efectividad del b-learning}

La experiencia didáctica en el ambiente el virtual es relativamente reciente la que se incrementa cada año con resultados positivos lo que permite al b-learning, según GonzálezVidegaray (2007), una entrada "suave" al mundo del aprendizaje en línea, evitando la percepción de que esta modalidad pudiera ser de menor calidad que la educación presencial y brindando a los estudiantes los beneficios de contar con un grupo y atención personales, y tal como lo señala Martín García (2014) no implica abandonar la modalidad convencional y sus ventajas.

Las investigaciones que reseñaremos más adelante, relacionadas con los resultados del $b$ learning en educación superior, abordan diversos aspectos de su efectividad, entendida ésta como la capacidad de lograr el efecto que se desea o se espera. Los efectos que se han estudiado dicen relación con: rendimiento académico; reducción de tasas de reprobación y deserción; evaluación de la calidad; el logro de determinadas competencias tecnológicas; implementación de ciertas orientaciones curriculares, como la perspectiva de género; capacidad para generar un aprendizaje significativo; si logran modificar de alguna manera los enfoques de aprendizaje de los alumnos; el manejo del tiempo; las expectativas y satisfacción de los estudiantes y docentes; opiniones del alumnado, antes de empezar y al finalizar la misma la experiencia virtual; ventajas y desventajas tecnológicas y pedagógicas del uso de herramientas en los espacios virtuales; diseño, organización y funcionamiento del b-learning; potencialidades y facilidades que genera un entorno virtual en el aprendizaje.

Martín García (2014), a partir de su estudio, nos ofrece un conjunto de variables o atributos percibidos como relevantes al implementar el b-learning: 
"Ventaja relativa (la percepción de los profesores sobre si aceptar la innovación implica una mejora en su desempeño profesional); compatibilidad (grado en que una innovación es compatible con los valores, experiencias o necesidades existentes en el sistema universitario dado); visibilidad (grado en que los resultados son visibles a otros miembros de la comunidad académica); complejidad (el grado de facilidad o dificultad de uso de b-learning) y, por último, el grado de experimentalidad (la posibilidad de probar la innovación b-learning para evaluar sus potencialidades y aplicación en la enseñanza superior)" (Martín García, 2014:73).

El ambiente de aprendizaje combinado es cada vez más utilizado en el mundo, especialmente en las titulaciones universitarias (Morán, 2012; Yilmaz, 2010). Este incremento y orientación del uso del e-learning, Singh (2003) lo había denominado como la segunda ola de e-learning, y más recientemente, un número creciente de diseñadores de aprendizaje están experimentando con el aprendizaje mixto, modelos que combinan varios modos de entrega. George-Palilonis (2009) en sus estudios han encontrado que los estudiantes adultos prefieren los diseños mezclados ya que ofrecen oportunidades para la personalización, la autodirección, el uso de una variedad de estrategias, medios y materiales, y la generación de comunidades de aprendizaje. Ya mencionamos en el capítulo anterior el estudio longitudinal ECAR aplicado desde el año 2004 (Dahlstrom et al, 2013), algunos de los principales hallazgos destacan que los estudiantes reconocen el valor de la tecnología, pero todavía necesitan orientación en lo que respecta a un mejor uso para fines académicos, y en esta perspectiva, señalan que prefieren ambientes de aprendizaje b-learning. Coinciden Monteiro et al (2013) y Osorio y Duart (2011b) con el estudio ECAR (2013) en cuanto al rol preponderante del profesor como factor de motivación para el uso de la tecnología en función de actividades académicas.

\subsubsection{Desempeño académico}

La efectividad es difícil de evaluar ya que es complicado encontrar datos que den respuesta a preguntas sobre cómo sabemos si los estudiantes aprenden más y mejor, si un 
determinado método hace más productivo el aprendizaje (Gros, 2007). Sin embargo, una de las preocupaciones de las instituciones es si la incorporación de nuevas metodologías soportadas por ciertas tecnologías, afectarán en los resultados académicos de los estudiantes. Las evidencias que nos aportan las investigaciones que en la generalidad de los casos se producen resultados levemente superiores o similares en la modalidad $b$ learning respecto a la tradicional cara a cara. Según las evidencias de los estudios de AlHuneidi y Schreurs, (2012), Back et al (2014), Bridges et al (2014), González Rogado et al (2010, 2013), Puentes y Cruz (2012), Rodrigues et al (2012), Singh (2003), el aprendizaje mixto no sólo ofrece más opciones, sino también es más efectivo, mejora los resultados de aprendizaje y la calidad, además de la consolidación del modelo $b$-learning. Por su parte Martín García y Gacía del Dujo (2014) constataron en su investigación que la expectativa frente a los resultados como el más fuerte predictor en la intención de uso de la modalidad b-learning, además que los cursos b-learning están logrando ser potencialmente la mejora manera de incrementar los resultados de aprendizaje en los estudiantes (Cubides y Martín García, 2014).

Means et al (2009), en un estudio encargado por el Gobierno de EEUU, analiza más de 1400 publicaciones relacionadas con el uso de tecnologías en educación, encontró que en promedio los estudiantes en las condiciones de aprendizaje en línea se desempeñaron mejor que los que recibieron instrucción cara a cara, y el contraste fue mayor en los que cursaron la modalidad de $b$-learning. Estas condiciones combinadas a menudo incluyen el tiempo adicional de aprendizaje y elementos de instrucción no han tenido los estudiantes de los grupos de control. Este hallazgo sugiere que los efectos positivos asociados con el aprendizaje mixto no deben atribuirse, en sí mismo, a los medios de comunicación utilizados. El propio Means et al (2013) en un nuevo meta análisis sigue constata, por un lado, que las diversas formas de educación a distancia no difieren significativamente de las clases regulares en términos de resultados de aprendizaje y, por otro lado, el b-learning obtiene mejores resultados en contraste a la modalidad tradicional cara a cara. Se refuerza la constatación de que en el b-learning las actividades tienden a implicar más tiempo de aprendizaje, más recursos educativos y fomento de la interacción entre los alumnos. La particularidad de este mayor tiempo de dedicación constatan varios autores es que está organizado, tanto los materiales como las actividades y la retroalimentación (Al-Huneidi y 
Schreurs, 2012; So, 2013). Con esta organización del tiempo la clase presencial tiene una continuidad en las actividades en línea, los alumnos llegan preparados a clases (Poon, 2013) transformándose paulatinamente la instancia presencial, cara a cara, en una plenaria. En estudio previo, Hun, Morris y Kupritz (2007) comprobaron que los estudiantes de la modalidad mixta experimentaron una carga mayor de trabajo respecto al grupo control en línea. Los alumnos los alumnos en formato de entrega en línea sintieron significativamente menos apoyo al aprendizaje durante el estudio que sus alumnos de contraparte en formato de entrega mezclado.

Si bien se aprecian buenos resultados académicos en términos de menores tasas de abandono (Pereira, 2007; López, Pérez, Rodríguez, 2013) y mayor rendimiento académico, con diferentes grados de significatividad estadística de la modalidad b-learning respecto a la presencial tradicional (Marzo, 2004; Ruiz, 2007; Pereira, 2007; Hun et al, 2007; Area, 2008; Campbell, 2008; Mayorga, 2009; Cabero, 2009; George-Palilonis, 2009; Essam, 2010; López, Pérez, Rodríguez, 2013; Li et al, 2014), la evaluación mediante los test tradicionales no miden otras competencias que pudieran lograrse en la modalidad $b$-learning que no se consiguen en la clase presencial. La potencia de las nuevas herramientas debiera medirse en función de sus particularidades. Como señalan Bigum y Rowan (2004), es como probar la capacidad de tracción de los coches uniendo arados para ello.

Revisaremos a continuación los resultados de diversas investigaciones centrándonos en el desarrollo de habilidades, satisfacción de los estudiantes y la valoración de la presencialidad.

\subsubsection{Desarrollo de habilidades}

Para los alumnos universitarios que participaron en asignaturas o cursos en la modalidad b-learning en comparación con el modelo tradicional de aprendizaje, constatan que han tenido un mayor desarrollo de sus disposiciones de pensamiento y de los niveles críticos (Ozgen, 2009); un mayor desarrollo de habilidad, presencia social y comunicación e interacción social (Akyol, 2009; Cubides y Martín García, 2014; Dettori, 2007); una mejora de las actitudes hacia Internet (Llorente, 2008); han pedido actividades de auto-control que 
les permitan evaluar el grado en que habían entendido con éxito el contenido de la sesión, se puede inferir que motivados por asumir la responsabilidad de dirigir y evaluar su propio aprendizaje (Frederickson, 2005; Pereira, 2007); mejoraran las competencias de idiomas (Morales, 2008); desarrollo de la competencia trabajar en equipo (Aguado et al, 2011); ahondar de manera autónoma en los conceptos (Durán, Costaguta, Gola, 2011); cambio de las motivaciones y estrategias de aprendizaje por medio de actividades orientadas al aprendizaje autogestionado y el trabajo colaborativo (Fernández, 2011; De Jong et al, 2014); interacciones en ambientes virtuales e híbridos (Osorio, Duart, 2011b); apoyar la comprensión lectora de textos expositivos desde la vinculación de diferentes recursos de aprendizaje (Quitian, 2011); la investigación y el compromiso en el trabajo autónomo en línea mejoran el desempeño en las presentaciones orales presenciales (Rodrigues et al 2012); la creación de comunidades de aprendizaje en línea para estudiantes a través de un enfoque mixto para el aprendizaje estimula la motivación y el compromiso intelectual (Bridges et al, 2014).

Los resultados del estudio de Shroff (2009) sugieren que no hubo diferencia estadística en la percepción de interés de los sujetos, tanto en la línea como en las discusiones cara a cara. Sin embargo, los sujetos en las discusiones en línea estaban ansiosos por participar en el diálogo textual y por lo tanto, participaron más en las discusiones respecto a los debates cara a cara. Por su parte, Penalva, Rey y Llinares (2011) seleccionaron intencionadamente la modalidad de $b$-learning porque podían desarrollar actividades auténticas para lograr la identidad profesional del psicopedagogo. Particularmente las actividades en línea en mayor medida que las presenciales, les facilitó a los alumnos tener participaciones más reflexivas y argumentadas, aspecto con el que coinciden ElMowafy et al (2013) en cuanto a la mejora de la participación de los estudiantes, especialmente la evaluación entre pares.

En otros estudios se constata que a través del $b$-learning los alumnos pueden desarrollar habilidades de procesamiento de la información, tales como: buscar y encontrar información relevante en la red; desarrollar criterios para valorar dicha información, poseer indicadores de calidad; aplicar información a la elaboración de nueva información. La opción de acceder a los contenidos de un curso a través de Internet, durante 24 horas al día, los siete días de la semana, favorece así el estudio y aprendizaje flexibilizado y adaptado al ritmo de cada alumno (Saavedra, 2007). Además, provee a los estudiantes de las experiencias tecnológicas y computacionales apropiadas, como lo harían "en la vida real", para discriminar información, trabajar de manera colaborativa (virtual o presencial), 
y que se puedan expresar de una forma adecuada, de manera oral y escrita (Pérez Navío, 2008). Los alumnos resuelven en horario no presencial casos sobre resolución de situaciones reales con el objeto de acercar la realidad profesional a un tipo de aprendizaje que se haga más contextualizado. Con este tipo de actividades el estudiante se involucra de una manera más activa en el proceso de aprendizaje, al mismo tiempo que desarrolla competencias de tipo profesional (Mayorga, 2009).

Las ventajas en el rendimiento académico y en el desarrollo de ciertas habilidades se deberían a la mayor preparación previa de las actividades en línea por parte del profesor. Los estudiantes indican que aprenden mucho del material en línea. Campbell (2005) constató que el aprendizaje logrado en línea permanece por un período más largo de tiempo sin la necesidad de que el profesor esté todo el tiempo. Por su parte Tempelaar (2009) ha verificado que aquellos estudiantes que tienen una menor autorregulación de sus actividades personales de aprendizaje, la disponibilidad de herramientas de aprendizaje electrónico, les favorece aprender a aprender y tienden a dedicar más tiempo al aprendizaje. Durán, Costaguta y Gola (2011) si bien valoran el b-learning en la formación de las titulaciones de ingeniería, en su investigación concluyen que las actividades a futuro deben diseñarla para lograr en los estudiantes la capacidad de mediar ante diferencias dentro de los grupos de trabajo, mejorar la participación y trabajo colaborativo. Es decir, la tecnología por sí misma en instancias formativas no logra el trabajo colaborativo si la actividad no se diseña con esa intencionalidad o la que se desee.

\subsubsection{Satisfacción de los estudiantes}

Los resultados que obtienen Ginns (2009), Precel (2009), Pérez Lorido (2007), muestran que los estudiantes prefieren b-learning. Otros estudios que coinciden en que los estudiantes tienen cierto grado de satisfacción hacia b-learning, se centran en las variables asociadas al contenido de los cursos, las técnicas empleadas, la flexibilidad, la comunidad de aprendizaje conformada (Back et al, 2014; Ruiz, 2007; Silva y Astudillo, 2012). Por su parte Ling (2010) aborda la motivación, la participación, el diálogo e interacción, el aprendizaje complementario y el aprendizaje personalizado; Yilmaz (2010) las expectativas de rendimiento; Wu (2010) la funcionalidad del sistema, el clima de aprendizaje y el 
material didáctico; López et al (2013) la experiencia global de aprender con una modalidad de aprendizaje combinado; Puentes y Cruz (2012) calidad de los materiales presentados y comunicación con el profesor; Flores (2012) la semipresencialidad es una oportunidad de conjugar una formación en el aula con un trabajo más flexible y autónomo para el alumno que da un valor añadido a la asignatura.

Otro de los aspectos estudiados es el aporte de ciertos enfoques didácticos como el aprendizaje basado en problemas y el método de proyectos al aumento en la motivación de los estudiantes (Derntl, 2005; Woltering, 2009), así como la comunicación establecida con los profesores y compañeros, con el empleo de la plataforma de formación, o con los contenidos ofrecidos (Cabero, 2009) y la relación profesor-alumno parece enriquecerse (Pereira, 2007; Pérez Lorido, 2007). El logro que señala George-Palilonis (2009: 254) es "tal vez el mayor resultado para nosotros fue la sensación de normalidad que se convirtió en parte de las actividades a través del tiempo. Los estudiantes simplemente ven el enfoque mixto como "parte del proceso" y para ello fueron capaces de adaptarse bien a este ambiente". Si bien los estudiantes valoran el uso de la tecnología, también valoran su privacidad y la tecnología para conectarse con ellos tiene sus límites, como lo constatan en su estudio Dahlstrom et al (2013).

\subsubsection{Valoración de la presencialidad}

La presencialidad sigue teniendo un rol importante, como lo constata Castañeda (2006), algunos de los profesores que han apostado por un modelo entero a través de la red creen que para futuras ediciones deben aumentar la cantidad de trabajo presencial, de manera que suponga un cambio menos radical al alumno proveniente de un marco presencial y además pueda tener mayor "contacto" con sus otros compañeros y con el docente. La presencialidad tiene también virtudes características difíciles de equiparar en un entorno tecnológico como el Campus virtual. López et al (2013) en su investigación que abarca la implementación de la modalidad b-leaning en alumnos de primer año, de diversas titulaciones en el periodo 2008-2010, con una población intervenida sobre 1400 alumnos por año, concluyen que los estudiantes si bien valoran las actividades en línea, las ven como complementarias sin llegar a reemplazar a las presenciales cara a cara. 
Por otro lado, si bien como apunta Pérez Lorido (2007), existe la necesidad de buscar alternativas a la presencialidad, sin embargo la valoración que hacen los docentes de las tecnologías tiende a ser desde el paradigma tradicional de la clase presencial (GarcíaValcárcel, 2007). La clase magistral tiende a imponer al estudiante aquello que ha de aprender sin tener muy en cuenta las estrategias o medios para aprenderlo (Marzo, 2006), en cambio el $b$-learning debe ofrecer las estrategias dada la no presencia del profesor. La valoración positiva que existe de la formación presencial y el contacto directo entre profesores y alumnos, llega hasta el punto de vincular tácitamente la identidad característica del docente a la presencialidad (Pérez Lorido, 2007).

En la clase tradicional la interacción entre el profesor y los estudiantes es manejada por éste. Ante la pregunta de un alumno, la respuesta sirve a todos al mismo tiempo y en grupos-curso numerosos, sólo algunos pueden participar. La clase presencial tiene mucho margen para la improvisación y el surgimiento de situaciones emergentes, cuestión que no es posible en programas o actividades de formación en ambientes virtuales, cualquier aspecto que no esté considerado y genere dudas, tendremos a cada estudiante preguntando. El diseño de la interacción no se puede dejar al azar. Bartolomé (2008) nos advierte que falsas ideas previas sobre el diseño de los entornos virtuales tales como: diseñar un curso virtual es preparar los materiales del curso y colocarlos en Internet; los Campus virtuales han de contener todas las herramientas que necesita utilizar el alumno, un Campus virtual necesita de una plataforma tecnológica. Los estudiantes y los profesores, según Poon (2013) todavía quieren la interacción cara a cara a la vez que valoran la facilidades que ofrece el b-learning para realizar seguimiento a las actividades y acompañamiento personal (Cubides y Martín García, 2014):

La versatilidad de recursos tecnológicos accesibles en las plataformas habituales facilita el que el diseño de los cursos pueda adecuarse tanto a las habilidades de los profesores como a las necesidades de alumnos y docentes. Hacen posible un mejor seguimiento, control y registro de las actividades personales de cada alumno (Mondéjar, 2007). Sin embargo, se debe estar atento ya que el proceso de enseñanza puede volverse frío y difícil de monitorear (Castañeda, 2006; Pérez Navío, 2008; Tirado, 2009). 
La Web puede servir para mantener a los grupos conectados, manteniendo la comunidad de aprendizaje con otros y con el contenido entre cada sesión presencial, creando experiencias interactivas y de simulación muy rico para los estudiantes. (George-Palilonis, 2009). Garrison y Cleveland-Innes (2005) citados por García Cabrero (2008) señalan que la interacción es el aspecto central de una experiencia educativa, y cuando se intenta promover el desarrollo del pensamiento crítico y reflexivo mediante estrategias de modelamiento y andamiaje, se requiere que la interacción sea más sistemática y estructurada.

Los criterios de diseño sugeridos por Coll (2006) ponen énfasis en organizar actividades prácticas que permitan la interacción del estudiante con el objeto de conocimiento, además a través del trabajo colaborativo permite la interacción entre estudiantes. Por medio del seguimiento, apoyo y tutorización continuados y personalizados por parte del profesor, logra la interacción profesor-alumno, de esta forma se establecen redes de trabajo. Si bien las redes constituyen formas muy antiguas de actividad humana, el impulso de las nuevas tecnologías le ha dado una renovada flexibilidad y adaptabilidad en su potencial de redes de información (Lion, 2006), por ello no se trata de que traigamos tal o cual medio a nuestra clase y lo usemos en una determinada situación, más bien sucede lo contrario, que nos llevamos la clase al medio y por lo mismo muchos elementos que antes eran del todo conocidos y, al menos en principio controlados, pasan a ser nuevos focos de reflexión, y, como no, de preocupación para el docente.

Coincidimos con Pérez Lorido $(2007,12)$ respecto a que "limitarse a reproducir las prácticas presenciales en la red no tiene demasiado sentido (especialmente en función del tipo de actividades que se desarrollen habitualmente en las aulas), elaborar propuestas didácticas bien fundamentadas pedagógicamente que se beneficien de la capacidad informativa y comunicativa de la red y de todo su potencial formativo, puede resultar un valor añadido para toda la comunidad educativa, constituyéndose como catalizador de procesos de renovación pedagógica."

El b-learning permite a la universidad vista como institución resaltar un sello tecnológico, junto con ello, ahorrar en economías de escala, ya que los contenidos multimedia para el ejercicio del b-learning pueden ser reutilizados y fácilmente adecuados a diferentes 
asignaturas de distintos planes de carrera, con el considerable ahorro por virtualización y en material impreso y fotocopiado; y disponer de infraestructura para más y mejores actividades académicas.

Cerramos este capítulo concluyendo que las nuevas tecnologías de la información y las comunicaciones, las que experimentando un constante avance, han generado un nuevo escenario educativo para la universidad que demanda cambios en los aspectos metodológicos. Se va perfilando en la investigación el estudio del uso de modelos pedagógico en situaciones, casos o experiencias del uso o incorporación de tecnologías, para lo que se demanda modelos teóricos sólidos pertinentes y que den cuenta del real impacto del uso de tecnologías en el proceso y los resultados. En el capítulo siguiente estudiaremos una de las teorías que está teniendo un creciente uso en el estudio de experiencias de aprendizaje con tecnologías, nos referimos a la teoría de la actividad, la que desde la década del treinta del siglo pasado hasta nuestra época, ha evolucionado demostrando ser un sólido modelo de análisis. 


\section{CAPÍTULO 4 \\ LA TEORÍA DE LA ACTIVIDAD COMO FUNDAMENTO PEDAGÓGICO DE LOS MODELOS BLENDED LEARNING}
4.1. Evolución de la teoría de la actividad
4.1.1 La mediación cultural de Vigotsky
4.1.2 La estructura jerárquica de la actividad definida por Leontiev
4.1.3 Expansión del modelo de Vigotsky hacia el sistema de actividad
4.1.4 Interacción de los sistemas de actividad
4.1.5 Los ciclos expansivos de la actividad
4.1.6. La actividad como base de la formación b-learning 


\section{CAPÍTULO 4}

\section{LA TEORÍA DE LA ACTIVIDAD COMO FUNDAMENTO PEDAGÓGICO DE LOS MODELOS BLENDED LEARNING}

La teoría de la actividad ofrece un marco conceptual en el que podemos situar los elementos sociales, pedagógicos y tecnológicos de un modelo blended learning, en una misma unidad de análisis, llamada actividad. Cuando una herramienta, tal como la tecnología, o cuando el docente incorpora innovaciones, la teoría de la actividad se convierte en buen lente (Murphy y Rodríguez, 2008), un marco de inteligibilidad pedagógica (García del Dujo y Martín, 2002) o dicho en palabras de García Carrasco (2007) es un buen macroscopio, una perspectiva, un marco conceptual. Precisa García Carrasco (2007) que los macroscopios los construimos con ciertos materiales como los supuestos básicos, sistemas de proposiciones aceptadas y compromisos intelectuales compartidos. Por ejemplo, el concepto de actividad ayuda a identificar integradamente los elementos necesarios para explicar la forma como aprende un grupo de trabajo o una comunidad de aprendizaje en el contexto de la educación superior.

La vigencia del interés y el incremento de la teoría de la actividad en el uso como marco de referencia teórico, como macroscopio, lo vemos reflejado en varias publicaciones, en campos muy diversos. Jonanssen (1999), a partir de la revisión de un conjunto de investigaciones, constata que la teoría de la actividad proporciona un lente diferente a otras teorías para analizar procesos de aprendizaje. Se explica, según Sandars (2005) y Jaworski et al (2012), la importancia que ha ido adquiriendo la teoría de la actividad por su aporte a ofrecer una visión integradora como método para analizar y comprender el aprendizaje humano, junto a comprender las tensiones y motivos que subyacen a la actividad en su conjunto Además, la teoría de la actividad reconoce la importancia de las influencias culturales y que la actividad se produce dentro de un sistema social. Puede ser una herramienta extremadamente útil para la el desarrollo de la práctica reflexiva, un 
componente clave para mejorar el aprendizaje en contextos reales en los que se utilicen herramientas tecnológicas (Barros, Vélez y Verdejo, 2004; Murphy y Rodríguez, 2008; Osorio y Duart, 2012). Asghar (2013) y Sam (2012) coinciden en su doble valoración de teoría de la actividad, por un lado les ofrece un nuevo marco conceptual para estudiar de manera integral el nexo de las personas, la tecnología y la comunidad en línea, y por otro, es un medio apropiado para diseñar formas de mejorar o remodelar las interacciones y el diseño actividades de aprendizaje logrando un cambio en las prácticas pedagógicas.

Una de las aplicaciones de la teoría de la actividad que podemos destacar es en el estudio, análisis e interpretación de los cambios necesarios para la transformación de las prácticas colectivas en las organizaciones, instituciones, empresas y otros sistemas de actividad. Engeström (2010) da cuenta de ello en una serie de estudios de caso de equipos de trabajo en los Estados Unidos y Finlandia, durante un período de tiempo de más de diez años. Las organizaciones y situaciones que analiza son diversas, tales como una productora de televisión, el trabajo de equipo de adversarios en un juicio en la corte, así como, el trabajo en equipo entre profesores en una institución educacional, un centro de atención médica primaria, cuestión que también aborda Kajamaa (2012) usando la teoría de actividad para estudiar la intervención en hospitales públicos. Otro equipo de investigadores (Allen, Karanasios y Slavova, 2011) reconocen el valor que les ha proporcionado los últimos siete años la teoría de la actividad como un lente teórico para dar cuenta del contexto y la actividad de mediación en los campos del comportamiento de la información y los sistemas de información.

Vamos verificando que la teoría de la actividad se muestra como un referente adecuado cuando se plantean situaciones que involucran a grupos de personas que realizan actividades mediadas o facilitadas por un soporte tecnológico. Varios investigadores abordan las posibilidades de aprendizaje colaborativo que generan diversas herramientas tecnológicas, tales como las plataformas tecnológicas (Gros, 2005), la tecnología móvil (Zurita, 2007), uso del software GeoGebra en el aprendizaje de matemática (Jaworski et al, 2012) y la experiencia de aprendizaje virtual en la enseñanza de matemática (Ramírez, Juárez y Remensal, 2012), los entornos tecnológicos modelados (Barros, Vélez y Verdejo, 2004), la integración pedagógica de Facebook para generar un andamiaje cognitivo (Rambe, 2012). Otros investigadores han estudiado las interacciones generadas en las 
situaciones de aprendizaje (Scanlon, 2005), los procesos cognitivos y el papel de la mediación de las herramientas en la educación matemática (2012); las nuevas relaciones sociales posibles de establecer con las redes tecnológicas (Mazzoni, 2009), el papel mediador de las tecnologías (Baran y Cagilaty, 2010), la generación de comunidades virtuales de aprendizaje (Miranda y Tirado, 2013).

También se ha usado la teoría de la actividad para comprender la implementación soluciones e-learning. En particular Mwanza y Engeström (2003) destacan la sensibilidad que ofrece la teoría de la actividad como referente teórico para analizar las condiciones específicas y las prioridades concretas, a nivel macro (fuerzas económicas y políticas) y nivel micro (enseñanza y aprendizaje) en estas incorporaciones de modalidades de uso de tecnologías a nivel institucional. Coincide Robertson (2008) al encontrar en la teoría de la actividad un lenguaje común para el análisis institucional en estos niveles macro y micro.

Constatamos una tendencia a estudiar los sistemas de enseñanza-aprendizaje con apoyo de tecnologías en sus respectivos contextos de las comunidades. El sujeto en el modelo de la teoría de la actividad puede ser el propio docente, cuando el investigador explora cómo afecta su práctica educativa en el cambio educativo al usar nuevas tecnologías (Murphy, 2008) y las preocupaciones que emergen en el docente al incorporar nuevas tecnologías en su práctica (Karasavvidis, 2009).

Desde hace más de cuatro décadas la teoría de la actividad comenzó alcanzar amplia aceptación en occidente, desde que ésta se dio a conocer a nivel internacional a finales de 1970 y principios de 1980 a través de dos publicaciones: la traducción al inglés del texto de Leontiev Activity, Consciousness, and Personality (1978), y una colección de trabajos de Leontiev y otros teóricos de la actividad editada por James Wertsch (The concept of activity in Soviet psychology, 1981).

El interés internacional en la teoría de la actividad aumentó durante el decenio de 1990 y su más importante crecimiento lo ha tenido entre el año 2000 y 2012, medido a través de la frecuencia de citas en revistas, según la base de datos de citas del Institute for Scientific Information (ISI) (Roth, 2007; 2012). El creciente interés en la teoría de la actividad en las últimas tres décadas Roth lo constata con cuatro indicadores de índices de citación de: 1) las palabras clave "teoría de la actividad", 2) los dos libros de Leontiev disponibles en inglés, 
3) el libro de Engeström Learning by Expanding (1987) y 4) el artículo A cultural historical approach to distributed cognition de Cole y Engeström de 1993. De acuerdo con Roth (2007; 2012), parte del crédito de la difusión y desarrollo de la teoría de la actividad se debe dar a Engeström, que a través de sus publicaciones y aplicaciones en una variedad de disciplinas ha dado a conocer esta teoría. Engeström (1999) visualiza que la teoría de la actividad ha trascendido sus propios orígenes y se está convirtiendo en una teoría internacional y multidisciplinaria.

\subsection{Evolución de la teoría de la actividad}

La teoría de la actividad nació como un enfoque filosófico para analizar diferentes formas de la práctica humana como procesos de desarrollo, con niveles interrelacionados tanto individuales como sociales. Tiene sus orígenes en el modelo de acción mediada planteada por Vigotsky, cuyos componentes son el sujeto, el objeto y los artefactos mediadores (materiales o simbólicos). Este planteamiento fue desarrollado posteriormente por Leontiev, discípulo de Vigotsky, quien expandió la idea de acción individual a la noción de actividad humana (Gros, 2005, 2006).

La teoría de la actividad es una teoría dinámica que ha evolucionado desde sus orígenes. Para caracterizar los distintos momentos de su evolución y acotar las aportaciones de los teóricos, usaremos la distinción de las tres generaciones de la teoría de la actividad establecida por Engeström (1987, 1993, 2001, 2007; 2010).

La primera generación se basa en la idea de Vigotsky de mediación cultural. Vigotsky (1979) concibe que toda acción humana del individuo está mediada por instrumentos y orientada hacia determinados objetos, idea que forma parte del uno de los tres núcleos de la estructura teórica de Vigotsky. En palabras de Wertsch (1988), los procesos mentales pueden entenderse solamente mediante la comprensión de los instrumentos y signos que actúan como mediadores. Los otros dos temas del núcleo de la teoría son la creencia en el método genético evolutivo y la tesis de que los procesos mentales superiores tienen sus orígenes en procesos sociales. 
La segunda generación, en gran medida inspirada por el trabajo de Leontiev, según Werstsch (1988) es uno de los principales continuadores de las ideas de Vigotsky, supera la limitación de la primera generación de enfocar la unidad de análisis en el individuo. Leontiev demuestra cómo la división del trabajo da lugar a la diferenciación entre una acción individual y una actividad colectiva. Engeström (1987) basado en los aportes de Vigotsky y Leontiev, amplía la representación original de los sistemas de actividad, usada por la primera generación, para explicitar los elementos sociales/colectivos de un sistema de actividad, añadiendo los elementos de la comunidad, las reglas y la división del trabajo, con lo que destaca la importancia de analizar las interacciones mutuas.

En la tercera generación de la teoría de la actividad, Engeström (2001) desarrolla las herramientas conceptuales para entender el diálogo, la multiplicidad de perspectivas y las redes de interacción de los sistemas de actividad. El objetivo del modelo de Engeström es trascender el carácter individual de la actividad, hacia un carácter colectivo, que represente de una mejor manera los elementos sociales e histórico-culturales que están presentes en toda actividad humana.

A continuación revisaremos cómo ha evolucionado la teoría de la actividad para constituirse en marco teórico de referencia para comprender el proceso de aprendizaje humano con el uso tecnologías de la información y la comunicación. En propias palabras de Engeström, "la teoría de la actividad es de hecho una teoría abierta que se ha enriquecido constantemente" (Engeström, 2007: 259).

\subsubsection{La mediación cultural de Vigotsky}

En la década de los años veinte del siglo pasado, un grupo de especialistas soviéticos plantearon una reestructuración de la psicología como ciencia, a partir de los principios de la filosofía marxista, con la intención de sobreponerse a la psicología subjetiva e idealista, dando fin a la disociación de la psiquis humana como portadora de las relaciones sociales. Muchos años después de la muerte de Vigotsky, Leontiev señala que "los investigadores americanos se dedican constantemente a averiguar cómo llega a ser el niño lo que es; en 
la URSS se intenta descubrir no como el niño llega a ser lo que es, sino cómo se puede llegar a ser lo que no es" (Leontiev, 1977, citado por Wertsch, 1988: 84).

Vigotsky $(1979,1987)$ esclareció en su obra el papel no sólo de la actividad, sino también de la comunicación en la socialización del individuo. Desarrolla el enfoque histórico-cultural para explicar el psiquismo humano y la formación de la personalidad desde la filosofía marxista, con lo cual revoluciona la psicología de su época y trasciende a la misma, manteniendo en la actualidad plena vigencia. Vigotsky y sus colaboradores destacaban la importancia de la actividad del hombre, mediada por las influencias históricas y culturales, así como el rol de todo ello en la formación y desarrollo de la psiquis humana.

Esta idea de mediación cultural en el contexto de la actividad Vigotsky (1979) la cristaliza en el modelo triangular expresado en la tríada de sujeto, objeto y artefacto mediador. Se trasciende la conexión directa entre el estímulo condicionado $(S)$ y la respuesta $(R)$ por un acto complejo. El eslabón intermedio $\mathrm{X}$, interpuesto entre ambos, sustituye al estímulo en la mediación cultural de las acciones (Figura 4.1.A). Comúnmente el modelo de mediación de Vigotsky se expresa como la tríada de sujeto, objeto y herramientas (Figura 4.1.B). El concepto de mediación según Wertsch, uno de los grandes estudiosos de la obra de Vigotsky, "es la contribución más original e importante de Vigotsky" (1988: 33).

15 Figura 4.1 Modelo de mediación (A) y su reformulación (B)
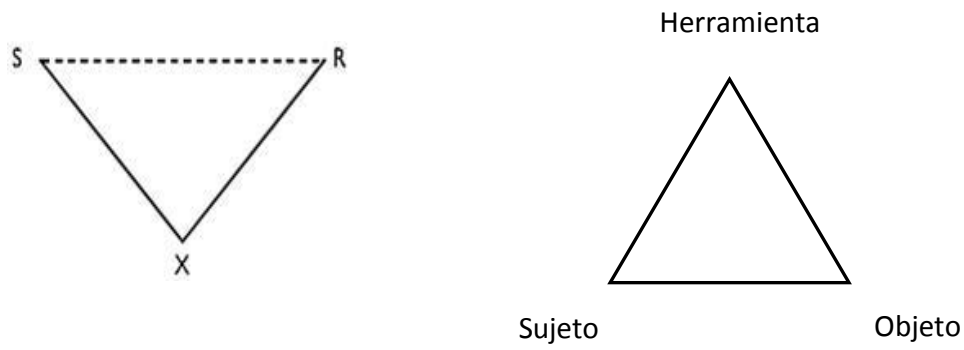

Fuente: Vigotsky, 1979

La vida material del hombre, según Vigotsky $(1979,1987)$ está mediada por los instrumentos y de la misma manera la actividad psicológica está mediada por eslabones producto de la vida social, de los cuales el más importante es el lenguaje. Vigotsky entendía 
que la vida del hombre no sería posible si tuviera que valerse sólo del cerebro y de las manos, sin los instrumentos o herramientas que son un producto social. La función de la herramienta es la de servir de conductor de la influencia humana en el objeto de la actividad para conducir a cambios en los objetos. Es un medio por el cual una actividad externa humana está destinada a dominar y triunfar sobre la naturaleza. Vigotsky junto a sus colegas Luria y Leontiev, propuso que toda actividad humana está motivada por la necesidad de alcanzar un objetivo (objeto, motivo) a través de la internalización de las herramientas y sistemas de signos de la cultura. Los signos pertenecen a la categoría más amplia de herramientas psicológicas.

Según el enfoque presentado hasta aquí del modelo de la primera generación de la teoría de la actividad, el objeto se refiere al "problema" al que la actividad está dirigida por el tema, y éste se transforma en los resultados por la acción de la mediación de influencias, tanto internas como externas. Esto significa que los objetos han dejado de ser solo materia prima para la formación de las operaciones. Los objetos se convirtieron en entidades culturales y la orientación hacia los objetos de la acción se convirtió en la clave para entender las limitaciones humanas. La importancia de los objetos, y su influencia mediadora sobre las acciones, es una característica central de la teoría de la actividad (Sandars, 2005). De todos modos, la unidad de análisis Vigotskyana queda circunscrita a las acciones individuales. Durante este período los estudios tendían a centrarse en los individuos.

El aporte de la primera generación de la teoría de la actividad, según el análisis de Engeström (2001), permite superar el dualismo cartesiano individuo-sociedad. El individuo no podría en lo sucesivo ser entendido sin sus medios culturales, y la sociedad no podría en lo sucesivo ser entendida sin la concurrencia de individuos que usan y producen instrumentos o herramientas, cuestión que apoya Cole (2003) argumentando que el objeto producido no es algo simplemente externo e indiferente a la naturaleza del productor. Si bien la idea de la actividad es un aporte como visión integradora, sin embargo, Engeström (1999) pone en evidencia que el problema de la representación de Vigotsky es que no explica totalmente la naturaleza social y colectiva de las acciones individuales. En otras palabras, no representa las acciones individuales en tanto eventos que forman parte de un sistema de actividad colectiva (Figura 4.2). 
16 Figura 4.2: Modelo de la primera generación de la teoría de la actividad

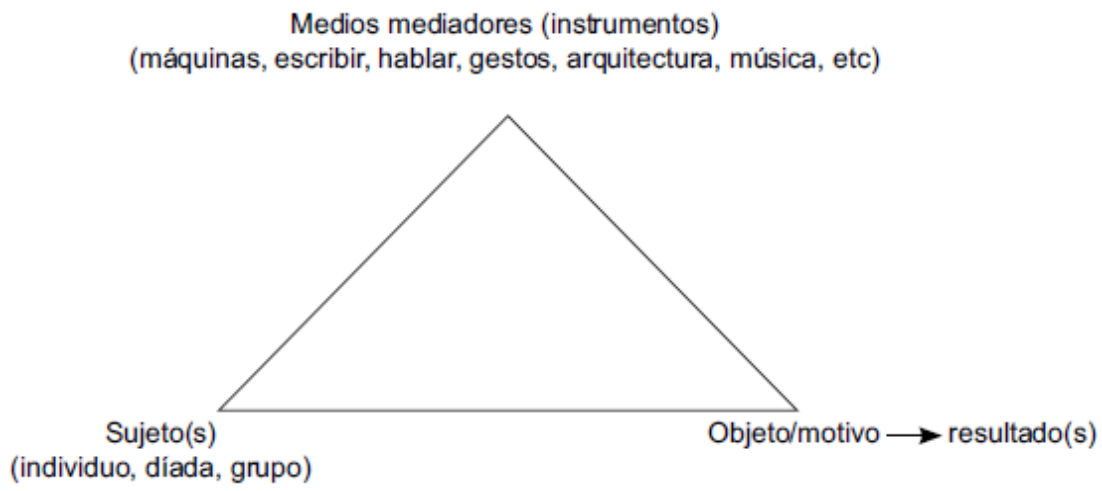

Fuente: Engeström, 1999

Además, la esencia de cada individuo, su personalidad, es el sistema de relaciones que establece con los que lo rodean. Los hombres interactúan en una formación históricocultural dada, creada por la propia actividad de producción y transformación de su realidad. La actividad humana, que permite el desarrollo de los procesos psíquicos y la apropiación de la cultura, es siempre social, implica la relación con otros hombres y la comunicación entre ellos en procesos culturalmente organizados.

En este afán de estudiar e intentar comprender el desarrollo de los procesos psíquicos y de apropiación de la cultura, Vigotsky aporta el valioso concepto de zona de desarrollo próximo. La idea de zona de desarrollo próximo Vigotsky (1979: 133) la define como "la distancia entre el nivel de desarrollo real, determinado por la capacidad de resolver independientemente un problema, y el nivel de desarrollo potencial, determinado a través de la solución de un problema bajo la guía de un adulto o en colaboración con otro compañero más capaz". La zona de desarrollo próximo será mañana el nivel real de desarrollo, es decir lo que una persona hoy es capaz de hacer con la ayuda de alguien, mañana podrá hacerlo por sí solo.

Esta idea de zona que aporta Vigotsky debemos distinguirla del concepto de objeto o motivo del modelo de la primera generación de la teoría de la actividad ya que es fundamentalmente diferente al de zona. Mientras que un objeto es un punto final fijo o estado final a alcanzar, la idea de zona es una distancia o área entre el presente y el futuro 
previsible que es posible recorrer mediado por otro $u$ otros individuos. En palabras de Engeström (1987: 174) es la distancia entre las acciones presentes cotidianas de los individuos y la forma históricamente nueva de actividad de la sociedad que puede ser generada colectivamente, como una solución al doble vínculo potencialmente inserto en las acciones de la vida cotidiana".

\subsubsection{La estructura jerárquica de la actividad definida por Leontiev}

El aprendizaje, de acuerdo con Leontiev (1978), es una actividad o sistema de actividades. Leontiev (1979) analiza críticamente la teoría histórico-cultural de Vigostky afirmando que no son los conceptos sino la actividad real la que une al organismo con la realidad circundante y determina el desarrollo de la conciencia. Llegó a mostrar de esta manera la unidad de la actividad exterior-práctica, con la interior-psíquica. Demostró, así mismo, la dependencia de la actividad interna en relación a la externa. De esta forma la psiquis y la conciencia no sólo se manifiestan, sino que se forman en la misma actividad, constituyendo las acciones la unidad de análisis de la actividad de aprendizaje. Wertsch (1988) reconoce que la teoría de la actividad es una de las mayores contribuciones de Leontiev y el concepto de actividad como la categoría fundamental de su teoría. El trabajo de Leontiev sobre la actividad aportó una elaboración de las nociones de objeto y objetivo y del carácter central del objeto para un análisis de la motivación. Estableció que la transformación del objeto/objetivo es lo que conduce a la integración de los elementos del sistema de actividad.

Por ello Leontiev (1978) se propuso la idea de analizar la actividad como un método científico de la psicología humana. Para lo cual Leontiev separa los tipos concretos de actividad, los que pueden diferir entre sí de acuerdo a varias características: según su forma, de acuerdo con los métodos para llevarlos a cabo, de acuerdo a su intensidad emocional, de acuerdo con su tiempo y espacio, de acuerdo a sus mecanismos fisiológicos. Lo principal que distingue a una actividad de otra es la diferencia de sus objetos. Es exactamente el objeto de una actividad el que le da una dirección determinada, es su verdadero motivo. Se entiende que el objeto o motivo puede ser material o ideal, presente en la percepción o exclusivamente en la imaginación o en el pensamiento. 
Así, el concepto de actividad está necesariamente relacionado con el concepto de motivación. Para Leontiev (1978) la actividad no existe sin un motivo, aunque el motivo subjetivo u objetivo puede estar oculto. Así mismo, la actividad humana no existe sino en la forma de acción o una cadena de acciones. Por ejemplo, la actividad laboral que existe en las acciones de trabajo, la actividad escolar en las acciones de la escuela, la actividad social en acciones de la sociedad.

Entonces en la noción de estructura jerárquica de la actividad definida por Leontiev (1979), plantea que la actividad humana está, en una primera fase, dirigida por un objeto o motivo, el cual surge de las necesidades humanas. En la segunda fase genera las acciones que están orientadas a objetivos o metas para alcanzar el objeto. En la tercera fase son operacionalizados los objetivos en variadas tareas, dependiendo del contexto en que se realicen. La actividad humana sólo existe en la forma de una acción o una cadena de acciones subordinadas a un motivo (Figura 4.3). Cualquier proceso concreto, externo o interno, se despliega ante nosotros, desde el punto de vista de su motivación.

Juntos, estos tres niveles (actividad, acción y operación), interrelacionados entre sí, comprenden una estructura de actividad, que Ramírez Garrido (en Wertsch, 1993) reconoce como un aporte de Leontiev con gran sentido metodológico. Así que para analizar cualquier actividad, es necesario identificar todas las acciones y operaciones que apoyan la actividad. La actividad es el trabajo del sistema considerado en la escala más general. Al movernos hacia abajo en la esta jerarquía, la escala de análisis se hace más pequeña y más específica. Una vez que se alcanza el nivel de operación, el trabajo se ha convertido en tareas rutinarias e incluso inconscientes. 
17 Figura 4.3. Estructura jerárquica de la actividad según Leontiev

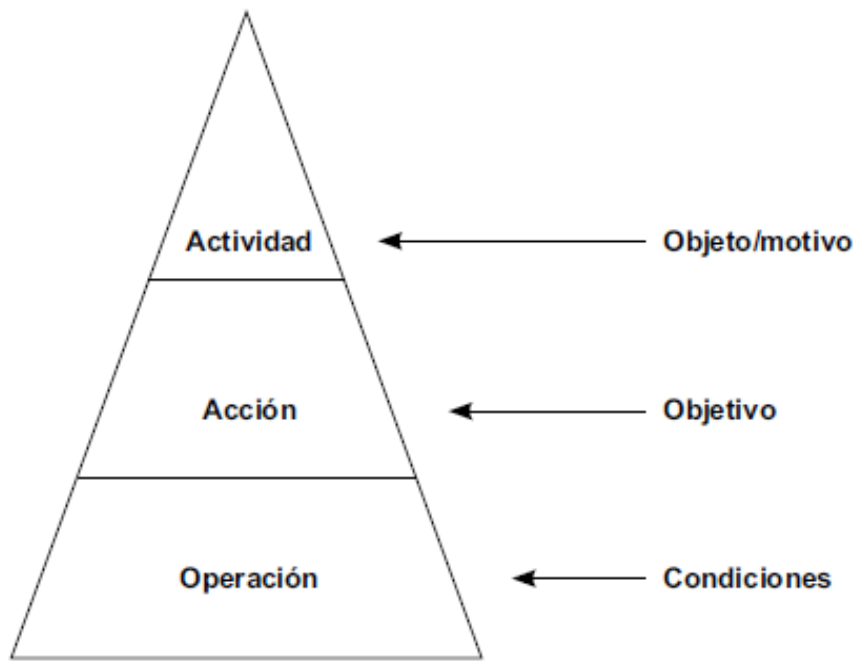

Fuente: Leontiev, 1981

Es necesario destacar que frecuentemente no se establecen diferencias entre los términos de acción y operación. En el contexto del análisis psicológico de la actividad, sin embargo, distinguir entre ellos es absolutamente necesario. Las acciones, como ya se ha dicho, están relacionadas con los objetivos o metas, los instrumentos disponibles para la acción y las operaciones están dirigidas por las condiciones, es decir por las circunstancias del momento. Supongamos que el objetivo sigue siendo el mismo, las condiciones en que se asignan, sin embargo cambian, entonces, sólo el contenido operativo de la acción es el que cambia. Las operaciones son los medios por los que se realiza la acción (Leontiev, 1978).

Esta consideración, tal como lo establece de Leontiev (1979), sobre la diferencia entre las acciones y operaciones, emerge con particular claridad en el caso de acciones que incluyan herramientas. Después de todo, una herramienta es un objeto material en el cual se cristalizó métodos y operaciones, y no las acciones u objetivos, los cuales dependen de los motivos de la persona, no forman parte del objeto material. Por ejemplo, físicamente se puede desmembrar un objeto material con la ayuda de una variedad de herramientas, cada una de ellas define un método para llevar a cabo la acción propuesta. Por ejemplo, en algunos casos, la operación de corte será mejor, y en otros, la operación de aserrado. En tanto se supone que la persona es capaz de dominar el instrumento adecuado, como un cuchillo, sierra, etc. Sucede lo mismo en casos más complejos. 
Podemos explicar la diferencia y a su vez la relación que existe entre actividad, acción y operación, a través de un ejemplo dado por Leontiev (1978) respecto a la caza:

- Actividad (de seres humanos) se rige por sus motivos / razones: el hombre se dedica a la caza comunal porque quiere alimentar a su familia.

- Las acciones se rigen por sus objetivos: el hombre desempeña el papel de "batidor" (el objetivo es asustar a la presa distante de sí mismo hacia los demás miembros de la partida de caza).

- Las operaciones se regirán por las condiciones de la caza. Cómo se llevan a cabo las diversas tareas necesarias para su función dependerá del terreno, tipo de animales buscados, la dirección del viento, el clima, la época del año, etc. (Leontiev, 1981: 53).

Estas relaciones entre actividad, acción y operación nos llevan a tener presente que las acciones al igual que las actividades también son complejas, y pueden ser divididas en cadenas de operaciones. Las operaciones normalmente están automatizadas o son comportamientos rutinarios. Los sujetos con el fin de completar la acción consciente, realizan operaciones que en su mayoría no requieren intenciones conscientes. Bedny (2005) para facilitar el análisis de una actividad, incorpora al esquema de la estructura jerárquica de Leontiev (Figura 4.4) las nociones de tarea y bloque de funciones. La tarea es un fragmento de la actividad que se organiza en torno a un objetivo de trabajo. Las operaciones pueden subdividirse cronométricamente en una serie de etapas distintas de procesamiento de la información, denominadas por Bedny (2005) como bloques de funciones, cada una ocupando una muy corta duración.

Wertsch (1993) ya había explicitado la importancia de la acción como unidad de análisis, ya que es la acción, más que los seres humanos o el ambiente considerados independientemente, la que proporciona el punto de entrada al análisis. Cuando se da a la acción prioridad analítica, los seres humanos son concebidos en contacto con su ambiente, creando a su ambiente y así mismos por medio de las acciones en que se involucran. 
18 Figura 4.4: Componentes estructurales de la actividad

\section{Actividad $\rightarrow$ Tarea $\rightarrow$ Acción $\rightarrow$ Operación $\rightarrow$ Bloques de funciones}

Fuente: Bedny, 2005

Con los aportes de Leontiev (1978) a la teoría de la actividad, se configura un constructo que permite realizar un análisis integral de la actividad humana, explicando su estructura a través de sus componentes principales (sujeto, objeto, motivos y objetivos) y las relaciones funcionales que entre ellos se producen. La actividad se concibe como un sistema de acciones y operaciones que realiza el sujeto sobre el objeto, en interrelación con otros sujetos. Ahora, podemos hablar de la actividad de una comunidad, pero nunca de la actividad individual, sólo las acciones son individuales.

Según esta distinción de actividad y acción, podemos establecer que las personas pueden realizar actividades individualmente en contextos como la escuela, pero su capacidad para llevarlas a cabo se basa en grupos de personas. El concertista de piano en solitario, por ejemplo, depende de los profesores, los fabricantes de pianos, los diseñadores y constructores de la sala de concierto, del director de la orquesta y los músicos acompañantes. Así que "la actividad del individuo humano es un sistema de relaciones sociales. No existe sin esas relaciones sociales" (Leontiev, 1981: 46-7). Es interesante, cómo resalta Wertsch (1988), que los sujetos tienden a no identificar el contexto situacional conscientemente. Agrega Wertsch que los contextos situacionales de actividad no se hallan determinados por el contexto físico. Es más, son creados por los participantes en el contexto. Esta distinción es relevante al momento de analizar los nuevos contextos virtuales propiciados por las tecnologías.

Otro aporte de Vigotsky que Leontiev valora es la introducción del concepto de herramienta para las operaciones, y más tarde, el motivo. El énfasis de la teoría de la actividad en los factores sociales y en la interacción entre los sujetos y su entorno, explica por qué el principio de la mediación de la herramienta juega un papel central en este enfoque. En primer lugar, las herramientas dan forma a la manera en que los seres 
humanos interactúan con la realidad. En segundo lugar, las herramientas suelen reflejar las experiencias de otras personas que han tratado de resolver problemas similares en un momento anterior e inventaron la herramienta para hacerlo más eficiente.

Esta experiencia se acumula en las propiedades estructurales de las herramientas, así como en el conocimiento de cómo la herramienta debe ser utilizada. Las herramientas son creadas y transformadas durante el desarrollo de la actividad en sí misma y llevan con ellas una cultura particular, la experiencia histórica de ese desarrollo. Por lo tanto, el uso de herramientas es un medio para la acumulación y transmisión del conocimiento social. Influye en la naturaleza, no sólo de la conducta externa, sino también del funcionamiento mental de los individuos.

\subsubsection{Expansión del modelo de Vigotsky hacia el sistema de actividad}

Como señala Wertsch (1988), la acción como unidad de análisis de la teoría de Leontiev cumple los requisitos de Vigotsky de que la unidad debe ser aplicable tanto al funcionamiento interpsicológico como al funcionamiento intrapsicológico. Si bien Leontiev supera la limitación de la primera generación, que se mantuvo enfocada en el análisis individual, no expande gráficamente el modelo original de un sistema de actividad colectiva. Este nuevo modelado lo realiza Engeström (1987). Amplía la representación triangular original de los sistemas de actividad usada por la primera generación.

La expansión propuesta por Engeström (1987) del triángulo vigotskyano básico intenta representar los elementos sociales/colectivos de un sistema de actividad añadiendo los elementos de la comunidad, las reglas y la división del trabajo (Figura 4.5). Con ello, pretende posibilitar el examen de las interacciones mutuas de los sistemas de actividad en el macronivel de lo colectivo y de la comunidad (parte inferior de la Figura 4.5), en lugar de concentrarse exclusivamente en el micronivel del actor o agente individual que opera con instrumentos, o en las relaciones intersubjetivas próximas de los vínculos cara a cara en microcontextos (parte superior de la Figura 4.5). 
19 Figura 4.5. Modelo de la segunda generación de la teoría de la actividad

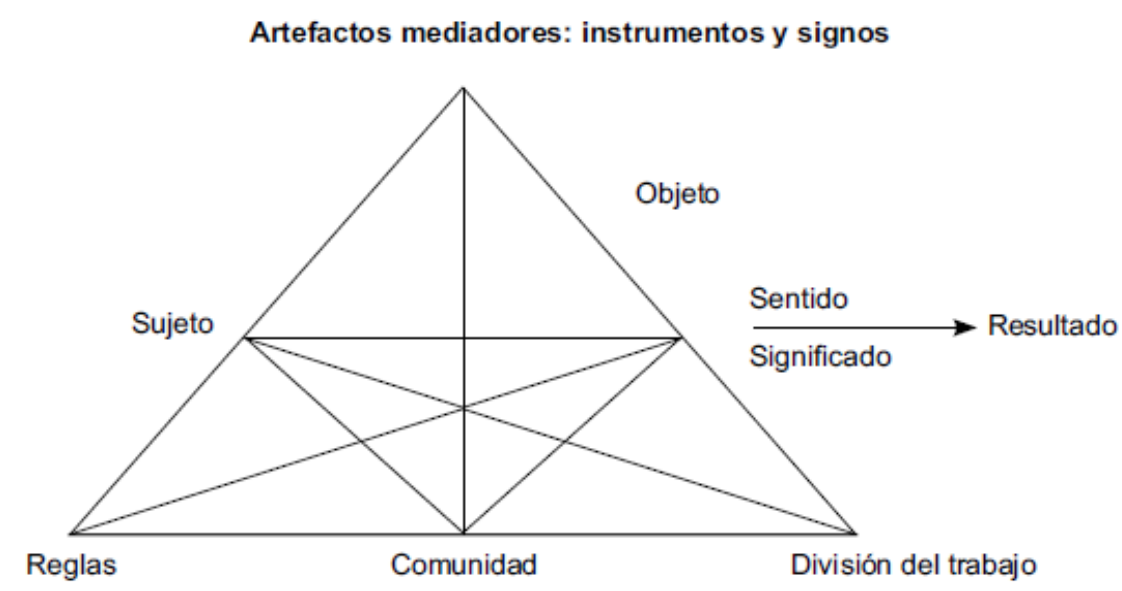

Fuente: Engestroöm, 1987

La relevancia de esta segunda generación de la teoría de la actividad es que se centra en las interrelaciones entre el sujeto como individuo y su comunidad. Al mismo tiempo, destaca la importancia de las contradicciones en los sistemas de actividad como fuerza impulsora del cambio. El aprendizaje y el conocimiento consciente emergen de la actividad (desempeño), y no como un precursor de la misma. Su unidad de análisis se centra en la interacción de la actividad humana y la conciencia dentro de su contexto ambiental pertinente.

Por tanto, los conocimientos como imágenes de los objetos, fenómenos, acciones del mundo material nunca existen en la cabeza del hombre fuera de alguna actividad, fuera de algunas acciones. Siguiendo el principio de la actividad y separando la acción como unidad de análisis, desde el inicio se incluyen los conocimientos en la estructura de la acción. Al ocupar el lugar estructural del objeto de la acción o al formar parte del contenido de la base orientadora, o constituyendo el objetivo de la acción, los conocimientos pasan por las mismas etapas de la actividad en su conjunto.

Esta representación de la teoría de la actividad devela que existen múltiples mediaciones en un sistema de actividad. El sujeto y el objeto, o el actor y el medio ambiente, están mediados por los instrumentos, incluidos los símbolos y las representaciones de diversos tipos. Este triángulo, sin embargo, según Engeström (1999) no es sino "la punta de un íceberg". Los mediadores sociales menos visibles de la actividad (las normas, la comunidad, 
y la división del trabajo) se muestran en la parte inferior del modelo (Figura 4.6). Entre los componentes del sistema, existen transformaciones continuas. El sistema de la actividad sin cesar se reconstruye.

20 Figura 4.7: Mediación en Modelo de la segunda generación de la teoría de la actividad

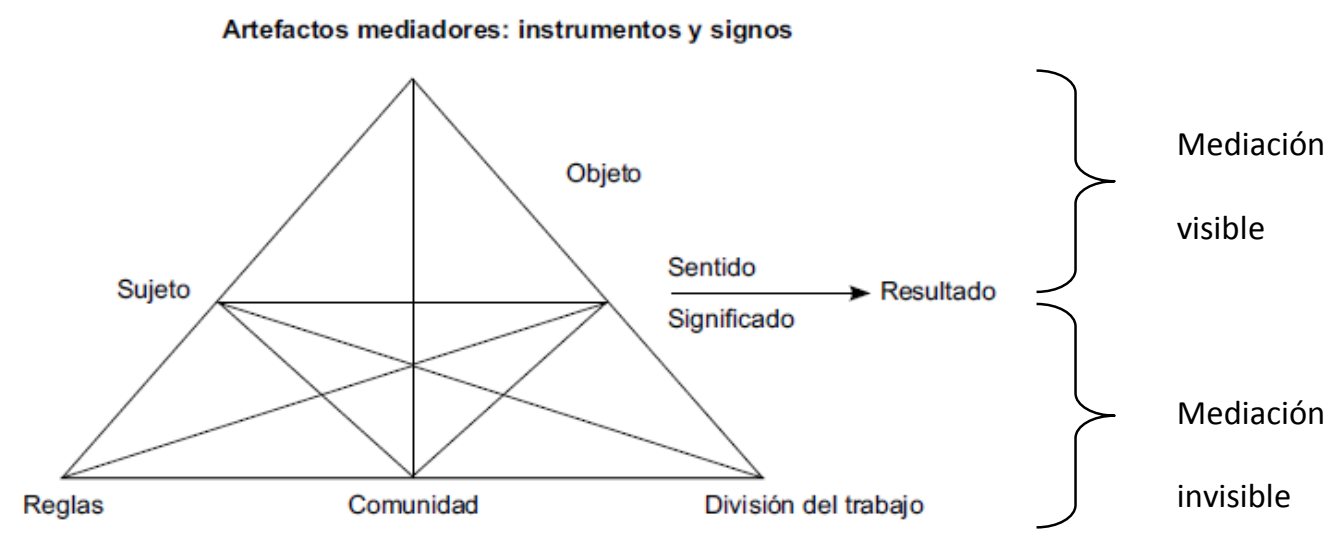

Fuente: Engeström, 1999

En síntesis, la actividad es un sistema dirigido a un objetivo, donde se integran la cognición, la conducta y la motivación y organizado por un mecanismo de autorregulación hacia el logro de un objetivo consciente (Bendy, 2005). En el caso de una situación educativa planificada, para efectos de su análisis e intervención, debe concebirse como un sistema de actividad cuyos componentes son los siguientes:

- La actividad que consiste en una jerarquía de acciones que se utilizan dirigidas a los objetos/objetivos, constituidas por las tareas, las acciones conscientes y las operaciones que transforman el objeto. Las acciones son las cadenas de las operaciones.

- El sujeto de la actividad corresponde al individuo o grupo que está en el centro de la actividad educativa, y a la vez, al sujeto que media (profesor, tutor, compañeros).

- Los artefactos mediadores constituidos por los instrumentos, herramientas y signos utilizados en la actividad. Los artefactos corresponden a los instrumentos físicos (máquinas, aparatos) y los mentales que median el proceso, tales como los 
conceptos clave involucrados en la actividad; los métodos, los modelos teóricos y heurísticos que se utilicen.

- El objeto del que hay que apropiarse o el objetivo que regula la actividad (contenidos, destrezas, habilidades, competencias), es el producto físico o mental que se solicita. El objeto representa la intención que motiva la actividad y los motivos, expectativas y objetivos de los participantes, considerando sus necesidades conscientes, sus valores y los deseos.

- Los resultados esperados en términos de productos a lograr, problemas a resolver. Es conveniente que los problemas o los proyectos surjan de contextos del mundo real. Los resultados ponen en evidencia lo que serán capaces de hacer los sujetos con autonomía una vez que concluya la actividad.

- Una comunidad, por un lado corresponde a los grupos de referencia social y cultural en la que se insertan la actividad y el sujeto que comparten el mismo objeto general. Y por otro lado, al conjunto de individuos que van a realizar una actividad de aprendizaje.

- Unas normas o reglas son las normas y convenciones explícitas e implícitas de comportamiento que regulan las acciones e interacciones dentro de esa actividad. Las normas de la comunidad definen la forma en que trabaja el grupo y cómo se tienen que concretar los acuerdos en el marco de la actividad.

- La división del trabajo aglutina la descripción del conjunto de acciones, tareas y operaciones que se van a llevar a cabo. Implica la división de tareas y funciones entre los miembros de la comunidad, en las que se asume las divisiones de poder y estatus.

Considerando estos rasgos, cuando aplicamos la teoría de la actividad en el ámbito educativo, el rol del profesor como mediador es, en primer lugar, ofrecer a los alumnos las condiciones propicias para aprender, las ocasiones para practicar los esquemas existentes, o sea, la manera de actuar y controlar mejor las operaciones, la posibilidad de automatizar cierta parte de lo aprendido; en segundo lugar, el papel del profesor es el de desarrollar 
esquemas nuevos, esto es, nuevas conceptualizaciones, nuevas reglas de acción para los objetivos y las tareas todavía no habituales.

Para facilitar y orientar este rol mediador del profesor, Mwanza junto a Engeström (2003) ofrecen un conjunto de preguntas abiertas que se pueden plantear al estudiante, las que forma parte de un Modelo de Ocho Pasos para orientar el desarrollo de actividades de aprendizaje, tanto en la planificación como en la evaluación de las mismas (Tabla 1).

5 Tabla 4.1: Preguntas abiertas Modelo de Ocho Pasos

\begin{tabular}{ll} 
Actividad & ¿Qué tipo de actividad me interesa? \\
\hline Objeto/objetivo & ¿Por qué esta actividad se realiza? \\
\hline Sujetos & ¿Quién está involucrado en la realización de la actividad? \\
\hline Herramientas & ¿Por qué medios los sujetos realizan la actividad? \\
\hline Normas y & ¿Existen normas culturales, normas o reglamentos que rigen el \\
reglamentos & desempeño de la actividad? \\
\hline División del & ¿Quiénes son responsables en el ejercicio de la actividad y cómo \\
trabajo & están organizados los roles? \\
\hline Comunidad & ¿Cuál es el entorno en el que se lleva a cabo esta actividad? \\
\hline Resultado & ¿Cuál es el resultado deseado de llevar a cabo esta actividad? \\
\hline & \multicolumn{2}{c}{ Fuente: Mwanza y Engeström, 2003 }
\end{tabular}

Otra guía de orientaciones para el profesor en el marco de la teoría de la actividad, lo entrega Jorba (1997) en función de los mecanismos que conducen a la auto-socioconstrucción del saber, los estudiantes requieren llegar a acuerdos en aspectos como:

- La claridad del problema, reconocer donde aplica, donde se proyecta y alguna idea de las posibles soluciones (evaluación diagnóstica más la representación de los objetivos).

- El plan (por etapas), para abordar la solución que se acepta como posible de ejecutar por los miembros del grupo (exploración desde lo conocido hacia lo por aprender más la gestión de donde se inicia y a donde se debe llegar en cada etapa).

- La ejecución del plan, verificando permanentemente (controlando) si las acciones que se ejecutan sí brindan una estructura de solución para el problema (relación y re-estructuración de los conceptos conocidos con los nuevos conceptos). 
- El desarrollo de procesos de realimentación para corregir y asegurar la aproximación a la solución. Es decir, asegurar que se compartan los criterios de evaluación a utilizar para regular la aplicación y generalización de lo aprendido en la solución parcial de la actual etapa, frente a lo que se espera aprender en la siguiente etapa.

- La coordinación de encadenamiento de las etapas definidas en el plan hasta llegar al final de manera autorregulada y con éxito.

El conjunto de guías y orientaciones descritos reflejan el interés principal de la teoría de la actividad en la mediación de la actividad por un particular tipo de artefacto conocido como un modelo mental, apreciación en la que Sandars (2005) coincide con Roth (2004). Todas las personas tienen creencias y opiniones acerca de su mundo y estos comprenden los modelos mentales del individuo. La participación en la actividad implica cambios en las condiciones de vida y de identidad del sujeto que actúa y en sus objetos asociados. Las personas construyen modelos a escala reducida de la realidad para comprender, explicar y anticipar eventos. Engeström (1987) ya sostenía que el interés en los modelos mentales se había incrementado en las últimas décadas, porque son dinámicos y modificables, pueden generar descripciones de un sistema de actividad, en su forma y propósito, como en su funcionamiento. Además aportan predicciones sobre los estados futuros de un sistema de actividad.

En síntesis, con Sandars (2005) podemos aceptar la importancia global del modelo de la segunda generación de la teoría de la actividad para el reconocimiento de que todos los resultados están determinados por una compleja mezcla de las influencias de la cultura derivadas de la mediación, que comprenden los modelos mentales en poder de cada individuo y en términos más amplios, el arraigo social de las influencias dentro de la comunidad de la cual cada sujeto es parte.

\subsubsection{Interacción de los sistemas de actividad}

La tercera generación de la teoría de la actividad suma las perspectivas de las dos generaciones anteriores e integra el desarrollo de herramientas conceptuales para 
entender el diálogo, la multiplicidad de perspectivas y las redes de interacción de los sistemas de actividad. En esta tercera generación, la investigación se amplía hacia las redes de actividades. Según este enfoque (Engeström, 2001), la actividad es una formación colectiva y sistémica con una compleja estructura mediadora.

Este sistema de actividad produce acciones y se desarrolla por medio de acciones; sin embargo, la actividad no es reducible a acciones, que son relativamente efímeras y tienen un principio y un final determinados en el tiempo de los individuos o grupos. Los sistemas de actividad, en cambio, evolucionan durante períodos de tiempo sociohistórico, adoptando la forma de instituciones y organizaciones, articuladas por los objetos.

De manera gráfica el sistema de actividad en el esquema del modelo se describe el rol del objeto con la ayuda de un óvalo (Figura 4.7) que indica que las acciones orientadas al objeto están siempre caracterizadas de manera explícita o implícita por la ambigüedad, la sorpresa, la interpretación, la comprensión y el potencial para el cambio (Engeström, 1999). Al mismo tiempo Engeström (citado por Daniels, 2003) destaca la importancia de las contradicciones en los sistemas de actividad como fuerza impulsora del cambio y el desarrollo. Engeström puntualiza que en la Rusia de los años 30, los sistemas de actividad sociales estudiados por los teóricos de la actividad se limitaron al juego y el aprendizaje entre los niños, ya que las contradicciones de la actividad colectiva constituían un tema difícil de abordar en dicho contexto sociohistórico.

Esta idea de las contradicciones en los sistemas de actividad como fuerza impulsora del cambio y el desarrollo es retomada y recontextualizada por investigadores de Occidente desde la década del 70 del siglo pasado. Nuevos dominios de actividad, incluyendo el trabajo, fueron enfocados por la investigación concreta. Pero desde el trabajo fundacional, el enfoque histórico-cultural permaneció como un discurso del desarrollo vertical hacia las funciones psicológicas superiores. Cole (2001) pone de manifiesto que la segunda generación de la teoría de la actividad permanece insensible a la diversidad cultural. La tercera generación de la teoría de la actividad desarrolla herramientas conceptuales para entender las múltiples perspectivas y las redes horizontales de sistemas de actividad.

Es así que la tercera generación de investigación formulada por Engeström (2001) toma dos sistemas de actividad como unidad mínima de análisis, lo que posibilita estudiar procesos 
de aprendizaje inter-organizacional, capturando tensiones y contradicciones que se producen intra e inter sistemas de actividad, aspectos no abordados por la segunda generación.

21 Figura 4.7: Modelo de la tercera generación de la teoría de la actividad

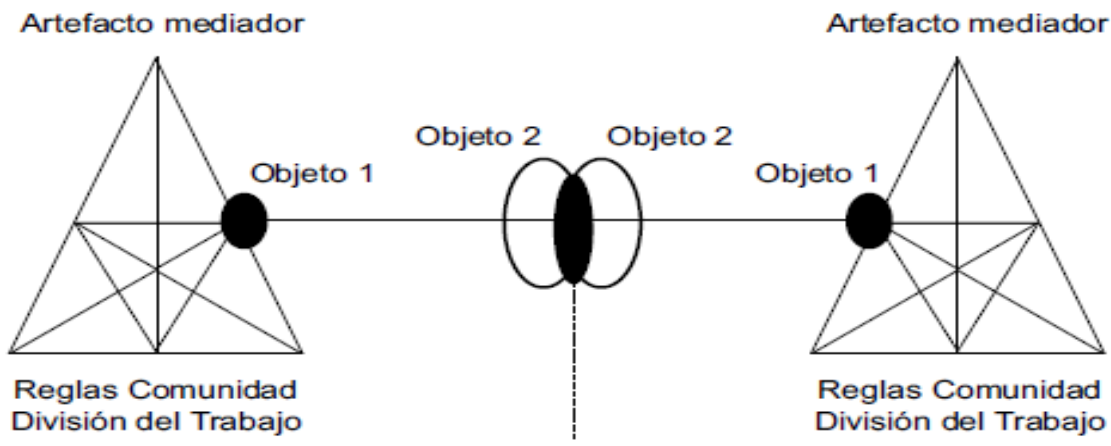

Objeto 3

Fuente: Engeström, 2001

Las relaciones en este sistema de actividad están mediadas por herramientas y lo importante es que en la actividad se va configurando un modo de comprender. Por ello la comprensión no es algo externo sino que se va conformando en la actividad que se lleva a cabo dentro del dominio. La forma de relacionarse con el conocimiento o el aprendizaje está contenida en las prácticas. La forma de actuar y comprender está entretejida con la actividad, y ésta constituye a la vez el contexto marco de la comprensión. Las personas aprenden en el seno de estas interacciones sociales y prácticas en el interior de una comunidad, les sirven de filtro a través de las cuales perciben lo que funciona como realidad.

En el análisis de estas prácticas en el interior de una comunidad, para Engeström (1999), la teoría de la actividad es la base teórica más apropiada, por ejemplo para realizar el análisis del aprendizaje innovador porque:

a) Es contextual y está orientada hacia la comprensión de prácticas locales históricamente específicas, sus objetos, sus artefactos mediadores y su organización social. 
b) Está basada en una teoría dialéctica del conocimiento y del pensamiento centrada en el potencial creativo de la cognición humana.

c) Es una teoría del desarrollo que intenta explicar los cambios cualitativos que se dan con el tiempo en las prácticas humanas e influir en ellos (Engeström, 1999: 133).

Por otra parte en el estudio del papel mediador de los artefactos, Engeström (1999) incluye tanto instrumentos como signos aunque afirma que es más útil categorizarlos por los procesos implicados en su uso que por el hecho de que sean externos y prácticos o internos y cognitivos. Distingue entre artefactos de los tipos "qué" (denominativos y descriptivos) "cómo" (procesales), "por qué" (diagnosticadores y explicativos) y "a dónde" (especulativos y potencializadores).

Podemos resumir la tercera generación de la teoría de la actividad a partir de los cinco principios que propone Engeström $(1999,2001,2009)$ considerar para estudiar los sistemas de actividad en su dinámica interna y su interrelación externa:

- El primer principio considera que la unidad mínima de análisis psicológico es un sistema de actividad en relación con otro/s sistema/s de actividad. Las acciones individuales y grupales son relativamente independientes, pero están subordinadas y entretejidas y sólo pueden llegar a comprenderse cuando se interpretan en relación con sistemas de actividad íntegros vinculados a otros sistemas de actividad que se relacionan entre sí. Un sistema de actividad colectivo, mediado por artefactos y orientado a objetos, es considerado en el contexto de sus relaciones de red con otros sistemas de actividad.

- El segundo principio entiende que la división del trabajo en una actividad crea distintas posiciones para los participantes, e implica agentes con múltiples puntos de vista, intereses y tradiciones. Esta multiplicidad de voces de los sistemas de actividad permite vislumbrar fuentes de problemas y prácticas de negociación. Ello permite pensar cómo se negocian, modifican o cristalizan los modelos mentales de situación que construyen y ponen en interacción los agentes psicoeducativos en escenarios socioculturales concretos. 
- El tercer principio rescata el carácter histórico de los sistemas de actividad, entendiendo que los mismos se conforman y transforman durante largos períodos de tiempo y que la historia se debe estudiar como historia local de la actividad y de sus objetos y como la historia de los instrumentos conceptuales y materiales que han dado forma a la actividad.

- El cuarto principio destaca las contradicciones históricas que acumulan los sistemas de actividad, como fuentes de cambio y desarrollo, entendidos como sistemas abiertos que al introducir nuevas tecnologías u objetos provocan contradicciones que abren la posibilidad de acciones innovadoras de cambio.

- El quinto principio establece la posibilidad de trasformaciones expansivas en los sistemas de actividad, generadas a partir de esfuerzos colectivos y deliberados por superar las contradicciones acumuladas. En algunos casos, ello desemboca en un objetivo colectivo nuevo y en un esfuerzo en colaboración para producir un cambio; objeto y motivo de la actividad se replantean para adoptar un horizonte de posibilidades más amplio que en el modo anterior de la actividad. Un ciclo completo de transformación expansiva se puede concebir como un viaje colectivo por la zona de desarrollo próximo de la actividad (Engeström, 1999: 4-5; 2001: 136-137; 2009 : 57-58).

\subsubsection{Los ciclos expansivos de la actividad}

Una característica atractiva de la teoría de la actividad es la idea del aprendizaje expansivo. Para Engeström (1999, 2001), la cognición es el "nuevo estado emergente" del conocimiento del sujeto resultante del análisis y la síntesis de por lo menos dos fuentes de información en tiempo real, siendo una el objeto que ya posee el sujeto y la otra el objeto representado por el medio. El autor postula un "ciclo expansivo" que representa una relación cíclica entre la interiorización y la exteriorización en una actividad que se encuentra en constante cambio (Figura 4.8). Su pensamiento refleja una teoría cultural de la mente donde la cognición se redistribuye entre formas de actividades conjuntas próximas y a distancia, y el pensamiento se da tanto entre individuos como dentro de ellos. 
Engeström considera que la interiorización está relacionada con la reproducción de la cultura y la exteriorización con la producción de nuevos artefactos culturales.

Desde la perspectiva histórico-temporal, Engeström (2001) analiza las diferencias entre el momento de una acción y el tiempo de una actividad. En el caso de una acción, el tiempo es lineal y al mismo tiempo finito en el de una actividad que es recurrente y cíclica. Estos ciclos son determinados por la aparición de nuevas estructuras o modelos de la actividad realizada. Tales ciclos no son predecibles o repetibles, ya que son vistos como hechos históricos sumergidos en un contexto determinado bajo ciertas condiciones dadas. Dado el carácter generativo de estos ciclos, Engeström los llama los ciclos expansivos de la actividad.

Un ciclo expansivo es una nueva orquestación de estas expresiones de los diferentes puntos de vista y perspectivas de los participantes del colectivo. El ciclo expansivo en los sistemas de la actividad colectiva puede verse como el equivalente de la zona de desarrollo próximo de Vigotsky, como lo señala Engeström (2001). Engeström utiliza este modelo para describir la actividad de aprendizaje, que representa en su modelo de actividad (Figura 4.9). El concepto de actividad de aprendizaje se ha derivado de la evolución del concepto general de la actividad.

Frente a esta posible equivalencia del ciclo expansivo en los sistemas de la actividad y la zona de desarrollo próximo de Vigotsky, desde el punto de vista pedagógico, Engeström da su propia definición de la zona de desarrollo próximo:

“significa que la enseñanza y el aprendizaje se desplazan dentro de la zona sólo cuando tienen por objeto el desarrollo de formas históricamente nuevas de actividad, no sólo en permitir que los alumnos adquieran las formas existentes o socialmente dominantes como algo nuevo. Para aspirar a la elaboración de formas de actividad históricamente nuevas implica una práctica de instrucción que sigue a los alumnos en sus actividades de la vida fuera del aula. También implica la necesidad de formar verdadera actividad de aprendizaje expansivo en y entre los alumnos. La tarea de instrucción es, pues, doble: desarrollar actividades de aprendizaje y desarrollar nuevas formas de la actividad (la actividad de aprendizaje 
es en sí el objetivo central de la actividad durante los primeros años escolares)." (Engeström, 1987, 144)

22 Figura 4.8: Aprendizaje expansivo en la tercera generación de la teoría de la actividad

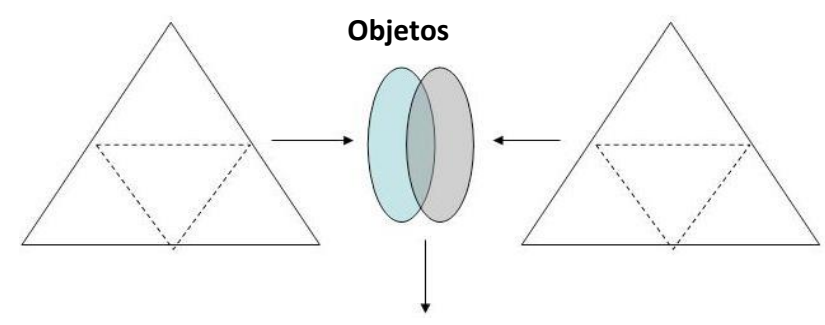

Aprendizaje expansivo

Fuente: Engeström, 2001

Frente a esta posible equivalencia del ciclo expansivo en los sistemas de la actividad y la zona de desarrollo próximo de Vigotsky, desde el punto de vista pedagógico, Engeström da su propia definición de la zona de desarrollo próximo:

“Significa que la enseñanza y el aprendizaje se desplazan dentro de la zona sólo cuando tienen por objeto el desarrollo de formas históricamente nuevas de actividad, no sólo en permitir que los alumnos adquieran las formas existentes o socialmente dominantes como algo nuevo. Para aspirar a la elaboración de formas de actividad históricamente nuevas implica una práctica de instrucción que sigue a los alumnos en sus actividades de la vida fuera del aula. También implica la necesidad de formar verdadera actividad de aprendizaje expansivo en y entre los alumnos. La tarea de instrucción es, pues, doble: desarrollar actividades de aprendizaje y desarrollar nuevas formas de la actividad (la actividad de aprendizaje es en sí el objetivo central de la actividad durante los primeros años escolares)." (Engeström, 1987, 144)

Ante esta ampliación del concepto de zona de desarrollo próximo y en el marco de la teoría de la actividad, Cubero (citado García Mendoza, 2009) entiende el aprendizaje como un 
proceso distribuido, interactivo, contextual y que es el resultado de la participación de los alumnos en una comunidad, dónde el profesor actúa como guía para el aprendizaje de los alumnos y al mismo tiempo participa junto con ellos ofreciendo varios tipos de ayudas:

a) construye puentes del nivel de comprensión y de habilidades del alumno hasta otros niveles más complejos;

b) estructura la participación de los alumnos, manipulando la presentación de la tarea de forma dinámica, ajustándose a las condiciones del momento;

c) transfiere gradualmente el control de la actividad hasta que el propio alumno sea capaz de controlar por sí mismo la ejecución de la tarea.

\section{Figura 4.9: La estructura de la actividad de aprendizaje}

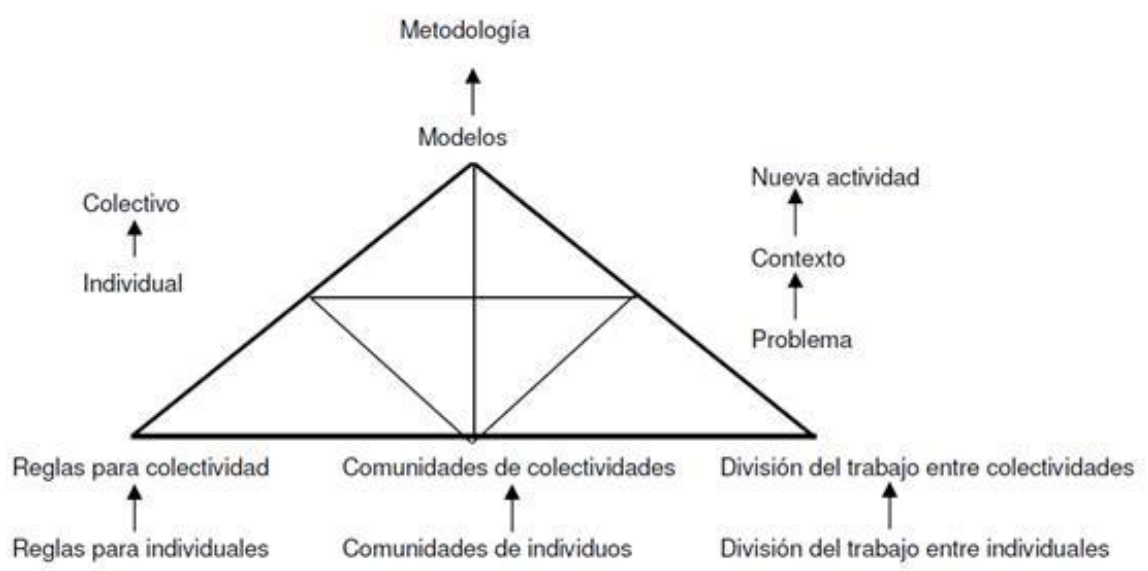

Fuente: Engeström, 1987

\subsubsection{La actividad como base de la formación b-learning}

A modo de conclusión de este capítulo, queremos destacar que la teoría de la actividad es una teoría dinámica la que desde sus orígenes ha estado en permanente transformación con lo que renueva su interés y utilidad para comprender los procesos de aprendizaje con uso de tecnologías de la información y la comunicación. El enfoque sociocultural, según García del Dujo y Martín García (2002) es el marco de inteligibilidad pedagógica, dentro del cual hemos situado la teoría de la actividad, más apropiado para abordar nuestro objeto 
de estudio, la uso de la modalidad blended learning en educación superior, dado que centra en el análisis en los instrumentos de mediación y mecanismos de interacción social que configuran los sistemas de actividad de los sujetos. Dentro del diseño metodológico de nuestra investigación, que se presenta en el siguiente capítulo, la definición de las dimensiones y variables a investigar se basan en la teoría de la actividad, además de los aportes de los modelos pedagógicos b-learning, estudiados en el capítulo precedente, en torno al manejo pedagógico de la actividad como base para la formación b-learning. 


\section{CAPÍTULO 5 \\ METODOLOGÍA DE LA INVESTIGACIÓN}

5.1 Estudio cuantitativo

5.1.1 Variables

5.1.2 Población y muestra

5.1.3 Técnica de recogida de información

5.1.4 Procedimiento de análisis

5.2 Estudio cualitativo

5.2.1 Apartados y categorías

5.2.2 Población y muestra

5.2.3 Técnicas de recogida de información

5.2.4 Procedimiento de análisis 


\section{CAPÍTULO 5 METODOLOGÍA DE LA INVESTIGACIÓN}

En el capítulo de introducción al problema de investigación hemos descrito el contexto de la investigación el que exhibe la complejidad y singularidad de los fenómenos sociales y educativos. La naturaleza del objeto educativo de investigación nos impone un enfoque que considere varias dimensiones. El método se constituye a partir de la realidad objeto de estudio y de los objetivos planteados. En el campo de la investigación en ciencias sociales y, concretamente, el ámbito educativo, como lo señalan Sabariego y Bisquerra, el diseño de la metodología de investigación "se caracteriza por una pluralidad metodológica o una diversidad de procedimientos posibles para realizar investigaciones empíricas" (2004, 31).

Se observa en los últimos años una complementariedad entre paradigmas, que combinan datos, métodos y técnicas de investigación, sin seguir una sola tendencia metodológica. El método cuantitativo se complementa e integra con un enfoque cualitativo (Cohen y Manion, 2002), tanto desde la perspectiva epistemológica como desde el diseño mixto de la investigación. Las aproximaciones metodológicas mixtas permiten, según Rodríguez y Valldeoriola (2009), entre otros beneficios, neutralizar o eliminar sesgos de determinados métodos cuando éstos se utilizan de forma aislada; además que los resultados de un método contribuyan al desarrollo de otros métodos; o que puedan convertirse en una especie de subproceso de otro método, proporcionándole datos sobre diferentes niveles o unidades de análisis.

Desde una visión pragmática, el investigador debe realizar la selección de técnicas para la recogida de datos abandonando posicionamientos metodológicos apriorísticos y centrándose en la interrelación del problema de investigación, los objetivos planteados y el contexto donde se desarrollará el proceso, constituyendo así un método de investigación propio y singular. 
Basados en las aproximaciones metodológicas mixtas propuestas por Creswell (2009), usaremos el procedimiento concurrente. En este procedimiento se utilizan de forma simultánea o convergente metodologías cuantitativas y cualitativas, consiguiendo así una mejor comprensión del objeto de estudio (Figura 5.1).

El objeto de la investigación se aborda en dos estudios. El primero corresponde a un estudio cuantitativo y el segundo a un estudio cualitativo. Los resultados cuantitativos y cualitativos junto a sus respectivos análisis e interpretación de los datos se integran en la fase de las conclusiones.

24 Figura 5.1: Procedimiento concurrente

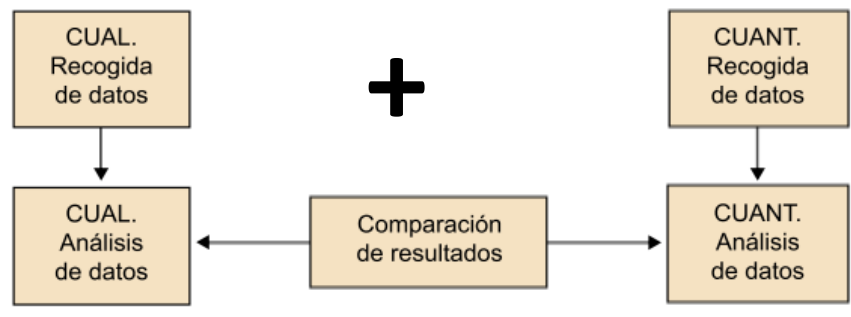

Fuente: Creswell, 2003

\subsection{Estudio cuantitativo}

Como nos indica Mateo (2004), las metodologías ex-post-facto son las más utilizadas en el ámbito educativo, proporcionándonos técnicas para describir la realidad, analizar relaciones, categorizar, simplificar y organizar las variables que configuran el objeto de estudio.

Este estudio cuantitativo, según el grado de intervención, corresponde a un diseño es expost-facto o no experimental ya que no se tiene ningún control sobre las variables independientes, porque el fenómeno estudiado ya ha ocurrido y porque no es posible controlar las variables independientes ni modificar el fenómeno objeto de estudio. Del mismo modo, tampoco es posible asignar a los participantes de forma aleatoria, ya que los sujetos de investigación están distribuidos en una situación real de conformación de los 
grupos según la carrera seleccionada por los alumnos, conformando conglomerados naturales. El estudio no pretende abordar los cambios ni provocar cambios en la situación estudiada.

El objetivo de nuestra investigación consiste en encontrar las causas o factores que se relacionan con el fenómeno estudiado y contribuyen a explicarlo. No se trata, por lo tanto, de una investigación experimental por cuanto no se produce una manipulación de las variables influyentes, sino más bien de una investigación de carácter comparativo y correlacional (Mateo, 2004).

El diseño por el que hemos optado es de tipo transversal, es decir recogemos información cuantitativa de un corte temporal del 2011 en la asignatura Técnicas de Comunicación Oral y Escrita (TCOE), dictada en la carrera Ingeniería en Prevención de Riesgos, Calidad y Ambiente (IPRCA), impartida en tres Campus ubicados en distintas regiones de la zona norte de Chile. La asignatura es ofrecida simultáneamente, en los tres Campus, en la modalidad b-learning y en la modalidad presencial tradicional.

\subsubsection{Variables}

\subsubsection{Variables dependientes}

Las variables dependientes del estudio cuantitativo son el aprendizaje percibido por los estudiantes y la satisfacción hacia las tecnologías en la asignatura en las dos modalidades estudiadas: $b$-learning y presencial tradicional.

\subsubsection{Variables independientes primarias}

Las variables independientes se han determinado de acuerdo a los componentes que define Engestöm $(1987,2000,2009,2010)$ en su esquema de la teoría de la actividad para una actividad de aprendizaje. Las variables a estudiar de la actividad de aprendizaje, en la asignatura Técnicas de la Comunicación Oral y Escrita en sus modalidades $b$-learning y presencial tradicional, son: la actividad de aprendizaje diseñada y ejecutada; los docentes 
y alumnos como sujetos participantes; las diferentes herramientas disponibles y las utilizadas por los alumnos y docentes; la conformación y funcionamiento de la comunidad de aprendizaje; las normas y reglamentos existentes en la comunidad de aprendizaje; la división del trabajo establecida en las actividades de aprendizaje (Tabla 5.1).

\subsubsection{Variables independientes secundarias o moderadoras}

Las variables moderadoras representan un tipo especial de variable independiente, que es secundaria, y se seleccionan con la finalidad de determinar si afectan la relación entre las variables independientes primarias y las variables dependientes. En nuestro estudio nos interesa determinar si algunas de las dimensiones de las variables independiente alumno, permiten describir y explicar las relaciones que se puedan establecer entre las variables dependientes e independientes primarias (Tabla 5.1).

25 Tabla 5.1: Variables dependientes e independientes

\begin{tabular}{lll} 
Variables & & \\
dependientes & Variables independientes \\
\hline & & V.I.P.1. Actividad de aprendizaje \\
& V.I.P.2. Herramientas de apoyo \\
V.D.1. Aprendizaje & Primarias & V.I.P.3. Comunidad de aprendizaje \\
percibido & V.I.P.4. Normas y reglamentos \\
V.D.2. Satisfacción & & V.I.P.5. División del trabajo \\
\cline { 2 - 3 } hacia las tecnologías & & V.I.S.1. Rasgos sociodemográficos \\
& V.I.S.2. Disponibilidad de tecnologías y \\
& Secundarias & Conexión a Internet \\
& & V.I.S.3. Dominio de recursos tecnológicos \\
& & V.I.S.4. Actitudes hacia Internet \\
\hline
\end{tabular}

Fuente: Elaboración propia basada en: Engeström, 1987, 2000, 2009, 2010; Llorente, 2008. 


\subsubsection{Población y muestra}

La población corresponde a 2092 alumnos de primer año de la cohorte del año 2011, que cursan la asignatura Técnicas de la Comunicación Oral y Escrita en la carrera de Ingeniería en Prevención de Riesgos, Calidad y Ambiente (IPRCA), dictada en veinte Campus de la Universidad Tecnológica de Chile INACAP (UTC INACAP), distribuidos en diferentes regiones políticas y geográficas a lo largo del país (Figura 5.2). Se ha seleccionado la carrera IPRCA porque es dictada en el $80 \%$ de los 25 Campus que posee la UTC INACAP (Tabla 5.2).

26 Figura 5.2: Ubicación geográfica de los Campus de la Universidad Tecnológica de Chile INACAP

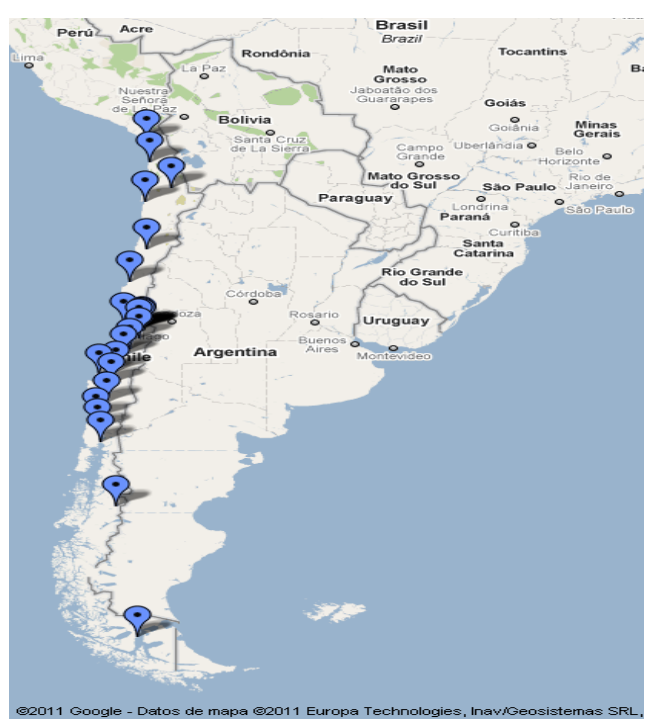

Fuente: Google Maps 
6 Tabla 5.2: Distribución de la población alumnos de primer año de la carrera de Ingeniería

\begin{tabular}{|c|c|c|c|c|c|}
\hline \multirow[b]{2}{*}{ Zona } & \multirow[b]{2}{*}{ Campus } & \multicolumn{2}{|c|}{2010} & \multicolumn{2}{|c|}{2011} \\
\hline & & $\begin{array}{c}\text { № } \\
\text { alumnus }\end{array}$ & $\begin{array}{c}\text { № } \\
\text { grupos } \\
\text { curso } \\
\end{array}$ & $\begin{array}{c}\text { № } \\
\text { alumnos }\end{array}$ & $\begin{array}{c}\text { № grupos } \\
\text { curso }\end{array}$ \\
\hline \multirow{6}{*}{ Norte } & Arica & 107 & 3 & 230 & 7 \\
\hline & Iquique & 104 & 3 & 249 & 6 \\
\hline & Calama & 130 & 4 & 134 & 5 \\
\hline & Antofagasta & 245 & 7 & 289 & 9 \\
\hline & Copiapó & 139 & 4 & 147 & 5 \\
\hline & La Serena & 185 & 5 & 243 & 8 \\
\hline \multirow{7}{*}{ Centro } & Santiago Sur & 196 & 6 & 196 & 6 \\
\hline & Renca & 71 & 2 & 71 & 2 \\
\hline & Maipú & 99 & 3 & 99 & 3 \\
\hline & Valparaíso & 88 & 3 & 88 & 3 \\
\hline & Rancagua & 100 & 3 & 207 & 6 \\
\hline & Curicó & 52 & 1 & 52 & 1 \\
\hline & Talca & 87 & 2 & 88 & 2 \\
\hline \multirow{8}{*}{ Sur } & Chillán & 97 & 3 & 119 & 4 \\
\hline & Concepción - Talcahuano & 87 & 2 & 440 & 11 \\
\hline & Temuco & 53 & 2 & 119 & 4 \\
\hline & Valdivia & 76 & 2 & 104 & 3 \\
\hline & Osorno & 45 & 1 & 69 & 3 \\
\hline & Puerto Montt & 61 & 2 & 84 & 2 \\
\hline & Punta Arenas & 70 & 2 & 122 & 4 \\
\hline & TOTAL & 2092 & 60 & 3150 & 94 \\
\hline
\end{tabular}

Fuente SIGA, Sistema Integrado de Gestión Académica, U. Tecnológica de Chile INACAP, 2011

La técnica de muestreo utilizada para seleccionar la muestra es intencional, no probabilística. Los alumnos están distribuidos en conglomerados naturales definidos en grupos de clase (Tejedor y Etxeberria, 2006) correspondientes a una carrera de determinados Campus de la UTC INACAP. En este caso la unidad de muestreo no es el individuo, sino el conglomerado a través del cual se accede a la unidad de análisis (Sabariego, 2004).

Los conglomerados de la población son 20 Campus de los cuales hemos seleccionado como muestra a tres: Campus Antofagasta, Campus Copiapó y Campus La Serena (Tabla 5.3). 
7 Tabla 5.3: Distribución de la muestra de alumnos de primer año de la carrera de Ingeniería en Prevención de Riesgos, Calidad y Ambiente de la Universidad Tecnológica de Chile INACAP

\begin{tabular}{lccccrcr}
\multirow{2}{*}{\multicolumn{1}{c}{ Campus }} & \multicolumn{2}{c}{ Alumnos } & \multicolumn{2}{c}{ B-learning } & \multicolumn{2}{c}{ Presencial } \\
\cline { 2 - 8 } & N & \multicolumn{1}{c}{$\%$} & \multicolumn{1}{c}{ N } & \% & \multicolumn{1}{c}{ N } & \multicolumn{1}{c}{$\%$} \\
\hline Antofagasta & $\mathbf{2 8 9}$ & 42.6 & 68 & 28.2 & 68 & 34.9 \\
\hline Copiapó & 147 & 21.6 & 89 & 36.9 & 58 & 29.7 \\
\hline La Serena & 243 & 35.8 & 84 & 34.9 & 69 & 35.4 \\
\hline TOTAL & $\mathbf{6 7 9}$ & 100 & 241 & 100 & 195 & 100 \\
\hline
\end{tabular}

Fuente: SIGA, Sistema Integrado de Gestión Académica, U. Tecnológica de Chile INACAP, 2010

Los criterios usados para acotar selección de la muestra son los siguientes:

- En primer término, se consideró aquellos Campus cuyo $\mathrm{N}$ de alumnos conforman un $\mathrm{N}$ de grupos curso que permitan realizar un estudio comparativo, estableciendo a lo menos dos grupos curso por Campus que cursan la asignatura en la modalidad b-learning y dos grupos que cursan la asignatura en la modalidad presencial tradicional. De acuerdo a este criterio, se acotan los Campus a los siguientes: Calama, Antofagasta, Copiapó, La Serena y Santiago Sur.

- El segundo criterio considerado, complementario al anterior, es la ubicación geográfica de los Campus y considerando un criterio de facilidad de acceso, debido a ello no se consideraron los Campus de los extremos geográficos, vale decir Calama y Santiago Sur, tomando como punto de referencia el Campus La Serena donde se ubica el investigador (Figura 5.3).

- Los tres Campus seleccionados se ubican en la zona norte del país la que comparte rasgos geográficos y económicos comunes. Geográficamente es una zona desértica, cuyos centros poblados están a grandes distancias unos de otros. La actividad productiva principal es la minería, la que tiene gran demanda de profesionales de las áreas de prevención de riesgos y cuidados del medio ambiente. Esto explica la alta tasa de matrícula en la carrera de Prevención de Riesgos, Calidad y Ambiente en los Campus de la zona norte a diferencia de los de la zona sur de Chile (Tabla 5.3). 
27 Figura 5.3: Ubicación geográfica de los Campus seleccionados de la Universidad Tecnológica de Chile INACAP

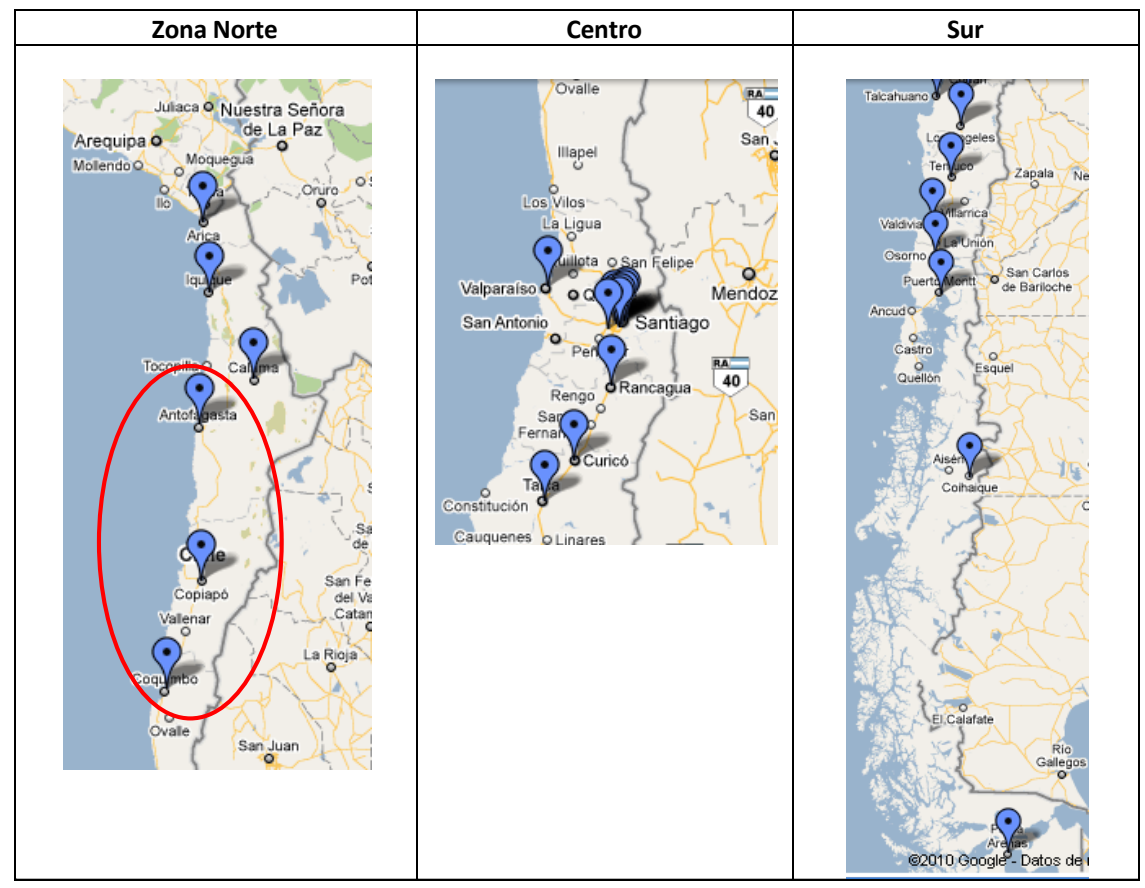

Fuente: Google Maps

\subsubsection{Técnica de recogida de información}

Una vez especificada la finalidad, la población y la muestra de la investigación, se decidió que la técnica de recogida de datos más adecuada para medir las variables del estudio es la encuesta, en la modalidad de dos cuestionarios (Tabla 5.4).

Los cuestionarios que se han aplicado son los siguientes:

- Cuestionario 1: Cuestionario sobre Conocimientos, Actitudes de Estudiantes de Educación Superior hacia las Tecnologías Usadas en el Proceso de EnseñanzaAprendizaje. Este cuestionario se aplicada al inicio del semestre académico, a modo de diagnóstico, y a final de semestre para constatar la permanencia de ciertos conocimientos que se verían afectados por el proceso de enseñanza en el periodo académico que se estudia.

Las variables secundarias que aborda este instrumento son las siguientes: V.I.S.1 Rasgos sociodemográficos, V.I.S.2 Disponibilidad de tecnologías y conexión a 
Internet y V.I.S.3 Dominio de recursos tecnológicos y V.I.S.4 Actitudes hacia Internet (Apéndice A).

- Cuestionario 2: Conocimientos y Satisfacción hacia Tecnologías Usadas en el Proceso de Enseñanza-Aprendizaje. Este instrumento mide las variables independientes primarias: V.I.P.1. Actividad de aprendizaje, V.I.P.2. Herramientas de apoyo, V.I.P.3. Comunidad de aprendizaje V.I.P.4., Normas y reglamentos, V.I.P.5. División del trabajo (Apéndice B).

8 Tabla 5.4: Técnicas de recogida de información según las variables

\begin{tabular}{|c|c|c|c|}
\hline $\begin{array}{c}\text { Variables } \\
\text { dependientes }\end{array}$ & & Variables independientes & $\begin{array}{l}\text { Técnica de recogida de } \\
\text { información }\end{array}$ \\
\hline \multirow{2}{*}{$\begin{array}{l}\text { V.D.1. Aprendizaje } \\
\text { percibido } \\
\text { V.D.2. Satisfacción } \\
\text { hacia las } \\
\text { tecnologías }\end{array}$} & 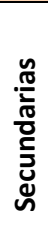 & $\begin{array}{l}\text { V.I.S.1. Rasgos sociodemográficos } \\
\text { V.I.S.2. Tecnologías y conexión a } \\
\quad \text { Internet } \\
\text { V.I.S.3. Dominio de recursos } \\
\text { tecnológicos } \\
\text { V.I.S.4. Actitudes hacia Internet }\end{array}$ & $\begin{array}{l}\text { Cuestionario 1: Conocimientos, } \\
\text { Actitudes de Estudiantes de } \\
\text { Educación Superior hacia las } \\
\text { Tecnologías Usadas en el Proceso } \\
\text { de Enseñanza-Aprendizaje } \\
\text { (CAEEST) }\end{array}$ \\
\hline & 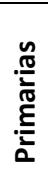 & $\begin{array}{l}\text { V.I.P.1. Actividad de aprendizaje } \\
\text { V.I.P.2. Herramientas de apoyo } \\
\text { V.I.P.3. Comunidad de aprendizaje } \\
\text { V.I.P.4. Normas y reglamentos } \\
\text { V.I.P.5. División del trabajo }\end{array}$ & $\begin{array}{l}\text { Cuestionario 2: Conocimientos y } \\
\text { Satisfacción hacia Tecnologías } \\
\text { Usadas en el Proceso de } \\
\text { Enseñanza-Aprendizaje (CSEEST) }\end{array}$ \\
\hline
\end{tabular}

La técnica de encuesta, ya sea en la modalidad de entrevista o de cuestionario, es exclusiva de las ciencias sociales y parte de la premisa que si queremos conocer algo sobre el comportamiento de las personas, lo mejor, lo más directo y simple, es preguntárselo directamente a ellas. Se trata por tanto de requerir información a un grupo socialmente significativo de personas acerca de los problemas en estudio para luego, mediante un análisis de tipo cuantitativo, sacar las conclusiones que se correspondan con los datos recogidos.

Las principales ventajas que han ayudado a difundir el diseño encuesta son las siguientes:

Su conocimiento de la realidad es primario, no mediado, y por lo tanto menos engañoso. Al acudir directamente las personas (a los actores sociales) para conocer su 
situación, conducta u opinión, nos precavemos contra una multiplicidad de distorsiones y nos ponemos a salvo de interpretaciones que pueden estar altamente teñidas de subjetividad.

- Como es posible agrupar los datos en forma de cuadros estadísticos se hace más accesible la medición de las variables en estudio. De esta forma se puede cuantificar una serie de variables operando con ellas con mayor precisión, permitiendo el uso de correlaciones y de otros recursos matemáticos.

- La encuesta es un método de trabajo relativamente económico y rápido. Si se cuenta con un equipo de entrevistadores y codificadores convenientemente entrenado, resulta fácil llegar rápidamente a una multitud de personas y obtener una gran cantidad de datos en poco tiempo. Su costo, para los casos simples, es sensiblemente bajo.

En cuanto a las desventajas más frecuentes que se le han reconocido, destacan las siguientes:

- La encuesta recoge la visión que la gente tiene de sí misma; no puede dudarse de que ésta es siempre una imagen singular y muy subjetiva y que, para algunos temas, puede ser deliberadamente falsa e imprecisa. No es lo mismo lo que las personas hacen, sienten o creen, que lo que ellas mismas dicen que hacen, creen o sienten.

- Existen algunos recursos para reducir la magnitud de este serio problema, entre los que se cuentan: omitir algunas preguntas que sabemos la mayoría no desea o no puede contestar con veracidad, buscar formas indirectas de contrastación, prestar cuidadosa atención a la presentación personal del encuestador, etc. A pesar de estas técnicas de trabajo es imposible eliminar por completo el fenómeno ante señalado, por lo que el investigador que tomar en cuenta, al momento de hacer el análisis, las limitaciones que el mismo acarrea.

- La encuesta no relata los hechos sociales desde el punto de vista de sus actores; puede, en este sentido, llegar a una cierta profundidad y sistematicidad, pero resulta poco apta para reconocer las relaciones sociales ya sean interpersonales o institucionales. 
- El diseño de la es básicamente estático. Tiende, de por sí, a proporcionar una especie de imagen instantánea de un determinado problema, pero no nos indica sus tendencias a la y menos aún sus posibles cambios estructurales. Esta característica reduce notablemente su eficacia predictiva, salvo para fenómenos de bastante simplicidad.

- El tratamiento de la información es estadístico, lo que supone agrupar a todas las respuestas dándole a cada una igual peso relativo. Ello puede resultar muy democrático y útil en ciertos casos, pero casi nunca se corresponde con la realidad de los hechos sociales, donde el liderazgo y la asimetría de las posiciones sociales son por lo general la norma.

La lógica de la verificación mediante encuestas se basa naturalmente en la correlación estadística que las distribuciones de frecuencias de dos o más variables sobre las cuales se supone que existen relaciones de determinación. De este modo se puede inferir si existe o no una asociación entre los valores de las mismas, con lo cual queda establecida una cierta relación. Determinar, más allá de esto, el tipo de relación que se ha detectado y el grado de influencia que ejerce una sobre otra requiere de otras nuevas pruebas que no siempre es posible realizar por medio de este diseño. 


\subsubsection{Cuestionario 1: Conocimientos, Actitudes de Estudiantes de Educación Superior hacia las Tecnologías Usadas en el Proceso de Enseñanza- Aprendizaje (CAEEST)}

\subsection{Especificación de la información requerida}

A través del Cuestionario CAEEST se recoge información de los ámbitos relacionados con cada una de las variables independientes secundarias o moderadores. El primer ámbito se refiere a los rasgos sociodemográficos: sexo, edad, jornada de clases diurna o vespertina, sección o grupo curso al cual pertenece, año de ingreso a la institución a fin de determinar las experiencias previas en el uso de la plataforma ya que los alumnos de la muestra son de primer año de la carrera. El segundo ámbito nos permite determinar la disponibilidad de tecnologías de la información y comunicaciones y el acceso y conexión a Internet. Con el tercer ámbito queremos determinar el nivel de dominio de variados recursos tecnológicos que presuponemos los alumnos han adquirido su dominio fuera de la universidad. En el cuarto ámbito queremos conocer la actitud que el alumnado de educación superior manifiesta tener hacia Internet como medio para la formación $b$ learning.

\subsection{Diseño del cuestionario}

Centrándonos en el proceso de diseño del Cuestionario CAEEST, detallamos las características que lo definen en su construcción:

a) Desde el punto de vista del formato, los ítems utilizados son de preguntas cerradas y abiertas.

b) Según su estructura, el cuestionario se articula en un total de 19 ítems divididos en dos partes. La primera parte está constituida por cuatro bloques de contenido. El bloque corresponde a antecedentes sociodemográficos (preguntas 1 a 14). A su vez, la segunda parte está constituida por un bloque de contenido referido al 
conocimientos hacia las tecnologías y frecuencia de uso en para tareas académicas (preguntas 14 a 18).

c) En cuanto a la escala valorativa hemos usado la tipo Likert de cinco puntos para las preguntas 15 y 16 :

\begin{tabular}{|l|l|}
\hline Conocimiento & Frecuencia de uso \\
\hline $0=$ Nada & Nunca \\
\hline $1=$ Poco & Ocasiones puntuales \\
\hline $2=$ Lo suficiente & 1 o 2 veces al mes \\
\hline $3=$ Bien & Varias veces en la semana \\
\hline 4= Muy bien & A diario \\
\hline
\end{tabular}

Para las preguntas relativas a la medición de las actitudes hacia Internet se usa una escala bipolar de adjetivos, según el siguiente ejemplo:

\begin{tabular}{|c|c|c|c|c|}
\hline Malo & 1 & ------- & 7 & Bueno \\
\hline
\end{tabular}

d) Por la finalidad u objetivo para el que se ha diseñado, el cuestionario es de tipo descriptivo y explicativo (Sabariego y Bisquerra, 2004).

e) Por su forma de administración es un cuestionario es de autoadministración, siendo aplicado presencialmente a la muestra durante el horario de clase de la asignatura seleccionada.

f) Según su dimensión temporal, el cuestionario es de tipo sincrónico o transversal, debido a que la información es recogida una única vez en un periodo de tiempo limitado (al finalizar el primer semestre académico de 2011).

g) Según el sentido y momento de recogida de información es una encuesta retrospectiva.

\subsection{Operacionalización de las variables}

Para la operacionalización de las variables del Cuestionario CAEEST se consideraron las dimensiones e indicadores asociadas a cada una de ellas. Para la variable "rasgos sociodemográficos" se consideraros los siguientes indicadores: sexo, edad, jornada de 
clases, sección, año de ingreso a la institución. En el caso de la variable "tecnologías y conexión a Internet" se acota a la dimensión de disponibilidad de tecnologías y conexión a Internet. La variable "dominio de recursos tecnológicos" se operacionaliza considerando los siguientes indicadores: uso de herramientas de Office; plataformas; redes sociales; herramientas colaborativas; herramientas de comunicación y entornos virtuales. Finalmente, para la variable "actitudes hacia Internet" se seleccionaron los indicadores acceso, rapidez, costos, utilidad, rasgos, usabilidad y valoración (Tabla 5.5).

9 Tabla 5.5: Variable independiente secundaria, dimensiones, indicadores e ítems en el Cuestionario CAEEST

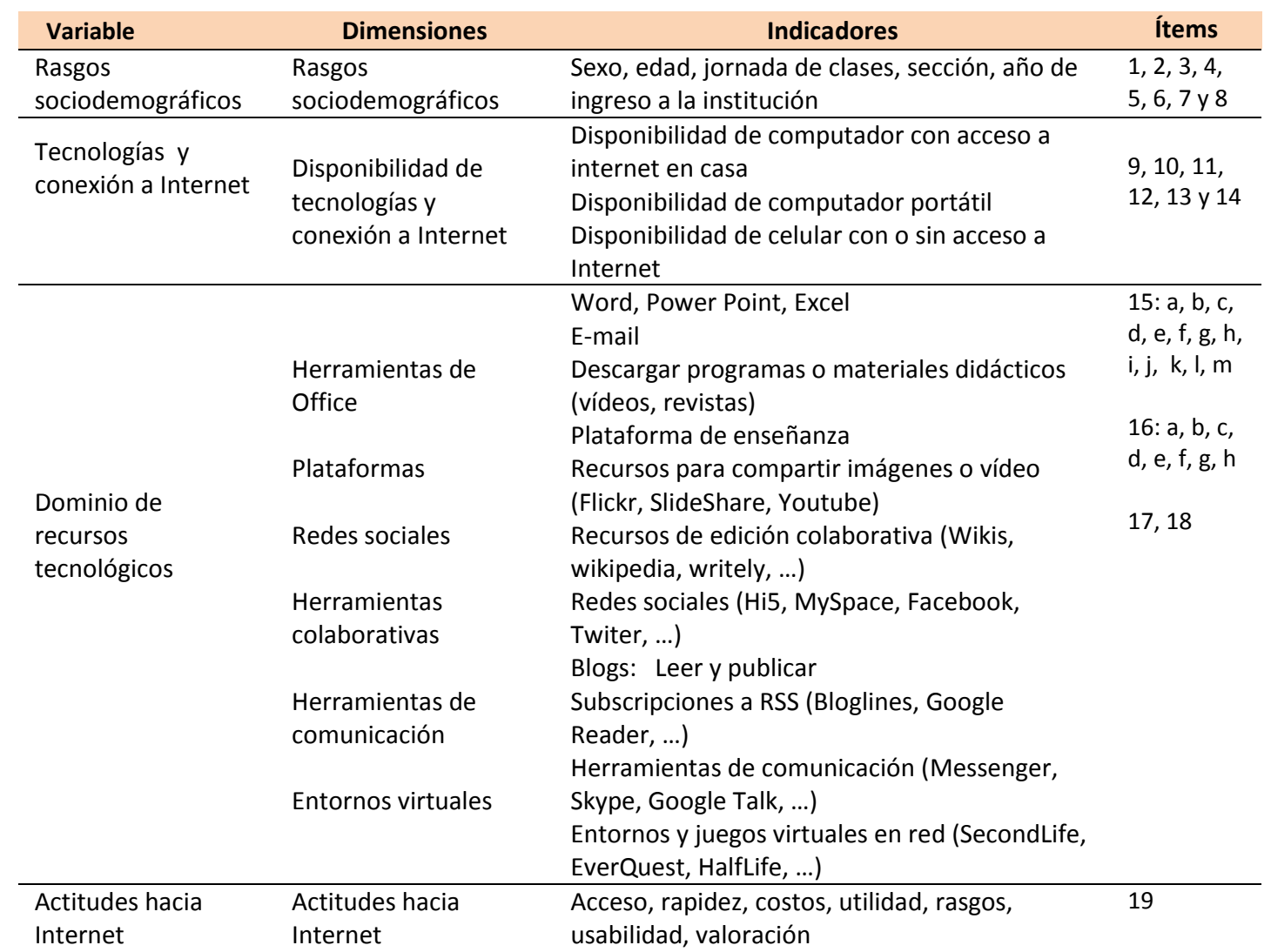

Fuente: Elaboración propia basada en: Barberà, Mauri y Onrubia, 2008; Barros, 2004; Engeström, 1987, 2000, 2009, 2010; González Sánchez et al, 2009; Llorente, 2008. 


\subsection{Validación del instrumento}

El instrumento diseñado se basa en dos cuestionarios preexistentes. Los ítems 1 a 18 son tomados del Cuestionario sobre Conocimientos y Actitudes de Estudiantes Universitarios hacia las Tecnologías Utilizadas en Procesos de Aprendizaje, desarrollado por un equipo de académicos de la Facultad de Educación de la Universidad de Salamanca (González Sánchez et al, 2009). En el caso del ítem 19 que mide la variable actitudes hacia Internet, ha sido usada íntegramente de una encuesta diseñada y validada por Llorente (2008) en el marco de una investigación acerca de la actitudes de alumnos universitarios en procesos de formación b-learning, por lo cual este ítem no fue sometido a consulta de los expertos validadores.

Si bien la base del Cuestionario CAEEST son instrumentos aplicados en investigaciones previas por otros investigadores, de todos modos lo hemos sometido a validación considerando los criterios de validez, cualidad esencial para Pérez Serrano (1998) que deben poseer todas las pruebas o instrumentos de carácter científico para la recogida de datos.

La validez se refiere a la homogeneidad, a la correspondencia entre el instrumento o técnica y el atributo que pretende medir dicho instrumento. Es decir, un instrumento o técnica es válido cuando mide aquello para lo que se ha elaborado. Para obtener la validez de contenido y de construcción del cuestionario, hemos usado la llamada validación mediante jueces o juicio de expertos (Del Rincón et al, 1995). El cuestionario fue revisado por una serie de once evaluadores expertos en el tema de investigación, quienes aportan aquellos que consideren adecuados para su mejora en los ítems (Apéndice A).

Las aportaciones de los diferentes expertos fueron detenidamente revisadas por el investigador e incorporadas cuando fue conveniente siguiendo los criterios de grado de acuerdo de los expertos entre sí; mejor comprensión de la variable medida y pertinencia de los cambios sugeridos con los objetivos de nuestra investigación (Tabla 5.6). 
10 Tabla 5.6: Sugerencias de los expertos

\begin{tabular}{|c|c|c|}
\hline Experto & Sugerencias & Medidas adoptadas \\
\hline Experto 1 & $\begin{array}{l}\text { Ítem 10: El término general "celular" } \\
\text { luego se aplica a un caso particular. }\end{array}$ & $\begin{array}{l}\text { Se elimina celular de las opciones y se } \\
\text { especifica mobile, android u otro }\end{array}$ \\
\hline \multirow[t]{2}{*}{ Experto 2} & $\begin{array}{l}\text { Ítem 1: Número de Sección supongo } \\
\text { que esto es claro para el } \\
\text { respondiente, yo no lo entiendo. }\end{array}$ & $\begin{array}{l}\text { Es una nomenclatura clara para los } \\
\text { alumnos, por lo cual no se realiza el } \\
\text { cambio }\end{array}$ \\
\hline & Ítem 10: Ambigüedad de categorías & $\begin{array}{l}\text { Se elimina celular de las opciones y se } \\
\text { especifica mobile, android u otro }\end{array}$ \\
\hline Experto 3 & $\begin{array}{l}\text { Ítem 15: sugiere cambiar "di" por } \\
\text { "explica" }\end{array}$ & $\begin{array}{l}\text { Se conserva "di", porque en el ítem sólo } \\
\text { deben seleccionar una alternativa }\end{array}$ \\
\hline Experto 4 & Ítem 1: añadiría “materia” & $\begin{array}{l}\text { La encuesta se aplica en una sola materia } \\
\text { o asignatura, por ello se incorpora en las } \\
\text { instrucciones del cuestionario }\end{array}$ \\
\hline Experto 5 & $\begin{array}{l}\text { Ítem 9: Se preguntan dos cosas, la } \\
\text { primera es si dispone de un } \\
\text { computador con Internet y la } \\
\text { segunda desde hace cuánto tiempo }\end{array}$ & $\begin{array}{l}\text { Se acoge el comentario, se agrega la } \\
\text { opción "no" y se conserva la escala menos } \\
\text { de } 1 \text { año, entre } 1 \text { y } 3 \text { años, entre } 4 \text { y } 5 \\
\text { años, más de } 5 \text { años }\end{array}$ \\
\hline \multirow{5}{*}{ Experto 6} & $\begin{array}{l}\text { Ítem 10: En "otro", sugiere poner } \\
\text { cuáles }\end{array}$ & Se especifica mobile y android \\
\hline & $\begin{array}{l}\text { Ítem 11: sugiere poner las opciones } \\
\text { sí /no }\end{array}$ & Se acoge la sugerencia \\
\hline & $\begin{array}{l}\text { Ítem 14: sugiere especificar a los } \\
\text { recursos de internet específicamente }\end{array}$ & $\begin{array}{l}\text { En los ítems } 14 \text { y } 15 \text { se pregunta de } \\
\text { manera específica por cada uno de los } \\
\text { recursos considerados }\end{array}$ \\
\hline & $\begin{array}{l}\text { Ítem 14: En la respuesta habría que } \\
\text { poner la escala de la frecuencia }\end{array}$ & $\begin{array}{l}\text { Efectivamente, se considera una escala de } \\
\text { frecuencia de uso }\end{array}$ \\
\hline & $\begin{array}{l}\text { Ítem 14: sugiere especificar la } \\
\text { plataforma }\end{array}$ & $\begin{array}{l}\text { Dado que es un conocimiento previo, no } \\
\text { se puede especificar una plataforma }\end{array}$ \\
\hline Experto 7 & $\begin{array}{l}\text { Ítem 6: edad: sugiere colocar fecha } \\
\text { de nacimiento }\end{array}$ & $\begin{array}{l}\text { Se conserva el concepto de edad para } \\
\text { facilitar la respuesta y tabulación }\end{array}$ \\
\hline $\begin{array}{l}\text { Expertos } 8 \\
9,10 \text { y } 11\end{array}$ & $\begin{array}{l}\text { No realizan comentarios ni } \\
\text { sugerencias }\end{array}$ & \\
\hline
\end{tabular}

Fuente: Elaboración propia basada en los aportes de los expertos validadores

Adicionalmente, frente a cada ítem redactado, se les solicitó que expresaran una puntuación numérica de 0 a 5, en función de dos criterios básicos. El primer criterio es el de pertinencia que hace referencia a la correspondencia entre el contenido del ítem y la dimensión para la cual va a ser utilizado. El segundo criterio es el de claridad, referido a en qué medida el ítem está redactado de forma clara y precisa, facilitando su comprensión por los sujetos encuestados (Tabla 5.7). 
11 Tabla 5.7: Validación de la pertinencia y claridad de jueces expertos del Cuestionario 1

\begin{tabular}{rrrrrrrr} 
& \multicolumn{3}{c}{ PERTINENCIA } & \multicolumn{3}{c}{ CLARIDAD } \\
\cline { 2 - 8 } ÍTEM & Media & Moda & $\begin{array}{c}\text { Desviación } \\
\text { Estándar }\end{array}$ & Media & Moda & $\begin{array}{c}\text { Desviación } \\
\text { Estándar }\end{array}$ \\
\hline 1 & 4.9 & 5 & 0.258 & 5.0 & 5 & 0.258 \\
\hline 2 & 4.5 & 5 & 0.737 & 4.8 & 5 & 0.737 \\
\hline 3 & 4.9 & 5 & 0.258 & 5.0 & 5 & 0.258 \\
\hline 4 & 4.6 & 5 & 0.775 & 5.0 & 5 & 0.775 \\
\hline 5 & 4.9 & 5 & 0.258 & 5.0 & 5 & 0.258 \\
\hline 6 & 4.9 & 5 & 0.258 & 5.0 & 5 & 0.258 \\
\hline 7 & 4.9 & 5 & 0.258 & 4.8 & 5 & 0.561 \\
\hline 8 & 5.0 & 5 & 0.258 & 4.8 & 5 & 0.352 \\
\hline 9 & 4.8 & 5 & 0.990 & 4.1 & 5 & 0.986 \\
\hline 10 & 4.9 & 5 & 0.352 & 4.8 & 5 & 0.414 \\
\hline 11 & 4.9 & 5 & 0.352 & 4.8 & 5 & 0.414 \\
\hline 12 & 5.0 & 5 & 0.258 & 4.9 & 5 & 0.258 \\
\hline 13 & 5.0 & 5 & 0.000 & 4.9 & 5 & 0.258 \\
\hline 14 & 5.0 & 5 & 0.258 & 4.6 & 5 & 0.561 \\
\hline 15 & 5.0 & 5 & 0.516 & 4.5 & 5 & 0.704 \\
\hline 16 & 4.9 & 5 & 0.258 & 5.0 & 5 & 0.258 \\
\hline 17 & 4.9 & 5 & 0.258 & 4.8 & 5 & 0.561 \\
\hline 18 & 5.0 & 5 & 0.258 & 4.8 & 5 & 0.352
\end{tabular}

Fuente: Elaboración propia basada en la respuesta de los expertos validadores

Considerando los comentarios y sugerencias aportados por los validadores expertos se diseñó la versión definitiva del cuestionario. Las sugerencias hacen referencia a aspectos formales de la redacción de las preguntas. A nivel de dimensiones y de ítems no hubo sugerencias para eliminar o incorporar algún ítem propuesto, por estimarlo pertinente o significativo en el cuestionario.

En cuanto a los criterios de pertinencia y claridad se aprecia un alto grado de valoración de cada uno de los ítems, considerando los resultados de la media, moda y desviación estándar. Estadísticamente tampoco es necesaria la eliminación de algunos de los ítems.

\subsection{Modalidad de aplicación del cuestionario}

En cuanto a la modalidad de aplicación, el cuestionario fue auto administrado. En este caso se les proporciona directamente a los alumnos, sujetos de la muestra, quienes lo contestan. No hay intermediarios y las respuestas las marcan ellos. La aplicación se realizará de manera simultánea a los alumnos según grupo curso o sección al que pertenecen en la 
asignatura Técnicas de la Comunicación Oral y Escrita, durante el horario de las clases presenciales en el periodo lectivo del semestre, antes de la realización de las evaluaciones finales de cierre del semestre académico.

Siguiendo el consejo de expertos en metodología cuantitativa, cada cuestionario va acompañado de una carta de presentación que contiene los elementos básicos para motivar la respuesta y que son: objetivos de la investigación, importancia y beneficios de la investigación, la garantía de confidencialidad, instrucciones y agradecimiento por la colaboración.

\subsection{Tabulación y elaboración de base de datos}

La tabulación de las preguntas cerradas se realizó usando como base una planilla Excel, la que posteriormente se codifica y traspasa al Paquete Estadístico para Ciencias Sociales SPSS (Statistical Package for Social Sciences). Usamos SPSS versión 17 para Windows, bajo Sistema Operativo Microsoft Windows XP.

\subsubsection{Cuestionario 2: Conocimientos y Satisfacción de Estudiantes de Educación Superior hacia las Tecnologías Usadas en el Proceso de Aprendizaje (CSEEST)}

\subsection{Especificación de la información requerida}

El primer ámbito de antecedentes considerado para el diseño de Cuestionario CSEEST es que aborde los resultados de la modalidad b-learning en comparación con la modalidad presencial tradicional, concerniente a dos variables dependientes: la primera se relaciona con al aprendizaje percibido de los estudiantes de competencias instrumentales, tecnológicas e interpersonales. La segunda variable apunta a la satisfacción hacia las tecnologías en un contexto de formación académica y orientada al aprendizaje. La asignatura seleccionada, Técnicas de la Comunicación Oral y Escrita, de acuerdo a los tipos de asignaturas definidas por el curriculum de la institución, es de tipo homogeneizada, es 
decir es una asignatura común y transversal en la mayoría de las carreras ofrecidas por la Universidad Tecnológica de Chile INACAP. Según el diseño curricular es una asignatura de carácter práctico, lo que de acuerdo al reglamento académico institucional, para su aprobación requiere de un $70 \%$ de asistencia a las clases presenciales y no realiza un examen final.

El segundo ámbito de información que recoge el Cuestionario CSEEST se refiere a las variables independientes primarias, las cuales son definidas a partir del modelo de la Teoría de la Actividad (Engeström, 1987), expuesto en detalle en el capítulo cuarto de la primera parte que plantea la fundamentación teórica de esta investigación. Las variables que aborda son las siguientes:

- Actividad de aprendizaje: organización pedagógica de la asignatura en torno a actividades estructuradas y secuenciadas presenciales y virtuales que requieren la interacción y trabajo colaborativo de los alumnos para realizarlas.

- Herramientas de apoyo: selección, disponibilidad y orientaciones de uso de herramientas tecnológicas, procedimentales y de información.

- Comunidad de aprendizaje: organización social de los alumnos orientada por el logro de objetivos y resultados académicos esperados en las actividades.

- Normas y reglamentos: definición y explicitación de normas y reglas que establecen las condiciones para un efectivo desenvolvimiento de la comunidad de aprendizaje.

- División del trabajo: definición de roles y tareas para cada uno de los participantes, que propendan a la transferencia del control de la actividad del docente al alumno.

\subsection{Diseño del cuestionario}

Centrándonos en el proceso de diseño del Cuestionario CSEEST, detallamos las características que lo definen en su construcción: 
a) Desde el punto de vista del formato, los ítems utilizados son de preguntas cerradas y abiertas.

b) Según su estructura, el cuestionario está constituido por en un total de 59 ítems, distribuidos en cuatro bloques de contenido. El primer bloque corresponde a antecedentes sociodemográficos (preguntas 1 a 6 ). El segundo bloque a las variables dependientes e independientes (pregunta 7 a 54), las que en cuanto escala valorativa hemos usado la tipo Likert de cinco puntos para las preguntas.

\begin{tabular}{|l|}
\hline Totalmente en desacuerdo \\
\hline En desacuerdo \\
\hline Indeciso \\
\hline De acuerdo \\
\hline Totalmente de acuerdo \\
\hline
\end{tabular}

El tercer bloque (preguntas 55 y 56) son ítems abiertos. Finalmente, para las preguntas relativas a antecedentes de asistencia a clases, participación en actividades y tiempo dedicado al estudio, se usa una escala de intervalos (preguntas 57 a 59).

Asistencia a clases:

\begin{tabular}{|l|l|l|l|l|l|l|l|l|l|}
\hline $10 \%$ & $20 \%$ & $30 \%$ & $40 \%$ & $50 \%$ & $60 \%$ & $70 \%$ & $80 \%$ & $90 \%$ & $100 \%$ \\
\hline
\end{tabular}

Participación en actividades en línea:

\begin{tabular}{|l|l|l|l|l|l|l|l|l|l|l|}
\hline $10 \%$ & $20 \%$ & $30 \%$ & $40 \%$ & $50 \%$ & $60 \%$ & $70 \%$ & $80 \%$ & $90 \%$ & $100 \%$ & No hubo \\
\hline
\end{tabular}

Horas dedicadas a la asignatura fuera de la hora de clases

\begin{tabular}{|l|l|l|l|l|l|l|l|l|l|l|}
\hline 0 & 1 & 2 & 3 & 4 & 5 & 6 & 7 & 8 & 9 & 10 ó más \\
\hline
\end{tabular}

c) Considerando la finalidad u objetivo para el que se ha diseñado, el cuestionario es de tipo descriptivo y explicativo (Sabariego y Bisquerra, 2004).

d) Por su forma de administración es un cuestionario es de autoadministración, siendo aplicado presencialmente a la muestra de sujetos durante el horario de clase de la asignatura seleccionada. 
e) Según su dimensión temporal, el cuestionario es de tipo sincrónico o transversal, debido a que la información es recogida una única vez en un periodo de tiempo limitado (finales del primer semestre académico de 2011).

f) Según el sentido y momento de recogida de información es una encuesta retrospectiva.

Los pasos seguidos en el diseño del cuestionario se presentan en la Figura 5.8:

12 Figura 5.8: Pasos en el diseño de cuestionario

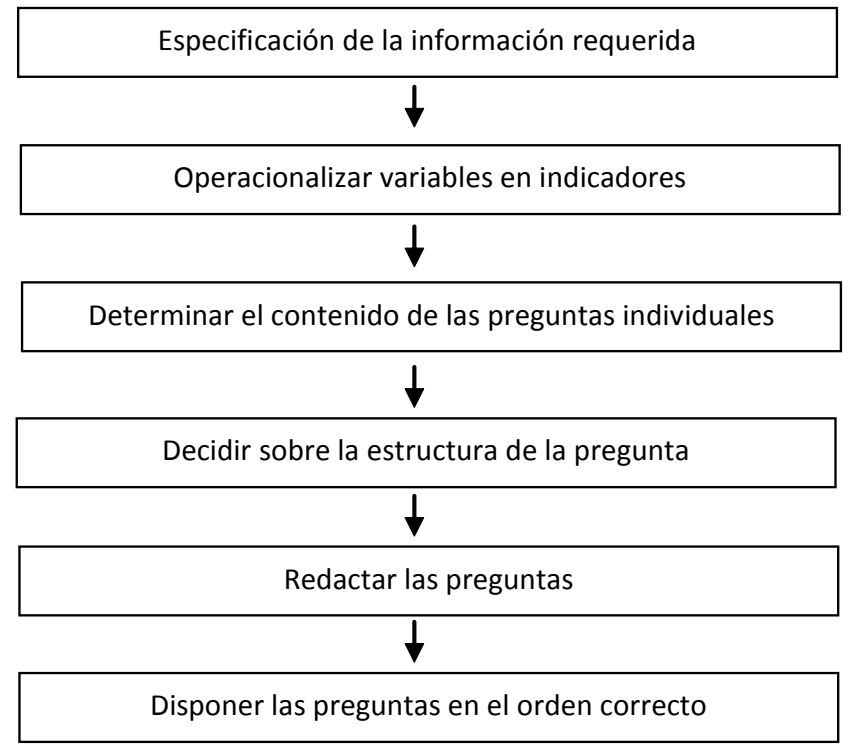

Fuente: basado en Cohen y Manion, 2002

\subsection{Operacionalización de la variables dependientes e independientes}

La primera variable dependiente objeto de estudio está definida como el aprendizaje percibido de competencias instrumentales, tecnológicas e interpersonales de los estudiantes. La segunda variable apunta a la satisfacción hacia las tecnologías en un contexto de formación académica y orientada al aprendizaje (Tabla 5.9).

Para los efectos de esta investigación, el aprendizaje percibido por los alumnos se concibió conceptualmente como la percepción que el sujeto tiene acerca de los progresos que ha efectuado en las actividades de aprendizaje durante el período académico acotado (Richmond, 1987). El constructo está conformado por las siguientes dimensiones: 

a) Competencias instrumentales.
b) Competencias tecnológicas.
c) Competencias interpersonales.

Como lo hemos señalado en un acápite anterior, en la investigación no realizamos manipulación de las variables influyentes, sino más bien se trata de una investigación de carácter comparativo-causal y correlacional (Mateo, 2004). Por ello, emplear las puntuaciones obtenidas por los alumnos en determinadas pruebas de evaluación como un indicador del aprendizaje adquirido por los mismos, no nos proporciona los mejores resultados. Dichas calificaciones pueden estar sujetas a una serie de influencias como la participación en clase, la asistencia, la habilidad para escribir, habilidades para el uso de las tecnologías, los trabajos entregados fuera de plazo, etc.

En el diseño de esta investigación, ante la ausencia de una medida del aprendizaje sólida y objetiva, usamos una medida subjetiva propuesta por Richmond et al (1987): el aprendizaje percibido por los alumnos. Aunque es razonable esperar que los estudiantes sean capaces de opinar sobre su grado de motivación o cuánto les gusta un profesor o una clase, no se da por hecho que los alumnos puedan determinar cuánto han aprendido. Sin embargo, los estudiantes de ciclos superiores, son adultos con bastante experiencia en el mundo educativo (Chesebro y McCroskey, 2000).

La opción de usar la variable aprendizaje percibido se apoya en los aportes de McCroskey y Richmond (1992), quienes rechazan la opción de emplear las notas de los alumnos porque no reflejan el grado en que éstos pueden aprender. Por ejemplo, las puntuaciones pueden estar afectadas por lo que los participantes saben al iniciar la asignatura y no muestran lo que han aprendido durante la misma. Por otro lado, puede que las notas no sean una medida válida del aprendizaje, en particular en el caso de pruebas no objetivas que son corregidas por profesores diferentes o incluso por el mismo profesor pero en momentos distintos, quienes probablemente no asignen las notas de manera consistente (Rovai, 2002).

Richmond et al. (1987) creen que es razonable considerar que estos estudiantes pueden estimar con bastante exactitud cuánto han aprendido en las clases recibidas. De hecho, opinan que se puede considerar que esta estimación es al menos tan buena como las notas 
subjetivas proporcionadas por algunos profesores o que son resultado de pruebas que no están basadas en unos objetivos claros. En definitiva, ninguno de estos métodos es inherentemente superior a otros en términos de validez. Más bien, cada uno de ellos mide el aprendizaje de maneras diferentes.

13 Tabla 5.9: Variables dependientes, dimensiones, indicadores e ítems en el cuestionario

\begin{tabular}{|c|c|c|c|c|}
\hline Variables & Dimensiones & & Indicadores & Ítems \\
\hline \multirow{9}{*}{$\begin{array}{l}\text { V.D.1 } \\
\text { Aprendizaje } \\
\text { percibido }\end{array}$} & \multirow{3}{*}{$\begin{array}{l}\text { Competencias } \\
\text { instrumentales }\end{array}$} & \multicolumn{2}{|c|}{$\begin{array}{l}\text { Usar criterios de calidad para valorar la información } \\
\text { obtenida en Internet }\end{array}$} & 33 \\
\hline & & \multicolumn{2}{|c|}{ Estrategias de aprendizaje en el campo del $b$-learning } & 34 \\
\hline & & \multicolumn{2}{|c|}{ Gestión del tiempo } & 32,38 \\
\hline & \multirow{2}{*}{$\begin{array}{l}\text { Competencias } \\
\text { Tecnológicas }\end{array}$} & \multicolumn{2}{|c|}{$\begin{array}{l}\text { Uso de herramientas o aplicaciones tecnológicas nuevas } \\
\text { para el alumno }\end{array}$} & 44 \\
\hline & & \multicolumn{2}{|c|}{ Uso de sitio web o plataforma tecnológica } & 45 \\
\hline & \multirow{4}{*}{$\begin{array}{l}\text { Competencias } \\
\text { interpersonales }\end{array}$} & \multirow[t]{3}{*}{$\begin{array}{l}\text { Colaboración } \\
\text { virtual }\end{array}$} & $\begin{array}{l}\text { Percibir la comunidad de aprendizaje } \\
\text { como propia }\end{array}$ & 23 \\
\hline & & & $\begin{array}{l}\text { Trabajo colaborativo usando las } \\
\text { tecnologías }\end{array}$ & 41 \\
\hline & & & Ofrecer y solicitar ayuda & 21,40 \\
\hline & & $\begin{array}{l}\text { Trabajo } \\
\text { autónomo }\end{array}$ & $\begin{array}{l}\text { Trabajar en red o entornos virtuales con } \\
\text { objetivos académicos }\end{array}$ & 30,37 \\
\hline \multirow{3}{*}{$\begin{array}{l}\text { V.D.2. } \\
\text { Satisfacción } \\
\text { hacia las } \\
\text { tecnologías }\end{array}$} & \multirow{3}{*}{$\begin{array}{l}\text { Satisfacción } \\
\text { respecto a la } \\
\text { mejora del } \\
\text { aprendizaje } \\
\text { basado en las } \\
\text { tecnologías }\end{array}$} & \multicolumn{2}{|c|}{ Actitud hacia internet como herramienta de aprendizaje } & 43 \\
\hline & & \multicolumn{2}{|c|}{ Estrategias de aprendizaje } & 47 \\
\hline & & \multicolumn{2}{|c|}{ Actitud hacia el uso de las tecnologías } & $\begin{array}{l}36,42 \\
48\end{array}$ \\
\hline
\end{tabular}

Fuente: Elaboración propia basada en: Barberà, 2008; Barros, 2004; Engeström, 1987; García De Andoain, 2005;

Gros, 2005; Mazzoni y Gaffuri, 2009; Mwanza y Engeström, 2003; Robertson, 2008; Scanlon, 2005; Zurita, 2007. 
14 Tabla 5.10: Variables independientes primarias, dimensiones, indicadores e items en el cuestionario

\begin{tabular}{|c|c|c|c|}
\hline Variables & Dimensiones & Indicadores & Ítems \\
\hline $\begin{array}{l}\text { Actividad de } \\
\text { aprendizaje }\end{array}$ & $\begin{array}{l}\text { Diseño pedagógico de } \\
\text { las actividades en línea } \\
\text { Diseño pedagógico de } \\
\text { las actividades } \\
\text { presenciales } \\
\text { Interactividad } \\
\text { pedagógica } \\
\text { Actividades de } \\
\text { evaluación }\end{array}$ & $\begin{array}{l}\text { Tipo de actividades/tareas formativas, frecuencia, } \\
\text { secuencia, naturaleza, finalidad } \\
\text { Sugerencias de estrategias } \\
\text { Articulación de las actividades presenciales y } \\
\text { virtuales } \\
\text { Interactividad entre alumnos, docente y alumnos } \\
\text { Utilidad y uso de las actividades de evaluación }\end{array}$ & $\begin{array}{l}1,2,3 \\
4,5,6 \\
8,9\end{array}$ \\
\hline \multirow{3}{*}{$\begin{array}{l}\text { Herramientas } \\
\text { de apoyo }\end{array}$} & Tecnológicas & $\begin{array}{l}\text { Uso de recursos tecnológicos disponibles en línea } \\
\text { Interactividad tecnológica } \\
\text { Frecuencia de uso durante el semestre académico }\end{array}$ & $\begin{array}{l}10,11 \\
12,13 \\
14,15\end{array}$ \\
\hline & Procedimentales & $\begin{array}{l}\text { Métodos de trabajo individual presencial y en línea } \\
\text { Métodos de trabajo grupal presencial y en línea } \\
\text { Sugerencias de procedimientos para el uso de las } \\
\text { herramientas tecnológicas }\end{array}$ & $\begin{array}{l}16,17 \\
18\end{array}$ \\
\hline & Información & $\begin{array}{l}\text { Artículos o recursos en Internet, libros digitales o } \\
\text { impresos usados y sugeridos } \\
\text { Link de sitios de Internet de apoyo a la asignatura }\end{array}$ & $\begin{array}{l}19,20 \\
46\end{array}$ \\
\hline $\begin{array}{l}\text { Comunidad de } \\
\text { aprendizaje }\end{array}$ & $\begin{array}{l}\text { Organización social de } \\
\text { los alumnos }\end{array}$ & $\begin{array}{l}\text { Existencia de grupos de trabajo presenciales y } \\
\text { virtuales } \\
\text { Interacción entre: docente/alumno, alumno/alumno, } \\
\text { grupo/grupo } \\
\text { Colaboración a/con compañeros del grupo de } \\
\text { trabajo y del grupo curso } \\
\text { Orientación y apoyo del docente } \\
\text { Sentimiento de comunidad }\end{array}$ & $\begin{array}{l}7,22 \\
24,25 \\
26\end{array}$ \\
\hline $\begin{array}{l}\text { Normas y } \\
\text { reglamentos }\end{array}$ & $\begin{array}{l}\text { Existencia de normas y } \\
\text { reglas }\end{array}$ & $\begin{array}{l}\text { Requisitos de participación sincrónica/asincrónica en } \\
\text { periodos de vigencia de la tareas en línea } \\
\text { Asistencia a clases presenciales } \\
\text { Participación en actividades en línea } \\
\text { Tiempo dedicado al estudio fuera de clases } \\
\text { Pautas de trabajo para las tareas en clase y virtuales } \\
\text { Pautas de evaluación del trabajo presencial y en } \\
\text { línea } \\
\text { Normas de comportamiento en Internet }\end{array}$ & 28,29 \\
\hline $\begin{array}{l}\text { División del } \\
\text { trabajo }\end{array}$ & $\begin{array}{l}\text { Roles de los alumnos } \\
\text { Roles del profesor }\end{array}$ & $\begin{array}{l}\text { Roles y tareas definidas por el docente y los alumnos } \\
\text { Transferencia del control de la actividad del docente } \\
\text { al alumno }\end{array}$ & 27,31 \\
\hline
\end{tabular}

FUENTE: Elaboración propia basada en: Barberà, 2008; Barros, 2004; Engeström, 1987; García De Andoain, 2005; Gros, 2005; Mazzoni y Gaffuri, 2009; Mwanza y Engeström, 2003; Robertson, 2008; Scanlon, 2005; Zurita, 2007.

\subsection{Validación del instrumento}

La validez se refiere a la homogeneidad, a la correspondencia entre el instrumento o técnica y el atributo que pretende medir dicho instrumento. Es decir, un instrumento o técnica es válido cuando mide aquello para lo que se ha elaborado. Para obtener la validez de contenido y de construcción del cuestionario, hemos usado la llamada validación mediante jueces o juicio de expertos (Del Rincón et al, 1995). El cuestionario es revisado 
por una serie de once evaluadores expertos en el tema de investigación, quienes aportan aquellos aspectos que consideren adecuados para su mejora en los ítems (Apéndice A). Las aportaciones de los diferentes expertos fueron detenidamente revisadas por el investigador e incorporadas cuando fue conveniente siguiendo los criterios de grado de acuerdo de los expertos validadores, mejor comprensión y relevancia de los objetivos de nuestra investigación (Tabla 5.11).

\section{Tabla 5.11: Sugerencias de los expertos validadores}

\begin{tabular}{|c|c|c|}
\hline Experto & Sugerencias & Medidas adoptadas \\
\hline Experto 1 & $\begin{array}{l}\text { Ítem 8: la pregunta es genérica que } \\
\text { la respuesta posiblemente tenga más } \\
\text { que ver con la percepción positiva o } \\
\text { no que del profesor tiene el alumno } \\
\text { que con una valoración del proceso } \\
\text { evaluativo. }\end{array}$ & $\begin{array}{l}\text { Se cambia la redacción de la pregunta } \\
\text { precisando el aspecto que se quiere } \\
\text { medir: "el proceso de evaluación en la } \\
\text { asignatura durante el semestre fue } \\
\text { coherente con las actividades } \\
\text { desarrolladas". }\end{array}$ \\
\hline Experto 2 & $\begin{array}{l}\text { Los reactivos deberían contextualizar } \\
\text { la experiencia indicando que se trata } \\
\text { de actividades de un curso o } \\
\text { asignatura. }\end{array}$ & $\begin{array}{l}\text { Se agrega una instrucción general al inicio } \\
\text { de los bloques de reactivos, para } \\
\text { especificar el contexto de aplicación }\end{array}$ \\
\hline \multirow[t]{2}{*}{ Experto 3} & $\begin{array}{l}\text { Ítem 1: sugiere cambiar el ítem por: } \\
\text { las actividades en línea individuales y } \\
\text { grupales estaban planteadas } \\
\text { paulatinamente según al grado de } \\
\text { dificultad }\end{array}$ & $\begin{array}{l}\text { Se acoge la sugerencia de la redacción } \\
\text { propuesta para este ítem. }\end{array}$ \\
\hline & $\begin{array}{l}\text { Ítem 2: sugiere cambiar el ítem por: } \\
\text { la organización de las actividades } \\
\text { realizadas en clases y planteadas por } \\
\text { el profesorado me ha ayudado en mi } \\
\text { labor de aprendizaje. }\end{array}$ & $\begin{array}{l}\text { Se acoge la sugerencia de la redacción } \\
\text { propuesta para este ítem. }\end{array}$ \\
\hline Experto 4 & $\begin{array}{l}\text { Ítem 4: sugiere cambiar la expresión } \\
\text { integrados por relacionados. }\end{array}$ & $\begin{array}{l}\text { Se acoge la sugerencia y se hace la } \\
\text { modificación en el ítem } 4 .\end{array}$ \\
\hline Experto 5 & $\begin{array}{l}\text { Ítem 14: comenta qué quiere decir } \\
\text { adecuado partido. Sugiere indicar los } \\
\text { aspectos específicos que se quiere } \\
\text { medir. }\end{array}$ & $\begin{array}{l}\text { Se acoge la sugerencia, se realizan } \\
\text { cambios en la redacción del ítem: "el } \\
\text { docente ha usado el entorno virtual como } \\
\text { apoyo a nuestro aprendizaje". }\end{array}$ \\
\hline Experto 6 & $\begin{array}{l}\text { Sugiere eliminar el ítem año de } \\
\text { ingreso en INACAP. }\end{array}$ & $\begin{array}{l}\text { No se acoge la sugerencia ya que se } \\
\text { pretende determinar la homogeneidad de } \\
\text { la muestra, según año de ingreso. }\end{array}$ \\
\hline Experto 7 & $\begin{array}{l}\text { Ítem 10: sugiere cambiar "fácil de } \\
\text { comprender" por "fácil de manejar". }\end{array}$ & $\begin{array}{l}\text { Se acoge la sugerencia y se hace la } \\
\text { modificación en el ítem } 10 .\end{array}$ \\
\hline Experto 8 & $\begin{array}{l}\text { Sugiere agregar una pregunta } \\
\text { respecto a las expectativas. }\end{array}$ & $\begin{array}{l}\text { Se acoge la sugerencia y se incorpora el } \\
\text { ítem: "mis expectativas de la asignatura } \\
\text { eran altas antes de iniciar las clases". }\end{array}$ \\
\hline Experto 9 & $\begin{array}{l}\text { Sugiere separar el ítem } 32 \text { en dos } \\
\text { preguntas, tiempo dedicado a la } \\
\text { asignatura y organización global del } \\
\text { tiempo. }\end{array}$ & $\begin{array}{l}\text { Se acoge la sugerencia y se incorpora un } \\
\text { ítem. }\end{array}$ \\
\hline $\begin{array}{l}\text { Expertos } \\
10 \text { y } 11\end{array}$ & $\begin{array}{l}\text { No realizan comentarios ni } \\
\text { sugerencias }\end{array}$ & \\
\hline
\end{tabular}


Adicionalmente, frente a cada ítem redactado, se les solicitó que expresaran una puntuación numérica de 0 a 5, en función de dos criterios básicos. El primer criterio es el de pertinencia que hace referencia a la correspondencia entre el contenido del ítem y la dimensión para la cual va a ser utilizado. El segundo criterio es el de claridad, referido a en qué medida el ítem está redactado de forma clara y precisa, facilitando su comprensión por los sujetos encuestados (Tabla 5.12).

16 Tabla 5.12: Validación de la pertinencia y claridad de expertos validadores del Cuestionario 1

\begin{tabular}{|c|c|c|c|c|c|c|}
\hline \multirow[b]{2}{*}{ ÍTEM } & \multicolumn{3}{|c|}{ PERTINENCIA } & \multicolumn{3}{|c|}{ CLARIDAD } \\
\hline & Media & Moda & $\begin{array}{l}\text { Desviación } \\
\text { Estándar }\end{array}$ & Media & Moda & $\begin{array}{l}\text { Desviación } \\
\text { Estándar }\end{array}$ \\
\hline 1 & 4.6 & 5 & 0.910 & 4.0 & 4 & 0.910 \\
\hline 2 & 4.8 & 5 & 0.743 & 4.0 & 4 & 0.828 \\
\hline 3 & 4.4 & 5 & 1.100 & 3.6 & 5 & 1.134 \\
\hline 4 & 4.5 & 5 & 1.100 & 3.8 & 5 & 1.125 \\
\hline 5 & 4.8 & 5 & 0.632 & 4.5 & 5 & 0.617 \\
\hline 6 & 4.6 & 5 & 0.594 & 4.9 & 5 & 0.352 \\
\hline 7 & 4.8 & 5 & 0.743 & 4.1 & 5 & 0.834 \\
\hline 8 & 4.9 & 5 & 0.915 & 4.3 & 5 & 0.915 \\
\hline 9 & 4.8 & 5 & 0.737 & 4.3 & 5 & 0.834 \\
\hline 10 & 4.8 & 5 & 0.458 & 4.5 & 5 & 0.617 \\
\hline 11 & 4.8 & 5 & 0.414 & 4.9 & 5 & 0.352 \\
\hline 12 & 4.5 & 5 & 0.743 & 4.6 & 5 & 0.617 \\
\hline 13 & 4.8 & 5 & 0.414 & 4.9 & 5 & 0.352 \\
\hline 14 & 4.6 & 5 & 0.724 & 4.8 & 5 & 0.561 \\
\hline 15 & 4.5 & 5 & 1.486 & 4.1 & 5 & 1.356 \\
\hline 16 & 4.8 & 5 & 0.414 & 4.9 & 5 & 0.352 \\
\hline 17 & 4.8 & 5 & 0.458 & 4.8 & 5 & 0.414 \\
\hline 18 & 4.9 & 5 & 0.352 & 4.9 & 5 & 0.352 \\
\hline 19 & 4.8 & 5 & 0.594 & 4.5 & 5 & 0.724 \\
\hline 20 & 4.3 & 5 & 0.915 & 4.8 & 5 & 0.617 \\
\hline 21 & 4.8 & 5 & 0.414 & 4.9 & 5 & 0.352 \\
\hline 22 & 4.8 & 5 & 0.414 & 4.9 & 5 & 0.352 \\
\hline 23 & 4.9 & 5 & 0.352 & 4.9 & 5 & 0.352 \\
\hline 24 & 4.9 & 5 & 0.594 & 4.6 & 5 & 0.594 \\
\hline 25 & 4.8 & 5 & 0.414 & 4.9 & 5 & 0.352 \\
\hline 26 & 4.6 & 5 & 0.737 & 4.4 & 5 & 0.737 \\
\hline 27 & 4.6 & 5 & 0.743 & 4.0 & 5 & 1.121 \\
\hline 28 & 4.5 & 5 & 0.976 & 3.8 & 5 & 1.265 \\
\hline 29 & 4.6 & 5 & 0.594 & 4.9 & 5 & 0.352 \\
\hline 30 & 4.3 & 5 & 1.060 & 4.8 & 5 & 1.060 \\
\hline 31 & 4.6 & 5 & 0.617 & 4.8 & 5 & 0.414 \\
\hline 32 & 4.8 & 5 & 0.617 & 4.6 & 5 & 0.594 \\
\hline 33 & 4.9 & 5 & 0.258 & 5.0 & 5 & 0.258 \\
\hline 34 & 4.9 & 5 & 0.352 & 4.9 & 5 & 0.352 \\
\hline 35 & 4.8 & 5 & 0.617 & 4.6 & 5 & 0.594 \\
\hline 36 & 4.5 & 5 & 0.828 & 4.5 & 5 & 0.617 \\
\hline 37 & 4.9 & 5 & 0.352 & 4.9 & 5 & 0.352 \\
\hline 38 & 4.8 & 5 & 0.414 & 4.9 & 5 & 0.352 \\
\hline 39 & 4.8 & 5 & 0.352 & 5.0 & 5 & 0.258 \\
\hline 40 & 4.8 & 5 & 0.617 & 4.6 & 5 & 0.594 \\
\hline
\end{tabular}


17 Tabla 5.12: Validación de la pertinencia y claridad de expertos validadores del Cuestionario 1 (continuación)

\begin{tabular}{|c|c|c|c|c|c|c|}
\hline \multirow[b]{3}{*}{ ÍTEM } & \multicolumn{3}{|c|}{ PERTINENCIA } & \multicolumn{3}{|c|}{ CLARIDAD } \\
\hline & \multicolumn{4}{|c|}{ Desviación } & & \multirow{2}{*}{$\begin{array}{l}\text { Desviación } \\
\text { Estándar }\end{array}$} \\
\hline & Media & Moda & Estándar & Media & Moda & \\
\hline 41 & 4.5 & 5 & 0.816 & 4.9 & 5 & 0.352 \\
\hline 42 & 4.8 & 5 & 0.594 & 4.5 & 5 & 0.724 \\
\hline 43 & 4.8 & 5 & 0.414 & 4.9 & 5 & 0.352 \\
\hline 44 & 4.6 & 5 & 0.594 & 4.9 & 5 & 0.352 \\
\hline 45 & 4.8 & 5 & 1.242 & 3.9 & 5 & 1.291 \\
\hline 46 & 4.1 & 5 & 1.060 & 4.9 & 5 & 0.816 \\
\hline 47 & 4.8 & 5 & 0.414 & 4.9 & 5 & 0.352 \\
\hline 48 & 4.3 & 5 & 0.915 & 4.8 & 5 & 0.617 \\
\hline
\end{tabular}

Fuente: Elaboración propia basada en la respuesta de los expertos validadores

Considerando los comentarios y sugerencias aportados por los validadores expertos se diseñó la versión definitiva del cuestionario. A nivel de dimensiones no hubo sugerencias para eliminar o incorporar alguna. A nivel de los ítems sí se realizaron sugerencias de eliminación e incorporación, cambios que se incorporaron en el cuestionario (Tabla 5.11).

En cuanto a los criterios de pertinencia y claridad se aprecia un alto grado de valoración de cada uno de los ítems, considerando los resultados de la media, moda y desviación estándar. Estadísticamente no es necesaria la eliminación de alguno de los ítems.

A continuación el cuestionario se aplica, siguiendo con la revisión y mejora de la validez del instrumento, a una pequeña muestra o grupo de personas con características similares a las de la muestra total de la población elegida para cumplir con los objetivos del estudio (Tabla 5.13). Briones (2002) nos señala que esta aplicación del cuestionario cumple algunas o todas estas funciones:

- Comprobar la comprensión de las preguntas por parte del entrevistado.

- Ubicar preguntas que suscitan rechazo o inhibición.

- Examinar las respuestas a preguntas abiertas que puedan reemplazarse por preguntas cerradas.

- Considerar la eliminación de preguntas con respuestas obvias, similares. 
18 Tabla 5.13: Resumen del procesamiento de los datos

\begin{tabular}{|c|c|c|c|}
\hline & & $\boldsymbol{N}$ & $\%$ \\
\hline \multirow{3}{*}{ Casos } & Válidos & 33 & 97,1 \\
\hline & Excluidos & 1 & 2,9 \\
\hline & Total & 34 & 100,0 \\
\hline
\end{tabular}

La segunda de las características con la que debemos contar es la fiabilidad, y hace referencia a la consistencia, estabilidad y equivalencia de los resultados. Un instrumento o técnica es fiable cuando nos ofrece resultados similares al aplicarla en situaciones similares, es decir, la precisión con la que mide lo que dice que mide. Para determinar la fiabilidad del cuestionario optamos por una medida de consistencia interna de las puntuaciones otorgadas por los estudiantes, utilizando el alfa de Cronbach. Este índice de consistencia interna y que toma valores entre 0 y 1 sirve para comprobar si el instrumento que se está evaluando recopila información defectuosa. Su interpretación será que, cuanto más se acerque el índice al extremo 1, mejor es la fiabilidad, considerando una fiabilidad respetable a partir de 0,70 y siendo la ideal la resultante entre 0,80 y 0,90 . El valor del alfa de Cronbach obtenido es de 0,96 (Tabla 5.14), lo cual nos indica que el instrumento resultante del proceso de validación con expertos, tiene un alto índice de consistencia interna (Ruiz Bolívar, 2002).

19 Tabla 5.14. Estadísticos de fiabilidad

\begin{tabular}{|c|c|c|}
\hline Alfa de Cronbach & $\begin{array}{c}\text { Alfa de Cronbach } \\
\text { basada en los } \\
\text { elementos tipificados }\end{array}$ & $\mathbf{N}$ de ítems \\
\hline ,962 & ,963 & 48 \\
\hline
\end{tabular}

\subsection{Codificación de las preguntas abiertas}

Las preguntas abiertas se codifican una vez que conocemos las respuestas de los sujetos a las cuales se les aplicaron o al menos las principales tendencias de respuesta en una muestra de cuestionarios aplicados. 
Para cerrar las preguntas abiertas, Hernández Sampieri, Fernández Collado y Baptista (2010: 312) sugieren los siguientes pasos:

- Seleccionar determinado número de cuestionarios mediante un método adecuado de muestreo, asegurando la representatividad de los sujetos investigados. En cuanto a la muestra Briones (2002) sugiere una muestra pequeña la que puede ser el $10 \%$ del total de cuestionarios respondidos.

- Observar a frecuencia con que aparece cada respuesta a la pregunta.

- Elegir las respuestas que se presentan con mayor frecuencia (patrones generales de respuesta).

- Clasificar las respuestas elegidas en temas, aspectos o rubros, de acuerdo con un criterio lógico, cuidando de que sean mutuamente excluyentes.

- Darle un nombre o título a cada tema, aspecto, rubro (patrón general de respuesta).

- Asignarle el código a cada patrón general de respuesta.

\subsubsection{Procedimiento de análisis}

El análisis de datos que hemos realizado ha consistido en la utilización de técnicas estadísticas descriptivas e inferenciales, adaptadas a la naturaleza de las variables incluidas en los cuestionarios. Gracias a estas técnicas de análisis podemos estudiar la información recogida dando respuesta a los objetivos que guían este proceso de evaluación. La selección de las mismas dependerá de varios criterios: los objetivos de la evaluación, el tipo de datos recogidos, el diseño de la evaluación y el modo de transmitir la información recogida.

En general, se han aplicado un análisis estadístico descriptivo e inferencial, a través de técnicas estadísticas pertinentes. En concreto:

- Análisis exploratorio de datos, con el fin de depurar los posibles errores efectuados en la informatización de las encuestas. La depuración se realizó utilizando, básicamente, dos vías: depuración de cuestionarios individuales analizando los valores inválidos o 
inconsistentes del cuestionario; análisis del comportamiento agregado de algunas variables, estudiando su distribución por las variables de clasificación.

- Análisis descriptivo, sobre las variables de información y clasificación incluidas en las encuestas estructuradas, a través de análisis de frecuencias, medidas de tendencia y central y de dispersión, según los casos, y análisis gráfico correspondiente.

- Análisis inferencial, con el fin de poder generalizar los resultados de las diferencias observadas entre las medidas de los grupos piloto y control, a partir de las hipótesis pertinentes; es decir, poder comprobar el impacto posible del modelo b-learning en las competencias percibidas y la satisfacción hacia las tecnologías. En función de la naturaleza de las variables y el objetivo del tratamiento estadístico, hemos optamos por aplicar pruebas $t$ de Student de diferencias de medias para muestras correlacionadas y el coeficiente de correlación Pearson. 


\subsection{Estudio cualitativo}

En la investigación cualitativa el diseño de la investigación se caracteriza por ser inductivo, abierto, flexible, cíclico y emergente; es decir, emerge de tal forma que es capaz de evolucionar y adaptarse en la medida que se va generando el conocimiento de la actividad estudiada (Massot, Dorio y Sabariego, 2004:284).

El estudio cualitativo se desarrolla a lo largo del primer semestre académico de 2011, a fin de estudiar los procesos que ocurren en la implementación de una misma asignatura en las modalidades $b$-learning y presencial tradicional.

\subsubsection{Apartados y categorías}

Los apartados y categorías que se abordan en el estudio cualitativo se han determinado de acuerdo a los componentes que define Engestöm $(1987,2000,2009,2010)$ en su esquema de la teoría de la actividad para una actividad de aprendizaje. Las categorías a estudiar de la actividad de aprendizaje, en la asignatura Técnicas de la Comunicación Oral y Escrita en sus modalidades b-learning y presencial tradicional, son: la actividad de aprendizaje diseñada y ejecutada; los docentes y alumnos como sujetos participantes; las diferentes herramientas disponibles y las utilizadas por los alumnos y docentes; la conformación y funcionamiento de la comunidad de aprendizaje; las normas y reglamentos existentes en la comunidad de aprendizaje; la división del trabajo establecida en las actividades de aprendizaje (Tabla 5.19).

\subsubsection{Población y muestra}

La población de referencia del estudio cualitativo corresponde a la misma del estudio cuantitativo (Tabla 5.1). Patton (1988) citado por Sandoval (2002), señala que la principal característica del muestreo cualitativo es su conducción intencional en búsqueda de casos ricos en información. De acuerdo con esto, identifica diez tipos de muestreo. Extremo o de casos desviados, de variación máxima, homogéneo, del caso típico, del caso crítico, en 
cadena o bola de nieve, según un criterio lógico, de casos confirmatorios o disconfirmatorios, de casos políticamente importantes y el de casos por conveniencia.

El muestreo que se sigue en la selección de informantes tiene un carácter intencional, dinámico y secuencial. En nuestra investigación usaremos el muestreo de casos homogéneos ya que buscamos describir subgrupos en profundidad. En el caso de los alumnos que forman parte de la muestra, están agrupados en conglomerados naturales de los grupos curso de la asignatura de Técnicas de la Comunicación Oral y Escrita en la carrera de de Ingeniería en Prevención de Riesgos, Calidad y Ambiente (Tabla 5.16). La muestra de docentes corresponde a los docentes que dictan la asignatura, tanto en la modalidad $b$ learning como en la modalidad presencial tradicional.

20 Tabla 5.16: Distribución de la muestra de alumnos y docentes de la carrera de Ingeniería en Prevención de Riesgos, Calidad y Medio Ambiente

\begin{tabular}{lcccc} 
Campus & $\begin{array}{c}\text { No focus } / \mathbf{N}^{\circ} \text { de } \\
\text { alumnos en } \\
\text { modalidad } \\
\text { b-learning }\end{array}$ & $\begin{array}{c}\text { No focus } / \mathbf{N}^{\circ} \text { de } \\
\text { alumnos en } \\
\text { modalidad } \\
\text { presencial }\end{array}$ & $\begin{array}{c}\text { № de } \\
\text { docentes } \\
\text { b-learning } \\
\text { entrevistados }\end{array}$ & $\begin{array}{c}\text { № de } \\
\text { docentes } \\
\text { presencial } \\
\text { entrevistados }\end{array}$ \\
\hline Antofagasta & $2 / 16$ & $2 / 12$ & 1 & 1 \\
\hline Copiapó & $2 / 11$ & $1 / 7$ & 1 & 1 \\
\hline La Serena & $2 / 12$ & $2 / 12$ & 1 & 1 \\
\hline TOTAL & $\mathbf{6 / 3 9}$ & $\mathbf{5 / 2 9}$ & $\mathbf{3}$ & $\mathbf{3}$
\end{tabular}

Fuente: elaboración propia

\subsubsection{Técnicas de recogida de información}

Un primer e importante rasgo que identifica el proceso de recolección de datos en la investigación cualitativa es su relativa y frecuente inestructuración, entendida en dos sentidos diferentes y complementarios: no homogenización y como no predeterminación. Lo anterior significa que el plan de recolección de información se va completando y precisando en la misma medida que avanza el contacto con las personas y situaciones fuentes de datos. Esto no es sinónimo, en modo alguno, de ausencia de intencionalidad o falta de lógica; significa, más bien, un recurrir a la flexibilidad como medio para acceder a lo que se quiere saber o comprender, desde la perspectiva del interlocutor, lo que requiere de un esfuerzo consciente del investigador para realizar su búsqueda siguiendo el curso del pensamiento y de las comprensiones de su interlocutor o interlocutores (Sandoval, 2002). 
Durante esta etapa, Rodríguez Gómez et al (1996) nos recomiendan asegurar el rigor de la investigación, teniendo en cuenta los criterios de suficiencia y adecuación de los datos. La suficiencia se consigue llegando a un estado de saturación informativa y la nueva información no aporta nada nuevo. La adecuación se refiere a la selección de la información de acuerdo a las necesidades teóricas del estudio y el modelo emergente.

Se aplicaron tres técnicas para la recogida de información: análisis documental, grupo focal con estudiantes y entrevista semiestructurada de docentes (Tabla 5.17).

21 Tabla 5.17: Técnicas, procedimientos e instrumentos del estudio cualitativo

\begin{tabular}{|c|c|c|c|}
\hline Categoría & Técnica & Procedimiento & Instrumento \\
\hline $\begin{array}{l}\text { Actividad de aprendizaje } \\
\text { Objetivo } \\
\text { Herramientas } \\
\text { Comunidad } \\
\text { Normas y reglamentos } \\
\text { División del trabajo }\end{array}$ & $\begin{array}{l}\text { Análisis } \\
\text { documental }\end{array}$ & $\begin{array}{l}\text { Revisión de } \\
\text { documentos } \\
\text { generado durante el } \\
\text { proceso }\end{array}$ & $\begin{array}{l}\text { Lista de cotejo con las } \\
\text { categorías e } \\
\text { indicadores }\end{array}$ \\
\hline $\begin{array}{l}\text { Actividad de aprendizaje } \\
\text { Docentes: experiencia } b \text {-learning } \\
\text { Herramientas } \\
\text { Comunidad } \\
\text { Normas y reglamentos } \\
\text { División del trabajo }\end{array}$ & $\begin{array}{l}\text { Entrevista semi } \\
\text { estructurada a } \\
\text { docentes }\end{array}$ & $\begin{array}{l}\text { Entrevista realizada } \\
\text { de manera individual }\end{array}$ & Guía de preguntas \\
\hline $\begin{array}{l}\text { Actividad de aprendizaje } \\
\text { Alumnos: expectativas, motivación } \\
\text { Herramientas } \\
\text { Comunidad } \\
\text { Normas y reglamentos } \\
\text { División del trabajo }\end{array}$ & $\begin{array}{l}\text { Grupos focales } \\
\text { de alumnos }\end{array}$ & $\begin{array}{l}\text { Trabajo grupal con } \\
\text { guía } \\
\text { semiestructurada }\end{array}$ & Guía de discusión \\
\hline
\end{tabular}

\subsubsection{Análisis documental}

El rigor de un proceso de investigación cualitativo tiene, como uno de sus puntos de partida, un acercamiento previo a la realidad que va a ser objeto de análisis, lo cual se realiza a través de dos mecanismos básicos: la revisión de toda la documentación existente y disponible sobre dicha realidad y una observación preliminar de la realidad en cuestión, la cual, en ocasiones, se complementa con algunas entrevistas a "informantes clave" (Sandoval, 2002). 
Debe entenderse por documento, todo tipo de fuente de información a la que el investigador pueda tener acceso. Los documentos fuente pueden ser de naturaleza diversa: personales, institucionales o grupales, formales o informales. Son una fuente bastante fidedigna y práctica para revelar los intereses y las perspectivas de comprensión de la realidad, que caracterizan a los que lo han escrito.

El análisis documental se desarrolla en cinco etapas (Massot et al, 2004:351-352):

- En la primera, se realiza el rastreo e inventario de los documentos existentes y disponibles.

- En la segunda, se hace una clasificación de los documentos identificados.

- En la tercera, se hace una selección de los documentos más pertinentes para los propósitos de la investigación.

- En la cuarta, se realiza una lectura en profundidad del contenido de los documentos seleccionados, para extraer elementos de análisis y consignarlos en "memos" o notas marginales que registren los patrones, tendencias, convergencias y contradicciones que se vayan descubriendo.

- En la quinta, se realiza una lectura cruzada y comparativa de los documentos en cuestión, ya no sobre la totalidad del contenido de cada uno, sino sobre los hallazgos previamente realizados, de modo que sea posible construir una síntesis comprensiva total, sobre la realidad analizada.

En cuanto a los documentos existentes y disponibles, en el marco de este estudio, la mayoría de ellos se encuentran en formato digital y se puede acceder a estos en la plataforma institucional. Los documentos oficiales tales como el descriptor oficial de la asignatura, la planificación semestral realizada por el docente, son de carácter oficial, los que, tal como señalan Massot et al (2004), son registros públicos y suelen reflejar la perspectiva oficial o institucional.

Las actividades en línea, si bien queda registro digital, sólo acceden oficialmente a ellas los docentes y los alumnos, debido a políticas de privacidad de la institución. Por su parte los instrumentos de evaluación, son administrados directamente por el docente y la institución 
no realiza ni revisión previa ni acopio de los mismos, por lo cual no se ha sido posible acceder a estos documentos.

22 Tabla 5.18: Inventario de documentos existentes y disponibles

\begin{tabular}{|c|c|}
\hline Documento & Fuente \\
\hline $\begin{array}{l}\text { 1. Descriptor oficial de la } \\
\text { asignatura }\end{array}$ & Plataforma institucional \\
\hline $\begin{array}{ll}\text { 2. } & \text { Planificación semestral } \\
\text { realizada por el docente }\end{array}$ & Plataforma institucional \\
\hline 3. $\quad$ Actividades en línea & Plataforma institucional \\
\hline
\end{tabular}

Para el análisis de los documentos seleccionados se confeccionó una lista de cotejo (Apéndice F), cuyos apartados y categorías se han definido sobre la base de la Teoría de la Actividad Engeström (1987, 2001, 2007), expuesta en detalle en el capítulo cuarto de este informe de investigación (Tabla 5.19).

\subsubsection{Grupo focal con estudiantes}

Para la conformación de los grupo de discusión o grupos de enfoque o focus group en inglés (Massot et al, 2004), que usaremos en nuestra investigación, optamos por el muestreo de casos homogéneos ya que buscamos describir subgrupos en profundidad. El punto de referencia para elegir los participantes de los grupos focales es que estos sean alumnos de primer año que cursan la asignatura Técnicas de la Comunicación Oral y Escrita de la carrera de Ingeniería en Prevención de Riesgos, Calidad y Ambiente de la Universidad Tecnológica de Chile INACAP, tanto en la modalidad b-learning como en la modalidad presencial tradicional (Tabla 5.16). 
23 Tabla 5.19: Categorías para guiar el análisis documental

\begin{tabular}{|c|c|c|}
\hline Apartados & Categorías & Descriptor \\
\hline \multirow{4}{*}{$\begin{array}{l}\text { A. Actividad de } \\
\text { aprendizaje }\end{array}$} & $\begin{array}{l}\text { A.1. Diseño pedagógico de las } \\
\text { actividades en línea }\end{array}$ & \multirow{4}{*}{$\begin{array}{l}\text { Secuencia de las actividades de las más simple a la más } \\
\text { complejas } \\
\text { Los alumnos responden en secuencia las actividades } \\
\text { Vínculo de las actividades en línea con las presenciales } \\
\text { Sugerencias de estrategias para la realización de las } \\
\text { actividades } \\
\text { Retroalimentación de las actividades en línea }\end{array}$} \\
\hline & A.2. Interactividad pedagógica & \\
\hline & & \\
\hline & A.3. Actividades de evaluación & \\
\hline \multirow{5}{*}{ B. Herramientas } & & $\begin{array}{l}\text { Sugerencias de herramientas tecnológicas disponibles } \\
\text { en línea }\end{array}$ \\
\hline & C.1. Tecnológicas & $\begin{array}{l}\text { Uso de recursos tecnológicos disponibles en línea en } \\
\text { las actividades diseñadas por el docente }\end{array}$ \\
\hline & & Sugerencia de estrategias de trabajo individual \\
\hline & C.2. Procedimentales & $\begin{array}{l}\text { Sugerencia de estrategias de trabajo grupal } \\
\text { Sugerencias de procedimientos para el uso de las } \\
\text { herramientas tecnológicas }\end{array}$ \\
\hline & C.3. Textuales & $\begin{array}{l}\text { Uso y sugerencia de artículos o recursos en Internet, } \\
\text { libros digitales o impresos }\end{array}$ \\
\hline \multirow[t]{2}{*}{ C. Comunidad } & $\begin{array}{l}\text { D.1. Organización social de los } \\
\text { alumnos }\end{array}$ & $\begin{array}{l}\text { Realización de actividades de integración social. } \\
\text { Orientación y apoyo del docente para la organización } \\
\text { de los grupos de trabajo }\end{array}$ \\
\hline & D.2. Contexto de referencia & $\begin{array}{l}\text { Relación de las actividades con el contexto de } \\
\text { referencia de la carrera }\end{array}$ \\
\hline $\begin{array}{l}\text { D. Normas y } \\
\text { reglamentos }\end{array}$ & $\begin{array}{l}\text { E.1. Existencia de normas y } \\
\text { reglas }\end{array}$ & $\begin{array}{l}\text { A los grupos de trabajo se les sugiere que definan } \\
\text { normas de funcionamiento } \\
\text { El profesor estable normas de funcionamiento }\end{array}$ \\
\hline \multirow[b]{2}{*}{$\begin{array}{l}\text { E. División del } \\
\text { trabajo }\end{array}$} & F.1. Roles de los alumnos & El profesor explicita su rol y el de los estudiantes \\
\hline & F.1. Roles del profesor & $\begin{array}{l}\text { El profesor va transferencia el control de la actividad a } \\
\text { los alumnos }\end{array}$ \\
\hline
\end{tabular}

Para aumentar la viabilidad de la investigación en cuanto a la participación de los asistentes seleccionados, las reuniones y entrevistas se realizarán en los respectivos Campus, durante el desarrollo del semestre académico, en el horario de clases de los alumnos y en el horario laboral, en el caso de los docentes.

La primera característica del grupo focal es su carácter colectivo. Recibe su denominación de focal por lo menos en dos sentidos: el primero se centra en el abordaje a fondo de un número muy reducido de tópicos o problemas; en el segundo, la configuración de los grupos de entrevista se hace a partir de la identificación de alguna particularidad relevante desde el punto de vista de los objetivos de la investigación, lo que lleva a elegir solamente sujetos que tengan dicha característica, por lo general entre cinco y diez sujetos (Massot et, 2004). 
De acuerdo con Morgan (1988), en Sandoval (2002), existen cuatro criterios para orientar las entrevistas de grupo focal en forma efectiva:

- Cubrir un rango máximo de tópicos relevantes.

- Proveer datos lo más específico posibles.

- Promover la interacción que explore los sentimientos de los participantes con una cierta profundidad.

- Tener en cuenta el contexto personal que los participantes usan para generar sus respuestas al tópico explorado.

El almacenamiento de los datos se realiza mediante una grabadora digital de tal manera que permita recoger las transcripciones de las grabaciones realizadas, de manera que sean fácilmente recuperables para su análisis e integración con los datos recogidos a partir de otras fuentes.

La redacción de la guía de preguntas (Apéndice $\mathrm{D}$ ) está orientada por las categorías que se han definido sobre la base de la Teoría de la Actividad Engeström (1987, 2001, 2007) (Tabla 5.20). 
24 Tabla 5.20: Categorías para guiar los grupos focales de alumnos

Apartados

Categorías

A.1. Diseño pedagógico de las actividades en línea

\begin{tabular}{|c|c|}
\hline \multirow{4}{*}{$\begin{array}{l}\text { A. Actividad de } \\
\text { aprendizaje }\end{array}$} & A.2. Diseño pedagógico de las actividades presenciales \\
\hline & A.3. Articulación de las actividades presenciales y virtuales \\
\hline & A.4. Interactividad pedagógica \\
\hline & A.5. Actividades de evaluación \\
\hline \multirow{3}{*}{ B. Herramientas } & B.1.Uso de recursos tecnológicos disponibles en línea \\
\hline & $\begin{array}{l}\text { B.2.Sugerencias de métodos y procedimientos para el uso de las herramientas } \\
\text { tecnológicas }\end{array}$ \\
\hline & B.3.Sugerencia y uso de recursos digitales \\
\hline \multirow{3}{*}{ C. Comunidad } & C.1. Organización social de los alumnos \\
\hline & C.2. Contexto de referencia \\
\hline & C.3. Sentimiento de comunidad \\
\hline \multirow{2}{*}{$\begin{array}{l}\text { D. Normas y } \\
\text { reglamentos }\end{array}$} & D.1. Normas de funcionamiento establecidas por los grupos de trabajo \\
\hline & D.2 Normas de funcionamiento establecidas por el profesor \\
\hline \multirow{2}{*}{$\begin{array}{l}\text { E. División del } \\
\text { trabajo }\end{array}$} & E.1. Roles de los alumnos y roles del profesor \\
\hline & E.2. Transferencia del control de la actividad del docente al alumno \\
\hline \multirow{2}{*}{$\begin{array}{l}\text { F. Valoración } \\
\text { global }\end{array}$} & F.1. Expectativas y satisfacción de la asignatura \\
\hline & F.2. Motivación hacia las tecnologías y el aprendizaje en línea \\
\hline
\end{tabular}

Fuente: elaboración propia basada en Barberà, Mauri y Onrubia, 2008;

Engeström, 1987, 2001, 2007; Salmon, 2001

\subsubsection{Entrevista semiestructurada a docentes}

En el caso de los docentes decidimos usar la técnica de la entrevista semiestructurada porque nos permite profundizar en las concepciones que tiene el docente en el uso de las tecnologías en educación superior, especialmente en la modalidad b-laerning. Además en un sentido práctico, el número de docentes es reducido (3 ó 4 docentes por Campus) y están ubicados en distintos Campus a una distancia geográfica sobre cuatrocientos kilómetros uno de otro.

El almacenamiento de los datos se realiza mediante una grabadora digital de tal manera que permita recoger las transcripciones de las grabaciones realizadas, de manera que sean fácilmente recuperables para su análisis e integración con los datos recogidos a partir de otras fuentes.

La redacción del guion o protocolo de entrevista se determina de ante mano la información que se quiere obtener (Apéndice E), orientada por las categorías que se han definido sobre la base de la Teoría de la Actividad Engeström (1987, 2001, 2007) (Tabla 5.21). 
25 Tabla 5.21: Apartados y categorías para guiar las entrevistas semiestructuradas a docentes

\begin{tabular}{|c|c|}
\hline Apartados & Categorías \\
\hline \multirow{6}{*}{$\begin{array}{l}\text { A. Actividad de } \\
\text { aprendizaje }\end{array}$} & A.1. Diseño pedagógico de las actividades en línea \\
\hline & A.2. Diseño pedagógico de las actividades presenciales \\
\hline & A.3. Articulación de las actividades presenciales y virtuales \\
\hline & A.4. Interactividad pedagógica \\
\hline & A.5. Actividades de evaluación \\
\hline & A.5. Intencionalidad de las actividades (objetivos y resultados esperados) \\
\hline \multirow{3}{*}{ B. Herramientas } & B.1. Finalidad del uso de recursos tecnológicos disponibles en línea \\
\hline & $\begin{array}{l}\text { B.2.Finalidad de las sugerencias de métodos y procedimientos para el uso de } \\
\text { las herramientas tecnológicas }\end{array}$ \\
\hline & B.3.Valoración de los recursos digitales sugeridos \\
\hline \multirow{4}{*}{ C. Comunidad } & C.1. Organización social de los alumnos \\
\hline & C.2. Facilidades y dificultades para la comunicación en línea \\
\hline & C.3. Contexto de referencia \\
\hline & C.4. Sentimiento de comunidad \\
\hline \multirow{2}{*}{$\begin{array}{l}\text { D. Normas y } \\
\text { reglamentos }\end{array}$} & D.1. Normas de funcionamiento establecidas por los grupos de trabajo \\
\hline & D.2. Normas de funcionamiento establecidas por el profesor \\
\hline \multirow{2}{*}{$\begin{array}{l}\text { E. División del } \\
\text { trabajo }\end{array}$} & E.1. Roles de los alumnos y roles del profesor \\
\hline & E.2. Transferencia del control de la actividad del docente al alumno \\
\hline \multirow{2}{*}{$\begin{array}{l}\text { F. Valoración } \\
\text { global }\end{array}$} & F.1. Expectativas y satisfacción de la participación de loa alumnos \\
\hline & F.2. Motivación hacia las tecnologías y la enseñanza en línea \\
\hline
\end{tabular}

\subsubsection{Confiabilidad y validez}

La metodología cualitativa se caracteriza por la flexibilidad de propuestas de análisis en forma que avanza el proceso de investigación, ante lo cual se debe tomar conciencia de la sistematización de los procesos y el rigor metodológico a fin de otorgar garantías de que los datos son fiables y válidos para los intereses de la investigación (García Llamas, 2003).

La fiabilidad se relaciona con la precisión de la medida, independiente de las circunstancias de recogida de datos, mientras que por validez se entiende un instrumento mide o evalúa aquello que realmente dice medir o evaluar.

En el caso de la investigación cualitativa, los procedimientos sugeridos para determinar la validez cualitativa son (Pérez Serrano, 1994b):

Triangulación: reunión de una amplia variedad de datos y métodos referidos al mismo problema de estudio, recogidos desde puntos de vista diferentes, realizando comparaciones múltiples sobre un mismo fenómeno. Existen diversos tipos de 
triangulación como la triangulación de tiempo, triangulación de espacio, combinación de niveles, triangulación centrada en el método, y la de investigadores.

Saturación: reunión de un número suficiente de evidencias que garantizan la credibilidad de la investigación, revisando el proceso o bien replicando el estudio para comprobar si los resultados se mantienen coherentemente.

Validez respondiente: los resultados de la investigación se contrastan con aportes de otros compañeros, informadores, observadores y personas implicadas en el asunto.

En nuestra investigación la validez la conseguimos con la triangulación de técnicas de recogida de información, es decir el análisis documental, los grupos focales y las entrevistas semiestructuradas. El número de grupos focales realizados estuvo determinado por la saturación, es así que en el caso del Campus Copiapó fue el último en que se realizaron los grupos focales, por la saturación de la información se decide no realizar un segundo grupo focal en el caso de los alumnos que cursan la modalidad presencial tradicional en la asignatura en estudio (Tabla 5.16). La validez respondiente, señalada por Pérez Serrano (1994b), se verifica en el contraste de los aportes de los diversos sujetos participantes.

\subsubsection{Procedimiento de análisis}

El análisis de los datos no se ha constituido como una fase independiente y diferenciada temporalmente en la investigación, puesto que se encuentra en completa interacción con otras fases de investigación como la obtención de la información. Parte del análisis se produce la recogida de datos. El procedimiento de análisis de datos diseñado es sistemático y ordenado, aunque no por ello rígido puesto que exigido volver sobre los datos, analizarlos y replantear el proceso.

El objetivo del análisis de datos cualitativos es la búsqueda de tendencias, tipologías, regularidades o patrones y la obtención de datos únicos. Estos datos recogidos se agrupan en categorías para poder realizar comparaciones y contrastes, debiendo considerarse la 
reducción de datos a lo largo de todo el proceso según los apartados y categorías definidos sobre la base del marco teórico de la investigación.

Las respuestas dadas por los participantes grupos focales y las entrevistas son grabadas digitalmente y luego trascritas. Se procesan los datos agrupando los fragmentos de respuestas de acuerdo a las categorías previamente definidas. Una vez realizada la categorización de todos los textos de los grupos focales y de las entrevistas, se realiza la reducción de los datos y contrastación por categoría y apartado.

En el caso del análisis documental se ha realizado un análisis del contenido en primer término considerando categorías emergentes a fin de analizar los componentes y estructura propia de los documentos estudiados. En una segunda fase se revisan los documentos con una pauta de cotejo para verificar la presencia o ausencia de los indicadores de las categorías previamente definidas en el estudio. La reducción de datos ha sido apoyada con la elaboración de Tablas de la contabilización de la frecuencia en que se presentan aquellos indicadores factibles de ser contabilizados. 


\section{CAPÍTULO 6}

\section{PRESENTACIÓN DE LOS RESULTADOS, ANÁLISIS E INTERPRETACIÓN}

6.1 Estudio cuantitativo
6.1.1 Cuestionario 1 sobre conocimientos y actitudes hacia las tecnologías
6.1.2 Cuestionario 2 sobre conocimientos y satisfacción hacia las tecnologías

6.2 Estudio cualitativo

6.2.1 Análisis documental

6.2.2 Entrevistas a profesores y grupos focales de estudiantes 


\section{CAPÍTULO 6 PRESENTACIÓN DE LOS RESULTADOS, ANÁLISIS E INTERPRETACIÓN}

\subsection{Estudio cuantitativo}

\subsubsection{Cuestionario 1 sobre conocimientos y actitudes hacia las tecnologías}

\subsubsection{Rasgos sociodemográficos}

En esta primera parte describimos un conjunto de indicadores relacionados con la información general o de identificación y clasificación de los alumnos que han respondido a los cuestionarios aplicados. Para ello, se ha solicitado en la encuesta información relativa al Campus en que cursa los estudios, sexo y edad.

26 Tabla 6.1: Distribución de la muestra global de alumnos por sexo y edad según en Campus

\begin{tabular}{|c|c|c|c|c|c|c|c|c|c|c|c|c|c|c|c|}
\hline \multirow{3}{*}{ Campus } & \multicolumn{4}{|c|}{ Sexo } & \multicolumn{10}{|c|}{ Edad } & \multirow{3}{*}{$\begin{array}{l}\overline{\text { J }} \\
\text { 으 }\end{array}$} \\
\hline & \multicolumn{2}{|c|}{ Masculino } & \multicolumn{2}{|c|}{ Femenino } & \multicolumn{2}{|c|}{$17-18$} & \multicolumn{2}{|c|}{$19-20$} & \multicolumn{2}{|c|}{$21-24$} & \multicolumn{2}{|c|}{$25-29$} & \multicolumn{2}{|c|}{$30-37$} & \\
\hline & $\mathbf{N}$ & $\%$ & $\mathbf{N}$ & $\%$ & $\mathbf{N}$ & $\%$ & $\mathbf{N}$ & $\%$ & $\mathbf{N}$ & $\%$ & $\mathbf{N}$ & $\%$ & $\mathbf{N}$ & $\%$ & \\
\hline Antofagasta & 20 & 35,7 & 36 & 64,3 & 20 & 35,7 & 20 & 35.7 & 11 & 19,6 & 2 & 3,6 & 3 & 5,4 & 56 \\
\hline Copiapó & 52 & 66,7 & 26 & 33,3 & 21 & 26,9 & 21 & 26,9 & 22 & 28,2 & 5 & 6,4 & 9 & 11,5 & 78 \\
\hline \multirow[t]{2}{*}{ La Serena } & 49 & 66,2 & 25 & 33,8 & 30 & 40,5 & 28 & 37,8 & 9 & 12,2 & 7 & 9,5 & 0 & 0 & 74 \\
\hline & 121 & 58,2 & 87 & 41,8 & 71 & 34,1 & 69 & 33,2 & 42 & 20,2 & 14 & 6,7 & 12 & 5,8 & 208 \\
\hline
\end{tabular}

La Tabla 6.1 indica la distribución de la muestra en relación a las variables sexo y edad. Se puede observar que los porcentajes de la variable sexo están muy equilibrados en los Campus Copiapó y La Serena con una mayor participación del sexo masculino, en cambio en el Campus Antofagasta se da la distribución contraria, con una mayor la participación de los mujeres. Estas diferencias se pueden explicar porque la muestra es intencional, no probabilística. Los alumnos están distribuidos en conglomerados naturales definidos en 
grupos de clase por lo cual se eligieron grupos de clases conformados de una asignatura del primer semestre de la carrera que participa en el estudio. En el caso del Campus Antofagasta, ubicado en la mayor zona minera del país, con alta tasa de alumnos trabajadores y que estudian en la jornada vespertina, explica la mayor proporción de mujeres $(64,3 \%)$ en la jornada diurna.

Al analizar la variable edad de los sujetos de la muestra, como se observa en la Tabla 6.1, nos encontramos que en los tres Campus predomina el rango 17 a 20 años. La distribución 17 a 18 años en el Campus La Serena predomina sólo levemente (40,5\%) respecto al rango que se sigue (19 a 20 años, 37,8\%), considerando que en este rango de edad se produce el egreso de la educación secundaria por lo que podemos estimar que no han tenido experiencia previa en educación superior antes de ingresar en esta institución. Por tanto, en los tres Campus la población respecto a la variable edad presenta cierta heterogeneidad.

Continuando con la caracterización de los rasgos demográficos de la muestra que forma parte del estudio (Tabla 6.2), según la modalidad de participación ya sea como grupo piloto o como grupo control, tenemos que en las dos modalidades predomina el sexo masculino, con una mayor predominancia en el caso del grupo control $(62,5 \%)$.

En cuanto a la distribución por edad, el 67,3\% en las dos modalidades se ubica en los rangos 17-18 años y 19-20 años. En los rangos 25-29 años y 30-37 años sólo representa el 15.5\%.

27 Tabla 6.2: Distribución de la muestra global de alumnos por sexo y edad según el tipo de grupo

\begin{tabular}{|c|c|c|c|c|c|c|c|c|c|c|c|c|c|c|c|}
\hline \multirow{3}{*}{ Grupo } & \multicolumn{4}{|c|}{ Sexo } & \multicolumn{10}{|c|}{ Edad } & \multirow{3}{*}{$\begin{array}{l}\overline{\text { Jँ }} \\
\stackrel{0}{\circ}\end{array}$} \\
\hline & \multicolumn{2}{|c|}{ Masculino } & \multicolumn{2}{|c|}{ Femenino } & \multicolumn{2}{|c|}{$17-18$} & \multicolumn{2}{|c|}{$19-20$} & \multicolumn{2}{|c|}{$21-24$} & \multicolumn{2}{|c|}{$25-29$} & \multicolumn{2}{|c|}{$30-37$} & \\
\hline & $\mathbf{N}$ & $\%$ & $\mathbf{N}$ & $\%$ & $\mathbf{N}$ & $\%$ & $\mathbf{N}$ & $\%$ & $\mathbf{N}$ & $\%$ & $\mathbf{N}$ & $\%$ & $\mathbf{N}$ & $\%$ & \\
\hline Piloto & 76 & 55,9 & 60 & 44,1 & 42 & 30,9 & 40 & 29,4 & 32 & 23,5 & 10 & 7,4 & 12 & 8,8 & 136 \\
\hline Control & 45 & 62,5 & 27 & 37,5 & 29 & 40,3 & 29 & 40,3 & 10 & 13,9 & 4 & 5,6 & 0 & 0 & 72 \\
\hline TOTAL & 121 & 58,2 & 87 & 41,8 & 71 & 34,1 & 69 & 33,2 & 42 & 20,2 & 14 & 6,7 & 12 & 5,8 & 208 \\
\hline
\end{tabular}




\subsubsection{Acceso a tecnologías y conexión a Internet}

La Tabla 6.3 muestra la disponibilidad de equipos y acceso a Internet distribuida por sexo y edad según el Campus. Los estudiantes del Campus Antofagasta son los que cuentan con mayor acceso a tecnologías tanto en la posesión de computador en casa con acceso a Internet $(94,6 \%)$, como teléfono móvil $(98,2 \%)$ y computador portátil $(75,0 \%)$. Por su parte, los estudiantes del Campus Copiapó son los que poseen menor acceso a tecnologías, por ejemplo teléfono celular con acceso a Internet (44,9\%). En términos globales, una alto promedio de los estudiantes posee computador portátil $(72,2 \%)$ y cerca del $50 \%$ cuenta con teléfono móvil con acceso a Internet.

Si bien una proporción pequeña de los alumnos no tiene acceso a tecnologías para trabajar en clases, sí fuera de clases la mayoría posee tecnología y acceso a Internet, sumado ello a los laboratorios informáticos disponibles en todos los Campus de la institución, podemos señalar que el acceso a la tecnología no representa una dificultad para la implementación de la metodología del modelo b-learning en estudio. Además, el \% de alumnos que no se conecta a Internet es marginal, un promedio de 1,4\% y a su vez, más de $70 \%$ en promedio, se conecta a Internet una o dos veces al día (Tabla 4).

28 Tabla 6.3: Disponibilidad de equipos y acceso a Internet

\begin{tabular}{|c|c|c|c|c|c|c|c|c|c|c|c|c|c|c|c|c|c|}
\hline \multirow{3}{*}{ Campus } & \multicolumn{4}{|c|}{ PCIC } & \multicolumn{4}{|c|}{ TM } & \multicolumn{4}{|c|}{ TMI } & \multicolumn{4}{|c|}{ CP } & \multirow{3}{*}{$\begin{array}{l}\overline{\text { J }} \\
\text { 。 }\end{array}$} \\
\hline & \multicolumn{2}{|c|}{ Sí } & \multicolumn{2}{|c|}{ No } & \multicolumn{2}{|c|}{ Sí } & \multicolumn{2}{|c|}{ No } & \multicolumn{2}{|c|}{ Sí } & \multicolumn{2}{|c|}{ No } & \multicolumn{2}{|c|}{ Sí } & \multicolumn{2}{|c|}{ No } & \\
\hline & $\mathbf{N}$ & $\%$ & $\mathbf{N}$ & $\%$ & $\mathbf{N}$ & $\%$ & $\mathbf{N}$ & $\%$ & $\mathbf{N}$ & $\%$ & $\mathbf{N}$ & $\%$ & $\mathbf{N}$ & $\%$ & $\mathbf{N}$ & $\%$ & \\
\hline Antofagasta & 53 & 94,6 & 3 & 5,4 & 55 & 98,2 & 1 & 1,8 & 32 & 57,1 & 24 & 42,9 & 42 & 75,0 & 14 & 25,0 & 56 \\
\hline Copiapó & 61 & 78,2 & 17 & 21,8 & 73 & 93,6 & 5 & 6,4 & 25 & 44,9 & 43 & 55,1 & 54 & 69,2 & 24 & 30,8 & 78 \\
\hline La Serena & 64 & 86,5 & 10 & 13,5 & 72 & 97,3 & 2 & 2,7 & 34 & 45,9 & 40 & 54,1 & 55 & 74,3 & 19 & 25,7 & 74 \\
\hline TOTAL & 178 & 85,6 & 30 & 14,4 & 200 & 96,2 & 8 & 3,8 & 101 & 48,6 & 107 & 51,4 & 151 & 72,6 & 57 & 27,4 & 208 \\
\hline
\end{tabular}


29 Tabla 6.4: Frecuencia de conexión a Internet

\begin{tabular}{|c|c|c|c|c|c|c|c|c|c|c|c|}
\hline \multirow[b]{2}{*}{ Campus } & \multicolumn{2}{|c|}{ VD } & \multicolumn{2}{|c|}{ UD } & \multicolumn{2}{|c|}{ AS } & \multicolumn{2}{|c|}{ US } & \multicolumn{2}{|c|}{ NC } & \multirow{2}{*}{$\begin{array}{l}\bar{\pi} \\
\text { ठ̊ }\end{array}$} \\
\hline & $\mathbf{N}$ & $\%$ & $\mathbf{N}$ & $\%$ & $\mathbf{N}$ & $\%$ & $\mathbf{N}$ & $\%$ & $\mathbf{N}$ & $\%$ & \\
\hline Antofagasta & 30 & 53,6 & 13 & 23,2 & 8 & 14,2 & 4 & 7,1 & 1 & 1,8 & 56 \\
\hline Copiapó & 36 & 46,2 & 20 & 25,6 & 15 & 56,0 & 5 & 6,4 & 2 & 2,6 & 78 \\
\hline La Serena & 46 & 62,2 & 14 & 18,9 & 14 & 18,9 & 0 & 0 & 0 & 0 & 74 \\
\hline TOTAL & 112 & 53,8 & 47 & 22,6 & 37 & 17,8 & 9 & 4,3 & 3 & 1,4 & 208 \\
\hline
\end{tabular}

\subsubsection{Dominio de recursos tecnológicos}

En cuanto al dominio de recursos tecnológicos, en la Tabla 6.5 presentamos cómo los estudiantes han adquirido formación para utilizar recursos de Internet para tareas académicas. Casi el $80 \%$ de los estudiantes afirma que han aprendido a usar Internet por cuenta propia cuenta o de un amigo, destacando los estudiantes del Campus Antofagasta en aprender por cuenta propia (71,4\%). En contraste, solo alrededor de un $10 \%$ aprendió a usar Internet en una instancia formal, ya sea en una asignatura, curso o taller.

En la Tabla 6.6 presentamos los resultados del grado de conocimiento y frecuencia de uso de recursos tecnológicos medidos en dos momentos, al inicio de la asignatura y al finalizar la misma, a fin de evaluar si la metodología b-learning produjo algún cambio en los conocimientos y frecuencias de uso de diversas tecnologías en un contexto académico.

Los estudiantes al inicio de la asignatura, tanto del grupo piloto como del grupo control, señalan tener más dominio en el uso de recursos tecnológicos para navegar por internet para buscar información de trabajos y utilizar una plataforma para descargar apuntes o documentos y leer anuncios o avisos del profesor. El menor grado de cocimiento al inicio de la asignatura, lo tienen para realizar tareas académicas contactando al profesor vía correo electrónico, en utilizar una plataforma para participar en un foro o en un chat, para crear o participar en glosarios o wikis. 
30 Tabla 6.5: Formación sobre cómo utilizar recursos de Internet para tareas académicas

\begin{tabular}{|c|c|c|c|c|c|c|c|c|c|c|c|}
\hline \multirow[b]{2}{*}{ Campus } & \multicolumn{2}{|c|}{ NPMM } & \multicolumn{2}{|c|}{ SA } & \multicolumn{2}{|c|}{ SC } & \multicolumn{2}{|c|}{ A } & \multicolumn{2}{|c|}{0} & \multirow[b]{2}{*}{$\mathbf{N}$} \\
\hline & $\mathbf{N}$ & $\%$ & $\mathbf{N}$ & $\%$ & $\mathbf{N}$ & $\%$ & $\mathbf{N}$ & $\%$ & $\mathbf{N}$ & $\%$ & \\
\hline Antofagasta & 40 & 71,4 & 3 & 5,4 & 5 & 8,9 & 6 & 10,7 & 2 & 3,6 & 56 \\
\hline Copiapó & 46 & 59,0 & 10 & 12.8 & 12 & $\begin{array}{r}15 \\
4\end{array}$ & 7 & 9,0 & 3 & 3,8 & 78 \\
\hline La Serena & 48 & 64,9 & 7 & 9,5 & 6 & 8,1 & 11 & 14,9 & 2 & 2,7 & 74 \\
\hline TOTAL & 134 & 64,4 & 20 & 9,6 & 23 & $\begin{array}{r}11 \\
1\end{array}$ & 24 & 11,5 & 7 & 3,4 & 208 \\
\hline
\end{tabular}

En cuanto a los recursos tecnológicos de mayor uso en tareas académicas están centrados en navegar por internet para buscar información de trabajos; utilizar una plataforma para descargar apuntes o documentos, revisar el propio progreso y leer anuncios o avisos del profesor. Por su parte, los que presentan menor nivel de uso son para contactar al profesor vía correo electrónico; utilizar una plataforma para participar en un foro o en un chat y para crear o participar en glosarios o wikis o para coordinar una actividad en grupo realizada en Internet.

Respecto a las tecnologías web 2.0, marcadamente el mayor nivel dominio y uso al inicio y término de la asignatura lo tienen los estudiantes en herramientas vinculadas a las redes sociales y las herramientas de comunicación.

Al comparar las diferencias en el uso y dominio de herramientas para tareas académicas y tecnologías web 2.0 al inicio y término de la asignatura, verificamos que en general todos los recursos experimentan leves cambios en cuanto a su conocimiento promediando 5,3\%. En cuanto al uso se generaron mayores diferencias con un promedio de incremento de $18,6 \%$, destacando con mayor incremento el uso de programas para realizar trabajos y presentaciones ( $25,7 \%$ en el piloto, $43,1 \%$ en el control); navegar por internet para buscar información para realizar trabajos y el uso de la web para descargar apuntes (en promedio piloto y control $22,2 \%$ ), materiales didácticos y programas (en promedio piloto y control $22,1 \%)$.

En casi la totalidad de las variables, al comparar el grado de conocimiento y uso al inicio y término de la asignatura, se produjo un mayor incremento en los grupos en la modalidad control, excepto en aquellas variables intencionadas por la modalidad b-learning en los 
grupos piloto como son: utilizar una plataforma en actividades de evaluación, para revisar el propio progreso, coordinar una actividad en grupo realizada en Internet y evaluar la autoría y fiabilidad de la información encontrada en Internet. Esta diferencia percepción de dominio y uso en las variables antes señaladas podría deberse a que al enfrentarse o no a un uso específico e intencionado de diversas herramientas para tareas académicas se puede tener la mayor percepción de dominio real.

Sin embargo, al consultar a los estudiantes por el conocimiento y uso de herramientas web 2.0 tales como recursos para compartir imágenes o vídeos, edición colaborativa, uso de blog, subscripciones a RSS, herramientas de comunicación, entornos y juegos virtuales en red, al comparar el inicio y final de semestre, en todas disminuyó el nivel de uso (1,3\% en promedio) y en la mayoría disminuyó la percepción de conocimiento de dichas herramientas $(-12,6 \%)$, tanto en los grupos control como piloto, aunque la diferencia es mayor en los grupos control y en aquellas variables que hubo incremento se dio en los grupos piloto.

En el grupo piloto presenta menores diferencias porque se utilizaron algunas de estas herramientas durante las actividades de la modalidad $b$-learning. Con este uso pedagógico de los recursos adquirieron la conciencia del dominio real de los mismos en tareas académicas específicas, ya que en cuanto a su uso social experimentó menor diferencia. Coincide este hallazgo con el estudio ECAR (2013) en cuanto a que los estudiantes tienen como expectativa que los propios profesores les enseñen a usar las herramientas tecnológicas en labores académicas.

\subsubsection{Actitudes hacia Internet}

En la Tabla 6.7 se exponen los resultados de un diferencial semántico de las actitudes hacia Internet al inicio y final de la asignatura en los grupos piloto y control. Al analizar las variaciones se aprecian leves cambios positivos en la valoración de Internet generándose los mayores incrementos en los grupos piloto.

En la variable dudoso-fiable el grupo piloto tuvo un incremento menor que el grupo control. Esto se explica porque en la modalidad b-learning usaron una pauta con un conjunto de 
indicadores para evaluar la fiabilidad de los recursos disponibles en Internet. Del mismo modo destaca que la variable con menor diferencia en el grupo control sea la referida al rol comunicativo y formativo de Internet, además aumenta en los grupos control la percepción de que Internet es distractor. La mayor diferencia entre los grupos piloto y control se produce en la variable complicado-simple. En el grupo piloto aumenta la percepción de que Internet es simple, en cambio en el grupo control aumenta ostensiblemente su percepción de que es complicado (22,2\%). Estos resultados refuerzan la idea del rol mediador del docente en el aprendizaje y valoración de uso de tecnologías de la información y las comunicaciones con fines académicos por parte de los alumnos. 
31 Tabla 6.6: Conocimiento y frecuencia de uso de recursos tecnológicos al inicio y final de la asignatura

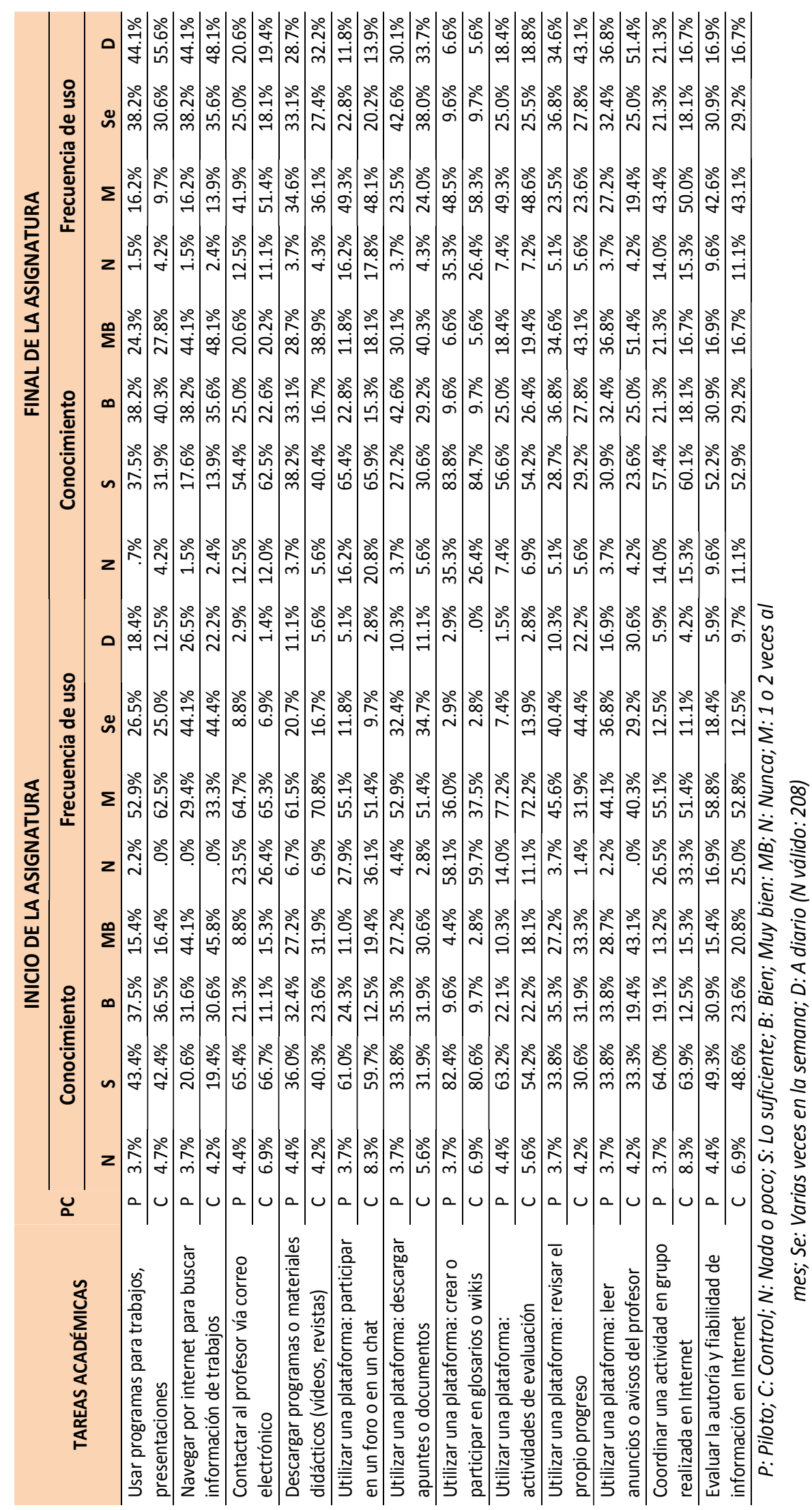


32 Tabla 6.6: Conocimiento y frecuencia de uso de recursos tecnológicos al inicio y final de la asignatura (continuación)

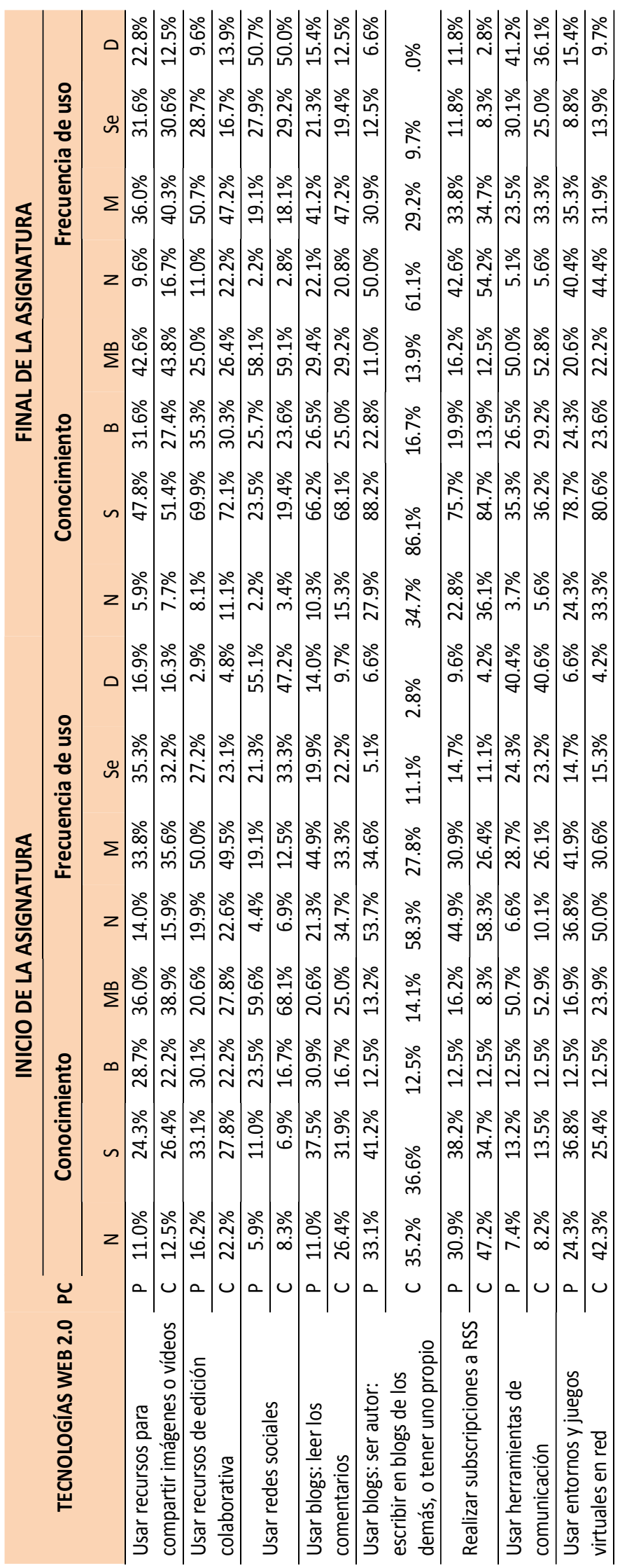


32 Tabla 6.7: Actitudes hacia Internet al inicio y final de la asignatura

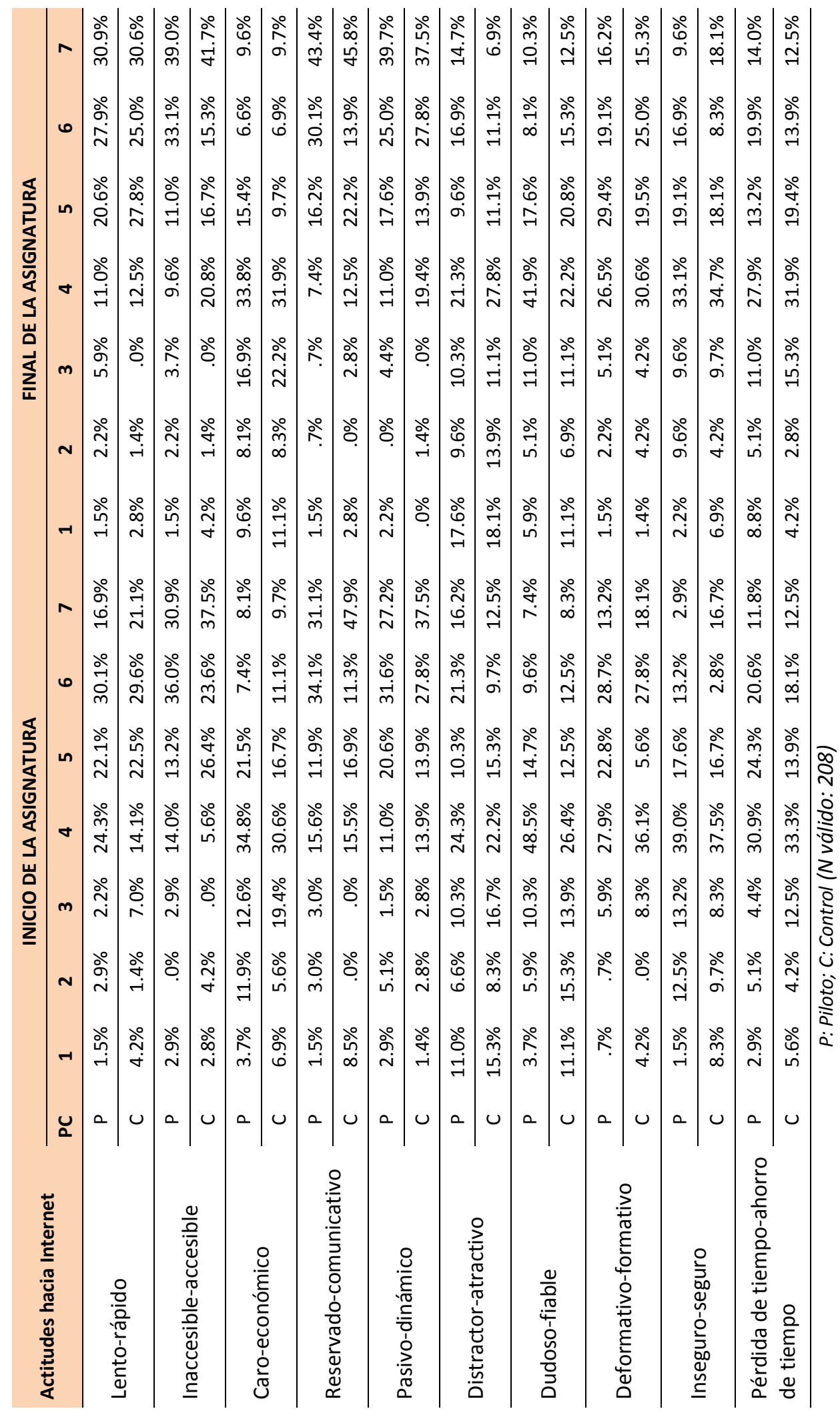




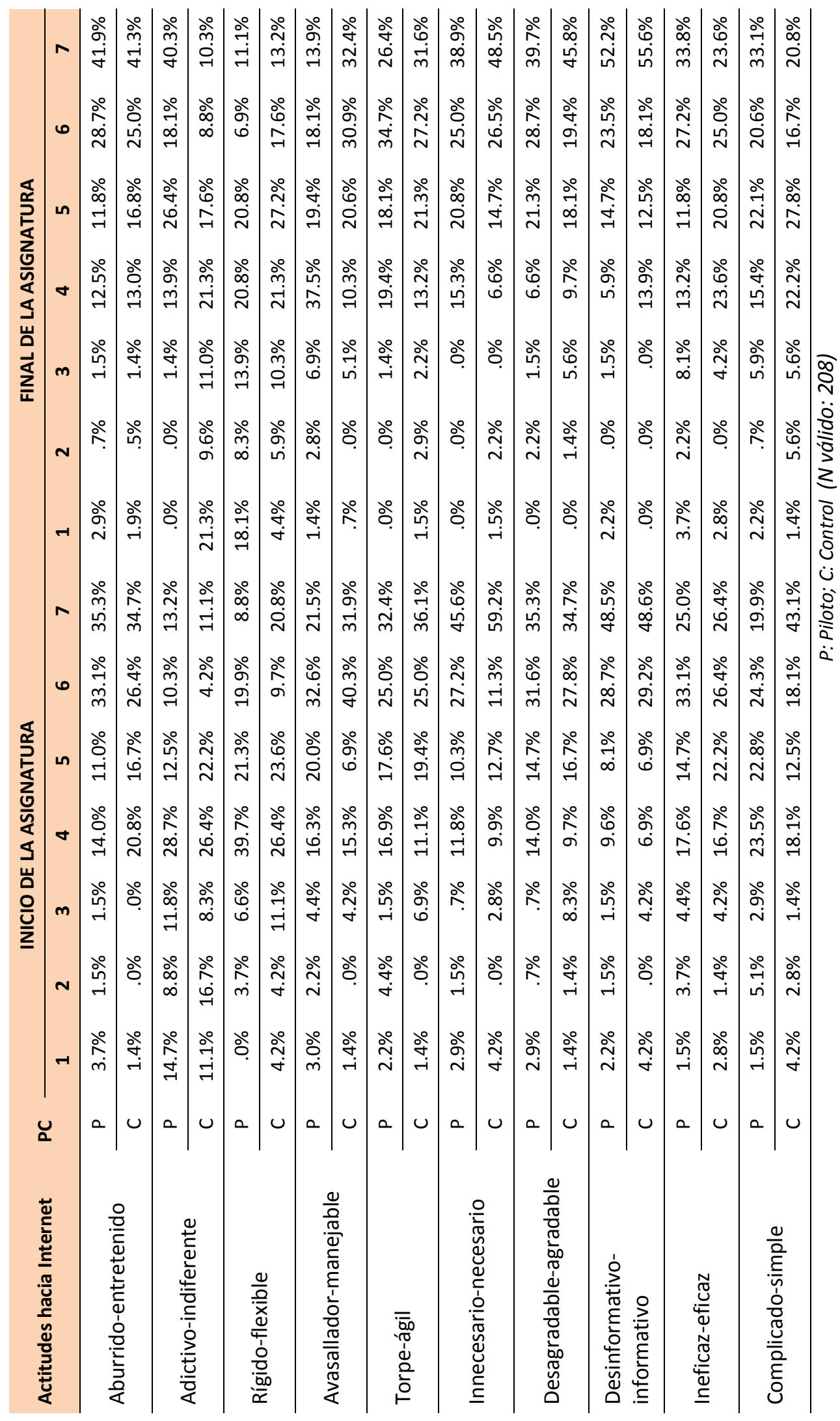




\subsubsection{Cuestionario 2 conocimientos y satisfacción hacia las tecnologías}

\subsubsection{Aprendizaje percibido}

En la Tabla 6.8 se exponen los resultados de los aprendizajes percibidos en las competencias instrumentales, tecnológicas e interpersonales las que dentro del diseño del estudio corresponden a variables dependientes. En casi todas las variables en los grupos piloto se aprecia se aprecia un leve aumento en el logro de las competencias, excepto en las variables relacionadas con sentirse parte de un grupo y el trabajo colaborativo. Los estudiantes de los grupos piloto sintieron mayor necesidad de trabajo colaborativo dado las actividades planificadas en la modalidad b-learning, cuyo diseño pedagógico propende a la interacción y colaboración en línea. A su vez en todas las variables, los mayores niveles de desacuerdo respecto al logro de las competencias se dan en los grupos control, lo que refleja que los estudiantes valoran la necesidad del logro de competencias instrumentales, tecnológicas e interpersonales.

En la Tabla 6.9 se exponen los resultados del aprendizaje percibido por Campus en las competencias instrumentales, tecnológicas e interpersonales, respectivamente. Sumando y promediando por Campus en las competencias instrumentales predomina en logro del Campus Copiapó $(76,0 \%)$, le sigue el Campus Antofagasta $(66,1 \%)$ y finalmente el Campus La Serena (62,1\%). Coincide en los tres Campus que la variable más baja de las competencias instrumentales por Campus es si las actividades en línea ayudaron a "organizar mejor el tiempo fuera de clases" dedicado a la asignatura. También coinciden los tres Campus en la variable con resultado más alto por Campus la relacionada con la capacidad lograda por los estudiantes para "organizar y participar en actividad grupal usando Internet" para realizar un trabajo académico con los compañeros en la asignatura.

Siguiendo con el análisis de los resultados del aprendizaje percibido de la variables agrupadas en la dimensión competencias tecnológicas, en conjunto obtiene mejor nivel de logro que las competencias instrumentales y también el Campus Copiapó, en promedio de las variables asociadas a competencias tecnológicas, obtiene el mayor valor (82,0\%), le sigue el Campus Antofagasta (78.6\%) y en tercer lugar el Campus La Serena (63,5\%). Sólo en el caso del Campus La Serena predomina la variable del aprendizaje del "uso de herramientas tecnológicas nuevas" para los estudiantes o que no las había usado antes. En 
los otros dos Campus predomina la variable relacionada con el "uso la plataforma tecnológica" o sitio web en el que se desarrollaron las actividades virtuales.

El tercer grupo de variables asociadas al aprendizaje percibido se agrupan en la dimensión de competencias interpersonales de cuyos resultados se repite la tendencia de los mejores promedios de resultados de las competencias analizadas anteriormente (instrumentales, tecnológicas), obteniendo nuevamente el Campus Copiapó el mayor resultado promedio (75,1\%), seguido de Antofagasta (68,1\%) y de La Serena (64,7\%). En Campus Copiapó la variable con más alto resultado es la de "autonomía personal usando Internet" para realizar tareas en línea. En la caso del Campus Antofagasta la variable que predominó es "ser parte de un grupo que aprende" teniendo la percepción de formar parte de un grupo de personas que aprende, más que ser un estudiante solitario. A su vez en el Campus La Serena predominó una variable distinta a las de los otros dos Campus. La variable con el más alto resultado es si "las actividades promueven la ayuda entre los compañeros". 
33 Tabla 6.8: Aprendizaje percibido: competencias instrumentales, tecnológicas e interpersonales

\begin{tabular}{|c|c|c|c|c|c|c|c|}
\hline & Competencias / variables & PC & TD & ED & I & DA & TA \\
\hline \multirow{8}{*}{ 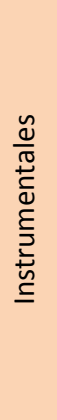 } & \multirow{2}{*}{$\begin{array}{l}\text { Organizar mejor el tiempo fuera de } \\
\text { clases }\end{array}$} & $\mathrm{P}$ & $2.2 \%$ & $8.1 \%$ & $19.9 \%$ & $44.9 \%$ & $25.0 \%$ \\
\hline & & $\mathrm{C}$ & $16.7 \%$ & $16.7 \%$ & $13.9 \%$ & $29.2 \%$ & $23.6 \%$ \\
\hline & \multirow{2}{*}{$\begin{array}{l}\text { Evaluar la calidad de las fuentes de } \\
\text { Internet }\end{array}$} & $\mathrm{P}$ & $3.7 \%$ & $4.4 \%$ & $16.9 \%$ & $45.6 \%$ & $29.4 \%$ \\
\hline & & C & $11.1 \%$ & $8.3 \%$ & $22.2 \%$ & $34.7 \%$ & $23.6 \%$ \\
\hline & \multirow{2}{*}{$\begin{array}{l}\text { Organizar y participar en actividad grupal } \\
\text { usando Internet }\end{array}$} & $P$ & $2.2 \%$ & $4.4 \%$ & $12.5 \%$ & $56.6 \%$ & $24.3 \%$ \\
\hline & & $\mathrm{C}$ & $3.4 \%$ & $6.3 \%$ & $16.3 \%$ & $50.5 \%$ & $23.6 \%$ \\
\hline & \multirow{2}{*}{ Organizar el tiempo en línea } & $P$ & $3.7 \%$ & $2.9 \%$ & $22.1 \%$ & $52.9 \%$ & $18.4 \%$ \\
\hline & & C & $8.2 \%$ & $5.8 \%$ & $19.7 \%$ & $48.6 \%$ & $17.8 \%$ \\
\hline \multirow{4}{*}{ 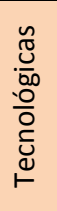 } & \multirow{2}{*}{ Usar nuevas herramientas tecnológicas } & $\mathrm{P}$ & $3.7 \%$ & $4.4 \%$ & $11.0 \%$ & $50.0 \%$ & $30.9 \%$ \\
\hline & & $\mathrm{C}$ & $9.7 \%$ & $11.1 \%$ & $19.4 \%$ & $34.7 \%$ & $25.0 \%$ \\
\hline & \multirow{2}{*}{ Usar la plataforma tecnológica } & $P$ & $3.7 \%$ & $2.9 \%$ & $13.2 \%$ & $51.5 \%$ & $28.7 \%$ \\
\hline & & $\mathrm{C}$ & $5.6 \%$ & $12.5 \%$ & $15.3 \%$ & $41.7 \%$ & $25.0 \%$ \\
\hline \multirow{12}{*}{$\begin{array}{l}\frac{\tilde{c}}{\pi} \\
\frac{0}{0} \\
\frac{\mathscr{n}}{0} \\
\frac{0}{2} \\
\stackrel{ \pm}{\leq}\end{array}$} & \multirow{2}{*}{ Ayuda recibida de los compañeros } & $P$ & $3.7 \%$ & $10.3 \%$ & $16.9 \%$ & $43.4 \%$ & $25.7 \%$ \\
\hline & & $\mathrm{C}$ & $11.1 \%$ & $6.9 \%$ & $22.2 \%$ & $38.9 \%$ & $20.8 \%$ \\
\hline & \multirow{2}{*}{$\begin{array}{l}\text { Percepción de ser parte de un grupo que } \\
\text { aprende, más que un estudiante solitario }\end{array}$} & $P$ & $2.2 \%$ & $3.7 \%$ & $18.4 \%$ & $55.1 \%$ & $20.6 \%$ \\
\hline & & C & $9.7 \%$ & $8.3 \%$ & $15.3 \%$ & $40.3 \%$ & $26.4 \%$ \\
\hline & \multirow{2}{*}{$\begin{array}{l}\text { Trabajamos cada vez más } \\
\text { autónomamente usando Internet }\end{array}$} & $P$ & $3.7 \%$ & $4.4 \%$ & $25.7 \%$ & $41.9 \%$ & $24.3 \%$ \\
\hline & & C & $12.5 \%$ & $16.7 \%$ & $20.8 \%$ & $29.2 \%$ & $20.8 \%$ \\
\hline & \multirow{2}{*}{$\begin{array}{l}\text { Las tareas en línea ayudaron al } \\
\text { desarrollo de mi autonomía usando } \\
\text { Internet }\end{array}$} & $P$ & $2.2 \%$ & $5.9 \%$ & $17.6 \%$ & $51.5 \%$ & $22.8 \%$ \\
\hline & & $\mathrm{C}$ & $13.9 \%$ & $8.3 \%$ & $22.2 \%$ & $34.7 \%$ & $20.8 \%$ \\
\hline & \multirow{2}{*}{$\begin{array}{l}\text { Las actividades promueven la ayuda } \\
\text { entre los compañeros }\end{array}$} & $P$ & $3.7 \%$ & $1.5 \%$ & $16.9 \%$ & $52.2 \%$ & $25.7 \%$ \\
\hline & & $C$ & $6.9 \%$ & $4.2 \%$ & $18.1 \%$ & $48.6 \%$ & $22.2 \%$ \\
\hline & \multirow{2}{*}{$\begin{array}{l}\text { Las herramientas tecnológicas } \\
\text { permitieron trabajar colaborativamente }\end{array}$} & $P$ & $1.5 \%$ & $5.1 \%$ & $14.0 \%$ & $52.9 \%$ & $26.5 \%$ \\
\hline & & $C$ & $3.8 \%$ & $5.8 \%$ & $15.4 \%$ & $49.5 \%$ & $25.5 \%$ \\
\hline
\end{tabular}

P: Piloto; C: Control; TD: totalmente en desacuerdo; ED: En desacuerdo; I: Indeciso; DA: De acuerdo; TA: Totalmente de acuerdo (N válido: 208) 
34 Tabla 6.9: Aprendizaje percibido por Campus: competencias instrumentales, tecnológicas e interpersonales

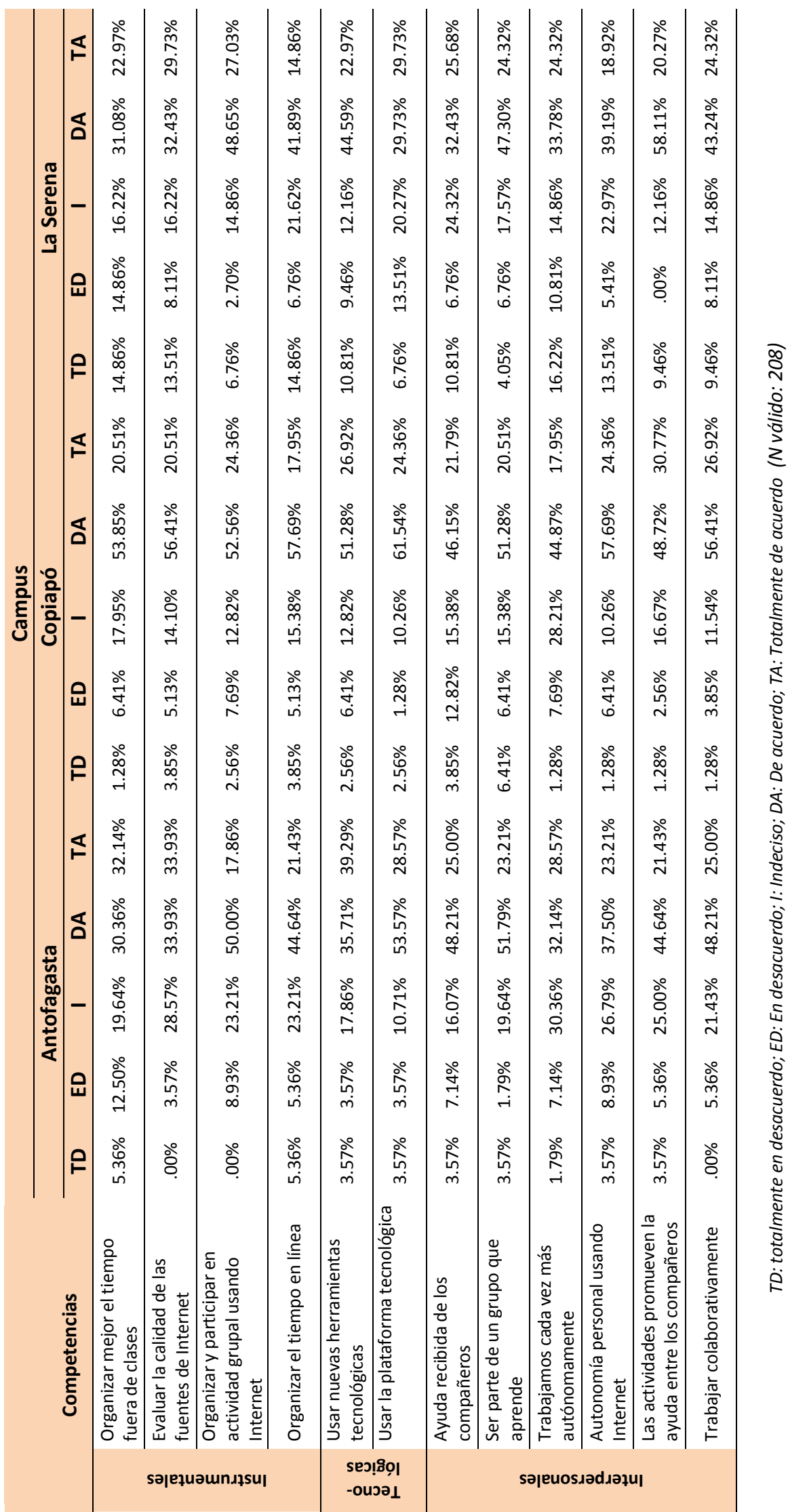




\subsubsection{Satisfacción hacia las tecnologías}

A continuación analizaremos las variables asociadas a la satisfacción de los estudiantes por el uso de tecnologías en el proceso de enseñanza aprendizaje. En la Tabla 6.10 se presenta los resultados de la satisfacción hacia las tecnologías agrupados según la modalidad del grupo, piloto y control. Al agrupar DA: De acuerdo; TA: Totalmente de acuerdo, en todas las variables hay un mayor grado de satisfacción el los grupos piloto. La variable con el resultado más alto de satisfacción en el grupo piloto es "utilizar Internet me posibilita aprender más por mí mismo" y en segundo lugar la variable "me gustaría que los docentes usaran más las tecnologías en línea para apoyar el aprendizaje en las distintas asignaturas" con lo que se aprecia una clara valoración del uso de Internet con finalidades académicas y de trabajo autónomo, cuestión que ya vimos como significativa en el caso de las variables de aprendizaje percibido en cuanto al trabajo autónomo grupal e individual.

35 Tabla 6.10: Satisfacción hacia las tecnologías por modalidad: piloto y control

\begin{tabular}{|c|c|c|c|c|c|c|}
\hline Variables & PC & TD & ED & 1 & DA & TA \\
\hline \multirow{2}{*}{$\begin{array}{l}\text { La combinación de actividades presenciales y } \\
\text { en línea enriquece la materia del programa de } \\
\text { la asignatura }\end{array}$} & $P$ & $2.94 \%$ & $5.88 \%$ & $18.38 \%$ & $50.00 \%$ & $22.79 \%$ \\
\hline & C & $12.50 \%$ & $9.72 \%$ & $15.28 \%$ & $41.67 \%$ & $20.83 \%$ \\
\hline \multirow{2}{*}{$\begin{array}{l}\text { Las actividades en línea me motivaron a } \\
\text { aprender más acerca de la asignatura }\end{array}$} & $P$ & $3.68 \%$ & $5.15 \%$ & $15.44 \%$ & $48.53 \%$ & $27.21 \%$ \\
\hline & $C$ & $13.89 \%$ & $15.28 \%$ & $19.44 \%$ & $31.94 \%$ & $19.44 \%$ \\
\hline \multirow{2}{*}{$\begin{array}{l}\text { Utilizar Internet me posibilita aprender más } \\
\text { por mí mismo/a }\end{array}$} & $P$ & $2.21 \%$ & $3.68 \%$ & $7.35 \%$ & $48.53 \%$ & $38.24 \%$ \\
\hline & C & $1.39 \%$ & $12.50 \%$ & $13.89 \%$ & $40.28 \%$ & $31.94 \%$ \\
\hline \multirow{2}{*}{$\begin{array}{l}\text { Al finalizar la asignatura, en términos } \\
\text { generales, han sido satisfactorias las } \\
\text { estrategias de enseñanza que se usamos }\end{array}$} & $P$ & $3.68 \%$ & $2.94 \%$ & $13.97 \%$ & $48.53 \%$ & $30.88 \%$ \\
\hline & C & $4.17 \%$ & $9.72 \%$ & $15.28 \%$ & $48.61 \%$ & $22.22 \%$ \\
\hline \multirow{2}{*}{$\begin{array}{l}\text { Me gustaría que los docentes usaran más las } \\
\text { tecnologías en línea para apoyar el } \\
\text { aprendizaje en las distintas asignaturas }\end{array}$} & $P$ & $4.41 \%$ & $2.94 \%$ & $11.76 \%$ & $42.65 \%$ & $38.24 \%$ \\
\hline & C & $8.33 \%$ & $8.33 \%$ & $11.11 \%$ & $33.33 \%$ & $38.89 \%$ \\
\hline
\end{tabular}

P: Piloto; C: Control; TD: totalmente en desacuerdo; ED: En desacuerdo; I: Indeciso; DA: De acuerdo; TA:

Totalmente de acuerdo (N válido: 208)

En cuanto al grado de satisfacción de los estudiantes por el uso de tecnologías por Campus presentamos los resultados en la Tabla 6.11. Al agrupar DA: De acuerdo; TA: Totalmente de acuerdo, el Campus Copiapó obtiene como promedio de todas las variables un $81,0 \%$, seguido del Campus Antofagasta (78,2\%) y finalmente el Campus La Serena (64,8\%). El mayor grado de satisfacción en los Campus Antofagasta (87,5\%) y La Serena $(73,0 \%)$ 
corresponde a la variable relativa a las estrategias de enseñanza usadas y esta misma variable es la que presenta el resultado más bajo en el Campus Copiapó y a su vez la de mejor logro es la variable "utilizar Internet me posibilita aprender más por mí mismo". La variable "las actividades en línea me motivaron a aprender más acerca de la asignatura" presenta los menores niveles de satisfacción en los Campus Antofagasta (62,5\%) y en La Serena $(55,4 \%)$. Si bien los alumnos valoran el trabajo autónomo este se circunscribe a las tareas asignadas y si bien en Internet se abre una gran opción de explorar contenidos y recursos asociados a la asignatura, espontáneamente los alumnos no lo realizan, lo que representa un desafío para los profesores en el diseño de las actividades. 
36 Tabla 6.11: Satisfacción hacia las tecnologías por Campus

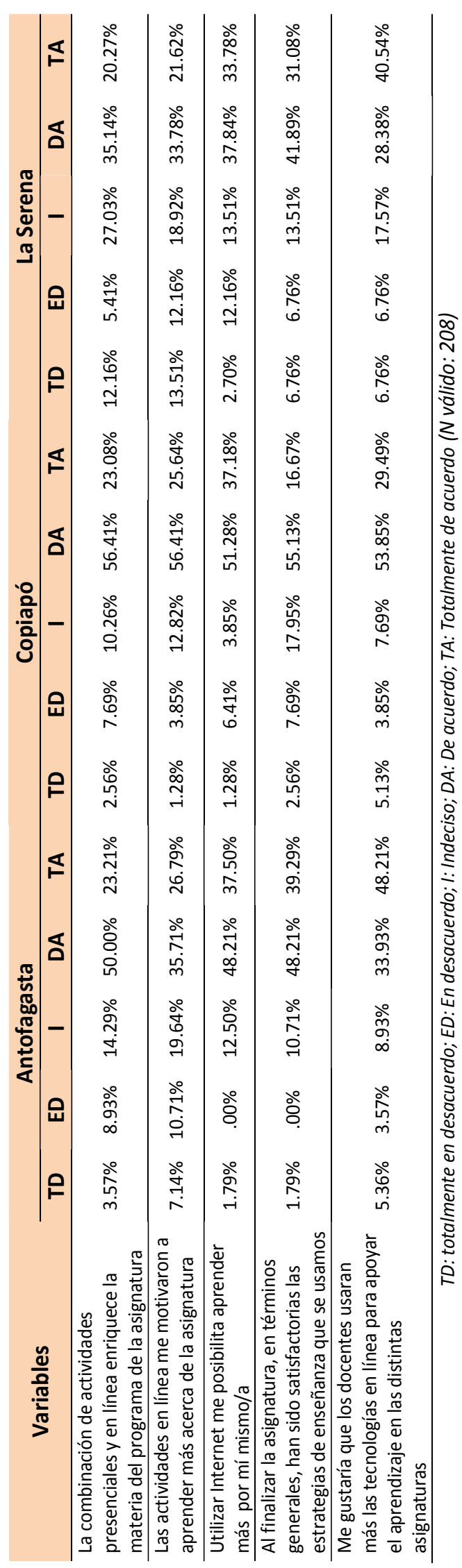




\subsubsection{Análisis comparativo de medias de variables dependientes e independientes}

Se aplicó prueba " $\mathrm{t}$ " para comparar medias con respecto a la valoración dada en las diferentes variables dependientes e independientes, contrastando los resultados obtenidos del grupo piloto con respecto al grupo control. Como hipótesis se espera la obtención de una mejor (mayor) valoración en las variables para el grupo piloto, en la prueba se evalúa la existencia diferencia, con un nivel significativo (alfa 5\%) y altamente significativo (significancia con alfa 0,01 (1\%)) (Apéndice G). Considerando estos resultados, para el análisis hemos seleccionado aquellas variables dependientes e independientes cuyos resultados son altamente significativos el grupo piloto respecto al control, lo que indica la existencia de una mejor valoración de la variable en el grupo piloto (Tabla 6.12).

37 Tabla 6.12: Variables altamente significativas según Prueba $t$

\begin{tabular}{|c|c|}
\hline Dimensiones & Variables dependientes \\
\hline \multirow[t]{2}{*}{ Instrumentales } & $\begin{array}{l}\text { Puedo organizar y participar en una actividad académica grupal usando } \\
\text { Internet }\end{array}$ \\
\hline & Las actividades en línea me ayudaron a organizar el tiempo en línea \\
\hline Tecnológicas & Aprendí a usar nuevas herramientas tecnológicas \\
\hline \multirow[t]{2}{*}{ Interpersonales } & $\begin{array}{l}\text { Las actividades en línea lograron que trabajáramos cada vez más } \\
\text { autónomamente }\end{array}$ \\
\hline & Las tareas en línea ayudaron al desarrollo de mi autonomía usando Internet \\
\hline Dimensiones & Variables independientes \\
\hline \multirow{5}{*}{$\begin{array}{l}\text { Actividad de } \\
\text { aprendizaje }\end{array}$} & La organización de las actividades realizadas en clases ayuda al aprendizaje \\
\hline & Las actividades y contenidos en línea y presenciales están relacionados \\
\hline & El docente se preocupa de la participación en actividades fuera de clases \\
\hline & Las actividades en línea fomentaron la participación de los estudiantes \\
\hline & $\begin{array}{l}\text { Autoevaluaciones suficientes para verificar mi comprensión de los } \\
\text { contenidos }\end{array}$ \\
\hline \multirow{6}{*}{$\begin{array}{l}\text { Herramientas de } \\
\text { apoyo }\end{array}$} & Funcionamiento técnico del sitio usado es fácil de manejar \\
\hline & Los tiempos de respuesta del sitio de Internet han sido adecuados \\
\hline & El docente ayudó en cuestiones técnicas del sitio de trabajo en línea \\
\hline & El docente ha usado el entorno virtual como apoyo a nuestro aprendizaje \\
\hline & El entorno en línea permite mejorar el proceso de enseñanza-aprendizaje \\
\hline & El docente realizó sugerencias para el uso de las herramientas tecnológicas \\
\hline \multirow{3}{*}{$\begin{array}{l}\text { Comunidad de } \\
\text { aprendizaje }\end{array}$} & $\begin{array}{l}\text { Di ayuda a mis compañeros través de herramientas en línea cuando me la } \\
\text { solicitaron }\end{array}$ \\
\hline & La comunicación en línea con el docente me ha resultado fácil \\
\hline & La comunicación en línea con mis compañeros me ha resultado sencilla \\
\hline \multirow{2}{*}{$\begin{array}{l}\text { Normas y } \\
\text { reglamentos }\end{array}$} & Normas adecuadas del docente para el trabajo en línea \\
\hline & Los grupos de trabajo pudieron establecer sus propias normas de trabajo \\
\hline \multirow{2}{*}{$\begin{array}{l}\text { División del } \\
\text { trabajo }\end{array}$} & $\begin{array}{l}\text { Pudimos definir recomendaciones generales para una mejor comunicación } \\
\text { en línea }\end{array}$ \\
\hline & Me conecté regularmente a las actividades en línea individuales y grupales \\
\hline
\end{tabular}




\subsubsection{Análisis correlacional entre variables dependientes e independientes}

En la Tabla 6.13 hemos seleccionado las variables que estadísticamente más significativas en la relación del grupo piloto y grupo control. Considerando dichas variables analizamos el grado de correlación que se da entre las variables dependientes e independientes, aislamos y visualizamos por Campus con objetivo de evaluar el efecto del Campus. Las celdas destacadas con un asterisco $\left({ }^{*}\right)$ indican que existe algún grado de correlación entre las variables, es decir existe una dependencia entre las respuestas de cada pregunta.

Esto se cuantifica por medio del coeficiente de correlación coeficiente de Pearson. Este coeficiente de correlación es una medida numérica de la fuerza de la relación entre dos variables que representan datos (Triola, 2009). El mismo autor agrega que existe una correlación con valores mayores a 0,256 del coeficiente, además si los valores son cercanos a 1, aumenta el grado de relación, y los valores positivos señalan que la relación es directa, por otra parte si el valor es cercano a cero no existe correlación.

En cuanto a la correlación entre competencias instrumentales y variables independientes del modelo b-learning estudiado se aprecia en general una correlación moderada (Tabla 6.13). En particular en la variable "puedo organizar y participar en una actividad académica grupal usando Internet" el Campus Copiapó presenta la menor correlación y a su vez en los tres Campus no se aprecia una influencia del diseño de la actividad de aprendizaje. La variable con mayor grado de correlación es "las actividades promueven la ayuda entre los compañeros" en el Campus La Serena. La variable "las actividades en línea me ayudaron a organizar el tiempo en línea" se constata un leve grado mayor de correlación, siendo nuevamente el Campus Copiapó con los menores logros.

Por su parte las en las competencias tecnológicas en la variable (Tabla 6.14) "aprendí a usar nuevas herramientas tecnológicas" predomina la escasa correlación, destacando en un extremo el Campus Copiapó con todas las variables con escasa correlación, y en el otro extremo, sí en grado moderado, el Campus La Serena con el mayor número de variables con correlación. La variable independiente "comunidad de aprendizaje" en ninguno de los tres Campus aporta al logro de la competencia tecnológica.

En cuanto a las competencias interpersonales de trabajo autónomo y colaborativo (Tabla 6.15) se repite la tendencia anterior de correlación moderada entre las variables así como 
el Campus Copiapó con los menores de niveles y número de variables correlacionadas. Destaca el Campus La Serena con una correlación moderada en casi todas las variables a excepción de algunas con una tendencia una correlación fuerte, aquellas relacionas con el rol del profesor en el uso de del entorno virtual como apoyo al aprendizaje y en la definición de normas para el trabajo en línea.

El componente actividad de aprendizaje del modelo b-learning implementado es el que evidencia el menor grado de correlación en relación a las competencias (instrumentales, tecnológicas, interpersonales) en las que se quiere impactar a través del diseño y participación de las actividades fuera de clases. Otro de los componentes con bajo nivel de correlación es la comunidad de aprendizaje. Las variables asociadas al profesor y entorno en línea en función del proceso de enseñanza-aprendizaje son las que presentan mayor grado de correlación. En síntesis se deben intencionar las estrategias de trabajo académico de los estudiantes por parte del profesor.

\subsubsection{Análisis correlacional entre variables dependientes y moderadoras sexo y edad}

En el caso de las variables sociodemográficas de sexo y edad las hemos omitido en el análisis, dado que para ninguna de las variables dependientes hemos encontrado resultados significativos según la prueba " $t$ ". En ambos pudimos concluir de manera altamente significativa (significancia con alfa 0,01 (1\%) que no existe diferencia entre los resultados obtenidos en ninguno de los casos, es decir las variables edad y sexo no generan diferencia en las respuestas. 
38 Tabla 6.13: Correlación entre competencias instrumentales y variables independientes

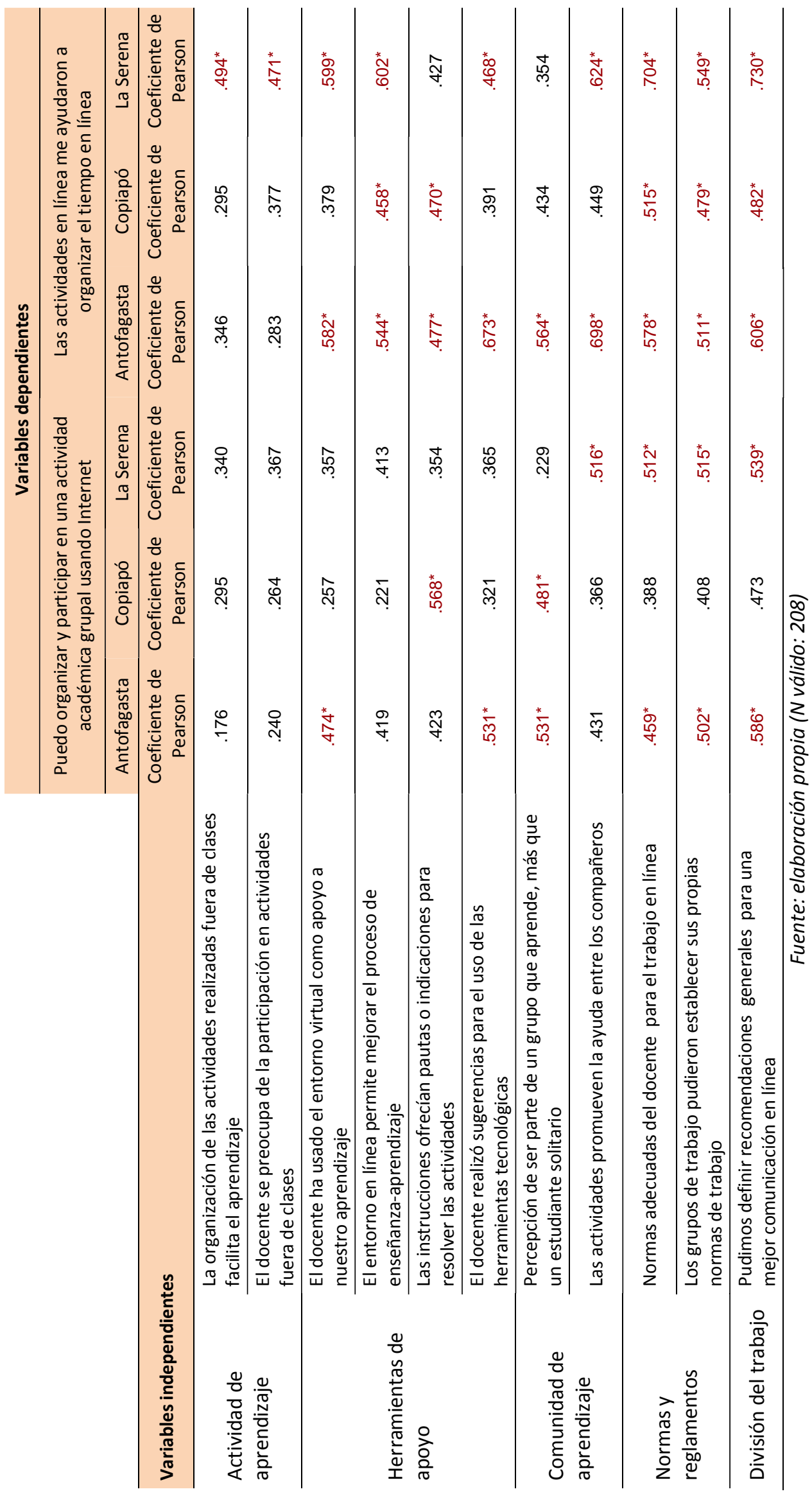


39 Tabla 6.14: Correlación entre competencias tecnológicas y variables independientes

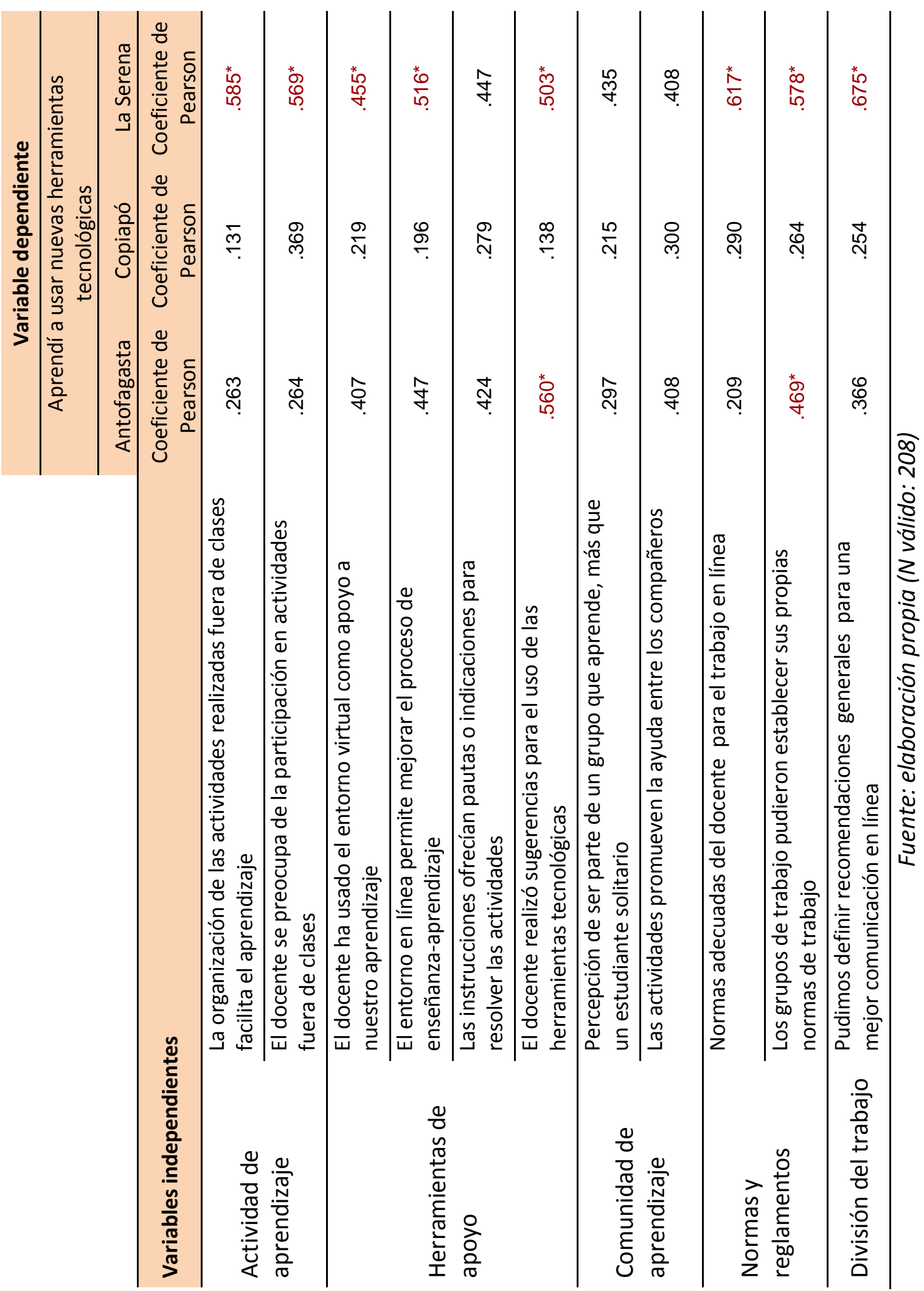


40 Tabla 6.15: Correlación entre competencias interpersonales y variables independientes

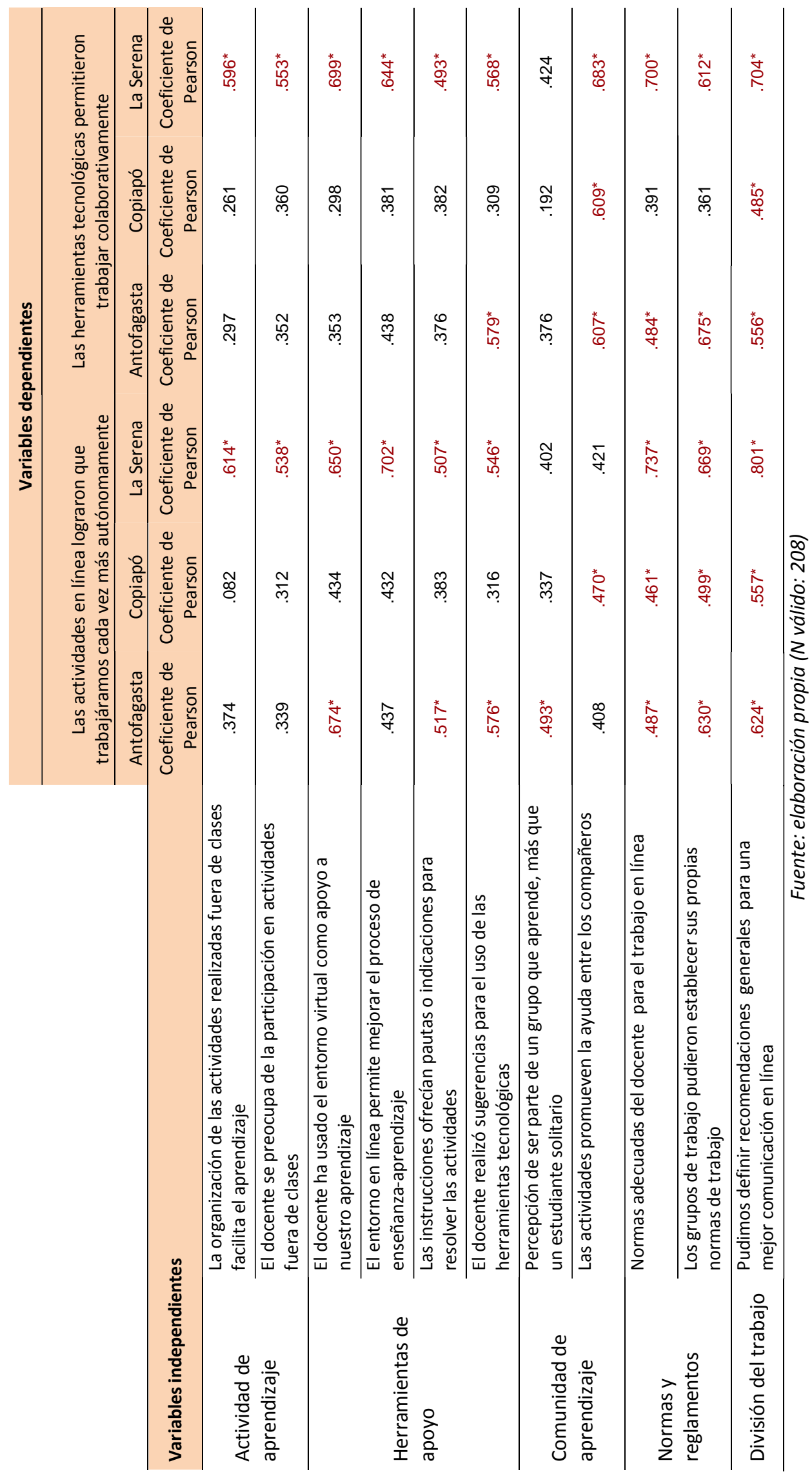




\subsubsection{Preguntas abiertas}

En el cuestionario se plantearon dos preguntas abiertas relacionadas con los elementos o aspectos más adecuados o más inadecuados para la formación del propio estudiante a través de Internet. En el caso de la pregunta de los elementos más adecuados, tanto del grupo piloto como del grupo control, de las 208 encuestas válidas, 61 estudiantes respondieron la pregunta abierta. La pregunta referida a los aspectos más inadecuados, fue respondida por 61 estudiantes.

En cuanto a los elementos más adecuados para una formación a través de Internet, al agrupar y contabilizar las respuestas en categorías emergentes, se aprecia que la mayor parte de los estudiantes (38,7\%) les preocupa tener recursos disponibles (Tabla 6.16), tales como herramientas tecnológicas y materiales digitales de apoyo a la asignatura (vídeos, guías). En segundo lugar, a los estudiantes valoran la facilidad y rapidez de acceso a los recursos y plataforma tecnológica. Las demás respuestas se distribuyen entre seis categorías entre la necesidad de apoyo virtual, pertinencia de los contenidos, necesidad de formación, entre otras.

41 Tabla 6.16: Pregunta abierta elementos adecuados en la formación a través de Internet

\begin{tabular}{lrr} 
Categoría & N & \% \\
\hline Recursos disponibles & 24 & 38.7 \\
\hline Facilitar el acceso & 19 & 30.6 \\
\hline Apoyo virtual & 7 & 11.3 \\
\hline Realización de actividad & 6 & 9.7 \\
\hline Contenido de la asignatura & 2 & 3.2 \\
\hline Formación tecnológica & 2 & 3.2 \\
\hline Mejorar la actitud & 1 & 1.6 \\
\hline Colaboración grupal & 1 & 1.6 \\
\hline \multicolumn{1}{c}{ Fuente: elaboración propia } & &
\end{tabular}

En la experiencia vivida por los estudiantes en cuanto a los elementos inadecuados, un $44,3 \%$ señala como inadecuadas varias de las herramientas sociales disponibles en Internet, tales como Facebook, Twitter y otras relacionadas al entretenimiento (Tabla 6.17). Por un lado, de momento no le dan un uso asociado a tareas académicas a estas 
herramientas sociales y por otro, falta el desarrollo de la autonomía, la autogestión para focalizarse en las tareas asignadas. En segundo lugar, los estudiantes manifiestan que las actividades y las estrategias de trabajo en línea son excesivas, les requiere mayor trabajo y conectase de manera permanente a la plataforma.

42 Tabla 6.17: Pregunta abierta elementos inadecuados en la formación a través de Internet

\begin{tabular}{lrr} 
Categoría & N & \% \\
\hline Recursos, herramientas de Internet & 27 & 44.3 \\
\hline Actividades, estrategias en línea & 17 & 27.9 \\
\hline Dificultades de acceso & 12 & 19.7 \\
\hline Desconcentra, distrae & 2 & 3.3 \\
\hline Falta de información & 2 & 3.3 \\
\hline Contenido de la asignatura & 1 & 1.6 \\
\hline \multicolumn{1}{c}{ Fuente: elaboración propia } & &
\end{tabular}

En síntesis, considerando la respuesta a las dos preguntas, las preocupaciones de los estudiantes están centradas en la primera fase del modelo de cinco etapas de Salmon (2004), la de acceso y motivación. Se aprecia un bajo nivel de valoración del trabajo autónomo y colaborativo fuera de clases en un entorno virtual, sumado a dificultades de acceso a la plataforma de trabajo lo que no genera una experiencia de éxito junto a cierta insatisfacción en la primera etapa de acceso y motivación para trabajar en línea. Si no se sortea adecuadamente esta etapa, es poco probable que se avance hacia etapas de socialización, procesamiento de información y construcción del conocimiento. 


\subsection{Estudio cualitativo}

\subsubsection{Análisis documental}

\subsubsection{Descriptor oficial de la asignatura}

Un resultado relevante de nuestra investigación es la constatación de que todos los docentes y estudiantes de los diferentes Campus tienen acceso al descriptor oficial de las asignaturas en la plataforma institucional, desde sus respectivos accesos de usuarios, publicado centralizadamente por la Casa Central para cada una de las asignaturas de todas las carreras impartidas.

En el descriptor oficial de la asignatura estudiada, Técnicas de Comunicación Oral y Escrita (TCOE), desde la perspectiva curricular, es definida como de formación general y de carácter práctica, la que tributa a fortalecer las capacidades de comunicación oral y escrita del alumno con su entorno académico-profesional en situaciones laborales relacionadas con el perfil profesional de la carrera del estudiante en formación.

Según el Reglamento Académico General de la institución, una asignatura práctica es aquella que tiene a lo menos un $70 \%$ de actividades de aprendizaje en las que el alumno desarrolla competencias a través de actividades prácticas, las que se realizan preferentemente en talleres, laboratorios, terrenos, aulas u otros, en forma presencial. Para aprobar una asignatura práctica se requiere una calificación final igual o superior a 4.0, en una escala de calificaciones de 1.0 a 7.0, y una asistencia igual o superior a un $70 \%$. A diferencia de las asignaturas lectivas, los alumnos no deben rendir un examen final en las asignaturas prácticas.

La asignatura TCOE propende al logro de competencias técnicas y genéricas. La primera competencia técnica se relaciona con la capacidad de comunicar ideas de manera efectiva y eficaz a través del lenguaje oral y escrito. La segunda, con la capacidad para comprender textos para el uso de la información como herramienta para el trabajo. Por su parte las competencias genéricas explicitadas en el documento son: demostrar compromiso con el trabajo bien hecho; trabajar en equipo agregando valor; resolver problemas aplicando 
criterio y de forma efectiva; demostrar destrezas básicas en el uso de herramientas tecnológicas.

TCOE tiene un régimen semestral distribuyéndose en 70 horas pedagógicas, de 45 minutos cada una, estructurada en cuatro unidades temáticas de aprendizaje. La primera unidad apunta a la comunicación oral y escrita; la segunda a la comprensión de lectura; la tercera a la redacción de documentos de uso frecuente $y$, finalmente, la cuarta al desarrollo de técnicas para una comunicación oral asertiva (Tabla 6.18).

43 Tabla 6.18: Unidades de aprendizaje y horas de la asignatura TCOE

\begin{tabular}{llc}
\multicolumn{2}{l}{ Unidades de aprendizaje } & Horas \\
\hline 1 & Comunicación oral y escrita & 18 \\
\hline 2 & Comprensión de lectura & 12 \\
\hline 3 & Redacción de documentos de uso frecuente & 12 \\
\hline 4 & Técnicas para una comunicación oral asertiva & 20 \\
\hline & Evaluación & 08 \\
\cline { 2 - 3 } & TOTAL & 70
\end{tabular}

Fuente: Sistema Integrado de Gestión Académica, INACAP

\subsubsection{Actividades en línea diseñadas}

Se aprecia que en los tres Campus usaron como base el diseño pedagógico ofrecido por la institución, el que se basa en una secuencia de las actividades de las más simples a las más complejas. Cada actividad en línea está estructurada claramente con un título o asunto descriptivo. A continuación, en cada una de ellas, se ofrece una breve presentación de la actividad a modo de motivación o "chispa". Luego se explicita el propósito expresado en términos concretos lo que se espera que el estudiante realice y logre como resultado de la actividad. Enseguida se describe en detalle la tarea, los pasos a seguir, según corresponda. En cada actividad en línea se le señala a los estudiantes que deben compartir con sus compañeros, según la actividad, ya sea con todo el grupo curso,

con un número mínimo de alumnos del grupo curso o con todos integrantes de su equipo de trabajo en aquellas actividades grupales. Finalmente, se explicita que las actividades en línea son de carácter obligatorio, la fecha y hora en que debe estar concluida. 
El diseño pedagógico de las actividades en línea se concibe en cinco etapas, según el modelo de Salmon (2004):

- Etapa 1: Acceso y motivación.

- Etapa 2: Socialización en línea

- Etapa 3: Intercambio de información

- Etapa 4: Construcción del conocimiento

- Etapa 5: Desarrollo

Las actividades están secuenciadas según estas etapas de las cuales se esperan resultados o productos concretos y el desarrollo de ciertas habilidades que irán logrando paulatinamente los alumnos (Apéndice $G$ ).

\subsubsection{Planificación semestral realizada por el docente}

En programación de las clases a lo largo del semestre en todas las asignaturas se asegura realización total de las horas de clases definidas curricularmente para la asignatura en el descriptor oficial, incluidas las actividades lectivas y evaluativas presenciales, según calendario académico definido por la Casa Central para todos los Campus que fija la fecha de inicio y término del semestre académico. En el número de horas totales de la TCOE no se incluye el tiempo destinado a la realización de actividades en línea, las que forman parte de las tareas fuera de clase que deben realizar los alumnos.

La disponibilidad y asignación de tiempo a la realización de tareas fuera de clases está cubierto en el Reglamento Académico General de la institución, al limitar la carga académica máxima de un estudiante de horas de clases semestrales, la que no podrá exceder de la equivalente a la suma de horas del semestre correspondiente, más un $25 \%$ y con un tope máximo de 650 horas pedagógicas. El semestre académico se distribuye entre 18 y un máximo de 20 semanas de clases. De esta forma, la carga horaria de clases presenciales máxima de un estudiante fluctúa entre 24 y 27 horas cronológicas semanales, lo que representa alrededor del 50\% de la carga de trabajo anual según el rango entre 1440 a 1900 acordado por las universidades chilenas en para el sistema de créditos transferibles, equivalente a 60 créditos anuales (STC-CHILE, 2007). 
Si bien la asignatura cuenta con un único descriptor, sin embargo la programación de las evaluaciones en los tres Campus presentan un número de evaluaciones diverso y de variada índole entre sí, tanto en los grupos piloto (Tabla 6.19) como en los grupos control (Tabla 6.20). Los tipos de evaluaciones abarcan exposiciones orales, pruebas escritas, informes escritos y portafolio digital e impreso. Sólo en el Campus La Serena se realiza explícitamente una evaluación de la producción y participación en línea a través del portafolio digital en los grupos piloto, cuya calificación tiene un $10 \%$ de ponderación en la nota final de la asignatura. En cambio, en los algunos de los grupos control de cada uno de los tres Campus usan la estrategia de evaluación portafolio impreso.

Se aprecia una preponderancia de evaluaciones de tipo test escrito, especialmente en el Campus Copiapó (para facilitar la identificación de los Campus, los identificaremos con la siguiente nomenclatura: C1: Campus Antofagasta; C2: Campus Copiapó; C3: Campus La Serena) en los grupos piloto en los que todas las evaluaciones planificadas son del tipo de pruebas escritas, las que son rendidas presencialmente por los alumnos durante el periodo de clases. Desde el diseño de la evaluación podemos inferir que los profesores no están asegurando ni acreditando el desarrollo de la mayoría de las competencias genéricas específicas de la asignatura, tales como trabajar en equipo, resolver problemas y uso de herramientas tecnológicas. 
44 Tabla 6.19: Programación de las Evaluaciones Grupos Piloto TCOE

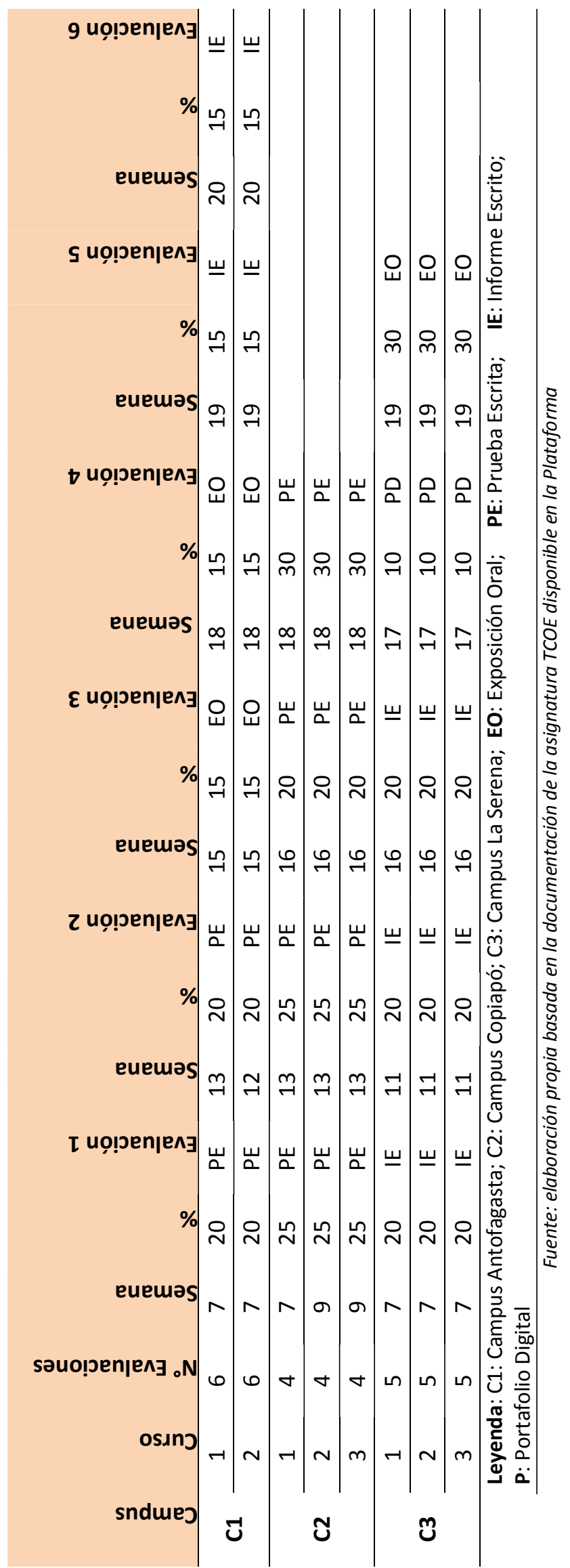


45 Tabla 6.20: Programación de las Evaluaciones Grupos Control TCOE

\begin{tabular}{|c|c|c|c|c|c|c|c|c|c|c|c|c|c|c|c|c|c|}
\hline 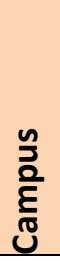 & 온 & 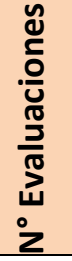 & 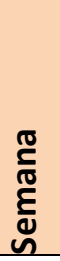 & de & 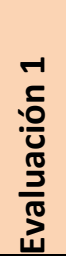 & 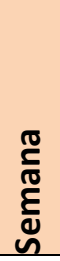 & de & 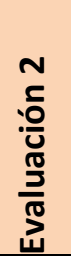 & 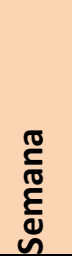 & de & 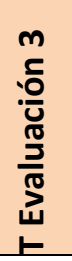 & 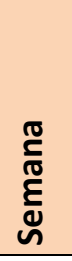 & de & 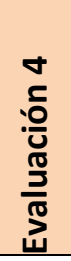 & 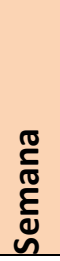 & dீ & 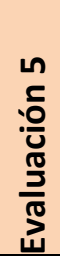 \\
\hline \multirow{2}{*}{ C1 } & 1 & 4 & 6 & 25 & $P E$ & 11 & 25 & PE & 15 & 25 & $P$ & 20 & 25 & EO & & & \\
\hline & 2 & 4 & 6 & 25 & $P E$ & 10 & 25 & PE & 14 & 25 & $P$ & 20 & 25 & EO & & & \\
\hline \multirow{2}{*}{ C2 } & 1 & 4 & 7 & 20 & PE & 12 & 20 & PE & 16 & 20 & PE & 18 & 40 & PE & & & \\
\hline & 2 & 5 & 6 & 15 & PE & 10 & 20 & EO & 14 & 25 & $P$ & 17 & 25 & EO & 18 & 15 & EO \\
\hline \multirow{2}{*}{ C3 } & 1 & 5 & 6 & 20 & $P E$ & 10 & 20 & PE & 13 & 20 & $P E$ & 16 & 20 & EO & 18 & 20 & EO \\
\hline & 2 & 5 & 6 & 20 & $P E$ & 10 & 20 & PE & 13 & 20 & $P$ & 16 & 20 & EO & 18 & 20 & EO \\
\hline \multicolumn{18}{|c|}{ Leyenda: C1: Campus Antofagasta; C2: Campus Copiapó; C3: Campus La Serena } \\
\hline & EO: & Expos & Sión & Oral; & & Pru & aba $E$ & scrita & & Info & rme & scritc & & : Port & afolic & & \\
\hline
\end{tabular}

\subsubsection{Participación en las actividades en línea publicadas}

En primer lugar hemos realizado una exploración y compilación de los documentos existentes y disponibles en cada uno de los ambientes virtuales de aprendizaje empleados por los docentes. Este registro virtual nos posibilita acceder a la actividad de aprendizaje en su dimensión real de planificación, ejecución, respuesta de los estudiantes y de las acciones de moderación del docente. Hemos omitido la documentación impresa dado que no tuvimos acceso a la totalidad de ella y es de diversa naturaleza conforme el estilo del docente, su formación previa diversa y los énfasis que da a la asignatura a partir de sus concepciones de los focos relevantes de las competencias a lograr por los alumnos. En cambio, en el caso de las actividades en línea, la institución ofreció a los docentes una propuesta de planificación y un corpus de doce actividades en línea prediseñadas que hace factible la comparación de las acciones pedagógicas de los profesores.

Las actividades en línea en TCOE se realizaron a lo largo de todo el semestre. A fin de dimensionar la participación de los alumnos, hemos contabilizado la totalidad de la producción de mensajes y conversaciones por Campus y curso, considerando la premisa de la competencia técnica inherente a la asignatura en estudio, como lo es "comunicar ideas de manera efectiva y eficaz a través del lenguaje oral y escrito" y las competencias genéricas trabajo en equipo, resolución problemas y uso de herramientas tecnológicas. 
46 Tabla 6.21: Actividades en línea programadas y ejecutadas por Campus

\begin{tabular}{|c|c|c|c|c|c|}
\hline Campus & Actividades en línea & Publicación & Plazo & $\begin{array}{l}\text { Días de } \\
\text { plazo }\end{array}$ & $\begin{array}{l}\text { Días entre } \\
\text { actividad }\end{array}$ \\
\hline \multirow{10}{*}{ C1 } & 1. Envía mensaje de saludo (I) & $27 / 03 / 2011$ & 20/03/2011 & ?? & -- \\
\hline & 2. Presentación personal (I) & $31 / 03 / 2011$ & 03/04/2011 & 3 & 4 \\
\hline & 3. Estilos de aprendizaje (I) & $07 / 05 / 2011$ & $08 / 05 / 2011$ & 1 & 37 \\
\hline & 4. Trabajar en grupo en línea (G) & $06 / 06 / 2011$ & $12 / 06 / 2011$ & 6 & 31 \\
\hline & $\begin{array}{l}\text { 5. ¿A qué persona de tu propia disciplina } \\
\text { te gustaría conocer? }(\mathrm{G})\end{array}$ & $11 / 06 / 2011$ & $19 / 06 / 2011$ & 8 & 5 \\
\hline & 6. Sitios web de mi especialidad (G) & $11 / 06 / 2011$ & $19 / 06 / 2011$ & 8 & 0 \\
\hline & 7. Comunicación virtual (G) & $22 / 06 / 2011$ & $26 / 06 / 2011$ & 4 & 11 \\
\hline & 8. Sitios web para TCOE (G) & $22 / 06 / 2011$ & $26 / 06 / 2011$ & 4 & 0 \\
\hline & 9. Selección de artículos (G) & $29 / 06 / 2011$ & 03/07/2011 & 4 & 7 \\
\hline & 10. Realizar subrayado de artículo (G) & 29/06/2011 & 03/07/2011 & 4 & 0 \\
\hline \multirow{3}{*}{ C2 } & 1. Envía mensaje de saludo (I) & $24 / 03 / 2011$ & $27 / 03 / 2011$ & 3 & -- \\
\hline & 2. Presentación personal (I) & 05/04/2011 & $10 / 04 / 2011$ & 5 & 11 \\
\hline & Actividades 1 a 12 (I y G) & $15 / 05 / 2011$ & $21 / 06 / 2011$ & 65 & 65 \\
\hline \multirow{12}{*}{ C3 } & 1. Envía mensaje de saludo (I) & $18 / 03 / 2011$ & $22 / 03 / 2011$ & 4 & -- \\
\hline & 2. Presentación personal (I) & 23/03/2011 & 27/03/2011 & 4 & 5 \\
\hline & 3. Estilos de aprendizaje (I) & $25 / 03 / 2011$ & $03 / 04 / 2011$ & 8 & 2 \\
\hline & 4. Trabajar en grupo en línea (G) & 08/04/2011 & $10 / 04 / 2011$ & 2 & 7 \\
\hline & $\begin{array}{l}\text { 5. ¿A qué persona de tu propia disciplina } \\
\text { te gustaría conocer? }(G)\end{array}$ & 08/04/2011 & $10 / 04 / 2011$ & 2 & 0 \\
\hline & 6. Sitios web de mi especialidad (G) & $19 / 04 / 2011$ & $01 / 05 / 2011$ & 11 & 11 \\
\hline & 7. Comunicación virtual (G) & $01 / 05 / 2011$ & $08 / 05 / 2011$ & 7 & 10 \\
\hline & 8. Sitios web para TCOE (G) & $06 / 05 / 2011$ & $22 / 05 / 2011$ & 16 & 5 \\
\hline & 9. Selección de artículos (G) & $21 / 05 / 2011$ & $29 / 05 / 2011$ & 8 & 15 \\
\hline & 10. Realizar subrayado de artículo (G) & $29 / 05 / 2011$ & $05 / 06 / 2011$ & 7 & 8 \\
\hline & 11. Mapa conceptual (G) & $04 / 06 / 2011$ & $12 / 06 / 2011$ & 8 & 6 \\
\hline & $\begin{array}{l}\text { 12. Competencias del profesional del } \\
\text { futuro (G) }\end{array}$ & $12 / 06 / 2011$ & $19 / 06 / 2011$ & 7 & 8 \\
\hline
\end{tabular}

Leyenda: C1: Campus Antofagasta; C2: Campus Copiapó; C3: Campus La Serena

(I): individual; (G): grupal

Fuente: elaboración propia basada en la documentación de la asignatura TCOE disponible en la Plataforma

La participación de los estudiantes es disímil entre los diferentes Campus, según los registros a los que se tuvo acceso en la herramienta tecnológica usada en cada Campus. En el Campus 1 se contabilizan durante el semestre 28 mensajes totales de los alumnos para dos grupos curso de la asignatura con una media de 0.7 y 0.3 de participación por alumno en las actividades publicadas por el docente. Las conversaciones corresponden a los mensajes que se agrupan en torno a un mensaje original al que los participantes responden directamente sin crear un nuevo mensaje. En el caso del grupo 1, de los 31 mensajes, 21 se 
agrupan en una misma actividad iniciada por el docente. En el grupo 2 sólo se registran 8 respuestas. La participación de los estudiantes en las actividades en línea se incrementa en los Campus 2 y 3 respecto al 1. Aumenta el número de participaciones totales $(102,315$ y 94 en el Campus 2; 455.172 y 294 en el Campus 3), así como la media (Campus 1: 0,45; Campus 1:6,7 y Campus 3: 10,6) (Tabla 6.23).

Se ha realizado un análisis de la pertinencia de la participación, es decir, si los mensajes y respuestas publicados por los alumnos tienen directa relación a la tarea en línea asignada por el docente. En el Campus 1 contamos con datos reducidos ya que sólo se pudo acceder al registro de dos actividades en línea publicadas por docente, en las cuales se aprecia casi una total pertinencia de las intervenciones de los estudiantes. Por su parte el Campus 2 las actividades diferentes realizadas por los estudiantes varían entre 4, 10 y 12 en los tres grupos curso estudiados y se aprecia un incremento en la participación, con desigual nivel de pertinencia de las respuestas de los estudiantes a la actividad plateada por el profesor. El Campus 3 casi duplica la participación de los alumnos respecto al Campus 2, así como la pertinencia casi total de la participación de los alumnos.

Otro indicador considerado es la conducción pedagógica de las actividades por parte del profesor, para ello se han contabilizado las conversaciones en línea iniciadas por el profesor y por los estudiantes. En el Campus 1, si bien en una alta proporción las inició el docente, dado el reducido número de mensajes no podemos caracterizar al proceder pedagógico del docente en este punto. Sí resulta interesante contrastar el rol del docente en los Campus 2 y 3. En el Campus 2 el docente da inicio a las actividades en una bajísima proporción en cada grupo curso (5/80, 4/238, 2/82). Si bien el número de actividades en línea es elevado (10 a 12), como se aprecia en la Tabla 6.22 de las actividades en línea programadas por Campus, constatamos que el docente en un solo momento publica todas las actividades en línea. En cambio, en el Campus 3 en más de $96 \%$ de los casos las actividades en línea son iniciadas por el profesor a cargo de la asignatura. 
47 Tabla 6.22: Producción de mensajes y conversaciones por Campus y cursos piloto

\begin{tabular}{|c|c|c|c|c|c|c|c|c|c|c|}
\hline \multirow{2}{*}{$\begin{array}{l}\frac{n}{\partial} \\
\frac{0}{E} \\
\text { ㄹ }\end{array}$} & \multirow[b]{2}{*}{ Curso } & \multirow{2}{*}{$\begin{array}{c}\mathbf{N}^{\circ} \\
\text { alumnos }\end{array}$} & \multicolumn{5}{|c|}{ Participación de los alumnos } & \multicolumn{3}{|c|}{ Conversaciones } \\
\hline & & & $\mathbf{N}^{\circ}$ & Media & Pertinencia & $\%$ & Actividades & Docente & Estudiante & Total \\
\hline \multirow{2}{*}{ C1 } & 1 & 30 & 21 & 0.7 & 19 & 90.5 & 2 & 10 & 0 & 10 \\
\hline & 2 & 38 & 8 & 0.2 & 8 & 100 & 2 & 10 & 5 & 15 \\
\hline \multirow{3}{*}{ C2 } & 1 & 43 & 102 & 2.4 & 39 & 38.2 & 4 & 5 & 75 & 80 \\
\hline & 2 & 30 & 315 & 10.5 & 247 & 78.4 & 12 & 4 & 234 & 238 \\
\hline & 3 & 13 & 94 & 7.2 & 70 & 74.5 & 10 & 2 & 80 & 82 \\
\hline \multirow{3}{*}{ C3 } & 1 & 33 & 455 & 13.8 & 455 & 100.0 & 10 & 56 & 2 & 58 \\
\hline & 2 & 21 & 172 & 8.2 & 172 & 100.0 & 12 & 40 & 0 & 40 \\
\hline & 3 & 30 & 294 & 9.8 & 293 & 99.7 & 12 & 50 & 1 & 52 \\
\hline
\end{tabular}

Fuente: elaboración propia basada en la documentación de la asignatura TCOE disponible en la plataforma

Las doce actividades, individuales (I) y grupales (G) en línea prediseñadas se ofrecieron a los docentes para que las implementaran en una secuencia definida sobre la base del modelo de las Cinco Etapas de Salmon, el que hemos descrito en detalle en el capítulo 3 acerca de algunos modelos b-learning.

Revisaremos la periodicidad en la realización de cada una de las actividades en línea. En el Campus 1 se realizaron 10 de las 12 actividades en línea. La programación es de las mismas es irregular toda vez que a la primera actividad se le asigna una fecha para ser presentada anterior a la propia fecha de publicación. El tiempo que media entre una actividad y otra no genera la periodicidad que marque un ritmo de trabajo de los alumnos ya que los días que transcurren entre la actividad 1 y 2 es de 7 días, y entre la actividad 3 y 4 transcurren 31 días. Luego, dos actividades se publican en una misma fecha y en la misma fecha deben concluirlas (Tabla 6.22).

En el Campus 2, si bien se publican las 12 actividades, esto se concentra en tres fechas. Las actividades 1 y 2 son publicadas por separado, sin embargo las restantes, incluidas además las dos primeras se publican en usa sola fecha, en un documento en formato Word. La publicación de las actividades en línea en el Campus 3 se aprecia una regularidad a lo largo del semestre en las fechas de publicación y en los plazos concedidos para su realización.

En las etapas 1 y 2 del modelo usado de referencia, no se espera que la motivación intrínseca ayude, lo que importa es la adquisición de la capacidad emocional y social de 
aprender juntos en línea y presencialmente. En las etapas 4 y 5 se debe promover motivadores intrínsecos.

La documentación revisada corresponde a las actividades publicadas por los profesores y todas las participaciones de los alumnos en la plataforma tecnológica usada en la asignatura para las actividades en línea, desde el inicio del semestre hasta el cierre del mismo (marzo a julio).

Para abordar la lectura en profundidad del contenido de los documentos seleccionados se confeccionó una lista de cotejo (Apéndice F), cuyas dimensiones e indicadores se han definido sobre la base de la Teoría de la Actividad Engeström (1987, 2001, 2007), expuesta en detalle en el capítulo cuarto de este informe de investigación.

Los principales hallazgos quedan sintetizados en la Tabla 6.23, los que se expresan sintéticamente en cada uno de sus apartados y respectivas categorías contrastando el desempeño de los profesores y de los alumnos con las categorías nunca, casi nunca, a veces, frecuentemente y sistemáticamente.

\subsection{Actividad de aprendizaje}

Al revisar la evidencia disponible del desarrollo de las actividades en línea, verificamos que en el Campus 1 las actividades se publicaron irregularmente lo que no permite marcar un ritmo de participación de los alumnos, lo que se ve reflejado en la irregular y escasa participación de los mismos. Por su parte en el Campus 2 se constató una mayor respuesta a las actividades en línea, sin embargo cada alumno iba decidiendo en qué orden las realizaban, ya que en la octava semana se les publicó la totalidad de las actividades en línea (1 a 12). La secuencia pedagógica del contenido sí se aprecia ejecutada en el Campus 3, ya que es el profesor el que marca el ritmo de la realización de las actividades. 


\subsection{Interactividad pedagógica}

En las actividades se esperaba la interacción entre los alumnos desde los niveles más simples de responder a un saludo hasta niveles más complejos en los que debían tomar acuerdos frente a una actividad propuesta. En el C1 no se constata interacción con finalidad pedagógica entre los estudiantes y ni entre los estudiantes y el profesor. Si bien en el Campus 2 en número de mensajes es claramente superior al $\mathrm{C} 1$, tampoco se produce la interactividad ya que los alumnos responden individualmente las actividades y sólo en algunas ocasiones responden a los mensajes de sus compañeros. La frecuencia y ritmo adecuados de participación de los alumnos se aprecian claramente en el C3 en todas las actividades en línea. El profesor publica las actividades en línea en una frecuencia concordante con la complejidad de la actividad. El liderazgo pedagógico del profesor del C3 y la práctica guiada marcó claras diferencias con los demás Campus.

La falta de periodicidad en la publicación de las actividades en línea afecta al logro de un el ritmo de trabajo de los alumnos, a su motivación en el uso de la tecnología y la adhesión afectiva, generando un efecto contraproducente. Por su parte la clase presencial se centra normalmente en el desempeño del profesor y se centra en el desempeño del docente, por tanto las actividades que realizan los alumnos tienden bajo nivel de planificación, además la comunicación cara a cara facilita la aclaración y adecuación de aquellas actividades que no hayan sido planificadas adecuadamente. 


\subsection{Actividades de evaluación}

Según la documentación disponible, examinamos los instrumentos de evaluación que les fueron enviados a los profesores participantes en los grupos pilotos de los tres Campus. Los instrumentos ofrecidos a los profesores son una pauta de autoevaluación de actividades en línea y portafolio digital; pauta de evaluación y temario y criterios del informe uno y, finalmente, una pauta de evaluación de exposición oral.

En la pauta de autoevaluación de las actividades en línea (actividades electrónicas o eactividades) se propone que el alumno se autoevalúe y que el líder del equipo refrende dicha autoevaluación mediante su firma. Al final de semestre el profesor revisa cada una de las actividades y asigna el puntaje de las actividades, respetando la autoevaluación de las tres primeras y las tres siguientes respaldadas por el líder y seis últimas la autoevaluación es sólo referencial. De acuerdo a la evidencia documental de la plataforma no tenemos acceso a contenido de dicha evaluación, sólo en la planificación de las evaluaciones, hay evidencia que sólo en el Campus 3 se evalúa y califica el portafolio digital.

La evaluación de las actividades en línea aparece sugerida en la pauta de evaluación y temario y criterios del informe uno. El temario del informe se agrupa en cinco tópicos, de los cuales cuatro evalúan y califican actividades en línea. El primer aspecto es la solicitud de una autobiografía personal en la que deben aplicar la estructura un plan de redacción y la estructura del párrafo. Estos tópicos no son abordados en ningunas de las e-actividades, por lo que presuponemos que estas temáticas se abordaron en las clases presenciales. Los siguientes cuatro tópicos sí están tratados en las e-actividades:

- Presentación personal a través de la selección de seis URL (direcciones de Internet) presentadas por sus compañeros en la "e-actividad 2: presentación personal". Deben señalar las razones por los cuales las seleccionaron cada una de ellas.

- En el tercer tópico deben exponer los resultados obtenidos en tres test y describir acciones concretas, cambios de hábitos y desarrollo de actividades. Dos de estos test son respondidos y analizados en las clases presenciales (Estilos de Aprendizaje VAK, Factores Asociados al Estudio) y el tercero que forma parte de la e-actividad tres (tu estilo de aprendizaje y Estilos de Aprendizaje de Honey y Alonso). 
- En el cuarto tópico deben presentar la información aportada en la e-actividad cinco ¿a qué persona de tu propia disciplina te gustaría conocer?

- Finalmente, el último tópico se refiere a los sitios web dela especialidad. Sobre la base de la e-actividad siete sitios web de la especialidad, realizan un cuadro comparativo de los cinco más relevantes para la formación profesional en diferentes asignaturas. Como referencia para la evaluación de fuentes electrónicas se les sugiere la lista de chequeo de la Universidad de Cornell, disponible en Internet.

La evaluación formal de las actividades en línea sólo constatamos su presencia en el caso del Campus 3. El profesor les solicita a los alumnos que publiquen los informes escritos, cuyo contenido refleja en los tres informes, tal como el detalle de la evaluación que hemos descrito en los párrafos anteriores, se evalúan tópicos de las actividades en línea, integradas con las actividades y temas de las clases presenciales.

Además de las pautas reseñadas, se les ofrece a los profesores una sugerencia de planificación de las actividades en línea, según el Modelo de las Cinco Etapas de Salmon. En este documento se dan indicaciones específicas para ir evaluando en proceso en la clase presencial, por ejemplo, "hacer un balance de los mensajes de saludo, asegurarse de que todos se han conectado", "comentar acerca de las presentaciones personales de la actividad en línea número dos", "Ios secretarios exponen la síntesis de la e-actividad cuatro: trabajar en grupo en línea", "comentar acerca de los personajes seleccionados en la eactividad 5", "chequear el avance del trabajo grupal de la e-actividad 6", entre otras.

\subsection{Herramientas}

En el apartado de herramientas revisamos la presencia de sugerencias de herramientas tecnológicas disponibles en línea, así como sugerencias de estrategias de trabajo individual y grupal, procedimientos para el uso de las herramientas tecnológicas y sugerencia de artículos o recursos en Internet, libros digitales o impresos.

El diseño de las actividades ofrece orientaciones concretas de las estrategias de trabajo y uso de herramientas. En el modelo de Salmon el acercamiento y uso de la tecnología es 
paulatino con un grado creciente de autonomía del alumno, para lo cual se genera una práctica guiada y moderada por el profesor. Como ya lo señalamos anteriormente, la falta de regularidad en el desarrollo de las actividades y la falta de acceso y uso de la herramienta tecnológica usada en el caso de los Campus 1 y 2, explican el bajo logro.

\subsection{Comunidad}

El modelo sugerido a los profesores propende a la integración social temprana de los alumnos, dada su condición de alumnos que inician su proceso formativo en educación superior. Durante el transcurso del semestre se espera que el profesor entregue orientación y apoyo para la organización de los grupos de trabajo, así como las actividades tengan relación con el contexto de referencia de su desempeño como estudiante y del ejercicio profesional de la carrera que estudian.

Las condiciones pedagógicas generadas por el docente Campus 3 contribuyeron directamente a la generación de una comunidad de aprendizaje por parte de los alumnos. En el Campus 1 la baja participación no generó ningún elemento de comunidad de aprendizaje en línea. Si bien, como ya lo hemos indicado, en el Campus 3 en algunos grupos tenemos alta participación, está orientada al cumplimiento individual de actividades, por tanto las conversaciones entre los estudiantes están desarticuladas y sin espacio temporal de referencia, además de la ausencia normativa y referencial del profesor (publicó todas las actividades en un solo momento), ya que mayoritariamente son los estudiantes los que inician las conversaciones o actividades en línea.

\subsection{Normas y roles}

La documentación examinada presenta la existencia de normas y reglas dirigidas a los grupos de trabajo, así como la sugerencia de que definan normas de funcionamiento. Se explicitan algunos roles de los estudiantes, no así el rol del profesor, excepto en la presentación de la asignatura publicada antes del inicio de las clases. 
Se aprecia en la interacción y los productos generados por el trabajo grupal la dificultad de los alumnos para establecer sus propias normas y roles. Coadyuva a este resultado la moderación en línea más explícita del profesor, la que presuponemos, sólo en el caso del Campus 3, que se da en la instancia presencial, tal como es sugerida en este modelo $b$ learning estudiado, en la que el profesor va transfiriendo paulatinamente el control de la actividad a los alumnos y explicita su rol y el de los estudiantes.

\subsubsection{Entrevistas a profesores y grupos focales de estudiantes}

Las entrevistas a los profesores y los resultados de los grupos focales realizados con alumnos de los tres campus que participan en los grupos piloto y grupos control se presentan sintetizados y agrupados por categorías, de las cuales hemos seleccionado algunos testimonios representativos de las categorías investigadas, evitando una repetición inoficiosa de la información. Primero presentamos los resultados de las entrevistas y de los grupos focales de los cursos piloto y luego los contrastamos con los resultados de las entrevistas de los grupos focales y de los cursos control.

\subsubsection{Actividad de aprendizaje}

\subsection{Diseño pedagógico de las actividades en línea}

Frente a este diseño propuesto los profesores de los tres Campus, aunque lo valoran como novedoso y desafiante, tienen acercamientos distintos, determinados por su experiencia previa declarada respecto al acceso y uso de tecnologías como apoyo a la labor docente. El profesor del C1 valora la modalidad b-learning ofrecida para ser implementada en TCOE especialmente en cuanto al uso de las tecnologías para desarrollar actividades en línea que poseen cierta periodicidad y le facilitan el uso del tiempo.

- Campus 1-Profesor Piloto: Lo distinto y novedoso para mí es que implica una periodicidad de las actividades en línea. 
- C1-PP: La ventaja de las actividades en línea tiene que ver con la posibilidad de que los jóvenes puedan utilizar Internet en otro sentido, en investigar acerca de un tema. Y ver la veracidad de la fuente.

- C1-PP: No había visto nada que tuviera que ver con el uso de tecnología a través de actividades en línea, porque yo soy un profesor estilo a la antigua, yo utilizo solo la pizarra y plumón.

- C1-PP: Principalmente no uso proyector multimedia porque hay que ir a buscarlo e ir a dejarlo, más el computador. Para mí es un problema.

- C1-PP: Las actividades en línea facilitan el uso del tiempo, porque uno puede avanzar en algunos contenidos ahí y nos quedaría tiempo para profundizar en otros.

- C2-PP: Yo creo que las actividades están bien diseñadas y secuenciadas, pienso que uno debiese buscar cómo aplicarlas. La cantidad de actividades me pareció bien, me faltó un poco de tiempo, a lo mejor reducir.

- C3-PP: Este nuevo enfoque es bastante novedoso y desafiante.

- C3-PP: Una de las ventajas es el hecho de que las actividades en línea estén secuenciadas pedagógicamente, una necesita de la otra.

- C3-PP: El hecho que las actividades ya estuvieran programadas te entregaba es una facilidad, una tranquilidad. Porque el modelo sí funciona.

El diseño pedagógico del modelo b-learning, que se desprende del análisis documental, tiene como propósito ofrecer a los estudiantes un andamiaje, una práctica guiada con la finalidad de desarrollar grados crecientes de autonomía. Los profesores de los grupos piloto reconocen que el diseño del modelo que implementaron consigue que los alumnos trabajen fuera de clases. En cambio los profesores de los grupos control, quienes usan la estrategia de auto organización espontánea de los alumnos, estiman que los alumnos no pueden trabajar por cuenta propia fuera de clases, con lo cual, tienden a no ceder el control de las actividades y del aprendizaje a los estudiantes.

La preocupación de los profesores de los grupos control está centrada en su actuación en la clase presencial y en cómo pueden cubrir los contenidos de la asignatura. Cuando usan tecnología optan por el correo electrónico como buzón de entrega más que instancia de 
trabajo colaborativo de tareas secuenciadas, además las actividades al no contar con un diseño pedagógico y no ofrecen estrategias para trabajar fuera de clases, el profesor se recarga de trabajo.

- Campus 2-Profesor Control: Pedía diez trabajos y al final se me juntaban más de mil quinientos en el momento en que tenía que abrir. Ahora, de esos mil quinientos me llegaban mil, pero mil es harto. Como primera experiencia estuvo buena, pero hay que colocar algunos atajos. Pedir creatividad es complicado.

- C2-PC: El trabajo colaborativo entre ellos fuera de la sala de clases cuesta mucho. Porque son distintos tiempos, distintos trabajos, no tienen hora de organización.

- C3-PC: La asignatura está sobrecargada de temáticas.

En cuanto a la organización pedagógica de las actividades en línea, si bien los alumnos del Campus 1 (C1) las perciben bien organizadas de acuerdo al nivel de complejidad, sin embargo la frecuencia de publicación es irregular ya que afirman que el profesor enviaba dos o tres por semana y de un total de doce actividades propuestas dentro del modelo $b$ learning para ser publicadas una a una semanalmente, los alumnos señala que realizaron sólo algunas.

- Campus 1-Estudiante 2 (C1-E2): Nuestro profesor tiene un plan bien organizado, por lo que fue recordándonos sobre lo que pasábamos (...) nos hizo hacer tareas por Internet.

- C1-E3: Hacía actividades semanales. Teníamos hasta el domingo a las 11:59 PM para responderla, y mandaba dos o tres por semana.

- C1-E4: Hicimos cinco actividades online.

- C1-E5: Fueron en cadena, cada vez iba aumentando la dificultad.

En el Campus 2 (C2) y en el Campus 3 (C3) los alumnos dan cuenta de la realización de un número mayor de actividades en línea respecto al C1. Aprecian un diseño pedagógico de las mismas en cuanto a que poseen un creciente nivel de dificultad y las instrucciones son adecuadas y ofrecen pautas de trabajo para la organización de los alumnos así como para redactar sus respuestas. En cuanto a los plazos y fechas fijadas para su publicación, en el C3 los alumnos manifiestan que los plazos son adecuados y asumen su responsabilidad de 
responder a tiempo ya que las condiciones y descripción de las tareas están informadas de manera precisa por parte del profesor.

- C2-E1: Las instrucciones estaban clarísimas.

- C2-E2: Las actividades iban de la más sencilla a la más compleja, porque después se hicieron los trabajos en grupo donde tenía que haber secretarios y alguien que investigara y todo.

- C3-E2: Tuvimos doce actividades online.

- C3-E5: Las instrucciones estaban claras, pero a veces no entendía y volvía a leer. Pero estaban súper bien estructuradas, ponían propósito, la tarea que hacer.

- C3-E6: Varios compañeros me preguntaban cómo se hacía esto. Es que no leían bien, pero no era problema de que el profesor no explicara bien.

- C3-E7: Pensé que todas las actividades en línea estaban prediseñadas.

En la categoría diseño pedagógico de las actividades en línea no tenemos resultados de los grupos control de cada uno de los Campus ya que no realizaron actividades en línea. Sólo en algunos casos puntuales los profesores usaron el correo electrónico para enviar algunos documentos, información acerca de fechas y pautas de evaluación.

A los profesores de los grupos piloto de los tres Campus se les ofreció un conjunto de actividades diseñadas para ser aplicadas en línea y sus respectivos materiales de trabajo de apoyo para las clases presenciales y las actividades en línea, las que fueron descritas en el análisis documental, en la primera parte de este capítulo. En cambio, por profesores de los grupos control no recibieron ninguna indicación previa ni fueron informados acerca de la aplicación del modelo b-learning en otros cursos de su mismo Campus en la misma asignatura. 


\subsection{Diseño pedagógico de las actividades presenciales}

Los profesores reconocen que el diseño pedagógico de las actividades en línea debe ser coherente con un diseño pedagógico de las actividades presenciales que marquen el ritmo de trabajo en clases y fuera de clases de los estudiantes. La secuencia de las clases está dada por la lógica del contenido y en esta asignatura, siendo de carácter práctico, el contenido no se visualiza como herramienta, sino como un fin en sí. El profesor se asegura de cubrir el contenido en clases, manteniendo el control de la clase y no planifica actividades secuenciadas de ejercitación fuera de clases.

- C1-PP: Las actividades en línea generan un hábito de trabajo en los alumnos. Yo también debí haber manejado una agenda de las clases, porque la incorporé muy encima.

- C1-PP: Lamentablemente no cumplí la programación a cabalidad.

- C3-PP: El hecho de ir complementando con actividades paralelas en lo que son las TIC, hace que uno se ponga desafíos. Y la complementación que se hace con la clase presencial, entonces uno ve los pros y contras casi de inmediato.

- C1-PC: Frente a la gran cantidad de trabajo de corrección, lo que ajustaría es qué es lo realmente importante y lo que debo exigir, por ejemplo buscar un currículum, debemos uniformarlo, ver cuál es el modelo de currículum oficial.

- C2-PC: Son 70 o 75 contenidos y las clases son alrededor de 35. Ahí hay un problema en cuanto a la entrega de contenidos y el espacio de la práctica.

Los alumnos valoran las posibilidades de participación activa en clases cuando esta se produjo, especialmente aquellas referidas al desarrollo de habilidades comunicacionales, ya sean orales o escritas. Se aprecia que algunas de las clases tienden a estar centradas en los alumnos incentivando la participación de los mismos.

- C1-E1: El profesor fue bien didáctico, porque más que una enseñanza, es reforzar lo que ya sabemos, fueron entretenidas las clases.

- C1-E3: Al final hubo buena aceptación de todos. 
- C1-E4: Lo más importante fueron las exposiciones, porque sacábamos nuestra personalidad, unos son tímidos y otros tienen dominio.

- C1-E6: No solo disertábamos, también había actividades que enseñaban a redactar. Eso me ayudó mucho, sabía muy poco de redacción y ortografía.

- C1-E7: Trabajamos en grupo, la última nota fue un debate.

En el C3 explicitan los alumnos cómo el profesor en el transcurso del semestre académico se transforma en un moderador el que conduce las actividades en clases, previamente planificadas por el profesor y cede el control de actividades durante las clases.

- C3P-E1: Este método es mucho más dinámico, al ser dinámico uno aprende más, porque uno mismo ve sus errores. Con otros profesores no veía eso, solo veía mis errores cuando me sacaba malas notas.

- C3-E3: El profesor tenía la práctica de "aprender haciendo", porque todas las actividades no fueron solo investigar, sino aplicar.

- C3-E6: El profesor fue totalmente didáctico, pasó de ser profesor, a ser moderador, porque en la clase todos participaban, todos compartíamos experiencias.

Un elemento común importante entre los grupos control y piloto es la clase presencial, no pierde preeminencia ante el gran desarrollo tecnológico fuera del aula. Se aprecian algunas diferencias en el diseño pedagógico de las actividades presenciales entre los grupos pilotos entre sí y en relación a los grupos control. En el caso de los grupos piloto tienden a organizarlas en torno a actividades presenciales las que se van nutriendo de las actividades en línea cuyos resultados presentan en la clase presencial. En cambio la planificación de la asignatura de los grupos control se organizó en torno a la lógica y secuencia de los contenidos, el foco es cubrir ciertos contenidos. El profesor se siente que será bien evaluado si él entrega o expone mayoritariamente los contenidos, ese es su rol.

- CC3-E1: Las actividades no tenían una secuencia.

- CC3-E2: Fueron cambiando los temas pero no la metodología. Muy centrado en el profesor. 


\subsection{Articulación de las actividades presenciales y virtuales}

La integración de las actividades presenciales y virtuales es un componente clave de los modelos b-learning. En la articulación de las actividades presenciales en cada uno de los Campus se implementó estrategias disímiles entre ellos. En el C1 existió escasa relación entre las actividades de las clases presenciales y las desarrollas en la modalidad en línea, siendo las actividades en línea actividades paralelas de las cuales sólo algunas se trataron en clases, ya sea para dar indicaciones o para exponer los resultados.

- C1-PP: Debí haber manejado una agenda, para ir ligando las actividades presenciales y virtuales, hay que revisar en clases lo que ellos han ido viendo, reflexionando.

- C1-PP: Mi dificultad fue que me quitaron tiempo para poder hacer mis actividades.

- C2-PP: Los alumnos no presentaban ante sus compañeros semanalmente o con alguna frecuencia sus resultados. Me entregaban a mí los resultados.

- C2-PP: Tenía un problema de tiempo. Tomé algunas cosas para experimentar, las actividades como iban diseñadas para crear la secuencia y la habilidad.

- C3-PP: Las actividades presenciales y en línea se complementaban. Llegaba un minuto en que uno podría pensar que la clase presencial es el fuerte y el complemento es la actividad. En algún minuto yo sentí que era al revés. Se invirtió el tema.

Los alumnos reconocen la conveniencia de revisar las actividades en línea en clases, de recibir retroalimentación acerca de los resultados obtenidos, junto a recibir sugerencias y estrategias de trabajo.

- C1-E1: Se conversaban las actividades en línea en clases, pero no de todas.

- C1-E3: No compartíamos en las clases presenciales lo que habíamos publicado. Mandábamos la actividad y no nos decía cómo nos había ido, nada.

- C1-E4: Solo realizábamos las actividades y el profesor nos enviaba más.

- C1-E5: Quizás eso provocó la desmotivación. A lo mejor si se hubiese conversado en clases, habría sido mejor. Pensando si estas actividades se hubiesen realizado todas por todo el curso. 
- C1-E6: Los trabajos presenciales en grupo, ahí podía conversar con mis compañeros. No participé en las actividades online.

El profesor del C2 usó como estrategia resolver directamente en las clases presenciales las actividades que estaban diseñadas para ser trabajadas en línea. Esta decisión de trabajar las actividades en línea en un laboratorio de computación resulta una opción interesante, porque genera un acompañamiento presencial y una práctica guiada de los estudiantes la que, sin embargo no se evidencia que los alumnos le dieran continuidad fuera de clases, más bien representó una oportunidad de seguir por criterio propio desarrollando las actividades dado que quedaban disponibles en línea.

- C2-E1: Algunas de las actividades en línea tenían vínculo con las clases presenciales.

- C2-E2: Nos enseñaron distintos tipos de carta de presentación, en clases y por Internet.

- C2-E3: Las actividades en línea las realizamos en clases y con el profesor presente en el laboratorio de computación.

- C2-E4: A veces el profesor decía "lo dejamos hasta aqui", pero como el sitio estaba abierto uno lo podía seguir trabajando en la casa.

En el C3 constatamos en los testimonios de los estudiantes una clara intencionalidad del profesor de articular las clases presenciales con las actividades online. En las primeras actividades en línea el profesor marcó un ritmo de trabajo generando un liderazgo directivo para que los alumnos realizaran las actividades en línea, todos los resultados de ellas debían exponerlos en clases. Esta dinámica se dio en la mayor parte del semestre, decayendo hacia el final. Los estudiantes al inicio no captaron la vinculación entre las actividades presenciales y las actividades en línea, ni que los aspectos evaluados en los informes están integrados en las actividades en línea y presenciales.

- C3-E1: Cada actividad se relacionaba con las clases, quizás hubo un desfase o desorden, pero todas se trataron en cada clase.

- C3-E3: También las presentaciones en la sala, uno ve la cara del compañero, no como en la primera actividad, que uno veía el comentario y aún no sabía el compañero que lo había enviado. 
- C3-E4: Un tema muy importante es la presión que pone el profesor para que se haga la actividad. Porque al principio cada vez que se hacía una actividad tenía que salir a exponer cada grupo. Pero ya como en la séptima u octava actividad, se perdió eso. Y eso no es por culpa del profesor, es porque además de las actividades, tenía que pasar la materia.

- C3-E5: Muchas actividades en línea se basaban en las mismas clases.

- C3-E6: Todo tenía relación. Las actividades en línea se relacionaban con las actividades que hacíamos en clases y el informe con las actividades en línea.

- C3-E7: Yo pensé que el informe uno iba a ser aparte, de otra temática, y al final era lo mismo que las actividades en línea, entonces uno al principio no ve la vinculación que existe.

Los profesores de los grupos control no consideraron el trabajo fuera de clase de los alumnos. El profesor es el encargado de exponer y abordar los contenidos y orienta la ejercitación de los alumnos sólo durante las clases.

\subsection{Actividades de evaluación}

La evaluación orienta el desempeño de los alumnos dado que entrega los criterios de desempeño, los que deben ser capaces de hacer con lo que aprenderán. Por otra parte, predomina en los estudiantes la motivación orientada a satisfacer metas extrínsecas con marcado valor instrumental, es decir realizaron las actividades en línea en la medida que percibieron cómo estas eran calificadas y tenía incidencia en la aprobación de la asignatura.

- C1-PP: Tuve que colocar nota, ya que en las primeras actividades no entregaron nada, no había una retroalimentación respecto del trabajo.

- C3-PP: Las actividades en línea las evalué a través de informes. Es una ventaja de la que ellos no se daban cuenta. Desvinculaban la evaluación de las actividades en línea.

- C3-PP: Evalué mediante tres informes, una exposición individual y una grupal. Fui subiendo la complejidad, es una estrategia que uno tiene. 
La modalidad de evaluación de las actividades en línea, en el caso del C1, no es informada desde el inicio de semestre lo que influyó en una baja participación de los alumnos. Además la evaluación se concentra hacia el final de semestre lo cual motiva un cumplimiento de las actividades, pero ya no produce el efecto pedagógico de proceso en el uso de la tecnología para promover el aprendizaje colaborativo y la comunidad de aprendizaje en línea.

- C1-E1: Las actividades eran evaluadas como nota de taller, se promediaban.

- C1-E8: Las actividades en línea son sumativas, equivalen al 15\% de la nota final.

- C1-E2: Hacia el final de semestre empezaron todos a participar, porque las actividades eran con puntos para finalizar una nota. Antes no les importaba.

- C1-E5: El profesor no especificaba si era con nota.

- C1-E6: Decían "de carácter obligatorio sumativo". Pero después no decían eso. De flojera, no las hice. Pero con nota las habría hecho.

- C1-E7: Hubo desmotivación para realizar las actividades en línea. Habría sido mejor la participación si hubiesen tenido evaluación.

La evaluación de las actividades en línea en el C3 se efectúa desde las primeras actividades, a través de la presentación oral en la clase presencial de los resultados obtenidos. Además se evalúan mediante tres informes escritos, tanto las actividades presenciales como las en línea, sin embargo los alumnos no percibieron desde el inicio esta estrategia de evaluación, es decir que el contenido de los informes como figura evaluativa se genera a partir de las propias actividades presenciales y en línea.

- C3-E1: Había un día en la semana en que exponíamos las actividades online. O sea, darla a conocer al curso.

- C3-E2: El hecho que no las revisaran frente al grupo produjo un relajo, se notó en el hecho que en la primera actividad éramos 32 y ya en la doce éramos cinco.

- C3-E3: Con mis profesores anteriores nunca vi mis equivocaciones hasta el día de la prueba. Aquí fui aprendiendo cosas clase a clase. Uno ya podía mejorar sus errores sin necesidad de la prueba.

- C3-E6: Al principio no nos dimos cuenta que los informes se iban generando con las actividades en línea y las presenciales.

- C3-E7: Creo que es bueno evaluar al líder y a los alumnos. 
En los grupos control predomina la evaluación tradicional mediante pruebas escritas, tipo test, respondidas individualmente en forma presencial. Además se evaluó exposiciones orales y la realización de debates, en ambos casos las pautas de evaluación no son conocidas previamente por los estudiantes.

\subsubsection{Herramientas}

\subsection{Uso de recursos tecnológicos disponibles en línea}

En los tres Campus usaron la misma herramienta tecnológica para realizar las actividades en línea. En el C1 se aprecia que los alumnos tuvieron dificultades de acceso y de administración de la herramienta tecnológica ya que el profesor delegó en los alumnos la generación de claves de acceso.

C1-PP: A lo mejor la herramienta tecnológica que usamos no es más adecuada, cambiaban la clave.

- C1-PP: Yo no soy un profesor tecnológico.

- C1-PP: Los estudiantes no manejan la manera de investigar en Internet, no saben utilizar Google o los otros buscadores, porque suelen hacerlo solo para comunicarse, nada más que eso.

- C3-PP: El hecho de poder manejar el texto de manera virtual, es notable que ellos lo adquirieran con propiedad, para aplicarlo con otros textos.

Los alumnos tienden a asumir que es una responsabilidad de ellos que la clave de acceso fuera única para el grupo curso y que algunos compañeros la cambiaran unilateralmente. En el C2 no se presentaron estas dificultades, el profesor administra el sitio de trabajo.

- C1-E1: Muchos no pudimos meternos.

- C1-E2: Nadie quería hacer las actividades online, había que crear un correo y nadie quería hacerlo. Entonces, la profesora decidió al azar, un compañero lo creó

- C1-E3: Se me perdió la clave y no pude hacer nada.

- C1-E4: La última no la hice, porque olvidé la dirección, todo. 
- E5: Hubo ese drama con el password, nadie lo sabía, después lo cambiaron y con eso se perdieron muchas actividades enviadas.

- C1-E6: Pero ese fue problema de nosotros, porque se cambiaba la clave.

- C1-E7: A mí me costó entrar. Nunca supe que existían las actividades hasta hace un tiempo atrás.

- C2-E1: El profesor tenía un sitio para desarrollar actividades.

- C2-E3: La comunicación fue vía Internet, estábamos todos conectados.

A fin de facilitar la comunicación, los estudiantes del C1, adicionalmente al correo formal usado en la asignatura, crearon por iniciativa propia una cuenta en Facebook, la que tampoco logró los resultados de comunicación expedita y en la participación en las actividades en línea.

- C1-E2: Es que hay muchos que no se conectan al Facebook que tenemos nosotros. Hay como seis que no entran mucho.

- C1-E4: Ha funcionado bastante bien.

- C1-E5: Yo soy más de estar en MSN, de entrar, entro 15 minutos diarios. Solo para ver lo del curso en el correo. No me meto mucho a Facebook.

- C1-E6: Es que de por sí, todo lo que avisamos en el Facebook, le llega al correo.

- C1-E7: Estoy incorporado al Facebook, pero no lo abro.

En los grupos control de los C1, C2 y C3 no hay un acercamiento sistemático al uso de recursos tecnológicos disponibles en línea. Los estudiantes no adquirieron criterios de búsqueda, selección y aplicación de información extraída de Internet. En la mayoría de las clases es el propio profesor que llevaba las guías de trabajo a la clase.

\subsection{Sugerencias de métodos y procedimientos para el uso de las herramientas} tecnológicas

En la revisión documental se verifica la presencia de sugerencias de métodos y procedimientos para el uso de herramientas tecnológicas, sin embargo en los C1 y C2 los alumnos no perciben la presencia de esta ayuda. El desarrollo asistemático de las 
actividades en línea no favoreció que los alumnos pusieran en práctica las sugerencias dadas. En el C3 sí se aprecia un mayor dominio de algunas herramientas y estrategias. Además reconocen la entrega de herramientas por parte del profesor para facilitar el trabajo, las cuales se habrían podido aprovechar en todo su potencial si algunas de las clases las hubieran realizado en el laboratorio de computación.

- C1-E1: No entendí las indicaciones, cómo se ponía la información para enviarla.

- C1-E2: Cuando buscamos en Internet, uno por lo general entra al primero que aparece.

- C1-E2: Quizás no es el material más fiable, pero es el que primero se encuentra.

- C2-E1: La asignatura nos ayudó a buscar información en Internet.

- C2-E2: No usamos ningún software para hacer esquemas o mapas conceptuales.

- C2-E2: El profesor nos recomendó un software para subrayar PDF, pero trataba de instalarlo y no se podía. Había una actividad con ese software.

- C3-E1: Quizás se necesitó una capacitación para usar algunas herramientas ocuparlo. Haber ido todos a un laboratorio.

- C3-E2: He aplicado algunos métodos con compañeros de otros cursos.

- C3-E3: Encontrar nuestro método de aprendizaje, saber cómo sacarle el mayor provecho al estudio.

- C3-E4: El profesor entregaba herramientas para facilitar el trabajo.

- C3-E6: Las indicaciones para evaluar páginas de Internet me sirvieron harto.

Como ya hemos constatado, en los grupos control los profesores no realizaron sugerencias de métodos y procedimientos para el uso de las herramientas tecnológicas y ellos mismos en sus clases las usan escasamente. Los alumnos reconocen usar fuera de clases varias herramientas de las redes sociales tales como Facebook y Twitter, pero no las tienen incorporadas en el trabajo académico en la asignatura de TCOE.

- C1-PC: Les pedí todos los trabajos por correo.

- C2-PC: Lo importante es que escriban bien. Mi especialidad es tecnología, pero yo sentí que no era necesario todavía. Lo mío fue manual, los trabajos escritos a mano, las clases en la sala con guías, todo muy manual. 
- C3-PC: En mis cursos creo no haber trabajado fuertemente el uso de Internet. Meterme en este tema, me habría tomado una buena cantidad de clases. Y no había ningún momento para poder incorporarlo.

- C3-PC: Utilicé la máquina de transparencias, porque me es más práctica que el proyector multimedia. Los alumnos no utilizaron otras tecnologías. Las exposiciones se hacen con papelógrafo.

El profesor del C1 usa la estrategia del dejar hacer y delegar a los alumnos desde el inicio la responsabilidad del manejo del sitio virtual de trabajo. Los alumnos tuvieron escasa conexión, no lograron valorar la tecnología en función del aprendizaje. La delegación de la administración de la herramienta a los alumnos generó una inestabilidad y falta de confianza ya que los alumnos borraron información. El profesor aparece más bien desentendido de las actividades en línea ya que para desarrollar las habilidades para trabajar en línea el incremento del control debiera ser paulatino e incremental.

El profesor del C1 acompaña presencialmente en laboratorios de computación el trabajo individual para la realización de las actividades en línea sin seguir una secuencia, ya que al estar publicadas todas en un solo documento, seleccionaban las que querían realizar, con lo cual no se logra una evolución en el logro de las habilidades para el trabajo colaborativo entre los alumnos.

\subsection{Sugerencia y uso de recursos digitales}

Al ser consultados los alumnos si el profesor les hizo sugerencias de algunos recursos digitales, no nombran herramientas concretas, sino más bien dan indicios de procedimiento entregados de cómo usarlas y del contenido de las actividades en línea. La baja participación que reconocen los alumnos del C1 no permite determinar la valoración que tienen de los recursos sugeridos por el profesor. En cambio, en los C2 y C3 hay una valoración del uso de herramientas tecnológicas, incluso de la más antigua en la historia de Internet como lo es el correo electrónico. 
- C1-E1: Me gustó encontrar páginas útiles para la carrera. Nos ayuda bastante.

- C1-E2: Los trabajos en grupo, ahí podía conversar con mis compañeros. No participé en las actividades online.

- C1-E3: No participé en las actividades online.

- C1-E4: Y lo online, no participé. Entré tarde y no sabía cómo ingresar.

- C1-E5: No sabía que había estilos de aprendizaje.

- C2-E1: A mí me gustó dar mi opinión libremente. Pienso que Internet es un arma de doble filo, en este caso se usó bien.

- C2-E2: Buscar una página que le sirva para la carrera, me agradó que se hiciera para los otros compañeros. Había una pauta para evaluarlas.

- C2-E3: Valoro el material del portal, todas las actividades que publicó el profesor.

- C2-E4: El profesor nos publicó una guía para acentuar palabras, corregir, puntuación, etc.

- C3-E1: Otra herramienta que aprendí a ocupar es el correo electrónico formal.

- C3-E3: Valoro la búsqueda de páginas que favorecían el estudio de una asignatura es algo que uno tiene que hacer por su propia cuenta, pero no lo hace

- C3-E5: Las actividades en línea nos ayudaron a saber como para buscar y tener mano cosas que nos sirven.

- C3-E6: Las actividades online son una pauta de lo que es casi obvio que uno tiene que hacer cuando uno entra a la universidad, pero no lo hacemos.

\subsubsection{Comunidad}

\subsection{Organización social de los alumnos}

Algunas de las actividades en línea promueven que los estudiantes practiquen más que el uso de la tecnología en sí misma, sino que trabajen juntos usando como medio la tecnología. Para ello, los estudiantes deben crear lazos, establecer normas basadas en la confianza.

Salmon (2004) propone tres motivaciones a considerar en el desarrollo de actividades en línea. La primera la denomina motivación aptitudinal referida a la convicción de los participantes sobre su capacidad de conseguir lo que para ellos parece una tarea difícil; la 
segunda es motivación intrínseca la que nace desde el propio sujeto, se ve reflejada en el reconocimiento y participación; la tercera motivación es la extrínseca, la que se logra dando alicientes y recompensas, o persuasiones negativas (castigos).

- C1-PP: Las actividades les permitió conocerse en aspectos distintos a los de la instancia presencial, noté una cohesión del grupo curso.

- C2-PP: En algunas actividades se generó un trabajo colaborativo, se fueron generando redes de apoyo.

- C3-PP: El profesor debe intervenir de una forma no invasiva, pero no dejarlo pasar para que el grupo siguiese funcionando.

Los testimonios de los estudiantes del C1 y C2 reflejan sensaciones sobre la imposibilidad de tomar parte con éxito en las actividades en línea. Si bien lo que se espera es la adquisición de la capacidad emocional y social de aprender juntos en línea, las habilidades técnicas, que se pueden adquirir y determinar según las necesidades, se transformaron en un obstáculo dado que no se generó la disposición a trabajar juntos en línea.

- C1-E1: Varios compañeros trataban de entrar al sitio, pero no sabían y no le preguntaban al profesor.

- C1-E2: Una dificultad para organizarnos es que usamos un correo a parte del institucional, pero todos nosotros sabíamos que teníamos actividades online.

- C1-E6: Yo le pedí ayuda a una compañera, pero estaba más perdida que yo.

- C1-E7: También está la falta de motivación de los alumnos. Porque son dejados y no se preocupan del mail del curso, solo del institucional. Con un poco más de dedicación se soluciona.

- C1-E8: Las indicaciones que dio el profesor es que había subido una actividad por Internet, y necesitaba que hiciéramos grupos con los que tenemos más afinidad. $Y$ ahí uno se pone de acuerdo.

- C2-E5: Yo las encontré interesantes, pero creo que les faltaba un detallito. Por ejemplo, había unas que había que hacer en grupo, pero dado que todos los compañeros no nos conocíamos o por otros factores, terminábamos haciéndolas individualmente. Pero aun así, nos servían, pero siento que faltó ordenarse, y en cursos más grandes fue más difícil, por un tema de afinidad. 
- C2-E6: Nosotros lo hacíamos de forma individual porque éramos cinco, entonces esas actividades en grupo no funcionaron mucho. Igual las hicimos.

Los estudiantes del C3 en la medida que experimentaron de manera más sistemática la experiencia de trabajo grupal, va quedando en evidencia la complejidad intrínseca del trabajo en equipo. La modalidad b-learning cuando generó espacios presenciales para la organización del trabajo grupal, produjo una gran satisfacción de los estudiantes, cuestión que presentaba ciertas dificultades en las actividades en línea. Los estudiantes reconocen la importancia del trabajo en equipo como una competencia a desarrollar para una adecuada inserción laboral y reconocen las dificultades que experimentaron en el logro de las tareas grupales.

- C3-E1: A veces era complicado el organizarse en línea, como grupo uno debía organizarse antes de conectarse. Tenía que ser primero presencial, y después uno recién lo hacía online.

- C3-E2: La interacción en clases era genial, pero en línea terminaban todos peleando, porque a veces había mala disposición de algunas personas.

- C3-E4: Creo que esta asignatura, más allá de que me sirva o no, cumplió con el objetivo, que es enseñar a comunicarse y vencer el miedo, entender que la única forma es atreviéndose.

- C3-E5: Para mí la dificultad era hacerlo en grupo. A mí nunca me han gustado mucho las cosas grupales, porque no me gusta depender de otra gente. La ventaja es que se aprende a trabajar en grupo, y es importante porque después en el trabajo vamos a necesitar trabajar en grupo, pero al principio fueron grandes desventajas.

- C3-E7: Cada grupo tenía su manera de recolectar la información. Nosotros teníamos un grupo en Facebook donde hacíamos las reuniones. Ahí juntábamos los aportes y publicábamos lo de cada uno, ahí elegíamos. Cuando se podía hacer eso, así lo hacíamos.

- C3-E8: El hecho de estar haciendo trabajos a través de un computador nos quita algo, quizás juntarnos en persona a hacer el trabajo, porque como grupo nosotros nunca nos juntamos. Se volvía algo como "tienes que mandar esto a tal hora" y delegar funciones. Se volvió algo más frío. 
El trabajo grupal en los grupos curso control se propone desde las primeras semanas de clases, de las doce actividades en línea, ocho de ellas están diseñadas para ser trabajadas grupalmente. Por ello, en menor o mayor medida en los grupos piloto de los tres Campus se promueve la organización social de los alumnos. En el caso de los grupos control de los tres Campus, el trabajo de los alumnos es preferentemente individual durante todo el semestre, sólo hacia el final, con ocasión de la evaluación del debate, los alumnos se organizan puntualmente para esta actividad en la que a su vez prima la intervención individual al momento de debatir los diferentes grupos.

- C1-PC: En la unidad de comprensión lectora, yo no solo veo el aspecto de lectura, sino comprensión de noticias, información, actualidad. Es importante aterrizarlos y hay que contextualizarlos en la información que tenemos hoy día en torno a su carrera.

- C3-PC: El hecho de que tengan que preparar trabajos, practicarlos, supone colaboración mutua.

\subsection{Contexto de referencia}

La asignatura TCOE, como lo indicamos en el análisis documental, pertenece a la línea curricular de formación general en esta carrera y en todas las carreras que está presente en su malla curricular. A su vez los profesores que dictan la asignatura realizan clases de esta asignatura en diversas carreras y tienden a no contextualizarla en la carrera respectiva. Estos antecedentes son relevantes al momento de revisar la existencia de una relación de las actividades presenciales y en línea con el contexto de referencia de la carrera. Los estudiantes no aprecian relación directa entre la temática y actividades de TCOE con el perfil profesional específico de su carrera, tanto en los grupos piloto como control.

- C3-PP: Al principio los alumnos pensaban que no tenía relación con su especialidad. Luego sintieron que fue tanto más difícil que un ramo de su especialidad, porque les demandaba tiempo y compromiso, y se daban cuenta que eso se podía aplicar directamente en su estudio diario. Entonces, no estaba desvinculado de lo que ellos hacen, me lo agradecieron bastante.

- C2-PC: Lo que más énfasis le doy es ortografía. 
- C3-PC: Creo que es una asignatura que es muy útil para los estudiantes, especialmente porque muchos de ellos vienen con serias dificultades en el desarrollo de sus habilidades de escritura, de comprensión de textos y de exposición oral.

\subsection{Sentimiento de comunidad}

El sentimiento y la vivencia de comunidad surgen en mayor o menor medida según la intencionalidad del profesor a través de las actividades. La visión sobre este punto es distinta en cada uno de los profesores de los grupos piloto, cuestión que vemos refrendada en la percepción que nos entregan los estudiantes a partir del párrafo subsiguiente.

- C1-PP: Yo creo que podría generar una comunidad de aprendizaje, depende de en qué parte de los contenidos de la asignatura.

- C2-PP: Si no hubiesen estado las actividades en línea, no se habría dado tanta cohesión.

- C2-PP: Desarrollaron en algún grado un mayor nivel de colaboración, más que en los grupos control, en los que no hubo este acercamiento de estar enfrentados a un tema común, entonces fue una cosa de socialización que se dio en ese grupo.

- C2-PP: A través del computador se estableció una relación afectiva.

- C3-PP: Las actividades en línea les permitió conocerse tempranamente. Después con la autobiografía, con los sitios que representan, de inmediato uno ya tenía un perfil de los jóvenes., $Y$ entre ellos mismos tenían su propio perfil, y ahí se generaba el tema de las afinidades y el de darse cuenta que había otros que eran muy distintos, y están conviviendo en el mismo espacio.

El sentimiento de comunidad en el C1 se dio de manera espontánea, más que por la intencionalidad de las actividades presenciales o en línea de la asignatura en estudio. Se aprecia una relación establecida a partir de la pertenencia a un grupo curso, más que una relación orientada por la existencia de objetivos o resultados comunes ante una actividad.

- C1-E2: Ahora hay mayor confianza.

- C1-E3: Ya hemos pasado más tiempo juntos.

- C1-E4: En las disertaciones hay menos errores. 
- C1-E5: Pero el compañerismo no se aplicó mucho acá, porque si yo cambio la clave sin decirle a nadie. Hay un tema de confianza de por medio.

- C1-E6: No hay problemas dentro del curso. La relación con todos es buena. No son todos amigos, pero hay buena relación de compañeros.

En cambio en el C2 se aprecia una clara influencia de las actividades en línea en el desarrollo de algunos elementos del sentimiento de comunidad. Algunas de las actividades les permitieron conocerse entre ellos más que en otras asignaturas.

- C2-E3: Yo creo que nos ayudaron a conocernos más, porque, por ejemplo, había una actividad en línea de decir qué personaje público te llama la atención, o con quién te identificas. Ayudaron a conocernos vía Internet.

- C2-E4: Esta asignatura nos permitió conocernos más que en otras asignaturas.

- C2-E5: En esta asignatura conocí a mis compañeros, sus intereses, en fin.

En el C3 la influencia de las actividades en línea es mayor que en los otros dos Campus en la generación de un sentimiento de comunidad, si bien los estudiantes no perciben con toda claridad si es intencionado por parte del profesor, sí reconocen que las actividades en línea les hacen sentirse más integrados al grupo porque conocen mejor a sus compañeros en distintas facetas, se ha generado una conexión, un sentido de respeto por los compañeros y de intercambio ("incluso para mí que soy de otra carrera, en ningún momento me sentí aislado").

- C3-E1: No sé si era la finalidad, pero de todas las asignaturas ha sido la única donde se integra al curso completo, todos nos conocimos. Las actividades al ser virtuales, más allá de leerlas todas uno se hacía una imagen de la gente, después al armar el grupo, exponer y debatir hizo que a lo mejor no sé los nombres, pero los puedo identificar. En la única asignatura donde me siento integrado es en ésta.

- C3-E2: A veces uno es muy cerrado y trabaja solo, porque mezclarse con más personas requiere dedicarle tiempo no solo a mí trabajo, sino de lo que va a entregar cada uno.

- C3-E3: Yo valoro el respeto que existe entre los compañeros. 
- C3-E4: Uno forma parte del interés de los demás. En el curso se ha dado una conexión tan rica, que a todos nos importa lo que le pasa al del lado. Hay un respeto único en esta asignatura más que en las otras.

- C3-E5: Intercambio de conocimientos muy bueno en el curso. Incluso para mí que soy de otra carrera, en ningún momento me sentí aislado.

- C3-E6: Fue más bien una clase para compartir experiencias.

- C3-E7: Las actividades a mí me ayudaron a trabajar en grupo y a conocer a mis compañeros en distintas facetas.

Contrasta de manera significativa el logro del sentimiento de comunidad de los grupos piloto con los grupos control, ya que en estos últimos durante el semestre no hubo actividades intencionadas para el logro de una integración social y académica de los estudiantes. Si bien reconocen algunas actividades al inicio de semestre, por ejemplo la presentación personal, pero fue muy puntual en la primera clase y sin diferenciación de cómo se realizó en las demás asignaturas. La autobiografía sólo fue realizada en algunos grupos del C3 y sólo fue revisada por el profesor. Hacia el final de semestre, como ya lo habíamos señalado, los estudiantes realizaron un debate grupal, el que no estimula el despliegue del sentimiento de comunidad. La integración social de los alumnos se da espontáneamente en los grupos control perdiendo la oportunidad de influir desde el curriculum en el desarrollo de habilidades para saber cómo relacionarse, cómo intervenir (conjunto de habilidades y destrezas cognitivas, emocionales, sociales y procedimentales que permiten aplicar el conocimiento que van adquiriendo en la asignatura). La capacidad de organización ayudando a los estudiantes para que aprendan las ventajas de trabajar conjuntamente en línea y ayudarles a conocer la forma de hacerlo, especialmente cómo cada uno puede contribuir al trabajo en grupo, sino más bien están los profesores centrados en el contenido conceptual.

- C2-PC: Nosotros hasta salíamos al patio a hacer cosas lúdicas para una mejor comunicación.

- C3-PC: Se da la instancia de conocerse cuando se habla de ciertos temas, a propósito de la lectura del periódico, se plantean temas y ahí los alumnos se plantean respecto de lo que piensan. Creo que al final el grupo curso se conoce bastante por la asignatura. 


\subsubsection{Normas y reglamentos}

\subsection{Normas de funcionamiento establecidas por los grupos de trabajo}

La opción de que las normas de funcionamiento fueran establecidas por los propios grupos de trabajo, es el componente del modelo de la Teoría de la Actividad que ha tenido menor nivel de avance en la experiencia estudiada. En el C1 la irregularidad de la publicación de las actividades en línea y escaso nexo es estas con las clases presenciales, desconectaron a los alumnos de la realización de las mismas y no se generó la necesidad de coordinarse y establecer normas de funcionamiento.

- C1-PP: Mis alumnos participaron poco. Yo creo que debe estar dado por mi poca participación o preocupación por la actividad en sí. No cuento con los equipos para estar haciendo estas revisiones en clases, el acceso a la tecnología acá no es fácil.

En cambio en el C2 las actividades en línea las resolvieron individualmente durante las clases presenciales al trabajar directamente en el laboratorio. El profesor publicó todas las actividades en línea de una vez, en un mismo documento Word con lo cual los estudiantes respondían alternativamente las actividades que elegían, sin organizarse con sus compañeros de grupo de trabajo. El diseño de cada actividad en línea propuesta puede ser abordada en tres etapas: una primera etapa es individual la que se publica para que en una segunda etapa los integrantes revises el aporte de todos para que en una tercera instancia, realicen un consenso de la respuesta del grupo.

Al igual que el logro del sentimiento de comunidad, en el sentimiento de trabajo en equipo los alumnos del C3 logran un mayor avance que los C1 y C2, sin embargo no logran percibir la necesidad de coordinarse y establecer normas de funcionamiento, aunque valoran que las actividades en línea en cuanto que les facilita el conocimiento entre ellos, aprender unos de otros y cierta dinámica de trabajo en equipo.

- C3-PP: Si bien es cierto, en algún minuto los alumnos se sentían avasallados por las actividades, era por un tema de la organización del grupo. El grupo como tal no lograba, el líder no lograba condicionar bien los tiempos.

- C3-E1: Como era un sitio común uno se daba cuenta de los intereses de tus compañeros. 
- C3-E5: Al final siempre terminaba siendo un trabajo en equipo. Aprendíamos de otros.

- C3-E7: Yo creo que sin las actividades en línea estaríamos interrumpiéndonos, no habría afinidad.

- C3-E8: Al principio el profesor nos dio una pauta de trabajo, pero luego no la seguimos, por autonomía.

Los grupos control no tuvieron oportunidades a lo largo del semestre de poner en práctica las habilidades sociales a través del trabajo grupal, como la escucha activa y empática, la generación de una relación de confianza en la que cada integrante del grupo debe cumplir con las tareas asumidas en torno a una actividad significativa en la que se debe lograr un resultado grupal concreto que es compartido con todo el grupo curso. Sólo al final de semestre, puntualmente se organizaron para realizar un debate en el marco de una figura evaluativa que da pocas posibilidades para trabajar colaborativamente y resolver conflictos, ya que lo que se evalúa primordialmente es la expresión oral y la argumentación.

- C2-PC: Trabajamos muchas guías grupales, entre ellos mismos se los revisan. Con guías, exposiciones, y aparte de exponer tienen que presentar trabajos escritos. Es mejor que opinen entre ellos acerca de la ortografía, porque si se los dice uno a veces les da vergüenza, y no lo corrigen, lo evaden y siguen teniendo mala ortografía.

\subsection{Normas de funcionamiento establecidas por el profesor}

Las normas de funcionamiento establecidas por el profesor están al servicio de un trabajo sistemático, orientadas al proceso. Las normas contenidas en las actividades en línea en el C1 se diluyeron por la escasa participación de los alumnos y porque ellos tendieron a establecer normas de funcionamiento sin la guía del profesor las que tampoco funcionaron.

- C1-E1: No participé en las actividades online.

- C1-E4: Algunos dejaron de revisar si había actividades.

- C1-E6: Realicé solo una actividad online. 
- C1-E7: Las exposiciones fueron lo mejor (...). Y lo online, no participé. Entré tarde y no sabía cómo ingresar.

- C1-E8: Yo participé en la primera no más, de las técnicas de estudio. Después me dio flojera participar. Después del cambio de contraseña no me conecté más. No la sabía. En el muro publicaron que casi nadie entraba.

Los alumnos del C2 si bien percibieron ciertas normas de funcionamiento establecidas por el profesor, en la práctica primó el trabajo individual autónomo y no lograron trabajar persistente y sistemáticamente en equipo.

- C2-E1: El profesor nos daba sugerencias para organizarnos.

- C2-E2: Éramos autónomos, el trabajo estaba pauteado

Como ya hemos revisado en las categorías anteriores, la mayor sistematicidad de las actividades en línea en el C3 ayuda a los estudiantes a percibir las normas de funcionamiento establecidas por el profesor, sin embargo en sí mismo no resuelve las dificultades de organización y cumplimiento de los compromisos por parte de los integrantes del equipo.

- C3-PP: Viendo lo útil que puede ser cuando alguien se compromete con la norma, yo planteaba una norma básica, y las demás tenían que surgir del grupo. Eso generó cosas que se podían y no se podían hacer. Entonces eso enriquecía, porque estaban involucrándose sin querer ellos estaban poniendo las normas de su funcionamiento.

- C3-E1: Desde un principio el profesor estableció el líder y el secretario.

- C3-E2: Hay que aprender a organizarse online.

- C3-E3: Sería bueno que las personas tomaran conciencia, porque a veces hay tan mala disposición que no hacen los trabajos.

Los profesores de los grupos control están centrados en su propio desempeño, más que en ofrecer estrategias de organización de los estudiantes.

- C1-PC: Todo depende de la motivación, la que nosotros provoquemos en los alumnos pueden influir en hagan trabajos fantásticos. Si nosotros estamos bien motivados y sabemos colocar el objetivo en su formación profesional y lo ve importante, se va a preocupar. 


\subsubsection{División del trabajo}

\subsection{Roles de los alumnos y roles del profesor}

El rol de los alumnos aparece explicitado en el diseño de las actividades, la información no llegó oportuna y claramente a los estudiantes. En el C1 tenían una noción de que debían formar grupos, definir un líder y un secretario por grupo. En el caso del C3 si bien las indicaciones del profesor ayudaron a los estudiantes a definir roles. Un elemento común en los $\mathrm{C} 1$ y C3 es que los alumnos esperan de parte de los profesores una conducción más directiva en la formación de los grupos, la definición de los roles y la entrega de dicha información.

- C1-PP: Entonces cuando llegan acá son muy poco participativos, muy para adentro. $Y$ yo aprendí que las primeras clases uno debe ser muy dinámico, yo trato de mentalizarlos.

- C3-PP: Los grupos que tenían líderes positivos, lograron cimentar una buena comunicación.

- C1-E1: Yo no tuve líder en mi grupo.

- C1-E2: Nos llegó una información que decía "elijan un líder y un secretario que haga la sintesis".

- C1-E3: Muchos no sabían tenían que hacer grupos, entonces estaban perdidos.

- C1-E4: La falta de participación se debió a una falta de comunicación con el profesor.

- C1-E5: Encuentro que hubiese sido mejor que el profesor eligiera los grupos, porque así hubiésemos tenido una mejor relación con todos.

- C3-E1: Hicimos varios trabajos donde nos sugirió nombrar un líder y un secretario, formas de trabajo, en ese tema estuvimos bien respaldados.

- C3-E2: De la actividad cinco en adelante se perdió la presión que ejercía el profesor hacia los que no realizaban las actividades. Como no había la mano firme del profesor, la gente simplemente no la hacía.

- C3-E3: Cuando teníamos que exponer siempre salía la misma persona. Quizás cambiarlo por persona.

- C3-E4: El líder habría que mantenerlo y el secretario rotarlo en cada actividad. 
- C3-E5: El líder es importante en el grupo, porque si hay liderazgo ayuda a todo el grupo.

- C3-E6: Que el profesor le dé más orientación a los líderes.

En los grupos control, como ya hemos constatado, el desarrollo de la asignatura se centró en la exposición de contenidos, con escasas actividades en las que se les ceda el control a los alumnos, por ello no verificamos que los roles establecidos son los tradicionales de la clase centrada en el profesor y el estudiante con una tendencia a ser pasivo, participando ocasionalmente.

\subsection{Transferencia del control de la actividad del profesor al alumno}

El diseño de las actividades en línea propende a lograr la transferencia del control de la actividad del docente al alumno, aspecto que se ve cierto nivel de logro en el C3, ya que algunos alumnos valoran la intencionalidad del profesor de hacerlos cada vez más partícipes de la clase y del control de las actividades presenciales y en línea. En cambio, para otros alumnos es más adecuado que el profesor les asigne los roles a desempeñar en el trabajo grupal, con lo cual se evita la natural comunicación, negociación y conflictos que forman parte del trabajo grupal.

- C2-E1: Todos logramos trabajar. Cada uno daba su opinión y ayudaba, y se mantuvo durante todo el semestre, porque conocimos a las personas, cada vez trabajamos mejor.

- C3-E2: Lo que más rescato es la dinámica, en la clase el profesor era parte del equipo, nunca fue autoritario. Si nosotros podíamos hacer la clase, mejor para él.

- C3-E3: Lo que ayudaría harto sería que dentro de la evaluación, el líder tuviese la oportunidad de dar comentarios sobre cada uno.

- C3-E3: Yo estoy de acuerdo con rotar al secretario, pero no al líder. Por un tema de liderazgo, de repente es muy poco el tiempo que se le da al líder, a veces está recién desarrollando sus habilidades y lo cortan.

- C3-E4: Es más fácil desarrollar la habilidad de secretario porque te dicen una pauta que tienes que seguir. 
- C3-E5: Yo digo que el profesor asigne cada semana el secretario.

- C3-E6: Pero después vamos a depender del profesor. No es la idea. Están diciendo que es bueno que el profesor elija, pero la idea de ese grupo es tener la capacidad de hacer eso.

- C3-E7: La autonomía depende de la conformación de los grupos. Otros grupos tuvieron problemas.

Las concepciones del rol del docente y el rol del estudiante en la educación superior que declaran los profesores participantes en la investigación, condicionan las acciones concretas que ellos realizan y en las que encomiendan a los alumnos. El profesor tiende a estar centrado en cubrir los contenidos de la asignatura. Se aprecia en los grupos piloto que no incorporan intencionadamente el desarrollo de habilidades, especialmente en el caso de los profesores de los Campus 1 y 2.

- C1-PP: La revisión de las actividades en línea a mí me significaba quitarle tiempo a los contenidos de mi asignatura, que es muy poco.

- C1-PP: No puedo estar chequeando semanalmente, eso por mi visión de la docencia. Porque se supone que si están en la universidad ellos deben ser más autónomos.

- C2-PP: Tenía que conversar con los alumnos, decirles que eso les sirve y no puede ser de otra manera.

- C3-PP: Los que no lograron enganchar en el tema se dieron cuenta tarde que dependía de ellos más que del modelo; el modelo funciona, pero funciona con mayor efectividad si uno se involucra bastante.

- C3-PP: Vienen de un sistema muy paternalista y se encuentran con uno donde tienen que hacer cosas, investigar, dar fe de lo que hacen y dicen. Es notable el avance, alcanzaron una alta autonomía.

- C3-PP: Creo que el modelo está dado para que aprenden a trabajar en grupo y de manera autónoma. Inicialmente puede que haya algo de reticencia por el hecho de entrar a la educación superior. 


\subsubsection{Valoración global}

\subsection{Expectativas y satisfacción de la asignatura}

Inicialmente la asignatura tiende a no ser valorada en sí misma ya que no pertenece a la línea curricular de especialidad de la carrera, sino a la línea de formación general. En C1 la satisfacción de la asignatura se centra en las actividades presenciales asociadas a la expresión oral y control de la ansiedad. No se aprecia una valoración de la experiencia que tuvieron en las actividades en línea, si las valoran como una posibilidad, siempre y cuando el profesor realice una adecuada planificación y conducción de las mismas.

- C1-PP: A mí se me olvidaba entre muchas cosas que tenía que hacer. Llegaba el día lunes y se me olvidaba enviar la actividad. Y empezaba a atrasarme.

- C1-E2: Me ayudó el manejo de los nervios en las disertaciones.

- C1-E4: Lo que más rescato de la asignatura fue aprender a expresarse bien.

- C1-E5: Nos enseñó técnicas para la respiración, para poder conversar más fluidamente.

- C1-E6: Actividades online, pero que el profesor lo controle.

- C1-E7: Hacer algo para aumentar la personalidad.

En el C2, si bien los estudiantes valoran las técnicas de estudio y de comunicación escrita, señalan la ausencia de la enseñanza de técnicas de expresión oral.

- C2-PP: El trabajo online lo realizamos de manera presencial, con lo que se genera una relación con los alumnos. Uno no se queda desvinculado por mandarles actividades en línea.

- C2-E1: Tratamos más que nada las técnicas de estudio y de comunicación.

- C2-E2: De las actividades en línea el tema que más me ayudó fue cómo estudiar.

- C2-E3: Pensé que se trataría de técnicas de como modular la voz o enfrentarte a los demás

- C2-E4: De comunicación oral no tuvo mucho, debería complementarse.

- C2-E5: Todos tenemos miedo de hablar en público y sería bueno reforzarlo.

- C2-E6: El tema escrito se reforzó, funcionó bien, pero faltó oral. 
Nuevamente en el C3 encontramos un mayor nivel de satisfacción de los estudiantes en diversos aspectos de la asignatura, la que les ayudó a mejorar la expresión oral y escrita, las técnicas de estudio y en algunos casos fue la que genera mayor cercanía entre los estudiantes y con el profesor. Varios alumnos valoran cómo la asignatura tributa a otras asignaturas a través del logro de ciertas habilidades para efectuar un trabajo autónomo aplicable en otras asignaturas.

- C3-PP: Me sentí bien con los logros de los estudiantes, el hecho de manejar la emocionalidad, sentirse ellos satisfechos y agradecidos porque aprendieron a ver la vida de otra forma.

- C3-E1: Encontré muy buena la asignatura, porque al fin y al cabo a nosotros nos sirve como expresarnos, hablar, escribir.

- C3-E3: De todas las asignaturas que tuvimos en el primer semestre, ésta es la que a uno le entrega más satisfacciones. La que encuentro de mayor cercanía.

- C3-E4: Las técnicas de estudio, grandísimo aporte para todos en general.

- C3-E5: En expresión oral, ha habido muchos avances, o sea, ver compañeros de cómo entraron a la asignatura, y cómo se están expresando ahora es súper gratificante.

- C3-E1: El balance de la asignatura es positivo porque todos aprendimos solos.

- C3-E2: Para mi carrera creía que era una pérdida de tiempo. Pero a través de las clases y actividades en línea me he dado cuenta que son herramientas que después le sirven a uno en el mundo profesional.

- C3-E3: La perspectiva al inicio de la asignatura es que no pensé iba a importar tanto, fue la que más utilicé en general. Me cambió la visión totalmente.

- C3-E4: Me gustó que fuera didáctico y práctico, porque mucho conocimiento y después sin poder juntarlo, creo que este ramo fue el que sirvió para juntar todas las otras asignaturas.

En los grupos control el grado de satisfacción es homogéneo y tienden a coincidir en los aspectos que valoran de la asignatura, tales como: mejorar la expresión oral y escrita, la redacción de ciertos tipos de documentos. Sugieren que la clase sea más participativa, no tan centrada en la figura del profesor y dar más oportunidades para las actividades de 
expresión oral. No realizan ninguna mención espontánea del uso de herramientas tecnológicas.

- C3-PC: En el momento de estar dictando la asignatura, la valoración puede no ser tan potente, y también es diversa porque depende mucho de las carreras, hay algunas donde se valora más que en otras.

\subsection{Motivación hacia las tecnologías y el aprendizaje en línea}

Los estudiantes, por un lado se encuentran fuera de clases inmersos en las tecnologías de la información y las comunicaciones, y por otro en las clases presenciales se ven enfrentados a la forma tradicional de comunicación de la clase frontal, la que sigue siendo valorada. Al valorar la motivación hacia las tecnologías y el aprendizaje en línea como efecto de esta experiencia b-learning, obtuvimos dos resultados muy disímiles. Por una parte, en el C1 los alumnos no valoraron las tecnologías como herramientas facilitadoras del aprendizaje, incluso sugieren no usarlas en la asignatura. En cambio en el C3 la visión es diametralmente opuesta, ya que las tecnologías les permitieron conocerse entre ellos, a organizarse en línea, ahorrar tiempo y sacarle más partido a Internet en función del aprendizaje.

- C1-PP: Con la tecnología todo cambia, uno como profesor también, uno necesita capacitarse y necesita tecnología junto con la pedagogía.

- C1-E1: Las actividades en línea no funcionaron tan bien.

- C1-E2: No fue una buena experiencia.

- C1-E3: Creo que resultan mejor estos trabajos en la clase. Online hay distractores, Messenger, Facebook.

- C1-E4: Las herramientas tecnológicas que existen en Internet opino que no ayudarían a esta asignatura.

- C1-E5: Tengo problemas con esto de Internet, yo estoy trabajando y es difícil organizar el tiempo.

- C2-PP: Lo que más te gustó es que aprendí mucho de mis alumnos. A veces me sorprendían. Yo no soy experto en informática, me manejo a nivel de usuario. Fue 
un desafío enorme, he tenido ciertas dificultades desde el punto de vista de las tecnologías.

- C2-E1: En realidad, me gustaron varias cosas. La conexión en línea con mis compañeros, conocernos más.

- C2-E2: Nosotros podíamos hacer lo que quisiéramos, estábamos todos conectados. Fue más entretenido.

- C2-E3: De hecho yo ahora lo estoy haciendo para un trabajo de laboratorio, nos estamos organizando por Internet, igual que en esta asignatura.

- C2-E4: Sugerimos que se sigan aplicando las actividades en línea.

- C3-PP: El próximo año de todas maneras voy a implementar el modelo. Si es necesario contar permanentemente con una proyectora multimedia en la sala. Hoy en día no pienso en una clase donde yo funcione sin Internet o con manejo de TIC.

- C3-PP: Creo que a partir de la guía que uno les entrega pudieron desarrollar ciertas habilidades, para las que daban por hecho que bastaba con conocer un computador, y no es así.

- C3-E1: Una de las grandes ventajas que tuvieron las actividades en línea es que ayudó a muchos compañeros que no se manejan en el tema de trabajar en línea.

- C3-E2: Aprendimos a trabajar en línea y a ser un poco más tecnológicos,

- C3-E3: Hay una desventaja que es el roce social, porque el debatir, conversar cara a cara es muy distinto a estar en línea.

- C3-E4: Es una ventaja el ahorrar tiempo, el conectarse todos a una hora y no complicarse en el "no puedo", uno lo hacía donde estuviera.

- C3-E5: Pero sí tiene como desventaja la comunicación afectiva.

- C3-E9: Aprendimos a sacarle provecho a Internet, no teníamos idea de hacerlo.

Finalmente, en los grupos control, dado el escaso contacto con las tecnologías en la asignatura, tanto en clases presenciales como fuera de ellas. Algunos profesores usaron el proyector multimedia así como también otro docente el único recurso que utilizó fue el retroproyector, incluso, usó recursos "antitecnológicas como los papelógrafos". Los alumnos de los grupos control no tienen ninguna valoración, ni positiva ni negativa, en cuanto a la motivación hacia las tecnologías y el aprendizaje en línea. 
- C2-PC: Los alumnos agradecen, dicen que el profesor se preocupa de cómo escriben, de enseñarles a hablar.

- C2-PC: Valoran la asignatura como un apoyo para ellos, para su futuro laboral, que tienen que hablar bien, que tienen que escribir bien; ahí recién reconocen la asignatura como necesaria. Y ahí recién se vuelve grato el ambiente. Pero la primera llegada de Técnicas de la Comunicación es mala, siempre. Es mal recibida. 


\section{CAPÍTULO 7 CONCLUSIONES}

En este capítulo expondremos las principales conclusiones integrando los resultados de los estudios cuantitativo y cualitativo los que hemos contrastado con el marco teórico y el estado del arte, a fin de identificar y constatar tendencias, hallazgos y proyecciones de investigación. El objeto de estudio es dinámico y cambiante dada su dualidad tecnológica y pedagógica cuyo enfoque de análisis lo hemos situado desde el uso de las nuevas tecnologías como generadoras de espacios o entornos virtuales integradas a las instancias presenciales como una oportunidad para elevar la calidad y pertinencia del aprendizaje.

El problema de investigación que nos plateamos es si la implementación pedagógica de la modalidad b-learning favorece el logro del aprendizaje percibido de competencias instrumentales, tecnológicas e interpersonales en estudiantes de primer año en una carrera de ingeniería. Además queríamos determinar si existe relación entre nivel de satisfacción en el uso de tecnologías como herramientas de aprendizaje y el diseño pedagógico orientado a la interacción y desarrollo de actividades virtuales.

Para lograr el objetivo general nos planteamos dos objetivos específicos los que guiaron el análisis crítico del uso pedagógico de los espacios virtuales y presenciales en la modalidad blended learning en el caso estudiado. Estos mismos objetivos guiaron el estudio del estado del arte y la selección del marco de referencia teórico más adecuado al cumplimiento de los objetivos de investigación según la naturaleza compleja de la modalidad blended learning en el actual contexto y demandas formativas que recibe la universidad, atendiendo a los diversos acuerdos internacionales de movilidad, calidad y acreditación. Hemos obtenido conclusiones relevantes en los planos teóricos, metodológicos y pedagógicos las que hemos agrupado en los apartados que exponemos a continuación. 


\section{Evolución de la investigación de lo tecnológico a lo pedagógico}

Llevamos a cabo una revisión de los elementos que aportan las investigaciones de tal forma que nos permitiera comprender cómo ha sido abordado su estudio. Si bien el $b$-learning es soportado por un componente tecnológico, comprobamos que las actuales tecnologías resultan rápidamente obsoletas, una conclusión relevante es que en la implementación del b-learning no se trata de ganar una carrera tecnológica delimitando los usos particulares para cada tecnología, sino de realizar un análisis crítico de cuáles son los marcos pedagógicos más adecuados para que las tecnologías tengan sentido en contextos académicos de actuación en la educación superior, ya que la tecnología en cuanto herramienta en línea, tal como apunta Asinsten (2013), potencia o amplifica la intencionalidad pedagógica del profesor.

Constatamos que el concepto $b$-learning presenta una diversidad de usos y acepciones por parte de los investigadores con énfasis en diferentes focos y aglutina muchas iniciativas formativas, como la combinación de los tradicionales métodos de enseñanza presencial y la enseñanza en línea o a distancia. Otros autores ponen el acento en las actividades de aprendizaje que impliquen una combinación sistemática de interacciones cara a cara e interacciones tecnológicamente mediadas entre estudiantes, profesores y recursos de aprendizaje o el simple uso de espacios virtuales para que los alumnos realicen actividades individuales y/o grupales como apoyo a la clase presencial, desde la cual se administran todas ellas. Los denominadores comunes de todos estos usos del concepto $b$-learning son la clase o interacción presencial y el apoyo e interacción en línea mediante el uso de diversas tecnologías, haciendo hincapié la expresión b-learning en el papel central de las tecnologías informáticas para el logro de aprendizajes, constituyendo una dualidad pedagógica y tecnológica, aunque al momento de diseñar un curso o una experiencia de aprendizaje b-learning, el énfasis es la pedagogía, no la tecnología (Graham, 2006, 2014).

Aunque inicialmente la preocupación en la temática de los investigadores es el estudio de la instalación de plataformas tecnológicas por parte de las instituciones (su funcionamiento técnico y las adaptaciones y percepciones de los profesores y alumnos), hoy ya forman parte de la estructura de las instituciones de educación superior con lo cual los temas de 
investigación están transitando, se están moviendo hacia los aspectos metodológicos y pedagógicos para establecer cómo impactan en el logro de los aprendizajes comprometidos, de tal forma de responder a la necesidad de diseñar nuevas propuestas formativas en los nuevos contextos tecnológicos y de cambios ante las demandas formativas en el marco de acuerdos nacionales e internacionales por lo que se ve influida la educación superior.

Validación de marco de referencia teórico para el análisis crítico-pedagógico del $b$ learning

Dada esta necesidad de realizar un análisis crítico del b-learning como objeto de estudio, de naturaleza dual, recurrimos a teoría de la actividad, la que nació como un enfoque filosófico para analizar diferentes formas de la práctica humana como procesos de desarrollo, centrada en la actividad real la que une al organismo con la realidad circundante y determina el desarrollo de la conciencia. En nuestra investigación la teoría de la actividad se ha comportado adecuadamente como marco conceptual con el que hemos efectuado el análisis crítico de los elementos pedagógicos, sociales y tecnológicos del caso de estudio $b$ learning, en una misma unidad de análisis, la actividad, cuestión sugerida por varios autores, entre ellos García del Dujo y Martín-García (2002), ya que es la actividad instancia donde tienen lugar los procesos cognitivos y donde intervienen los individuos en interacción permanente con elementos mediadores que estructuran la experiencia humana, físicos, simbólicos y sociales. En esta actividad cuando una herramienta, tal como la tecnología, forma parte de ella o cuando el docente incorpora innovaciones metodológicas, la teoría de la actividad se convierte en un adecuado lente, es un buen macroscopio o una perspectiva de análisis. La teoría de la actividad constituye un aporte para estudiar el actual fenómeno de la educación, en el que los límites de la sala de clases se han tornado difusos al surgir el tercer entorno gracias a las tecnologías telemáticas. El espacio virtual es omnipresente, mientras el estudiante permanece en el aula presencial, a través de los diversos dispositivos tecnológicos interactúa simultáneamente con otras personas distantes físicamente sin estar sujeto a limitaciones gracias al entorno virtual configurado por el conjunto de estas tecnologías telemáticas. 
Entonces, en el caso de estudio, para efectos de su análisis, la experiencia de aplicación de un modelo b-learning en una carrera de ingeniería se ha concebido como un sistema de actividad cuyos componentes son, por un lado, la actividad, la que consiste en una jerarquía de acciones dirigidas a resultados esperados en términos de productos a lograr 0 problemas a resolver definidos en el curriculum del programa de estudios o carrera, en nuestro caso focalizadas en competencias instrumentales, tecnológicas e interpersonales. Por otro, el sujeto del modelo corresponde al individuo o grupo que está en el centro de la actividad educativa, y a la vez, al sujeto que media (profesor, tutor, compañeros). Este sujeto para lograr ciertos resultados que se propone el uso de artefactos, ya sea instrumentos físicos (máquinas, aparatos) y/o los mentales que median el proceso, tales como los conceptos clave, los métodos, los modelos teóricos y heurísticos. Hasta aquí tenemos un sujeto usando herramientas, físicas o mentales, comportamiento histórico del ser humano, las que serían elementos desarticulados si no tenemos en cuenta que el objeto del que hay que apropiarse o el objetivo que se quiere alcanzar, el producto físico o mental que se solicita lograr (destrezas, habilidades, competencias), regulan la actividad. Este es un de los principales aportes de la teoría de la actividad, organizar una actividad formativa a partir del objeto (el curriculum) desde el cual dirigimos todas las acciones para conseguir resultados del dominio de este objeto (evidencias de aprendizaje) usando herramientas, entre ellas, el tradicional contenido cultural del curriculum. Coincidimos con las conclusiones de varios autores, entre ellos Asghar (2013), Murphy y Rodríguez, 2008; Osorio y Duart, 2012) y Sam (2012), en cuanto a que la teoría de la actividad nos ofrece un marco conceptual sólido y práctico para estudiar de manera integral el nexo de las personas, la tecnología, la comunidad en línea y el contenido cultural.

De lo anterior deriva una conclusión relevante respecto al contenido cultural, el cual es concebido como un medio, una herramienta con el que interactúa una comunidad, un conjunto de individuos que van a realizar una actividad de aprendizaje (colaboración), para ello definen unas normas o reglas explícitas e implícitas de comportamiento que regulan las acciones e interacciones dentro de esa actividad (autonomía) y establecen la división del trabajo, es decir, la división de tareas y funciones entre los miembros de la comunidad, en las que se asume las divisiones de poder y estatus (autocontrol). En particular, cuando el contenido cultural se lleva al curriculum, se debe avanzar desde el contenido como dato, 
información o temáticas, al saber disciplinar, al saber epistemológico de las disciplinas estudiadas, a fin de que los estudiantes puedan mover transitar entre disciplinas desde el objeto de estudio. El tratamiento del contenido cultural en los grupos piloto de la investigación tienden a tratarlo como herramienta de la actividad, en cambio en los grupos control, es visualizado como un fin, como información a obtener.

\section{Diseño de la investigación acorde a la complejidad del objeto de estudio}

Dada la complejidad del objeto de estudio, concebido como actividad en la que el sujeto interactúa con el objeto para lograr un resultado junto a otros sujetos, según normas y división de tareas, usamos un modelo mixto de investigación, en el que concurren los enfoques cuantitativo y cuantitativo. El componente cuantitativo de la investigación nos dio la amplitud de estudio y de inferencias del caso de estudio y por su parte, el elemento cualitativo nos permitió profundizar y adentrarnos en el análisis crítico-pedagógico de los modelos blended learning en educación superior desde el discurso declarado de los sujetos y sus acciones registradas en la plataforma tecnológica. Concordamos con González Rogado et al $(2010,2013)$ en cuanto a la necesidad de aplicar metodologías de investigación mixtas, basados en metodologías empíricas que proporcionan a los investigadores nuevas teorías acerca de la nueva realidad educativa que nos encontramos hoy en día.

Una conclusión significativa es que el diseño de la investigación inicial que contuvo dos estudios paralelos, uno cuantitativo y otro cualitativo, cuyo análisis e interpretación de los resultados se integraban en la fase de las conclusiones, sin embargo la simultaneidad se produjo durante todo el proceso de investigación permeando mutuamente los dos estudios, consiguiendo así una mejor comprensión crítica del objeto de la investigación sobre la base del marco teórico y contextual.

\section{Implementación pedagógica de la modalidad b-learning}

El diseño pedagógico de la modelidad b-learning, que desprendemos del análisis documental efectuado en esta documentación, tiene como claro propósito ofrecer a los 
estudiantes un andamiaje, una práctica guiada de las actividades en línea con la finalidad de desarrollar grados crecientes de autonomía, por tanto el énfasis del caso de estudio lo hemos puesto en el componente pedagógico del $b$-learning. Los profesores de los grupos piloto reconocen que el diseño del modelo que implementaron consigue que los alumnos trabajen fuera de clases. En cambio los profesores de los grupos control quienes usan la estrategia de auto organización espontánea de los alumnos estiman que los alumnos no pueden trabajar por cuenta propia fuera de clases, con lo cual, tienden a no ceder el control de las actividades y del aprendizaje a los estudiantes, es el propio profesor que lleva a la clase el contenido y las guías de trabajo sin promover que los estudiantes adquirieran criterios de búsqueda, selección y aplicación de información. Existe una diferencia altamente significativa del grupo piloto respecto al grupo control en cuanto a que el profesor se preocupa por la participación fuera de clases de los estudiantes. Sí se debe avanzar en que las actividades y contenidos en línea estén relacionados, ya que la diferencia de apreciación en este punto, estadísticamente es sólo significativa entre ambos grupos.

En cuanto a la participación de los estudiantes en las actividades en línea es disímil entre los diferentes campus, lo que podría explicarse por el grado de conducción pedagógica de las actividades por parte del profesor, considerando las dispares orientaciones dadas por éste al inicio de cada actividad y la asistemática periodicidad de publicación de las mismas, debido a que tienen acercamientos distintos a la tecnología, determinados por su experiencia previa respecto al acceso y uso de tecnologías como apoyo a la labor docente, aunque valoran como novedoso y desafiante el $b$-learning. La valoración que realizan los alumnos del piloto respecto a que la organización de las actividades realizadas fuera de clases facilita el aprendizaje es altamente significativa, sí se requiere que las actividades en línea fomenten intencionalmente la participación colaborativa de los estudiantes.

\section{Estrategias de trabajo para enseñar y aprender en entornos $b$-learning}

El acceso a tecnologías de la comunicación en la institución objeto de estudio está resuelto, tanto por los dispositivos personales de los estudiantes como por los accesos a laboratorios 
informáticos, la cobertura total de conectividad a Internet dentro del campus y el acceso a la plataforma tecnológica como espacio virtual, tercer entorno, sin embargo las herramientas informáticas por sí solas no cambian automáticamente las metodologías de enseñanza. En este contexto tecnológico, el profesor en la universidad sigue teniendo un rol preponderante de motivación de los estudiantes para el uso de la tecnología en función de actividades académicas. Los estudiantes reconocen el valor de la tecnología, pero necesitan orientación del profesor en lo que respecta a un mejor uso para fines académicos, y en esta perspectiva, prefieren ambientes de aprendizaje b-learning, resultados coincidentes con varios estudios internacionales, entre ellos el estudio longitudinal ECAR 2004-2013 (Dahlstrom et al, 2013). Un resultado de la investigación de esta tesis es que los estudiantes de manera mayoritaria reconocen que el uso de tecnologías lo aprenden por cuenta propia o con la ayuda de amigos para un uso de interacción social, lo que representa para las instituciones educacionales una doble oportunidad, una de ellas es la capitalización del potencial de aprendizaje autónomo y colaborativo de los estudiantes en situaciones auténticas y significativas, así como integrar en el diseño de las actividades el dominio de uso que poseen de las tecnologías. Por otro lado, representa desafíos en cuanto a entregar las competencias procedimentales para utilizar las tecnologías de manera efectiva en tareas académicas. Cuando los estudiantes comprenden el alcance del uso de herramientas y aplicaciones tecnológicas para realizar tareas académicas, el dominio declarado de uso de tecnologías al inicio de semestre, disminuye hacia final de semestre, especialmente para producir trabajos académicos y organizar el tiempo de trabajo individual y colaborativo.

El uso de las herramientas de apoyo al aprendizaje por parte del profesor tiene una valoración altamente significativa en el piloto y significativa respecto a que el entorno en línea permita mejorar el proceso de enseñanza aprendizaje. No hay ninguna diferencia estadísticamente significativa entre el piloto y control en la existencia de instrucciones que ofrecieran pautas e indicaciones para resolver las actividades ni la realización de sugerencias para el uso de las herramientas tecnológicas por parte del profesor, llegando a percibir las tecnologías los estudiantes como distractoras al momento de realizar tareas académicas y, por otro lado, una de las variables con mayor logro es la capacidad para trabajar con otros usando tecnologías, resultados que obligan al análisis del diseño 
pedagógico integrado de las actividades académicas del aula y fuera del aula con apoyo de tecnologías, complementando el segundo entorno presencial, en el que aula ha resultado ser un sistema sorprendentemente duradero (Tiffin, 1997), con el tercer entorno virtual ofreciendo estrategias para trabajar con tecnologías.

La teoría de la actividad destaca las contradicciones históricas que acumulan los sistemas de actividad, como fuentes de cambio y desarrollo, entendidos como sistemas abiertos que al introducir nuevas tecnologías u objetos provocan contradicciones que abren la posibilidad de acciones innovadoras de cambio.

\section{Fortalecimiento de la figura del profesor}

Un elemento de gran interés pedagógico, que hemos extraído de nuestro trabajo es que, lejos de pensar en la desaparición o sustitución progresiva del profesor como efecto de la introducción de las tecnologías en los procesos de formación, aspecto que se ha acentuado en determinados momentos del pasado siglo, el inherente componente tecnológico de la modalidad b-learning fortalece el rol de diseñador de actividades de aprendizaje. Estas tecnologías no poseen en sí mismas cualidades educativas o pedagógicas, por tanto la figura del profesor es fundamental, porque apoya, guía y refuerza el sistema de comunicación e interacción que da sentido de pertenencia, ritmo de trabajo y un andamiaje de apoyo como valores intrínsecos de la enseñanza que no ha sido socavado por las tecnologías.

Desde que aparecieron las primeras universidades europeas en los siglos XI y XII, los principios básicos de la universidad han cambiado bien poco mientras que las nuevas tecnologías han aparecido y desaparecido, la forma y función de la universidad persisten. En aquellas universidades que vienen desde hace una década usando tecnologías constatan que la figura del profesor se fortalece, en nuevos roles, con nuevas competencias ya que los estudiantes plantean nuevas necesidades propias de las nuevas herramientas y estrategias metodológicas.

Los resultados ya señalados respecto a la implementación tecnológica y pedagógica del caso de estudio b-learning siguen la tendencia de las investigaciones sistematizadas en el 
estado del arte (De Jong et al, 2014; Dettori, 2007; Fernández, 2011; Llorente, 2008). Del mismo modo se verifica que en los modelos b-learning se explicita y planifica la carga de trabajo necesaria del estudiante para la consecución de los objetivos de un programa está constituida por el tiempo que asiste a clases y el tiempo de trabajo personal y/o grupal fuera del aula, el que en menor o mayor medida es programado y cuenta con un seguimiento mediante tutorías por parte de los profesores.

De esta perspectiva el b-learning es un desafío para los docentes porque aumenta el compromiso pedagógico: al utilizar b-learning los profesores deben resaltar su perfil académico como profesionales innovadores, asumiendo riesgos y desafíos para el beneficio de sus alumnos, centrado en el usuario y el refuerzo sistemático de las actividades de aprendizaje, comunicación, apoyo y evaluación

\section{Autocontrol y autogestión de la comunidad de aprendizaje}

El grado de sentimiento y la vivencia de comunidad de aprendizaje constatamos que surge en mayor o menor medida según la intencionalidad que da del profesor a través de las actividades. La visión en cuanto al rol que le compete al profesor respecto a este punto, es distinta en entre los profesores de los grupos piloto, cuestión que vemos refrendada en la percepción que entregan los estudiantes. Contrasta de manera significativa el logro del sentimiento de comunidad de los grupos piloto con los grupos control, ya que en estos últimos durante el semestre no hubo actividades intencionadas para el logro de una integración social y académica de los estudiantes. Esta es la variable menos lograda tanto en el piloto como en el control, no existen diferencias estadísticas significativas en los resultados. En estudios posteriores (El-Mowafy et al, 2013; Penalva, Rey y Llinares, 2011) a los resultados obtenidos en esta tesis, concluyen que la modalidad $b$-learning mejora de la participación de los estudiantes.

Sí bien en el diseño de las actividades se explicitan las sugerencias para que los estudiantes se organicen, logren el autocontrol y la autogestión, esta dimensión de la teoría de la actividad ha tenido bajo nivel de logro en los grupos piloto. Esto se explica porque los 
estudiantes esperan de parte de los profesores una conducción más directiva. Además influye la irregularidad de la publicación de las actividades en línea, junto a la falta de nexo de estas con las clases presenciales; la ausencia de monitoreo en la realización de las mismas; el predominio del clases expositivas a las cuales los estudiantes están habituados y valoran positivamente por sobre aquellas en que se les coloca en un rol activo. Asimismo se da la tendencia en los estudiantes a la ejecución individual de las tareas sin posibilitar el consenso de la respuesta grupal, con ello, no logran percibir la necesidad de coordinarse y establecer normas de funcionamiento. La división del trabajo en una actividad crea distintas posiciones para los participantes, e implica agentes con múltiples puntos de vista, intereses y tradiciones. Esta multiplicidad de voces posibilita vislumbrar fuentes de problemas y prácticas de negociación. Ello permite pensar cómo se negocian, modifican o cristalizan los modelos mentales de situación que construyen y ponen en interacción los agentes psicoeducativos en escenarios socioculturales concretos, tanto en el segundo entorno presencial como en el tercer entono virtual. Solo en un aspecto puntual se logra una diferencia altamente significativa el piloto respecto al control en cuanto a que los estudiantes pudieron definir recomendaciones generales para una mejor comunicación en línea, explicable por la casi total ausencia de actividades en línea en grupo control.

\section{Líneas futuras de investigación}

En la investigación hemos identificado la coexistencia de varios modelos pedagógicos para implementación de la modalidad b-learning, con mayor o menor énfasis en la tecnología o en la pedagogía. Independiente de los modelos, en futuras investigaciones debemos avanzar en dos ámbitos, uno de ellos que estudie cómo el sujeto interactúa expansivamente con otros sujetos mediados por la tecnología en el marco de una actividad b-learning. El otro ámbito es precisar las condiciones pedagógicas y didácticas del trabajo colaborativo de la modalidad b-learning. A continuación describimos con mayor detalle estas dos líneas de investigación proyectadas.

La primera línea de investigación sugerida es la aplicación de los ciclos expansivos de la actividad a nivel del individuo, en el caso de los profesores y los alumnos, marco de análisis 
aportado por Engeström $(2001,2009,2010)$ en la tercera generación de la teoría de la actividad. Un ciclo expansivo es una nueva orquestación de estas expresiones de los diferentes puntos de vista y perspectivas de los participantes del colectivo. Como ya señalábamos, introducir nuevas tecnologías u objetos provocan contradicciones que abren la posibilidad de acciones innovadoras de cambio, por tanto se sugiere estudiar las naturales contradicciones individuales y colectivas desde la gestión institucional, ya que en la presente investigación abordamos cómo desde el sujeto se asume la incorporación de la modalidad b-learning en las prácticas pedagógicas, como primera aproximación sistemática al objeto de estudio, sin abordar las condiciones requeridas para integrar el blearning en la práctica individual e institucional.

La segunda línea de investigación tiene relación con el ámbito de las condiciones pedagógicas y didácticas de las actividades en línea y presenciales del trabajo colaborativo de la modalidad $b$-learning. La teoría de la actividad ofrece herramientas conceptuales para comprender cómo la cognición se redistribuye entre formas de actividades conjuntas próximas y a distancia, y cómo el pensamiento se da tanto entre individuos (proceso inter) como dentro de ellos (intra). Por ello la comprensión no es algo externo sino que se va conformando en la actividad que se lleva a cabo. La forma de relacionarse con el conocimiento o el aprendizaje está contenida en las prácticas. La forma de actuar y comprender está entretejida con la actividad, y ésta constituye a la vez el contexto marco de la comprensión. Las personas aprenden en el seno de estas interacciones sociales y prácticas en el interior de una comunidad, les sirven de filtro a través de las cuales perciben lo que funciona como realidad. 


\section{REFERENCIAS}

AGUADO, D.; ARRANZ, V. (2005). Desarrollo de competencias mediante blended learning. Un análisis descriptivo; Píxel-Bit, Revista de Medios y Educación, n. 26, julio, pp. 7988. Documento en línea [Fecha de consulta. 04-05-2008] en http.//redalyc.uaemex.mx/redalyc/pdf/368/36802607.pdf.

AGUADO, D.; ARRANZ, V.; VALERA-RUBIO, A.; MARÍN-TORRES, S. (2011). Evaluación de un programa blended-learning para el desarrollo de la competencia trabajar en equipo. Psicothema. Vol. 23, no 3, pp. 356-361.

AGUILERA, O. (2006). Propuesta de un modelo de evaluación para cursos en modalidad a distancia, Calidad en la Educación I № 25, diciembre. Documento en línea [Fecha de consulta. 02/10/2008] en http.//www.cse.cl/public/Secciones/seccionestudios/estudios_y_documentos_Otro s.aspx.

AIELLO, M.; WILLEM, C. (2004). El Blended Learning como práctica transformadora. Monográfico Blended Learning. Pixel-Bit. Revista de Medios y Educación № 23, mayo pp. 21-26. Documento en línea [Fecha de consulta. 05-06-2008] en http.//www.sav.us.es/pixelbit/articulos/n23/PIXEL_BIT_23.pdf.

AKKOYUNLU, B.; YILMAZ, M. (2006). A Study on Students' Views On Blended Learning Environment; Turkish Online Journal of Distance Education-TOJDE July, volume 7, number 3. Documento en línea [Fecha de consulta. 12/07/2008] en http.//tojde.anadolu.edu.tr/tojde23/pdf/article_3.pdf. 
AKYOL, Z., GARRISON, R., OZDEN,Y. (2009). Online and Blended Communities of Inquiry. Exploring the Developmental and Perceptional Differences; International Review of Research in Open and Distance Learning. v10, №6.

ALBA PASTOR, C. (Director) (2005). Estudio sobre la viabilidad de las propuestas metodológicas derivadas de la aplicación del crédito europeo por parte del profesorado de las universidades españolas, vinculadas a la utilización de las TIC en la docencia y la investigación. Madrid. Ministerio de Educación y Ciencia, España.

ALLEN, I.; SEAMAN, J.; GARRETT, R. (2007). Blending in the extent and promise of blended education in the United States. Sloan-C. United States of America.

ALLEN, D., KARANASIOS, S., SLAVOVA, M. (2011). Working with activity theory: Context, technology, and information behavior. Journal of the American Society for Information Science and Technology, 62(4), pp. 776-788.

AL-HUNEIDI, A.; SCHREURS, J. (2012). Constructivism based blended learning in higher education. IJET, volume 7, march.

ALTBACH, P. (2008). FUNCIONES COMPLEJAS DE LAS UNIVERSIDADES EN LA ERA DE LA GLOBALIZACIÓN EN GLOBAL UNIVERSITY NETWORK FOR INNOVATION. La educación superior en el mundo 3. Educación superior. Nuevos retos y roles emergentes para el desarrollo humano, Madrid, Ediciones Mundi-Prensa.

ANDRADE, A. (2007). Aprendizaje combinado como propuesta en la convergencia europea para la enseñanza de las ciencias naturales. E-learning Papers, no. 3. Documento en línea dFecha consulta. 03/03/2008] en http.//www.elearningeuropa.info/files/media/media11971.pdf.

ANECA (2003). Programa de Convergencia Europea. El crédito Europeo. Documento en línea [Fecha de consulta. 07-09-2008] en http.//www.aneca.es.

ARBAUGH, J. B., GODFREY, M. R., JOHNSON, M., LEISEN POLLACK, B., NIENDORF, B. \& WRESCH, W. (2009). Research in online and blended learning in the business disciplines. Key findings and possible future directions. The Internet and Higher Education, 12 (2). 71-87. 
AREA, M. (2006). La enseñanza universitaria en tiempos de cambio. El papel de las bibliotecas en la innovación educativa. En. IV Jornadas CRAI de la Red de Bibliotecas Universitarias (REBIUN). Experiencias en el ámbito de la organización y la convergencia de servicios. Universidad de Burgos, 10-12 mayo 2006. Documento en línea dFecha consulta. 16/08/2008] en. http.//www.rebiun.org/export/docReb/manuel_area.pdf.

AREA, M.; SANABRIA, A.; GONZÁLEZ, M. (2008). Análisis de una experiencia de docencia universitaria semipresencial desde la perspectiva del alumnado; RIED. Revista Iberoamericana de Educación a Distancia, vol. 11, I № 1, (ejemplar dedicado a. La docencia virtual en las universidades presenciales (vol. 2), pags. 231-254. Documento en línea [Fecha de consulta. 16/08/2008] en http.//www.utpl.edu.ec/ried/images/pdfs/volumen11/manuel-area.pdf.

ARDIZZONE, P. y RIVOLETTA, P. (2004). Didáctica para e-learning. Métodos e instrumentos para la innovación de la enseñanza universitaria, Málaga, Ediciones Aljibe.

ASGHAR, M. (2013). Exploring Formative Assessment Using Cultural Historical Activity Theory. Turkish Online Journal of Qualitative Inquiry, 4(2), pp.18-32.

ASINSTEN, J. C. (2013). Aulas expandidas: la potenciación de la educación presencial. Revista Universidad de La Salle, (60), 97-113.

ATTWELL (2007). Personal Learning Environments, the future of e-learning? E-learning Papers, vol. 2, № 1, January, p.1-8.

BACK, D. A., HABERSTROH, N., ANTOLIC, A., SOSTMANN, K., SCHMIDMAIER, G., HOFF, E. (2014). Blended learning approach improves teaching in a problem-based learning environment in orthopedics-a pilot study. BMC Medical Education. Vol. 14.

BAINTON, T. (2001). Aptitudes para el acceso y uso de la información en la enseñanza superior: la postura de SCONUL, IFLA Council and General Conference, no 67. Documento en línea [Fecha de consulta. 17/07/2010] en http://www.ifla.org/IV/ifla67/papers/016-126s.pdf. 
BAIRRAL, M. (2005). Debate virtual y desarrollo profesional. Una metodología para el análisis del discurso docente, Revista de Educación, Madrid, Ministerio de Educación y Ciencia, número 336, enero-abril, p. 439-465. Documento en línea [Fecha de consulta. $17 / 07 / 2008]$ en http.//www.revistaeducacion.mec.es/re336/re336_23.pdf.

BALlesteros, M. (2002). En MARCELO, C.; PUENTE, D.; BALleEsteros, M.; PALAZÓN, A. (2002). E-learning-teleformación. Diseño, desarrollo y evaluación de la formación a través de Internet, Barcelona, Ediciones Gestión 2000.

BANG, J. (2006). El e-learning revisado. ¿Satisfacen las expectativas el e-learning y las universidades virtuales? Documento en línea [Fecha de consulta. 05-04-2007] en http.//elearningeuropa.info.

BARAN, B.; CAGILTAY, K. (2010). The dynamics of online communities in the activity theory framework. Educational Technology \& Society, 13(4), 155-166. Documento en línea [Fecha de consulta. 23/02/2014] en http://www.ifets.info/journals/13_4/14.pdf.

BARBERÀ, E. (2004). Pautas para el análisis de la intervención en entornos de aprendizaje virtual. Dimensiones relevantes e instrumentos de evaluación. Documento en línea [Fecha de consulta. 03/03/2008] en http.//www.uoc.edu/in3/dt/esp/barbera0704.html.

BARBERÀ, E. (2008). Aprender e-learning, Barcelona, Ediciones Paidós.

BARBERÀ, E.; MAURI, T.; ONRUBIA (coords.) (2008). Cómo evaluar la calidad de la enseñanza basada en las TIC. Pautas e instrumentos de análisis, Barcelona, Editorial Graó.

BARKER, P. (2007). Blended Learning with Webs, Wikis and Weblogs; Joseph Fong, Fu Lee Wang (Eds.) Blended Learning Workshop on Blended Learning 2007 Edinburgh, United Kingdom.

BARROS, B.; VERDEJO M. (2000). DEGREE. Un sistema para la realización y evaluación de experiencias de aprendizaje colaborativo en enseñanza a distancia, Departamento de Ingeniería Eléctrica, Electrónica y de Control (U.N.E.D.). Documento en línea [Fecha 
de

consulta.

07/10/2008]

en

http.//sensei.Isi.uned.es/ bbarros/papers/caepia99.pdf.

BARROS B.; VÉLEZ, J; VERDEJO M. (2004). Aplicaciones de la Teoría de la Actividad en el desarrollo de sistemas colaborativos de enseñanza y aprendizaje. Experiencias y resultados, Revista Iberoamericana de Inteligencia Artificial, vol. 8, número 24.

BARROSO, J.; CASTAÑO, M.; ROMÁN, P.; LLORENTE, C.; PRENDES, M.; CEBRIÁN, M.; PÉREZ, A.; BALLESTERO, C.; MARTíNEZ, F. PÍO, A.; GISBERT, M.; SALINAS, J. (2006). Formación del profesorado universitario en estrategias metodológicas para la incorporación del aprendizaje en red en el espacio europeo de educación superior (EEES); Pixel-Bit. Revista de medios y educación, I №. 27, pags. 11-29. Documento en línea [Fecha de consulta.

02/10/2008]

en http.//www.sav.us.es/pixelbit/pixelbit/articulos/n27/n27art/art2702.htm.

BARTOLOMÉ, A. (2002). Universidades en la Red. ¿Universidad presencial o virtual? Crítica, LII № 896. pp. 34-38. Documento en línea [Fecha de consulta. 05-06-2008] en http.//www.Imi.ub.es/personal/bartolome/articuloshtml/bartolomeSPcritica02.pdf

BARTOLOMÉ, A. (2004). Blended Learning. Conceptos Básicos. Monográfico Blended Learning. Pixel-Bit. Revista de Medios y Educación № 23. Mayo pp. 7-20. Documento en línea [Fecha de consulta. 05-06-2008] en http.//www.sav.us.es/pixelbit/articulos/n23/PIXEL_BIT_23.pdf.

BARTOLOMÉ, A. (2008). Entornos de aprendizaje mixto en educación superior; RIEDRevista Iberoamericana de Educación a Distancia, v. 11. 1, pp 15-51. Documento en línea [Fecha de consulta. 05-02-2009] en http.//www.utpl.edu.ec/ried/images/pdfs/volumen11/bartolome.pdf.

BAROLOMÉ, A. (2011). Comunicación y aprendizaje en la sociedad del conocimiento. VEsC - Año 2 - Número 2. Documento en línea [Fecha de consulta. 03-02-2014] en http://revistas.unc.edu.ar/index.php/vesc/article/viewFile/332/331.

BDM (2009). Información general, Biblioteca Digital Mundial. Documento en línea [Fecha de consulta. 04-05-2008] en http.//www.wdl.org/es/about/background.html. 
BENSON, A.; LAWLER, C.; WHITWORTH, A. (2008). Rules, roles and tools. Activity theory and the comparative study of e-learning. British Journal of Educational Technology, 39(3), 456-467.

BERASATEGUI, M. (2008). Nativos digitales, Web 2.0 y educación superior. Una propuesta de integración. Documento en línea [Fecha de consulta. 05-07-2008] en http.//www.atapistudio.com/nativos-digitales-Web-20-educacion-superior/.

BERNAZA, G.; DOUGLAS, C. (2005). Directo a la diana. Sobre la orientación del estudiante para aprender, Revista Iberoamericana de Educación, №35/7.

BERSIN, A. W. (2004). The blended learning book. Best practices, proven methodologies and lessons learned. San Francisco. Pfeiffer.

BIGUM, C.; ROWAM, L. (2004). Flexible learning in teacher education. Myths, muddles and models; Asia-Pacific Journal of Teacher Education, vol. 32, №3.

BIKAS C. SANYAL, B. LÓPEZ, F. (2008). Visión general de las percepciones regionales sobre el rol de la educación superior para el desarrollo humano y social en GLOBAL UNIVERSITY NETWORK FOR INNOVATION. La educación superior en el mundo 3. Educación Superior. Nuevos retos y roles emergentes para el desarrollo humano, Madrid, Ediciones Mundi-Prensa.

BISQUERRA, R. (2004a). Métodos de investigación educativa. Guía práctica. Barcelona. CEAC.

BISQUERRA, R. (Coord.). (2004b). Metodología de la investigación educativa. Madrid. La Muralla.

BLIUC A.; GOODYEAR, P.; ELLIS, R. (2007). Research focus and methodological choices in studies into students experiences of blended learning in higher education, Internet and Higher Education, 10.

BOSCO, M. A.; RODRÍGUEZ, D. (2008). Docencia Virtual y Aprendizaje Autónomo. Algunas contribuciones al Espacio Europeo de Educación Superior; RIED-Revista Iberoamericana de Educación a Distancia, Vol. 11, № 1, págs. 157-182. Documento 
en línea [Fecha de consulta. 02/10/2008] en http.//www.utpl.edu.ec/ried/images/pdfs/volumen11/bosco.pdf.

BRICEÑO, M. (2002). El docente y la gestión del conocimiento en la mestría virtual en tecnología y diseño educativo. Universidad Simón Rodríguez - (UNESR) -Venezuela; Acta de la Conferencia de Virtual Educa 2002, Valencia. Documento en línea [Fecha de consulta. 16/07/2008] en http.//www.virtualeduca.org/encuentros/valencia2002/actas2002/actas02/140.pdf

BRIDGES, S., CHANG, J. W. W., CHU, C. H., GARDNER, K. (2014). Blended learning in situated contexts: 3-year evaluation of an online peer review project. European Journal of Dental Education.

BURGOS, D.; CORBALÁN, G. (2007). Modelado y uso de escenarios de aprendizaje en entornos b-learning desde la práctica educativa; Innovación en el Campus virtual. Metodologías y herramientas / III Jornada Campus virtual UCM / coord. Por Alfredo Fernández-Valmayor Crespo, Ana Fernández-Pampillón Cesteros, Jorge Merino Granizo, págs. 187-194. Documento en línea [Fecha de consulta. 16/07/2008] en http.//dspace.learningnetworks.org/bitstream/1820/716/1/BURGOSandCORBALAN _15June2006_Review.pdf.

BUSTOS S. (2004). Un modelo para blended-learning aplicado a la formación en el trabajo. Compartimos prácticas - ¿compartimos saberes? Revista Iberoamericana de Educación a Distancia. 7-2004, (1 y 2), 113-132. Documento en línea [Fecha de consulta. 07-07-2008] en http.//www.utpl.edu.ec/ried/images/pdfs/vol7-12/un_modelo.pdf.

CABERO, J.; ROMÁN, P. (coords.) (2006). E-actividades. Un referente básico para la formación en Internet, Sevilla, Editorial MAD, S.L.

CABERO, J. (2007). Nuevas metodologías aplicadas a la educación, Madrid, McGraw-Hill.

CABERO, J (2012). Tendencias para el aprendizaje digital: de los contenidos cerrados al diseño de materiales centrado en las actividades. El Proyecto Dipro 2.0. RED. Revista de Educación a Distancia, (32), 1-27. 
CABERO, J., LLORENTE, M. (2009). Actitudes, satisfacción, rendimiento académico y comunicación online en procesos de formación universitaria en blended learning. En SAN MARTÍN ALONSO, A. (Coord.) Convergencia Tecnológica. La producción de pedagogía high tech [monográfico en línea]. Revista Electrónica Teoría de la Educación. Educación y Cultura en la Sociedad de la Información. Vol. 10, no 1. Universidad de Salamanca [Fecha de consulta. 20/10/2010] http.//www.usal.es/ teoriaeducacion/rev_numero_10_01/n10_01_cabero_llorente .pdf

CAMPBELL, M., GIBSON, W., HALL, A., RICHARDS, D., CALLERY, P. (2008). Online vs. face-toface discussion in a Web-based research methods course for postgraduate nursing students. A quasi-experimental study. International Journal of Nursing Studies, v45, №5.

CAMPBELL, M., LOGAN, J., \& FROST, D. (2005). Mixed-mode learning for students of school. Paper presented at The AARE International Educational Research Conference, Parramatta, Australia.

CANALES, F.; ALVARADO, E.; PINEDA, E. (1986). Metodología de la Investigación. Manual para el desarrollo de Personal de Salud. México D.F. Limusa.

CASTAÑEDA, L.; PRENDES, M. (2006). Flexibilización de Modelos Docentes con Redes Telemáticas en la Universidad de Murcia, Informe Técnico, Instituto de Ciencias de la Educación Universidad de Murcia. Documento en línea [Fecha de consulta. 03/06/2008] en http.//www.um.es/ice/publicaciones/primeras-asignaturasumu.pdf.

CASTAÑEDA, L. (2007). Implementación de materiales en red en contextos universitarios presenciales. La perspectiva del alumnado, eLearning Papers, I № 4, mayo. Documento en línea [Fecha de consulta. 16/07/2008] en http.//www.elearningeuropa.info/files/media/media12743.pdf.

CASTELLS, M. (2000). Internet y la sociedad en red. Documento en línea [Fecha de consulta. 05-06-2008] en http.//Campus.uoc.es/Web/cat/index.html. 
CASTELLS, M. (2001). La galaxia Internet. Reflexiones sobre Internet, empresa y sociedad, Barcelona, Plaza Janés Editores S.A.

CASTILLO, S. (2007). Teoría de la actividad. Una perspectiva en la enseñanza de la matemática apoyada en el uso de las tecnologías de información y comunicación; volumen 4, № 8, julio- diciembre. Revista Kaleidoscopio. Documento en línea [Fecha de consulta.

$12 / 02 / 2010]$

en

http.//kaleidoscopio.uneg.edu.ve/numeros/k08/k08.html.

CASTILLO, A.; LUGO A. (2008). B-learning para el impulso de la equidad de género en una Institución de Educación Superior del estado de Querétaro, México, Ponencia en el IX Encuentro Internacional Virtual Educa Zaragoza 2008. Documento en línea [Fecha de consulta. 02/10/2008] en http.//www.virtualeduca.info/ponencias/118/PONENCIA_CASTILLO-LUGO.doc.

CEBRIÁN, M. (coord.) (2007). Enseñanza virtual para la innovación universitaria, Narcea, S.A. de Ediciones, Madrid.

CENICH, G.; SANTOS, G. (2006). Aprendizaje Colaborativo Online. Indagación de las Estrategias de Funcionamiento, TE\&ET Revista Iberoamericana de Tecnología en Educación y Educación en Tecnología, volumen 1, número 1, diciembre. Documento en línea [Fecha de consulta. 14/07/2008] en http.//teyetrevista.info.unlp.edu.ar/files/No1/10_Aprendizaje_Colaborativo_Online.pdf.

CHAVEZ, J. (2008). Estructura de los diseños didácticos e instruccional con enfoque $b$ learning en la educación superior en México. Caso Instituto Politénico Nacional; IX Encuentro Internacional Virtual Educa Zaragoza 2008, julio. Documento en línea [Fecha de consulta. 16/07/2008] en http.//www.virtualeduca.info/ponencias/131/MAGALI\%20CARDENAS\%20TAPIA\%20 M\%C9XICO\%20IPN.doc.

CHESEBRO, J. L.; MCCROSKEY, J. C. (2000). The Relationship between Students Reports of Learning and their Actual Recall of Lecture Material: A Validity Test. Communication Education, 49, 3, 297-301. 
CHEW, E., JONES, N., TURNER, D. (2007). The Marriage of Rousseau and Blended Learning. An Investigation of Higher Educational Institutions; FONG, J., KWAN, R., LEE WANG, (Eds.) Blended Learning Workshop on Blended Learning 2007 Edinburgh, United Kingdom.

CHEW, E., JONES, N., TURNER, D. (2008). Critical Review of the Blended Learning Models Based on Maslow's and Vygotsky's Educational Theory; FONG, J., KWAN, R., LEE WANG, F. (Eds.), Hybrid Learning and Education. First International Conference, Ichl 2008 Hong Kong, China.

CHIECHER, A.; DONOLO, D.; RINAUDO, M. (2008). Manejo del tiempo y el ambiente en una experiencia didáctica con instancias presenciales y virtuales. RED. Revista de Educación a Distancia, número 20. Documento en línea [Fecha de consulta. 16/07/2008] en http.//www.um.es/ead/red/20.

COBO, C.; PARDO, H. (2007). Planeta Web 2.0. Inteligencia colectiva o medios fast food. Grup de Recerca d'Interaccions Digitals, Universitat de Vic y Flacso México, Barcelona y México DF.

COLE, M.; ENGESTRÖM, Y. (2001). A cultural historical approach to distributed cognition en SALOMON, G. (Ed.); Distributed cognitions. Psychological and educational considerations; Cambridge; Cambridge University Press.

COLE, M. (2003). Psicología cultural: una disciplina del pasado y del futuro. Ediciones Morata, Madrid.

COLL, C.; MAURI, T.; ONRUBIA, J. (2006). Análisis y resolución de casos-problema mediante el aprendizaje colaborativo; en. Antoni BADIA (coord.). Enseñanza y aprendizaje con TIC en la educación superior [monográfico en línea]. Revista de Universidad y Sociedad del Conocimiento (RUSC). Vol. 3, n. ${ }^{\circ}$ 2. UOC. [Documento en línea [Fecha de consulta. $16 / 07 / 2008]$ en http.//www.uoc.edu/rusc/3/2/dt/esp/coll_mauri_onrubia.pdf.

COMISIÓN EUROPEA (1999). Declaración de Bolonia. Declaración conjunta de los Ministros Europeos de Educación. Documento en línea [Fecha de consulta. 03-06-2008] en http.//www.eees.ua.es/documentos/declaracionBolonia.pdf. 
COMISIÓN EUROPEA (2000). Memorándum sobre el aprendizaje permanente, documento de trabajo de los servicios de la comisión, Bruselas, Comisión de las Comunidades Europeas. Documento en línea [Fecha de consulta. 03/06/2008] en http.//www.oei.es/eduytrabajo2/Memoaprenpermanente.pdf

CONTANDRIOPOULOS, A.; CHAMPAGNE, F.; POTVIN L.; DENIS, J.; BOYLE, P. (1991). Preparar un proyecto de investigación, Barcelona. SG Editores SA.

CORREA, J. M., PAREDES, J. (2009). Cambio tecnológico, usos de plataformas de e-learning y transformación de la enseñanza en las universidades españolas. La perspectiva de los profesores; Revista de Psicodidáctica, Vol.14, № 2.

CRESWELL, J. W. (2009). Research Design. Qualitative, quantitative, and mixed methods approaches (3. $\mathrm{a}$ ed.). Londres. Sage.

CUBIDES SALAZAR, N., MARTÍN GARCÍA, A. V. (2014). Los modelos formativos combinados b-Learning: perspectivas para la enseñanza universitaria. En MARTíN GARCÍA, A. V. (Coord.). Blended Learning en educación superior. Perspectivas de innovación y cambio. Madrid, Editorial Síntesis S.A.

DAHLSTROM, E; WALKER, J.D.; DZIUBAN, C.; MORGAN, G. (2013). ECAR Study of Undergraduate Students and Information Technology, 2013. Louisville, CO: EDUCAUSE Center for Analysis and Research. Documento en línea [Fecha de consulta 17/02/2014] https://net.educause.edu/ir/library/pdf/ERS1302/ERS1302.pdf.

DANIELS, H. (2003). Vygotsky y la pedagogía; Barcelona, Ediciones Paidós Ibérica S.A.

DEL RINCÓN, D., ARNAL, J., LATORRE, A., \& SANS, A. (1995). Técnicas de investigación en ciencias sociales. Dykinson.

DELORS, J. (1996). La educación encierra un tesoro, Madrid, Santillana, Ediciones UNESCO.

DELTORI, G., DONATELLA, P. (2007). Supporting Self-Regulated Learning in a Blended Course, FONG, J., KWAN, R., LEE WANG, (Eds.), Workshop on Blended Learning 2007, Edinburgh, United Kingdom. 
DERNTL, M., MOTSCHNIG-PITRIK, R. (2005). The role of structure, patterns, and people in blended learning; Internet and Higher Education, №8.

DE JONG, N., SAVIN-BADEN, M., CUNNINGHAM, A. M., VERSTEGEN, D. M. (2014). Blended learning in health education: three case studies. Perspectives on medical education, 1-11.

DE PABLOS PONS, J. (2012). El cambio metodológico en el espacio europeo de educación superior y el papel de las tecnologías de la información y la comunicación. RIED. Revista Iberoamericana de Educación a Distancia, 10(2).

DIEZ, M. (1989). Manual para la elaboración y aprovechamiento del pizarrón, México, D. F., Instituto Latinoamericano de la Comunicación Educativa.

DORIO, I.; SABARIEGO, M.; MASSOT, I. (2004). Características generales de la metodología cualitativa. En BISQUERRA, R. (Coord.). (2004b). Metodología de la investigación educativa. Madrid. La Muralla.

DUART, J. M.; GIL, M.; PUJOL, M. y CASTAÑO, J. (2008). La Universidad en la Sociedad Red. Usos de Internet en Educación Superior. Barcelona, Ariel.

DURÁN, E.; COSTAGUTA, R.; GOLA, M. (2011). El modelo B-learning implementado en la asignatura simulación. RIED. Revista Iberoamericana de Educación a Distancia, volumen 14, no 2, pp. 149-166.

ECDL (2002). Acreditación europea de manejo de ordenador. Syllabus versión 4.0, Irlanda. The European Computer Driving Licence.

EL-MOWAFY, A., KUHN, M.; SNOW, T. (2013). A blended learning approach in higher education: a case study from surveying education. In Design, develop, evaluate: the core of the learning environment. Proceedings of the 22nd Annual Teaching Learning Forum, 7-8. February. Perth: Murdoch University. Documento en línea [Fecha de consulta $22 / 02 / 2014]$ en http://ctl.curtin.edu.au/professionaldevelopment/conferences/tlf/tlf2013/refereed /el-mowafy.html 
ECHEVERRÍA, J. (2000). Educación y tecnologías telemáticas, Revista Iberoamericana de Educación, Monográfico. TIC en la educación, №24, septiembre - diciembre,

ECHEVERRÍA, J. (2004). Los señores del aire. Telepolis y tercer entorno, Barcelona, Ediciones Destino.

ECHEVERRÍA, R. (2005). Ontología del lenguaje. Santiago de Chile, Lom Ediciones S.A.

ENGESTRÖM, Y. (1987). Learning by Expanding. An Activity-Theoretical Approachto Developmental Research, Helsinki. Finland. Orienta-Konsultit.

ENGESTRÖM, Y. (1996). Interobjectivity, Ideality, and Dialectics; Mind, Culture, and Activity; Vol. 3, № 4.

ENGESTRÖM, Y. (1999a). Expansive visibilization of work. An activity-theoretical perspective, Computer Supported Cooperative Work, 8. Kluwer Academic Publishers. Documento en línea [Fecha de consulta. 02/03/2009] en http.//lchc.ucsd.edu/MCA/Paper/Engestrom/expanding/intro.htm.

ENGESTRÖM, Y.; MIETTINEN, R.; PUNÄMAKI, R-L. (1999b). Perspectives on activity theory; Cambridge University Press; United Kingdom.

ENGESTRÖM, Y. (2000). Activity theory as a framework for analyzing and redesigning work; Ergonomics, vol. 43, №7.

ENGESTRÖM, Y. (2001). Expansive Learning at Work. Toward an activity theoretical reconceptualization; Journal of Education and Work, Vol. 14, №1.

ENGESTRÖM, Y. (2008a). Enriching activity theory without shortcuts, Interacting with Computers, 20. Documento en línea [Fecha de consulta. 04/04/2009] en www.sciencedirect.com.

ENGESTRÖM, Y. (2008b). The future of activity theory. A rough draft; ISCAR Conference in San Diego; Documento en línea [Fecha de consulta. 20/10/2010] en http.//lchc.ucsd.edu/mca/Paper/ISCARkeyEngestrom.pdf. 
ENGESTRÖM, Y. (2009). Expansive learning. Toward an activity-theoretical reconceptualization, Chapter 4 en ILLERIS, K. (2009). Contemporary Theories of Learning. Learning Theorists...In Their Own Words; United Kingdom, Routledge.

ENGESTRÖM, Y. (2010). From teams to knots. Activity-theoretical studies of collaboration and learning at work. New York, Cambridge University Press.

ESAINS, V. (2008). Una cronología de las tecnologías para la educación, Informes Especiales LR/2 Tecnologías para e-learning de Learning Review España. Documento en línea [Fecha de consulta. 04/04/2009] en http.//www.revistasamedida.com/espanainforme/edicion2/index.html.

ESSAM, R. (2010). Software Application for Computer Aided Vocabulary Learning in a Blended Learning Environment; Thesis of Master of Arts/Science, The American University in Cairo.

FAINHOLC, B. (2008). Educación a distancia y presencial. Diferencias en los componentes cognitivo y motivacional de estudiantes universitarios; RIED-Revista Iberoamericana de Educación a Distancia, v. 11. 1, p. 53-79. Documento en línea [Fecha de consulta. 02/03/2009] en http.//www.utpl.edu.ec/ried/images/pdfs/volumen11/beatrizfainholc.pdf.

FALCONER, I., LITTLEJOHN, A. (2007). Designing for blended learning, sharing and reuse; Journal of Further and Higher Education Vol. 31, № 1.

FERNÁNDEZ, J. (2006). Clases virtuales, clases reales. La plataforma educativa Moodle, Linux Magazine №14. [Fecha de consulta. 08/02/2010] en. http.//www.linuxmagazine.es/issue/14/Educacion.pdf.

FERNÁNDEZ SÁNCHEZ, N. (2011). Promoción del cambio de estilos de aprendizaje y motivaciones en estudiantes de educación superior mediante actividades de trabajo colaborativo en Blended Learning. RIED. Revista Iberoamericana de Educación a Distancia, volumen 14, n 2, pp. 189-208.

FISHER, T.; HIGGINS, C.; LOVELESS, A. (2006). Teachers Learning with Digital Technologies. A review of research and project. Bristol, Future Lab. 
FLORES, O. (2012). Tic y docencia universitaria: ¿cambian las metodologías docentes según el grado de presencialidad de las asignaturas? El caso de la universidad de Lleida. Pixel-Bit, Revista de Medios y Educacion, (41).

FREDERICKSON, N., REED, O., CLIFFORD, V. (2005). Evaluating web-supported learning versus lecture-based teaching. Quantitative and qualitative perspectives; Higher Education, v50.

FUMERO, A.; ROCA, G. (2007). Web 2.0, Fundación Orange. Documento en línea [Fecha de consulta. 04/06/2008] en http.//www.fundacionorange.es/areas/25_publicaciones/WEB_DEF_COMPLETO.pd f.

GARCÍA DE ANDOAIN, J. (Director) (2005). Determinación de un modelo causal de los factores de calidad docente en entornos virtuales de aprendizaje; Dirección General de Universidades Secretaría de Estado de Universidades e Investigación Ministerio de Educación y Ciencia, España. Documento en línea [Fecha de consulta. 19/07/2008] en http.//www.mec.es/univ/proyectos2005/EA2005-0146.pdf.

DEL DUJO, Á. G., MARTín GARCÍA, A. V. (2009). Caracterización pedagógica de los entornos virtuales de aprendizaje. Teoría de la Educación. Revista Interuniversitaria, 14.

GARCÍA CABRERO, B.; MÁRQUEZ, L.; BUSTOS, A.; MIRANDA, G. A.; ESPÍNDOLA, S. (2008). Análisis de los patrones de interacción y construcción del conocimiento en ambientes de aprendizaje en línea una estrategia metodológica. Revista Electrónica de Investigación Educativa, 10 (1). Documento en línea [Fecha de consulta. 13/07/2008] en. http.//redie.uabc.mx/vol10no1/contenido-bustos.html.

GARCÍA CARRASCO, J. (2007). Leer en la cara y en el mundo, Barcelona, Herder.

GARCÍA CUÉ, J.; SANTIZO, J.; ALONSO GARCÍA, C. (2009). Uso de las TIC de acuerdo a los estilos de aprendizaje de docentes y discentes; Revista Iberoamericana de Educación, Número 48/2. Documento en línea [Fecha de consulta. 20/03/2009] en http.//www.rieoei.org/deloslectores/2308Cue.pdf. 
GARCÍA MENDOZA, H.; ORTIZ, A.; MARTíNEZ, J.; TINTORER, O. (2009). La teoría de la actividad de formación por etapas de las acciones mentales en la resolución de problemas, Inter Science Place. Revista Científica Internacional, año 2, número 9. Documento en línea [Fecha de consulta. 12/02/2010] en http.//www.interscienceplace.org/interscienceplace/article/viewArticle/103.

GARCÍA NIETO, N (Dir.) (2005). Programa de Formación del Profesorado universitario para la realización de la Función Tutorial dentro del marco del Espacio Europeo de Educación Superior (E.E.E.S.). Documento en línea [Fecha de consulta. 04/04/2007] en www.mec.es/univ/proyectos2005/EA2005-0027.pdf.

GARCÍA-VALCÁRCEL, A. (2007). Herramientas tecnológicas para mejorar la docencia universitaria. Una reflexión desde la experiencia y la investigación, RIED. Revista Iberoamericana de Educación a Distancia, Vol. 10, № 2, (ejemplar dedicado a la docencia virtual en las universidades presenciales (vol. I), p. 125-148; Documento en línea [Fecha de consulta. 15/07/2008] en http.//www.utpl.edu.ec/ried/images/pdfs/volumendiez/herramientastecnologicas.pdf.

GARRIDO, J; GROS, B.; RODRÍGUEZ, J.; SILVA, J.; NERVI, H. (2008). Más allá de laptops y pizarras digitales, Revista Calidad en la Educación No 29, diciembre.

GARRISON, D.; VAUGHAN, N., D. (2008). Blended Learning in Higher Education. Framework, Principles and Guidelines. Jossey-Bass, San Francisco (2008).

GEORGE-PALILONIS, F.; FILAK, V. (2009). Blended Learning in the Visual Communications Classroom. Student Reflections on a Multimedia Course, Electronic Journal of eLearning Volume 7 Issue 3.

GINNS, P., ELLIS, R. (2009). Evaluating the quality of e-learning at the degree level in the student experience of blended learning. British Journal of Educational Technology, 40.

GLOBAL UNIVERSITY NETWORK FOR INNOVATION (2008). La educación superior en el mundo 3. Educación superior: nuevos retos y roles emergentes para el desarrollo humano, Madrid, Ediciones Mundi-Prensa. 
GODOY, S. (director) (2009). Los internautas chilenos y sus símiles en el resto del mundo. resultados del estudio WIP-Chile 2008; Facultad de Comunicaciones UC, Instituto de Sociología UC, Escuela de Ingeniería UC/CETIUC, Centro de Estudios de la Economía Digital CCS; Santiago de Chile, marzo. Documento en línea [Fecha de consulta. 1/05/2009] en. http.//www.acti.cl/userfiles/file/Documentos\%20EBiblioteca/Wip\%20Chile_marzo\%202009.pdf

GONZÁLEZ J.C. (2006). B-learning utilizando software libre, una alternativa viable en Educación Superior; Revista Complutense de Educación, vol. 17, I № 1, págs. 121-134. Documento en línea [Fecha de consulta. 16/07/2008] en http.//revistas.ucm.es/edu/11302496/articulos/RCED0606120121A.PDF.

GONZÁLEZ, J.; WAGENAAR, R.; BENEITONE, P. (2004). Tuning-América Latina. Un proyecto de las universidades, núm. 35, mayo-agosto, pp. 151-164, Revista Iberoamericana de Educación, Organización de Estados Iberoamericanos para la Educación, la Ciencia y la Cultura (OEI). Documento en línea [Fecha de consulta. 02/10/2008] en http.//www.rieoei.org/rie35a08.htm.

GONZÁLEZ, J.; WAGENAAR, R. (2007). Tuning Educational Structures in Europe, España, Socrates-Tempus.

GONZÁLEZ ROGADO, A., RODRÍGUEZ CONDE, M. J., OLMOS MIGUELÁÑEZ, BORHAM, M., GARCÍA, F. (2013). Experimental evaluation of the impact of b-learning methodologies on engineering students in Spain. Computers in Human Behavior, 29(2), 370-377.

GONZÁLEZ ROGADO, A., RODRÍGUEZ CONDE, M. J., OLMOS MIGUELÁÑEZ, S., GARCÍA RIAZA, B. (2010). Assessment of a blended-learning methodology in engineering. International Journal of Technology Enhanced Learning, 2(4), 347-357.

GONZÁLEZ ROGADO, A., RODRÍGUEZ CONDE, M. J., OLMOS MIGUELÁÑEZ, S., GARCÍA RIAZA, B., GARCÍA PEÑALVO (2010). Efficiency Assessment of a Blended-Learning Educational Methodology in Engineering. International Journal of Technology Enhanced Learning (pp. 148-155). 
GONZÁLEZ SÁNCHEZ, M.; HERNÁNDEZ SERRANO, M.; GARCÍA DEL DUJO, A.; MARTÍN GARCÍA, A.; MUÑOZ RODRÍGUEZ, J. (2009). Diseño de actividades para la coordinación de asignaturas integradas. Informe del proyecto de innovación. Código del proyecto. ID/0034. Universidad de Salamanca Vicerrectorado de Docencia y Convergencia Europea. Documento en línea [Fecha de consulta. 12/12/2010] en http.//gredos.usal.es/jspui/handle/10366/72024.

GONZÁLEZ-VIDEGARAY, M.C. (2007). Evaluación de la reacción de alumnos y docente en un modelo mixto de aprendizaje para educación superior. RELIEVE, v13, №1.

GRAHAM, C.R. (2006). Blended learning systems. Definition, current trends, and future directions, en Bonk, C.J.; Graham, C.R., The handbook of blended learning. Global perspectives, local designs. San Francisco. Pfeiffer.

GRAHAM, C.R. (2014). Developing model and theory blended learning research. Cap. 2 en PICCIANO, A. G., DZIUBAN, C. D., GRAHAM, C. R. (Eds.). Blended learning: Research perspectives. (Vol. 2). New York. Routledge.

GROS, B.; SILVA, J.; BARBERÀ, E. (2006). Metodologías para el análisis de espacios virtuales colaborativos. RED. Revista de Educación a Distancia, número 16. Documento en línea [Fecha de consulta. 02/03/2008] en http.//www.um.es/ead/red/16.

GROS, B. (2007). Tendencias actuales de la investigación en docencia universitaria, Edusfarm, revista d'educació superior en Farmàcia. Núm. 1. Documento en línea [Fecha de consulta. 13/07/2008] en. http.//www.publicacions.ub.es/revistes/edusfarm1/documentos/93.pdf.

GROS, B.; GUERRA, V.; SÁCHEZ, J. (2005). The design of computer-supported collaborative learning environments in higher education. Encounters on Education, 6.

GROS, B. (2008). Aprendizajes, conexiones y artefactos. La producción colaborativa del conocimiento. Colección Comunicación Educativa. Barcelona, Gedisa Editorial.

GROS, B. (2011). Evolución y retos de la educación virtual. Construyendo el e-learning del siglo XXI. Barcelona, Editorial UOC. 
GURDIÁN-FERNÁNDEZ, A. (2007). El Paradigma Cualitativo en la Investigación SocioEducativa, Coordinación Educativa y Cultural Centroamericana (CECC); San José, Costa Rica, Agencia Española de Cooperación Internacional (AECI).

GUlBAHAR, Y., MADRAN, O. (2009). Communication and Collaboration, Satisfaction, Equity, and Autonomy in Blended Learning Environments. A Case from Turkey; International Review of Research in Open and Distance Learning, v10, №2.

HADJERROUIT, S. (2008). Evaluating the Pedagogical Value of Blended Learning in Informatics and Mathematics Education: A Comparative Study. In J. Luca \& E. Weippl (Eds.), Proceedings of World Conference on Educational Multimedia, Hypermedia and Telecommunications. Documento en línea [Fecha de consulta. 20/07/2011] en http://www.editlib.org/p/28904.

HANNAH, D.; VENKATACHARY, R. (2010). "Organizations" into an Organization Theory Course. A Hybrid CAO Model For Teaching Organization Theory. Journal of Management Education, Volumen 34, № 2.

HERNÁNDEZ, J. M. (2005). Software libre técnicamente viable, económicamente sostenible y socialmente justo. Zero Factory S.L. Barcelona.

HERNÁNDEZ CASTILLA, R. Y OPAZO CARVAJAL, H. (2010). Apuntes de Análisis Cualitativo en Educación. Documento en línea [Fecha de consulta. 20/07/2011] en http://www.uam.es/personal_pdi/stmaria/jmurillo/Met_Inves_Avan/Materiales/Ap untes_Cualit

ativo.pdf.

HIMANEN; P (2002). La ética del hacker y el espíritu de la era de la información. Barcelona, Destino.

HUN, D.; MORRIS, M.; KUPRITZ, V. (2007). Online vs. Blended learning: differences in instructional outcomes and learner satisfaction. Journal of Asynchronous Learning Networks. Jul, Vol. 11, pp. 27-42. 
IMBERNÓN, F. (Coord.) (2008). Análisis y propuestas de competencias docentes universitarias para el desarrollo del aprendizaje significativo del alumnado a través del e-learning y el b-learning en el marco del EEES; Programa de Estudio y Análisis Ministerio de Educación y Ciencia. Documento en línea [Fecha de consulta. 20/10/2010] http.//tecnologiaedu.us.es/nweb/htm/pdf/EA20070049_Dr_Francisco_ Imbernon.pdf.

IMBERNÓN, F.; SILVA, P.; GUZMÁN, C. (2011). Competencias en los procesos de enseñanzaaprendizaje virtual y semipresencial. Comunicar. Revista Científica de Educomunicación. № 36, v. XVIII, pp 107-114.

INFANTE MORO, A. (Director) (2006). La enseñanza virtual en España ante el Nuevo Espacio Europeo de Educación Superior, Grupo Editorial Universitario, Granada, 1a edición.

JAWORSKI, B., ROBINSON, C., MATTHEWS, J., CROFT, T. (2012). An Activity Theory Analysis of Teaching Goals versus Student Epistemological Positions. International Journal For Technology In Mathematics Education, 19(4), pp.147-150.

JOHNSON, L.; LEVINE, A.; SMITH, R. (2009). The 2009 Horizon Report, Austin, Texas. The New Media Consortium. Documento en línea [Fecha de consulta. 23/04/2009] en http.//www.nmc.org/pdf/2009-Horizon-Report.pdf.

JOHNSON, L., SMITH, R., LEVINE, A., STONE, S. (2010). The 2010 Horizon Report. Edición en español. (Xavier Canals, Eva Durall, Translation.) Austin, Texas. The New Media Consortium. Documento en línea [Fecha de consulta. 14/10/2010] http.//www.nmc.org/pdf/2010-Horizon-Report-es.pdf.

JONASSEN, D.; ROHRER-MURPHY, L. (1999). Activity theory as a framework for designing constructivist learning environments. Educational Technology, Research \& Development, Vol. 47, №1.

JONES, N. (2007). The Disruptive Effect of Technology a University Case Study, FONG, J., KWAN, R., LEE WANG, (Eds.), Workshop on Blended Learning 2007, Edinburgh, United Kingdom. 
JORBA, J.; CASELLAS, E. (ed.) (1997). Estrategias y técnicas para la gestión social del aula. La regulación y la autorregulación de los aprendizajes, Madrid, Editorial Síntesis S.A. e ICE-UAB (Institut de Ciències de l’Educació - Universidad Autónoma de Barcelona), volumen I.

KAJAMAA, A. (2012). Enriching action research with the narrative approach and activity theory: analyzing the consequences of an intervention in a public sector hospital in Finland. Educational Action Research, 20(1), pp.75-93.

KARASAVVIDIS, I. (2009). Activity Theory as a conceptual framework for understanding teacher approaches to Information and Communication Technologies. Computers \& Education, Vol. 53, №2.

KERRES, M.; WITT, C. (2003). A didactical framework for the design of blended learning arrangements. Journal of Educational Media, 28, 101-114.

LARRIPA, M.; ERAUSQUIN, C. (2008). Teoría de la actividad y modelos mentales. Instrumentos para la reflexión sobre la práctica profesional. "aprendizaje expansivo", intercambio cognitivo y transformación de intervenciones de psicólogos y otros agentes en escenarios educativos; Facultad de Psicología - UBA, Anuario de Investigaciones, Volumen XV.

LAVIÑA, J.; MENGUAL, L. (dir. y coord.) (2008). Libro Blanco de la Universidad Digital 2010, Fundación Telefónica y Editorial Ariel, S.A., España. Documento en línea [Fecha de consulta. 05-02-2009] en http.//www.universidaddigital2010.es/portal/page/udf/inicio/publico.

LEONTIEV, A.N. (1978). Activity, Consciousness, and Personality; New Jersey, Prentice-Hall.

LEONTIEV, A.N. (1979). The problem of activity in psychology. En Wertsch, J.V. (Ed.) The concept of activity in Soviet psychology. Armonk, NY. Sharpe.

LEONTIEV, A.N. (1981). Problems of the Development of the Mind. Moscow. Progress Publishers. 
LEVINE, A. (2006). Educación superior. Una revolución externa, una evolución interna; en PITTINSKY, M.S. (2006) (coord.). La Universidad conectada. Perspectivas del impacto de Internet en la educación superior en EEUU, Ediciones Aljibe, Málaga, España.

LÉVY, P. (1999); ¿Qué es lo virtual?, Barcelona, Paidós.

LI, Z., TSAI, M. H., TAO, J., LORENTZ, C. (2014). Switching to blended learning: The impact on students' academic performance. Journal of Nursing Education and Practice, 4(3), p245.

LIM, D.; LANE MORRIS, M.; KUPRITZ, V. (2006). Online vs. Blended Learning. Differences in Instructional Outcomes and Learner Satisfaction, Academy of Human Resource Development International Conference (AHRD). Documento en línea [Fecha de consulta. 13/07/2008] en http.//www.eric.ed.gov/ ERICWebPortal/contentdelivery/servlet/ERICServlet?accno=ED492755.

LIM, D., MORRIS, M. (2009). Learner and instructional factors influencing learning outcomes within a blended learning environment; Educational Technology \& Society, v12, №4.

LING, S-E, ARIFFIN, S., SAEMAH, B., LAI, K-L. (2010). Diversity in education using blended learning in Sarawak; US-China Education Review, Volume 7, №2.

LION, C. (2006). Imaginar con tecnologías. Relaciones entre tecnologías y conocimiento, Buenos Aires, La Crujía Ediciones.

LLORENTE CEJUDO, M. (2008). Actitudes de alumnos universitarios en procesos de formación blended learning; Revista Internacional de Ciencias Sociales y Humanidades, SOCIOTAM, Vol. XVIII, №2.

LÓPEZ, M.; PÉREZ, M; RODRÍGUEZ, L. (2013). Aplicación del aprendizaje combinado en contabilidad.

Un análisis comparativo entre diferentes titulaciones universitarias. Revista de Educación. $\mathrm{N}^{\circ}$ 360. Enero-abril, pp. 461-482. 
LÓPEZ-VARELA, A. (2006). Experiencias innovadoras de formación colaborativa y combinada (b-learning); II Encuentro sobre experiencias grupales innovadoras en la docencia universitaria. Documento en línea [Fecha de consulta. 19/07/2008] en http.//www.ucm.es/info/tropico/EGI02/conclusiones/lopez\%20varela.pdf.

LORENZO, A.; MARTínEZ, A.B.; MARTÍNEZ, E. (2004). Fuentes de información en investigación socioeducativa. RELIEVE. v. 10, n. 2, p. 117-134. Documento en línea [Fecha de consulta. 15/07/2008] en http.//www.uv.es/RELIEVE/v10n2/RELIEVEv10n2_6.htm.

MCANALLY-SALAS, L.; NAVARRO, M.; RODRÍGUEZ-LARES, J. (2006). La integración de la tecnología educativa como alternativa para ampliar la cobertura en la educación superior. Revista Mexicana de Investigación Educativa, XI (28).11- 30. Documento en línea [Fecha de consulta. 21/11/2010] en http.//red-academica.net/mcanally/wpcontent/uploads/2006/10/mcanally_rmie_2006.pdf.

McCROSKEY, J. C.; RICHMOND, V. P. (1992). Increasing Teacher Influence through Immediacy, en: Richmond, V. P.; McCroskey, J. C. (Eds.), Power in the Classroom: Communication, Control and Concern. Hillsdale, New York: Lawrence Erlbaum. Documento en línea [Fecha de consulta. 20/08/2009] http://www.as.wvu.edu/ richmond/articles/chap7-mccroskey-increasing.pdf.

MARCELO, C.; PUENTE, D.; BALLEESTEROS, M.; PALAZÓN, A. (2002). E-learningteleformación. Diseño, desarrollo y evaluación de la formación a través de Internet, Barcelona, Ediciones Gestión 2000.

MARCELO, C. (2004). Estudio sobre competencias profesionales para e-learning, Andalucía, Consejería de Empleo, Dirección General de Formación para el Empleo, Junta de Andalucía.

MARCELO, C., YOT, C., SÁNCHEZ, M., MURILLO, P., MAYOR, C. (2011). Diseñar el aprendizaje en la universidad: Identificación de patrones de actividades. Profesorado. Revista de Currículum y Formación de Profesorado, 15(2), 181-198.

MARTÍN GARCÍA, A. V. (2014). Blended Learning desde la perspectiva de los modelos de adopción y difusión de innovaciones tecnológicas. En MARTíN GARCÍA, A. V. (Coord.). 
Blended Learning en educación superior. Perspectivas de innovación y cambio. Madrid, Editorial Síntesis S.A.

MARTÍN GARCÍA, A. V., GARCÍA DEL DUJO, Á., MUÑOZ RODRÍGUEZ, J. M. (2014). Factores determinantes de adopción de blended learning en educación superior. Adaptación del modelo UTAUT. Educación XX1, 17(2).

MARTíNEZ ORTEGA, R. M., TUYA PENDÁS, L. C., MARTíNEZ ORTEGA, M., PÉREZ ABREU, A., CÁNOVAS, A. M. (2009). El coeficiente de correlación de los rangos de Spearman. Caracterizacion. Revista Habanera de Ciencias Médicas, 8(2).

MARZO NAVARRO, M.; MARIN, A; ESTEBAN, L.; GARGALLO, A. (2003). Un estudio exploratorio sobre la valoración realizada por los estudiantes del uso de las nuevas tecnologías; XI Congreso Universitario de Innovación Educativa en la Enseñanza de las Técnicas, julio. Documento en línea [Fecha de consulta. 16/07/2008] en http.//www.epsevg.upc.es/xic/cd/ponencias/R0050.pdf.

MARZO, M., ESTEBAN, S., GARGALLO, A. (2006). ¿Inciden las nuevas tecnologías en los resultados alcanzados por los alumnos? Un estudio exploratorio; Revista de Educación, 340. Mayo-agosto 2006. Documento en línea en [Fecha de consulta. 30/06/2007] en http.//www.revistaeducacion.mec.es/ re340/re340_25.pdf.

MASON, R.; RENNIE, F. (2006). Elearning. The key concepts. Key Guides. Abingdon, Oxon, Inglaterra. Routledge.

MAZZONI, E.; GAFFURI, P. (2009). Entornos de aprendizaje personales para superar fronteras de conocimiento entre sistemas de actividad en la edad adulta temprana; eLearning Papers, № 15, junio. Documento en línea [Fecha de consulta. 12/02/2010] en http.//www.elearningeuropa.info/files/media/media20165.pdf.

MAYORGA, M.C. (2009). Actividades no presenciales y herramientas web 2.0 en la enseñanza-aprendizaje de Derecho Bancario y Bursátil; III Congreso Nacional de Innovación Docente en Ciencias Jurídicas, Innovación y Calidad en la docencia del Derecho, Universidad de Sevilla. Documento en línea [Fecha de consulta. 20-10-2010] http.//www.innovaciondocentejuridica.es/Comunicaciones\%20pdf/ Mayorga\%20Toledano,\%20M\%C2\%AA\%20Cruz.pdf. 
MEANS, B.; TOYAMA, Y.; MURPHY, R.; BAKIA, M.; JONES, K. (2009). Evaluation of EvidenceBased Practices in Online Learning A Meta-Analysis and Review of Online Learning Studies, U.S. Department of Education Office of Planning, Evaluation, and Policy Development Policy and Program Studies Service. Documento en línea [Fecha de consulta. 12/02/2010] en http.//www.ed.gov/rschstat/eval/tech/evidence-basedpractices/finalreport.pdf.

MEANS, B., TOYAMA, Y., MURPHY, R., BAKI, M. (2013). The Effectiveness of Online and Blended Learning: A Meta-Analysis of the Empirical Literature. Teachers College Record, 115(3), 1-47.

MECD (2003). La Integración del Sistema Universitario Español en el Espacio Europeo de Enseñanza Superior. Documento Marco. Febrero de 2003. Documento en línea [Fecha de consulta. 07-09-2008] en http.//www.mecd.es.

MIGUEL, M. (Coord.) (2006). Metodologías de enseñanza y aprendizaje para el desarrollo de competencias. Orientaciones para el profesorado universitario ante el espacio europeo de educación superior, Madrid, Alianza Editorial.

MINISTERIO DE EDUCACIÓN DE CHILE (2002). Estudio Internacional Tecnologías de Información en el Sistema Escolar. SITES el caso de Chile. Síntesis de resultados; Documento en línea [Fecha de consulta. 21/07/2008] en http.//www.redal.net/red_privada/biblioteca/84.pdf.

MIRANDA, G., TIRADO, F. (2013). Análisis sistémico en la generación cultural de una comunidad virtual de aprendizaje. Revista Electrónica de Investigación Educativa, 15(1), 1-16. ; Documento en línea [Fecha de consulta. 16/02/2014] en http://redie.uabc.mx/vol15no1/contenido-mirandatirado.html.

MONDÉJAR, J.; MONDÉJAR JIMÉNEZ, J.; VARGAS, M. (2007). Docencia virtual en universidades presenciales. Experiencia en la Universidad de Castilla-La Mancha; RIED, Revista Iberoamericana de Educación a Distancia Volumen 10, I № 2. Documento en línea [Fecha de consulta. 16/07/2008] en http.//www.utpl.edu.ec/ried/images/pdfs/volumendiez/docencia-virtual.pdf. 
MONEREO, C. (coord.) (2005). Internet y competencias básicas. Aprender a colaborar, a comunicarse, a participar, a aprender. Barcelona. Editorial Graó.

MONTEIRO, A.; LEITE, C.; LIMA, L. (2013). Quality of blended learning within the scope of the Bologna process. TOJET: The Turkish Online Journal of Educational Technology. January, volume 12 .

MORALES, S. (2008). La efectividad de un modelo de aprendizaje combinado para la enseñanza del inglés como lengua extranjera. Estudio empírico; RLA. Revista de Lingüística Teórica y Aplicada, v46, №2.

MORAN, L. (2012). Blended-learning. Desafío y oportunidad para la educación actual. Edutec, Revista Electrónica de Tecnología Educativa, 39. Documento en línea [Fecha de consulta. 16/02/2014] en http://edutec.rediris.es/Revelec2/Revelec39/blended_learning_desafio_oportunida d_educacion_actual.html.

MORAN, B. (2013). Implementing a learning management system. Lessons learned. Training \& Development, 40(3), 22.

MORENO, F. y SANTIAGO, R. (2003). Formación on-line. Guía para profesores universitarios, España, Universidad de la Rioja.

MUJICA, C.; PRIETO, J.C. (2007). Sistema de Créditos Transferibles y carga de trabajo de los estudiantes en las Universidades del Consejo de Rectores, Revista Calidad en la Educación No 26, julio. Documento en línea [Fecha de consulta. 12/10/2008] en http.//www.cse.cl/public/Secciones/seccionpublicaciones/doc/56/cse_articulo597. pdf.

MURPHY, E.; RODRÍGUEZ, M. (2008). Contradictions between the virtual and physical high school classroom. A third-generation Activity Theory perspective. British Journal of Educational Technology, Vol. 39, №6.

MWANZA, D.; ENGESTROM, Y. (2003). Pedagogical adeptness in the design of elearning environments. Experiences from Lab@Future project. Paper presented at the E-Learn 2003 International Conference on E-Learning in Corporate, Government, Healthcare, 
\& Higher Education, Phoenix, AR. Documento en línea [Fecha de consulta. 12/02/2010] en http.//tlc.zmml.uni-bremen.de/resource_files/resources/190/ Pedagogical_Adeptness_in_the_Design_of_E-learning_Environments.pdf.

NAVARRO, M. (2006). Análisis de algunos resultados en la evaluación de los ambientes virtuales de aprendizaje; Graffylia. Revista de la Facultad de Filosofía y Letras, I №. 6, págs. 120-125. Documento en línea [Fecha de consulta. 16/07/2008] en http.//www.filosofia.buap.mx/Graffylia/6/120.pdf.

NORMAN, D. (2000). El ordenador invisible, Barcelona, Ediciones Paidós Ibérica S.A.

NOVELL, M., BOHIGAS, X., JAEN, X. (2009). Description and evaluation of a hybrid basic optics course. Innovations in Education and Teaching International, v46, № 4.

OCDE (2010). Habilidades y competencias del siglo XXI para los aprendices del nuevo milenio en los países de la OCDE. Instituto de Tecnologías Educativas. Documento en línea [Fecha de consulta. 12/09/2011] en http://www.ite.educacion.es.

O.E.I. (2008). Metas Educativas 2021. La educación que queremos para la generación de los Bicentenarios, Organización de Estados Iberoamericanos para la Educación, la Ciencia y La Cultura, Madrid. Documento en línea [Fecha de consulta. 12/01/2009] en http.//www.oei.es/metas2021/todo.pdf.

OSORIO, L.; DUART, J. (2011). Análisis de la interacción en ambientes híbridos de aprendizaje. Comunicar, 18(37), 65-72.

OSORIO, L., DUART, J. M. (2012). A hybrid approach to university subject learning activities. British Journal of Educational Technology, 43(2), pp. 259-271.

OZGEN, K.; UFUK, K. (2009). The Impact of Blended Learning Model on Student Attitudes towards Geography Course and Their Critical Thinking Dispositions and Levels, SourceTurkish Online Journal of Educational Technology- TOJET, v8, №4.

PARDO H.; SCOLARI, C. (2006). Web 2.0. Caos conceptual y nuevos mitos en el discurso cibercultural. IX Congreso IBERCOM. El espacio iberoamericano de comunicación en la era digital. Universidad de Sevilla. Sevilla. 
PENALVA, M.; REY, C.; LLINARES, S. (2011). Identidad y aprendizaje de estudiantes de psicopedagogía. Análisis en un contexto b-learning en didáctica de la matemática. Revista Española de Pedagogía. Año LXIX, no 248, enero-abril.

PEÑALOSA CASTRO, E.; GARCÍA HERNÁNDEZ, C.; MARTÍNEZ ROMERO, R.; ROJAS BRAVO, G. (2010). Modelo estratégico de comunicación educativa para entornos mixtos de aprendizaje. Estudio piloto. Pixel-Bit. Revista de Medios y Educación. № 37, pp. 43 55. Documento en línea [Fecha de consulta. 06-11-2010] en http.//www.sav.us.es/pixelbit/pixelbit/articulos/n37/4.pdf.

PereirA, J., PlegueZuelos, A., MOlinA-ROS, A., MOlinA-TOMA'S, M., MASDEU, C. (2007). Effectiveness of using blended learning strategies for teaching and learning human anatomy; Medical Education; 41.

PARELLADA, M. (2009). Informe CYD 2008, sobre la contribución de las universidades españolas al desarrollo. Fundación Conocimiento y Desarrollo, Barcelona. Documento en línea [Fecha de consulta. 1/05/2009] en http.//www.fundacioncyd.org.

PÉREZ, E; HERRERA, L.; MALDONADO, G.; MENDOZA, N (2008). Aplicación de un LMS como herramienta de b-learning en estudios de posgrado. Documento en línea [Fecha de consulta.

12/01/2009] enhttp.//www.eduonline.ua.es/jornadas2008/comunicaciones/3B2.pdf?PHPSESSID $=91262$ e94ab96efOfedc96c276c41747e.

PÉREZ, J. (2004). Evaluación pedagógica de cursos virtuales, Comunicación en el VII Congreso Iberoamericano de Informática Educativa, Monterrey, México, octubre. Documento en línea [Fecha de consulta. 12/07/2008] en http.//www.niee.ufrgs.br/eventos/RIBIE/2004/comunicacao/com374-383.pdf.

PÉREZ LORIDO, M. (2007). Asignaturas Virtuales en Universidades Presenciales. Perspectivas y Problemas, Pixel-Bit. Revista de Medios y Educación, ISSN 1133-8482, I №. 30. Documento en línea [Fecha de consulta. 02/10/2008] en http.//www.sav.us.es/pixelbit/articulos/n25/n25art/art2510.htm. 
PÉREZ LORIDO, M (2010). Una reflexión sobre la aplicación de nuevas tecnologías en el contexto escolar. Revista Galego-Portuguesa de Psicoloxía e Educación, Vol. 18, (2), Ano 14--2010.

PÉREZ NAVÍO, E.; HERRERA CORONA, L.; AURORA MALDONADO BEREA, G. (2008). Aplicación de un LMS como Herramienta de B-learning en Estudios de Posgrado, VI Jornadas de Redes de Investigación en Docencia Universitaria, Universidad de Alicante, 9 y 10 de junio.

PÉREZ SERRANO, G. (1998). Investigación cualitativa. Retos e interrogantes. Vol. Métodos (2a ed.). Madrid. Editorial La Muralla S.A.

PICCIANO, A.G.; DZIUBAN, C. (2007). Blended learning. Research perspectives. Needham, MA. The Sloan Consortium.

PICCIANO, A. G., DZIUBAN, C. D., GRAHAM, C. R. (Eds.). (2014). Blended learning: Research perspectives. (Vol. 2). New York. Routledge.

PITTINSKY, M.S. (2006) (coord.). La Universidad conectada. Perspectivas del impacto de Internet en la educación superior en EEUU, Ediciones Aljibe, Málaga, España.

POON, J. (2013). Blended learning: an institutional approach for enhancing students' learning experiences. MERLOT Journal of Online Learning and Teaching. Vol. 9, No. 2, June.

POSTICO, D. (2009). Wolfram Alpha revolucionará la Red, Elmundo.es. Documento en línea [Fecha de consulta. 10/05/2009] en http.//www.elmundo.es/elmundo/2009/05/04/navegante/1241424712.html.

POSTMAN, N. (2006). Cuestionamiento de los medios de comunicación. En PITTINSKY, M.S. (2006) (coord.). La Universidad conectada. Perspectivas del impacto de Internet en la educación superior en EEUU, Ediciones Aljibe, Málaga, España.

PRECEL, A., ESHET-ALKALAI, Y., ALBERTON, Y. (2009). Pedagogical and design aspects of a blended learning course. International Review of Research in Open and Distance Learning, №10. 
PRENDES, M.P., GUTIÉRREZ, I., MARTÍNEZ, F. (2010). Recursos Educativos en Red. Editorial Sintesis, Madrid.

PRENSKY, M. (2001). Digital natives, digital immigrants, MCB University Press, Vol. 9, No. 5, octubre. Documento en línea [Fecha de consulta. 17/09/2007] en http.//www.marcprensky.com/writing/

Prensky\%20-20Digital\%20Natives,\%20Digital\%20Immigrants\%20-\%20Part1.pdf

PUENTE, D (2002). En MARCELO, C.; PUENTE, D.; BALLEESTEROS, M.; PALAZÓN, A. (2002). E-learning-teleformación. Diseño, desarrollo y evaluación de la formación a través de Internet, Barcelona, Ediciones Gestión 2000.

PUENTES, A.; CRUZ, I. (2012). Innovación educativa: implementación de la física introductoria en la modalidad semipresencial. Píxel-Bit. Revista de Medios y Educación. № 40, enero, pp. 125-136. Documento en línea [Fecha de consulta. 21-022014] en http://acdc.sav.us.es/pixelbit/images/stories/p40/12.pdf.

QUITIÁN, S. (2011). Papel del diálogo como estrategia oral en la comprensión de textos expositivos en ambientes de aprendizaje b-learning. Enunciación, v. 16, n. 2, p. 4862, febrero. Documento en línea [Fecha de consulta. 21-02-2014] en <http://revistas.udistrital.edu.co/ojs/index.php/enunc/article/view/3904/5517>.

RAMBE, P. (2012). Activity theory and technology mediated interaction: Cognitive scaffolding using question-based consultation on Facebook. Australasian Journal Of Educational Technology, 28(8).

RAMÍREZ CONDE, D. (2012). Modelo de acción docente para el desarrollo de prácticas pedagógicas con medios informáticos y telemáticos en el contexto aula. Píxel-Bit. Revista de Medios y Educación. N 40, enero, pp. 151-170. Documento en línea [Fecha de consulta. 21-02-2014] en http://acdc.sav.us.es/pixelbit/images/stories/p40/12.pdf.

RAMÍREZ, J.; JUÁREZ, M.; REMESAL, A. (2012). Teoría de la actividad y diseño de cursos virtuales: la enseñanza de matemáticas discretas en Ciencias de la Computación. Aprendizaje virtual de las matemáticas. Revista de Universidad y Sociedad del 
Conocimiento (RUSC). Vol. 9, n. 1, pp. 130-149. [Documento en línea [Fecha de consulta. 21-02-2014] en http://rusc.uoc.edu/ojs/index.php/rusc/article/view/v9n1ramirez-juarez-remesal/v9n1-ramirez-juarez-remesal.

RECIO, M.; CABERO, J. (2005). Enfoques de aprendizaje, rendimiento académico y satisfacción de los alumnos en formación en entornos virtuales, Pixel-Bit. Revista de Medios y Educación, ISSN 1133-8482, I №25. Documento en línea [Fecha de consulta. 02/10/2008] en http.//www.sav.us.es/pixelbit/articulos/n25/n25art/art2510.htm.

REYERO, D.; MORCILLO, J.; RODRÍGUEZ, E.; GIL, F.; JOVER, G. (2008). Elaboración de criterios pedagógicos para un mejor aprovechamiento de los Campus virtuales. Revista Electrónica de la Educación. Educación y Cultura en la Sociedad de la Información. Vol. 9, №1. Universidad de Salamanca.

RICHMOND, V. P.; MCCROSKEY, J. C.; KEARNEY, P.; PLAX, T. G. (1987). Power in Classroom VII: Linking Behaviour Alteration Techniques to Cognitive Learning. Communication Education, 36, 1, 1-12. Documento en línea [Fecha de consulta. 21/11/2010] en http://www.jamescmccroskey.com/publications/141.pdf.

RIPA, M. (2007). ¿Cómo abordar el estudio de una comunidad de aprendizaje Blended Learning? en RODRÍGUEZ ILLERA, J. (Coord.) Comunidades virtuales de práctica y de aprendizaje. Revista Electrónica de la Educación. Educación y Cultura en la Sociedad de la Información. Vol. 8, №3. Universidad de Salamanca.

ROBERTS, G. (2003). Teaching using the web. Conceptions and approaches from a phenomenographic perspective. Instructional Science, Vol. 31, No. 1-2, 127-150.

ROBERTSON, I. (2008). Sustainable e-learning, activity theory and professional development', in Hello! Where are You in the Landscape of Educational Technology? Proceedings ASCILITE Melbourne 2008, Melbourne, Australia. Documento en línea [Fecha de consulta. 10-11-2010] en http.//www.ascilite.org.au/conferences/melbourne08/procs/robertson.pdf.

ROCO, R. (2007). Mirando entre los intersticios de la brecha digital en la educación superior, Calidad en la Educación I № 26, julio. Documento en línea [Fecha de consulta. 02/10/2008] 
enhttp.//www.cse.cl/public/Secciones/seccionestudios/estudios_y_documentos_Ot ros.aspx.

RODRIGUES, A; PAVAN, N.; CASALE, A. (2012) PBL and B-Learning for civil engineering students in a transportation course. Journal of professional issues in engineering education \& practice. October.

RODRÍGUEZ CONDE, M. J., GARCÍA, A. B. S. (2002). Competencias docentes del profesor universitario para el uso didáctico de recursos tecnológicos, ante el Espacio Europeo de Educación Superior. Aula, 14. Ediciones Universidad de Salamanca.

RODRÍGUEZ GÓMEZ, D., VALLDEORIOLA ROQUET J. (2009). Metodología de la investigación. FUOC. Documento en línea [Fecha de consulta. 11/12/2010] en http.//cv.uoc.edu/continguts/PID_00148557/index.html.

RODRÍGUEZ SABIOTE, C. (2003). Nociones y destrezas básicas sobre el análisis de datos cualitativos. Seminario Internacional El proceso de Investigación en educación, algunos elementos clave. Santo Domingo, República Dominicana, 29 y 30 de agosto, Facultad Latinoamericana de Ciencias Sociales (FLACSO).

ROSENBERG, M. (2001). E-learning. Estrategias para transmitir conocimiento en la era digital, Bogotá, McGraw Hill.

ROSNAY, J. (1977). El Macroscopio. Hacia una visión global, Madrid. AC, D.L.

ROTH, W-M. (2004). Activity theory and education. An introduction, Mind, Culture and Activity, II, 1.

ROTH, W-M.; LEE, Y-J. (2007). Vygotsky's neglected legacy. Cultural-historical activity theory. Review of Educational Research, Vol. 77, №2.

ROTH, W. M. (2012). Societal Mediation of Mathematical Cognition and Learning. Orbis Scholae, 6(2).

RUBIO, M. J. (2003). Enfoques y modelos de evaluación del b-learning. Revista ELectrónica de Investigación y EValuación Educativa, v. 9, n. 2. http.//www.uv.es/RELIEVE/v9n2/RELIEVEv9n2_1.htm. 
RUIPÉREZ, G., CASTRILLO, M., GARCÍA CABRERO, J. (2006). Implantación del "Five-Step Model" de G. Salmon en la Creación de Cursos Virtuales. Descripción Metodológica y Algunas Conclusiones de Varios Estudios de Caso de la UNED; Revista de Lingüística y Lenguas Aplicadas, v1.

RUIZ, C.; MAS TORELLÓ, O.; TEJADA FERNÁNDEZ, J. (2008). El uso de un entorno virtual en la enseñanza superior. Una experiencia en los estudios de pedagogía de la Universitat Autònoma de Barcelona (UAB) y la Universitat Rovira i Virgili (URV), Revista Iberoamericana de Educación № 46/3 - 25 de mayo, Organización de Estados Iberoamericanos para la Educación, la Ciencia y la Cultura (OEI). Documento en línea [Fecha de consulta. 24/04/2009] en http.//www.rieoei.org/expe/2193RuizBuenov2.pdf.

RUÍZ BOLIVAR, C. (2007). El blended learning. Evaluación de una experiencia de aprendizaje en el nivel de posgrado. RODRÍGUEZ ILLERA, José Luis. (Coord.) Comunidades virtuales de práctica y de aprendizaje. Revista Electrónica de la Educación. Educación y Cultura en la Sociedad de la Información. Vol. 8, I №3. Universidad de Salamanca. Documento en línea [Fecha de consulta. 02/03/2008] en http.//www.usal.es/ teoriaeducacion/rev_numero_08_03/n8_03_ruiz_bolivar.

RUIZ MARTíN, P. (2013). Presente y futuro de los Massive Open Online Courses (MOOC): Análisis de la oferta completa de cursos de las plataformas Coursera, EdX, Miríada X y Udacity. Universidad Complutense de Madrid, Facultad de Ciencias de la Documentación, Máster en Gestión de la Documentación, Archivos y Bibliotecas.

RYDER, M. (2010). Activity Theory, University of Colorado at Denver. Documento en línea [Fecha de consulta. 08-11-2010], http.//carbon.ucdenver.edu/ mryder/itc_data/activity.html.

SAAVEDRA, O; CELIS, R. (2007). Estudio del Modelo B-learning en el Proceso Educativo, XXI Congreso de Educación en Ingeniería, 3, 4 y 5 de octubre, Santiago, Chile.

SABARIEGO, M. (2004). Metodología de la investigación educativa. Madrid, La Muralla. 
SABARIEGO, M.; BISQUERRA, R. (2004). Fundamentos metodológicos de la investigación educativa. En BISQUERRA, R. (Coord.). (2004b). Metodología de la investigación educativa. Madrid. La Muralla.

SÁEZ VACAS, F. (2004). Más allá de Internet. La Red Universal Digital. X-Economía y nuevo entorno tecnosocial, Madrid, Editorial Centro de Estudios Ramón Areces S.A.

SALINAS, J. (2004). Innovación docente y uso de las TIC en la enseñanza universitaria, Revista de Universidad y Sociedad del Conocimiento, RUSC, vol. 1, no 1. Documento en línea [Fecha de consulta.07-09-2008] en http.//www.uoc.edu/rusc/dt/esp/salinas1104.pdf.

SAM, C. (2012). Activity Theory and Qualitative Research in Digital Domains. Theory Into Practice, 51(2), pp. 83-90.

SALMON, G. (2011). E-moderating. The key to teaching and learning online, United Kingdom, Routledge.

SALMON, G. (2004). E-actividades. Factor clave para una formación en línea activa, Barcelona, Editorial UOC.

SANDARS, J. (2005). An activity theory perspective, Work Based Learning in Primary Care, 3.

SANGRÀ, A.; GONZÁLEZ, M. (coord.) (2004). La transformación de las universidades a través de las TIC. Discursos y prácticas, Editorial UOC, Barcelona.

SAUTU, R.; BONIOLO, P.; DALLE, P.; ELBERT, R. (2005). Manual de metodología. Construcción del marco teórico, formulación de los objetivos y elección de la metodología. CLACSO, Consejo Latinoamericano de Ciencias Sociales, Buenos Aires. Documento en línea [Fecha de consulta. 19/04/2009] en http.//bibliotecavirtual.clacso.org.ar/ar/libros/Campus/metodo/metodo.html.

SCAGNOLI, N. (2003). Uso de Internet en Clases Presenciales F.O.D.A., CONTEC 2003. Documento en línea [Fecha de consulta. 16/07/2008] en http.//students.ed.uiuc.edu/scagnoli/pubs/Web-asistida-FODA.pdf. 
SCANLON, E.; ISSROFF, K. (2005). Activity theory and higher education. Evaluating learning technologies. Journal of Computer Assisted Learning, Vol. 21, №6.

SCHIEDERIG, K. (2007). Using b-learning for social sciences. Practical lessons from the Free University of Berlin, eLearning Papers, I № 3 marzo. Documento en línea [Fecha de consulta. 16/07/2008] en www.elearningpapers.eu.

SCHWIER, R.A., MORRISON, D., DANIEL, B.K. (2009). A preliminary investigation of selfdirected learning activities in a non-formal blended learning environment; Annual Conference of the American Educational Research Association, San Diego, California.

SHROFF, R., VOGEL, D. (2010). An Investigation on Individual Students' Perceptions of Interest Utilizing a Blended Learning, International Journal on E-Learning, v9 nㅇ.2.

SIGOSSEE; JOIN (2005). Evaluación de las plataformas LMS. Open Source for Education in Europe. Documento en línea [Fecha de consulta. 05-06-2008] en http.//www.ossite.org/join/sp/Ims.

SILVA, J. Y ASTUDILLO, A. (2012). CBL-Cálculo: Curso b-learning para el apoyo de la enseñanza y aprendizaje de cálculo en ingeniería. RED, Revista de Educación a Distancia. $\mathrm{N}^{\circ}$ 30. Documento en línea [Fecha de consulta. 16/02/2014] en http://www.um.es/ead/red/30

SILVA, J.; GROS, B. (2007). Una propuesta para el análisis de interacciones en un espacio virtual de aprendizaje para la formación continua de los docentes. En SÁNCHEZ, Mạ Cruz y REVUELTA DOMÍNGUEZ, Francisco I. (Coords.) Estudio de los comportamientos emocionales en la red [monográfico en línea]. Revista Electrónica Teoría de la Educación. Educación y Cultura en la Sociedad de la Información. Vol. 8, I № 1. Universidad de Salamanca. Documento en línea [Fecha de consulta. 02/03/2008] en http.//www.usal.es/ teoriaeducacion/rev_numero_08_01/n8_01_silva_gros.pdf.

SINGH, H. (2003). Building Effective Blended Learning Programs, Educational Technology 43.6, pp 51-54.

SINGLETON, D. (2013). Transitioning to blended learning: the importance of communication and culture. Journal of Applied Learning Technology. Volume 3. N¹. 
SO, L. (2013). A case study on the effects of an 12 writing instructional model for blended learning in higher education. TOJET: The Turkish Online Journal of Educational Technology. October, volume 12.

STALLMAN, R. (2004). Software Libre para una Sociedad Libre. Madrid. GNU Press.

STC-CHILE (2013). Manual para la Implementación del SCT-Chile. Documento en línea [Fecha de consulta. 05-06-2008] en http://sctchile.consejoderectores.cl/que_es_sct_chile.php.

STOKES, H. (2004). La interactividad en la educación a distancia. Evaluación de comunidades de aprendizaje; Revista Iberoamericana de Educación a Distancia, RIED, vol. 7, I № 1-2, págs. 147-162. Documento en línea [Fecha de consulta. 02/03/2008] en http.//www.utpl.edu.ec/ried/images/pdfs/vol7-1-2/la_interactividad.pdf.

STUBBS, M., MARTIN, I., ENDLAR, L. (2006). The structuration of blended learning. Putting holistic design principles into practice; British Journal of Educational Technology, v37 №2.

SUÁREZ, J.M.; ANAYA, D. (2004). Educación a distancia y presencial. Diferencias en los componentes cognitivo y motivacional de estudiantes universitarios; RIED-Revista Iberoamericana de Educación a Distancia, 7 (1-2), p. 65-75. Documento en línea [Fecha de consulta. 02/10/2008] en http.//espacio.uned.es/fez/eserv.php?pid=bibliuned.20632\&dsID=educacion_distancia_pre sencial.pdf.

TAYLOR, P. (2008). El currículo de la educación superior para el desarrollo humano y social en GLOBAL UNIVERSITY NETWORK FOR INNOVATION. La educación superior en el mundo 3. Educación superior. Nuevos retos y roles emergentes para el desarrollo humano, Madrid, Ediciones Mundi-Prensa.

TEJADA, J. (director) (2006). Las comunidades virtuales de aprendizaje. Nuevas fórmulas, viejos retos en los procesos educativos; Current Developments in TechnologyAssisted Education. Documento en línea [Fecha de consulta. 16/07/2008] en http.//www.formatex.org/micte2006/pdf/1462-1466.pdf. 
TEJADA FERNÁNDEZ, J.; NAVÍO GÁMEZ, A.; RUIZ BUENO, C. (2007). La didáctica en un entorno virtual interuniversitario. Experimentación de ECTS apoyados en TIC; PixelBit. Revista de Medios y Educación, julio, número 030, p95-118. Documento en línea [Fecha de consulta. 23/04/2009] en http.//redalyc.uaemex.mx/redalyc/pdf/368/36803009.pdf.

TEMPELAAR, D., RIENTIES, B., GIESBERS, B. (2009). Who Profits Most from Blended Learning?, Industry and Higher Education, v23 №4.

TIFFIN, J.; RAJASINGHAM, L. (1997). En busca de la clase virtual. Educación en la sociedad de la información, Barcelona, Paidós.

TIRADO, R.; AGUADED, J.; MÉNDEZ, J. (2009). Interacciones en grupos de aprendizaje online; Revista Iberoamericana de Educación n. - 48/5 - 25 de febrero, ISSN. 16815653, Organización de Estados Iberoamericanos para la Educación, la Ciencia y la Cultura (OEI). Documento en línea [Fecha de consulta. 28/02/2009] en http.//www.rieoei.org/2788.htm.

TIRADO, R.; PÉREZ, M.; AGUADED, J. (2011). Blended e-learning en universidades andaluzas. Aula Abierta. Vol. 39, N², pp. 47-58. Documento en línea [Fecha de consulta.

en http://rabida.uhu.es/dspace/bitstream/handle/10272/6288/Blended_e_learning.pd f?sequence $=2$.

TOLMAN, C.W. (1988). The basic vocabulary of Activity Theory. Activity Theory. Documento en línea [Fecha de consulta. 01/11/2010] en http.//www.comnet.ca/ pballan/AT2.htm.

TRIOLA, M. (2009). Estadística. México: Pearson Educación.

TURPO GEBERA, O., HERNÁNDEZ SERRRANO, M. J. (2014). La convergencia pedagógica y tecnológica de la modalidad Blended Learning. En MARTín GARCÍA, A. V. (Coord.). Blended Learning en educación superior. Perspectivas de innovación y cambio. Madrid, Editorial Síntesis S.A. 
UCEDA, J.; SENÉN A. (Directores) (2008). Las TIC en el Sistema Universitario Español (2008), Conferencia de Rectores de las Universidades Españolas (CRUE). Documento en línea [Fecha de consulta. 16/07/2008] en http.//www.crue.org/export/sites/Crue/Publicaciones/Documentos/Universitic/uni versitic_2008.pdf.

UNESCO (1998). Declaración Mundial sobre la Educación Superior en el Siglo XXI. Visión y Acción; United Nations Educational, Scientific, and Cultural Organization, (UNESCO). Documento en línea [Fecha de consulta. 18/11/2008] en http.//www.unesco.org/education/educprog/wche/declaration_spa.htm.

UNESCO (2009). La UNESCO pone en marcha la Biblioteca Digital Mundial en cooperación con la Biblioteca del Congreso de EEUU y otras instituciones. Documento en línea [Fecha de consulta. 12/01/2009] en http.//portal.unesco.org/geography/es/ev.php URL_ID=11215\&URL_DO=DO_TOPIC\&URL_SECTION=201.html

USAL (2009). Estrategia Universidad Digital 2010, Universidad de Salamanca. Documento en línea [Fecha de consulta. 12/03/2009] en http.//www.usal.es/Webusal/node/1257?bcp=universidad_digital.

VALIATHAN, P. (2002). Designing a Blended Learning Solution. Documento en línea [Fecha de consulta. 16/07/2008] en http.//www.learningcircuits.org/2002/aug2002/valiathan.html.

VÁSQUEZ, M. (2007). Tutor virtual. Desarrollo de competencias en la sociedad del conocimiento. GARCÍA CARRASCO, J. \& SEOANE PARDO, A. (Coords.) Tutoría virtual y e-moderación en red [monográfico en línea]. Revista Electrónica Teoría de la Educación. Educación y Cultura en la Sociedad de la Información. Vol. 8, no2. Universidad de Salamanca. Documento en línea [Fecha de consulta. 18/11/2008] en http.//www.usal.es/ teoriaeducacion/rev_numero_08_02/n8_02_vazques.pdf>

VÁSQUEZ, M. (2009). B-learning en Educación Superior. Trabajo Tutelado de Investigación del Doctorado Proceso de Formación en Espacios Virtuales. Departamento de Teoría e Historia de la Educación. Universidad de Salamanca. 
VÁSQUEZ, M. (2009). Metodología de la Investigación en b-learning. Trabajo Tutelado de Investigación del Doctorado Proceso de Formación en Espacios Virtuales. Departamento de Teoría e Historia de la Educación. Universidad de Salamanca.

VAUGHAN, N. (2010). Designing for a blended community of inquiry. En JOUTSENVIRTA, T y MYYRY, L. (eds.) Blended learning in Finland. Publicado por la Facultad de Ciencias Sociales de la Universidad de Helsinki. Documento en línea [Fecha de consulta. 28/12/2010] en http.//www.helsinki.fi/valtiotieteellinen/julkaisut/blended_learning_Finland.pdf.

VILLAR, G. (2008). La evaluación de un curso virtual. Propuesta de un modelo, Organización de Estados Iberoamericanos para la Educación, la Ciencia y la Cultura. Documento en línea [Fecha de consulta. 18/07/2008] en http.//www.oei.es/tic/villar.pdf.

VIGOTSKY, L. (1979). El desarrollo de los procesos psicológicos superiores; Barcelona, Editorial Crítica.

VIGOTSKY, L. (1987). Pensamiento y lenguaje; Buenos Aires, Editorial la Pléyade.

WENGER, M., S., FERGUSON, C. (2006). Chapter 6. A Learning Ecology Model For Blended Learning from Sun Microsoftsystems, In C. J. Bonk, C. R. Graham (eds.). Handbook of blended learning. Global Perspectives, local designs. Pfeiffer Publishing, San Francisco, CA.

WERTSCH, J. (Ed.) (1981). The concept of activity in Soviet psychology. Armonk, NY. Sharpe.

WERTSCH, J. (1988). Vygotsky y la formación social de la mente. Barcelona. Paidós.

WERTSCH, J. (1993). Voces de la mente. Un enfoque sociocultural para el estudio de la acción mediada. Madrid. Visor.

WOlTERING, V., HERRLER, A., SPITZER, K., SPRECKELSEN, C. (2009). Blended learning positively affects students' satisfaction and the role of the tutor in the problem-based learning process. Results of a mixed-method evaluation; Advances in Health Sciences Education, Volume 14, №5. 
WU, J-H., TENNYSON, R., HSIA, T-L. (2010). A study of student satisfaction in a blended elearning system environment; Computers \& Education, Volume 55, №1.

YILMAZ, M., ORHAN, F. (2010), Pre-Service English Teachers in Blended Learning Environment in Respect to Their Learning Approaches, SourceTurkish Online Journal of Educational Technology - TOJET. v9, №1.

ZURITA, G. (2007). A conceptual framework based on Activity Theory for mobile CSCL. British Journal of Educational Technology, Vol .38, № 2. 


\section{Apéndice A: Validación de cuestionario}

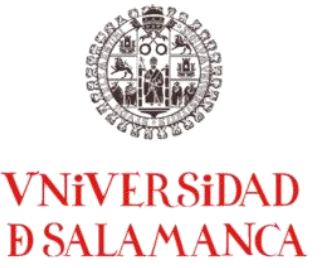

VALIDACIÓN DE CUESTIONARIO

Conocimientos y Satisfacción de Estudiantes de Educación Superior hacia las Tecnologías Integradas en el Proceso de Enseñanza-Aprendizaje

Estimada/o experta/o:

Me dirijo a usted a fin de solicitar su valiosa colaboración como Juez en la validación del "Cuestionario sobre Conocimientos y Satisfacción de Estudiantes de Educación Superior hacia las Tecnologías Integradas en el Proceso de Enseñanza-Aprendizaje". Con dicho cuestionario se pretende recoger información acerca de los conocimientos, aprendizaje percibido y el grado de satisfacción de los alumnos y alumnas universitarios sobre el uso de las tecnologías y herramientas en línea como apoyo a las clases presenciales.

La población destinataria corresponde a alumnos de primer año de la cohorte 2011, que cursan una asignatura en la modalidad blended learning, en la carrera de "Ingeniería en Prevención de Riesgos, Calidad y Ambiente", en diferentes Campus de la Universidad Tecnológica de Chile INACAP (www.inacap.cl), Chile.

Se han contemplado varias dimensiones o aspectos objeto de estudio, agrupados en dos partes:

1a Parte: conocimientos de tecnologías utilizadas en tareas académicas y tecnologías web 2.0. Se aplica al inicio y final de semestre académico.

2a Parte: Satisfacción hacia las tecnologías y aprendizaje percibido. Se aplica al final del semestre académico.

En relación a cada uno de los ítems redactados, le pedimos que exprese una puntuación numérica de 0 a 5 , en función de dos criterios básicos que pasamos a definir:

\begin{tabular}{|l|l|}
\hline PERTINENCIA & $\begin{array}{l}\text { Correspondencia entre el contenido del ítem y la dimensión para la } \\
\text { cual va a ser utilizado. }\end{array}$ \\
\hline CLARIDAD & $\begin{array}{l}\text { Grado en que el ítem está redactado de forma clara y precisa, } \\
\text { facilitando su comprensión por los sujetos encuestados }\end{array}$ \\
\hline
\end{tabular}

El valor 0 indica la mínima pertinencia o claridad en el ítem, mientras que el 5 indica el máximo valor en estos criterios.

A fin de cumplir con el cronograma de la investigación, le solicito que me envíe sus respuestas antes del 4 de febrero de 2011.

Muchísimas gracias de antemano por su colaboración. 


\begin{tabular}{|c|c|c|c|}
\hline Dimensión & Ítem & $\begin{array}{l}\text { Pertinencia } \\
\text { (De } 0 \text { a } 5 \text { ) }\end{array}$ & $\begin{array}{l}\text { Claridad } \\
\text { (De } 0 \text { a } 5 \text { ) }\end{array}$ \\
\hline \multirow{7}{*}{$\begin{array}{l}\text { Aspectos generales } \\
\text { personales del } \\
\text { alumno }\end{array}$} & Asignatura & & \\
\hline & Número de Sección & & \\
\hline & Sede o Campus & & \\
\hline & Año de Ingreso a INACAP & & \\
\hline & Jornada: Diurna / Vespertina & & \\
\hline & Género: Hombre / Mujer & & \\
\hline & Edad & & \\
\hline \multirow{5}{*}{$\begin{array}{l}\text { Disponibilidad de } \\
\text { tecnologías y } \\
\text { conexión a Internet }\end{array}$} & $\begin{array}{l}\text { ¿Dispones de un computador (PC) con Internet en casa o residencia? ¿Desde hace } \\
\text { cuánto tiempo?: Menos de } 1 \text { año, entre } 1 \text { y } 3 \text { años, entre } 4 \text { y } 5 \text { años, más de } 5 \text { años. }\end{array}$ & & \\
\hline & ¿Dispones de celular?: celular, blackberry, iphone, ipod, otro & & \\
\hline & Si posees celular, ¿tienes acceso a Internet? & & \\
\hline & ¿Dispones de computador portátil? & & \\
\hline & $\begin{array}{l}\text { ¿Con qué frecuencia te conectas a Internet? } \\
\text { - Varias veces en el día } \\
\text { - Una vez al día } \\
\text { - } \quad \text { Unanas veces en la semana } \\
\text { - No me conecto }\end{array}$ & & \\
\hline \multirow{3}{*}{$\begin{array}{l}\text { Dominio } \\
\text { de recursos } \\
\text { tecnológicos }\end{array}$} & $\begin{array}{l}\text { ¿Has recibido formación sobre cómo utilizar recursos de Internet para tareas } \\
\text { académicas? } \\
\text { - No, aprendí por mí mismo } \\
\text { - Sí, en una asignatura ¿Cuál?, ¿Cuándo? } \\
\text { - Sí, en un curso, taller, etc. } \\
\text { - Sí, un amigo, conocido me enseñó } \\
\quad \text { Otras situaciones (especificar) }\end{array}$ & & \\
\hline & 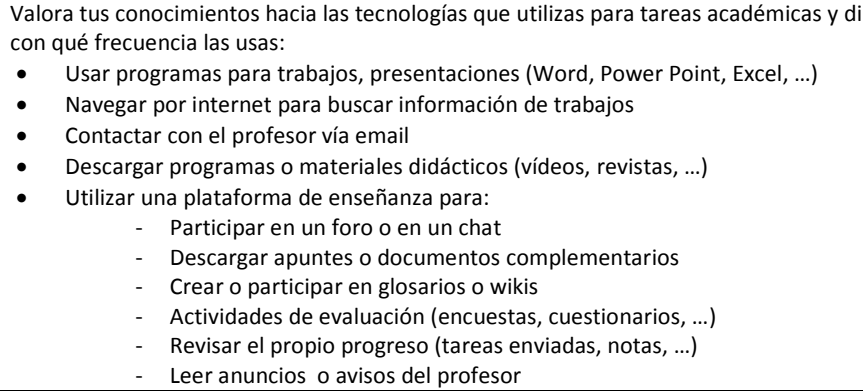 & & \\
\hline & 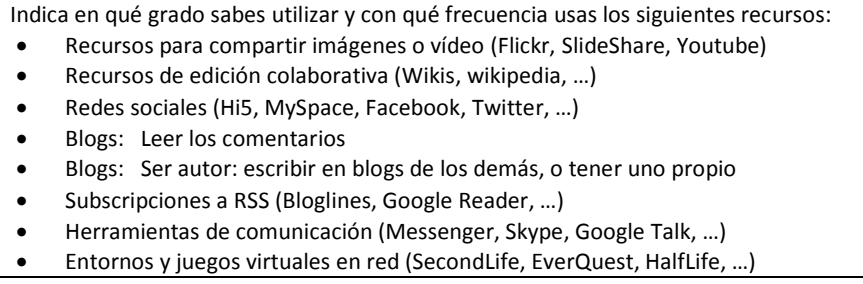 & & \\
\hline
\end{tabular}




\begin{tabular}{|c|c|c|c|}
\hline Dimensión & Ítem & $\begin{array}{l}\text { Pertinencia } \\
\text { (De } 0 \text { a } 5 \text { ) }\end{array}$ & $\begin{array}{l}\text { Claridad } \\
\text { (De } 0 \text { a } 5)\end{array}$ \\
\hline \multirow{10}{*}{$\begin{array}{l}\text { Actividades } \\
\text { de } \\
\text { aprendizaje } \\
\text { presenciales y } \\
\text { en línea }\end{array}$} & $\begin{array}{l}\text { Las actividades en línea in dividuales y grupales estaban distribuidas a lo } \\
\text { largo del semestre, desde las más sencillas a las más complejas }\end{array}$ & & \\
\hline & $\begin{array}{l}\text { La organización de las actividades realizadas en clases ha facilitado mi } \\
\text { aprendizaje }\end{array}$ & & \\
\hline & $\begin{array}{l}\text { La organización de las actividades realizadas fuera de clases ha facilitado mi } \\
\text { aprendizaje }\end{array}$ & & \\
\hline & Las actividades y contenidos en línea y presenciales estaban integrados & & \\
\hline & $\begin{array}{l}\text { La combinación de actividades presenciales y en línea enriquece la } \\
\text { asignatura }\end{array}$ & & \\
\hline & $\begin{array}{l}\text { Las actividades en línea me motivaron a aprender más acerca de la } \\
\text { asignatura }\end{array}$ & & \\
\hline & $\begin{array}{l}\text { Las actividades en línea fomentaron la participación de los estudiantes en } \\
\text { la asignatura }\end{array}$ & & \\
\hline & $\begin{array}{l}\text { El profesor se ha preocupado que to dos participemos en las actividades } \\
\text { realizadas fuera de clases }\end{array}$ & & \\
\hline & El proceso de evaluación ha sido adecuado & & \\
\hline & $\begin{array}{l}\text { Se han realizado actividades de autoevaluación suficientes para verificar mi } \\
\text { comprensión de los contenidos }\end{array}$ & & \\
\hline \multirow{7}{*}{$\begin{array}{l}\text { Uso de } \\
\text { recursos } \\
\text { tecnológicos } \\
\text { disponibles } \\
\text { en línea }\end{array}$} & $\begin{array}{l}\text { El funcionamiento técnico de la plat aforma o sitio usado es fácil de } \\
\text { comprender }\end{array}$ & & \\
\hline & $\begin{array}{l}\text { Los tiempos de respuesta de la plataforma o sitio (espera para acceder a } \\
\text { un vínculo, acceso a las diferentes herramientas, etc.) han sido adecuados }\end{array}$ & & \\
\hline & $\begin{array}{l}\text { El profesor nos ayudó a la comprensión de las cuestiones técnicas de la } \\
\text { plataforma o el sitio de trabajo en línea }\end{array}$ & & \\
\hline & $\begin{array}{l}\text { Creo que el profesor ha sacado un adecuado partido a las posibilidades que } \\
\text { ofrece el entorno virtual }\end{array}$ & & \\
\hline & $\begin{array}{l}\text { Mis conocimientos tecnológicos previos a cursar la asignatura fueron } \\
\text { suficientes para desarrollar las actividades en línea }\end{array}$ & & \\
\hline & $\begin{array}{l}\text { Me gustaría que los profesores usaran más las tecnologías en línea para } \\
\text { apoyar el aprendizaje en distintas asignaturas }\end{array}$ & & \\
\hline & $\begin{array}{l}\text { Los recursos y herram ientas del entorno en línea permiten mejorar el } \\
\text { proceso de enseñanza-aprendizaje }\end{array}$ & & \\
\hline \multirow{4}{*}{$\begin{array}{l}\text { Métodos de } \\
\text { trabajo grupal } \\
\text { presencial y } \\
\text { en línea }\end{array}$} & $\begin{array}{l}\text { Las instrucciones de las actividades ofrecían pautas o indicaciones para } \\
\text { resolverlas }\end{array}$ & & \\
\hline & Las instrucciones de las actividades me han resultado útiles para resolverlas & & \\
\hline & $\begin{array}{l}\text { El profesor realizó sugerencias de estrategias que nos ayudaron a realizar } \\
\text { las actividades en línea }\end{array}$ & & \\
\hline & $\begin{array}{l}\text { En términos generales, he quedado muy satisfecho con las estrategias de } \\
\text { aprendizaje que se usaron en la asignatura }\end{array}$ & & \\
\hline \multirow{2}{*}{$\begin{array}{l}\text { Contenidosy } \\
\text { recursos } \\
\text { digitales }\end{array}$} & Los contenidos de la asignatura están actualizados y son relevantes & & \\
\hline & $\begin{array}{l}\text { El profesor publicó o envió por correo recursos digitales o link de sitios de } \\
\text { Internet }\end{array}$ & & \\
\hline
\end{tabular}




\begin{tabular}{|c|c|c|c|}
\hline Dimensión & Ítem & $\begin{array}{l}\text { Pertinencia } \\
\text { (De } 0 \text { a } 5 \text { ) }\end{array}$ & $\begin{array}{l}\text { Claridad } \\
\text { (De 0 a 5) }\end{array}$ \\
\hline \multirow{7}{*}{$\begin{array}{l}\text { Interacción y } \\
\text { comunicación }\end{array}$} & El nivel de interacción con los compañeros de mi grupo ha sido alto & & \\
\hline & $\begin{array}{l}\text { Me ha resultado sencilla la comunicación con el resto de mis compañeros en el entorno } \\
\text { en línea }\end{array}$ & & \\
\hline & Estoy satisfecho con la ayuda que he recibido de mis compañeros & & \\
\hline & Di ayuda a mis compañeros través de herramientas en línea cuando me la solicitaron & & \\
\hline & $\begin{array}{l}\text { He tenido la percepción de formar parte de un grupo de personas que aprende, más que } \\
\text { un estudiante solitario }\end{array}$ & & \\
\hline & $\begin{array}{l}\text { La comunicación con el profesor-tutor me ha resultado fácil mediante las herramientas } \\
\text { de comunicación: correo, foro o chat }\end{array}$ & & \\
\hline & $\begin{array}{l}\text { El profesor realizó una adecuada animación y estimuló la participación de las actividades } \\
\text { en línea durante las clases presenciales }\end{array}$ & & \\
\hline \multirow{5}{*}{$\begin{array}{l}\text { Normas de trabajo } \\
\text { y roles }\end{array}$} & $\begin{array}{l}\text { Considero adecuadas las normas del profesor que regulan el trabajo sobre el entorno } \\
\text { formativo en línea }\end{array}$ & & \\
\hline & $\begin{array}{l}\text { Las actividades nos permitieron definir recomendaciones generales para una mejor } \\
\text { comunicación en línea }\end{array}$ & & \\
\hline & Los grupos pudieron establecer sus propias normas de trabajo & & \\
\hline & Me conecté semanalmente para realizar las actividades en línea individuales y grupales & & \\
\hline & $\begin{array}{l}\text { El desarrollo de las actividades en línea hizo que mi grupo trabajara cada vez más } \\
\text { autónomamente }\end{array}$ & & \\
\hline \multirow{7}{*}{$\begin{array}{l}\text { Aprendizaje } \\
\text { percibido: } \\
\text { instrumentales y } \\
\text { tecnológicos }\end{array}$} & $\begin{array}{l}\text { Las actividades en línea me ayudaron a organizar mejor mi tiempo dedicado a la } \\
\text { asignatura fuera de clases }\end{array}$ & & \\
\hline & $\begin{array}{l}\text { En la asignatura aprendí pautas para evaluar la calidad de las fuentes de información } \\
\text { disponibles en Internet }\end{array}$ & & \\
\hline & $\begin{array}{l}\text { Puedo organizar y participar en una actividad grupal usando Internet para desarrollar un } \\
\text { trabajo académico con mis compañeros }\end{array}$ & & \\
\hline & $\begin{array}{l}\text { Las tareas en línea ayudaron al desarrollo de mi autonomía para trabajar en tareas } \\
\text { académicas usando Internet }\end{array}$ & & \\
\hline & $\begin{array}{l}\text { Aprendí a usar herramientas tecnológicas que eran nuevas para mí o no las había usado } \\
\text { antes }\end{array}$ & & \\
\hline & $\begin{array}{l}\text { Aprendí a usar la plataforma o sitio web en el que se desarrollaron las actividades } \\
\text { virtuales }\end{array}$ & & \\
\hline & Utilizar Internet me posibilita aprender más por mí mismo & & \\
\hline \multirow{4}{*}{$\begin{array}{l}\text { Aprendizaje } \\
\text { percibido: } \\
\text { habilidades } \\
\text { interpersonales }\end{array}$} & $\begin{array}{l}\text { Las actividades en línea me permitieron conocer mejor a mis compañeros, en aspectos } \\
\text { distintos a los de las clases presenciales }\end{array}$ & & \\
\hline & Las actividades en línea de la asignatura promueven la ayuda entre los compañeros & & \\
\hline & $\begin{array}{l}\text { Las herramientas tecnológicas usadas nos permitieron realizar actividades y trabajos } \\
\text { colaborativamente }\end{array}$ & & \\
\hline & Realizar trabajos en línea en forma colaborativa ha sido positivo para mi aprendizaje & & \\
\hline
\end{tabular}




\section{COMENTARIOS}

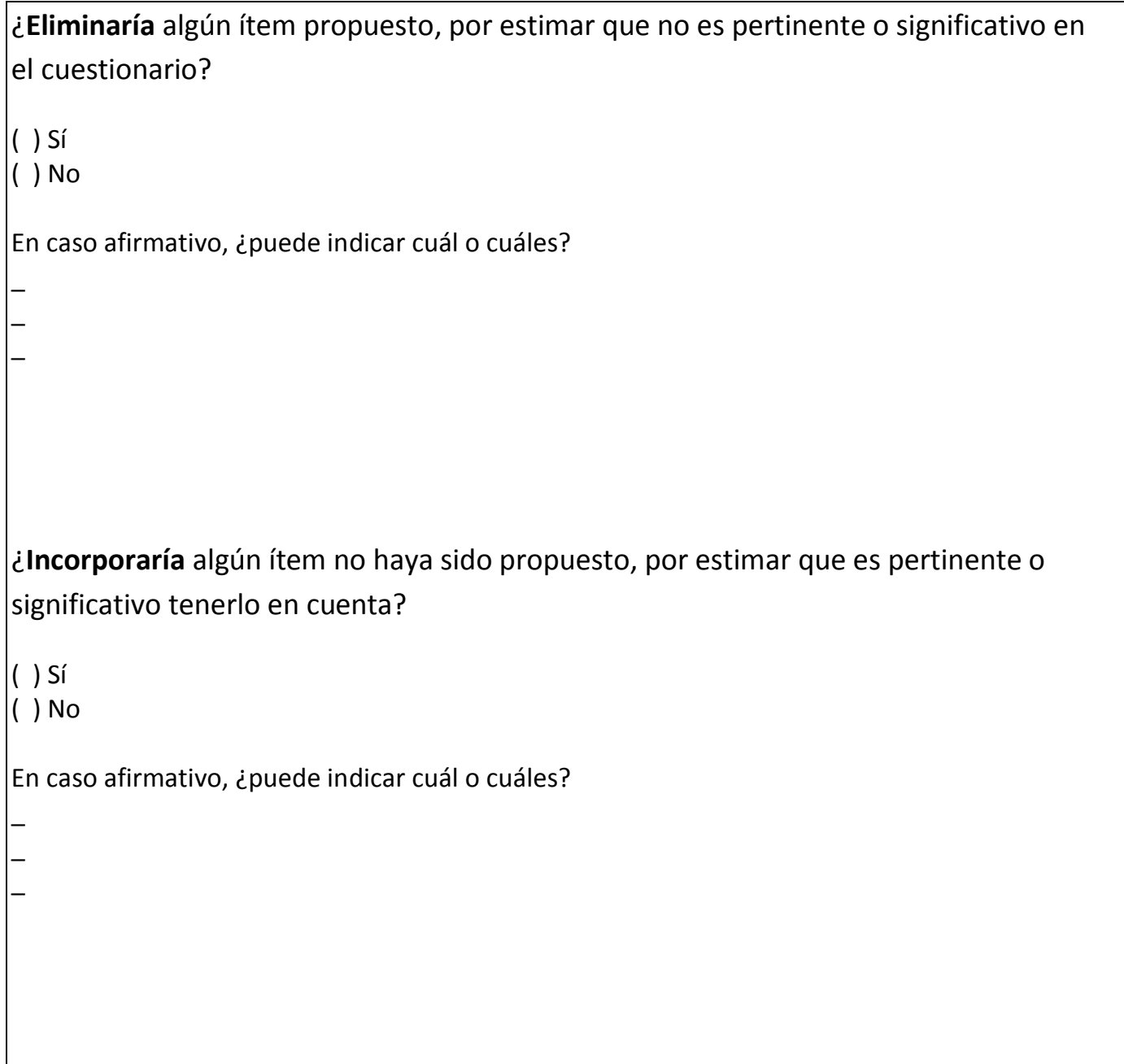

¿Sugiere modificaciones y modos alternativos de formular aquellos ítems que consideres inadecuados por su falta de claridad o pertinencia?

( ) Sí

( ) No

En caso afirmativo, ¿’puede indicar cuál o cuáles? 


\section{Apéndice B: Cuestionario 1}

UNIVERSIDAD TECNOLOGICA DE CHILE INSTITUTO PROFESIONAL
CENTRO DE FORMACION TECNICA

Inacap

Cuestionario sobre Conocimientos, Actitudes y Satisfacción de Estudiantes de Educación

Superior hacia las Tecnologías Usadas en el

Proceso de Enseñanza-Aprendizaje (*)

Estimado/a estudiante:

El presente cuestionario tiene como objetivo conocer tu opinión sobre el conocimiento y uso de algunas tecnologías. Te agradecemos que respondas con tu sinceridad habitual, pues sólo de esta forma podremos realizar mejoras en futuras experiencias formativas en nuestra institución.

Te recordamos que NO es un examen y que no hay aciertos o errores en tu respuesta.

¡Muchas gracias por tu colaboración!

\section{PRIMERA PARTE:}

\section{ANTECEDENTES}

\begin{tabular}{|l|l|l|l|l|}
\hline 1. Sección № & 4. Jornada & Diurna $\square$ & Vespertina $\square$ \\
\hline 2. Sede & & 5. Sexo & Hombre $\square$ & Mujer \\
\hline 3. Año ingreso a INACAP & 6. Edad & & \\
\hline 7. Nombre & 8. RUT & & \\
\hline
\end{tabular}

A continuación, marca con una $X$ tus respuestas:

\begin{tabular}{|c|l|l|c|c|c|c|}
\hline 9 & $\begin{array}{l}\text { ¿Dispones de un computador (PC) con Internet } \\
\text { en casa o residencia? ¿Desde hace cuánto } \\
\text { tiempo? }\end{array}$ & No & $\begin{array}{c}\text { Menos de } \\
\text { año }\end{array}$ & $\begin{array}{c}\text { Entre } \\
1 \text { y } 3 \\
\text { años }\end{array}$ & $\begin{array}{c}\text { Entre } \\
4 \text { y } 5 \\
\text { años }\end{array}$ & $\begin{array}{c}\text { Más } \\
\text { de } 5 \\
\text { años }\end{array}$ \\
\cline { 2 - 7 } & & & & & \\
\hline
\end{tabular}

\begin{tabular}{|l|l|c|c|c|c|c|c|c|}
\hline \multirow{2}{*}{10} & \multirow{2}{*}{ ¿Dispones de celular? } & No & blackberry & iphone & ipod & mobile & android & otro \\
\cline { 3 - 9 } & $\square$ & $\square$ & $\square$ & $\square$ & $\square$ & $\square$ & $\square$ \\
\hline
\end{tabular}

\begin{tabular}{|l|l|c|l|l|l|}
\hline 11 & Si posees celular, ¿tienes acceso a Internet? & Sí & & No & \\
\hline
\end{tabular}




\begin{tabular}{|l|l|l|l|l|}
\hline 12 & ¿Dispones de computador portátil? & \multicolumn{1}{|c|}{ Sí } & No & \\
\hline \multirow{4}{*}{13} & \multirow{4}{*}{ ¿Con qué frecuencia te conectas a Internet? } & Varias veces al día & \\
\cline { 3 - 4 } & & Una vez al día & \\
\cline { 3 - 5 } & Algunas veces en la semana & \\
\cline { 3 - 5 } & Una vez a la semana & \\
\cline { 3 - 4 } & No me conecto & \\
\hline
\end{tabular}

14. ¿Has recibido formación sobre cómo utilizar recursos de Internet para tareas académicas?

No, aprendí por mí mismo

Sí, en una asignatura ¿Cuál? ¿Cuándo?

$\square \quad$ Sí, en un curso, taller, etc.

Sí, un amigo, conocido me enseñó

Otras situaciones (especificar)

(*) Esta encuesta forma parte de la investigación acerca de Modelos Blended Learning en Educación Superior, Doctorado en Procesos de Formación Virtual, Universidad de Salamanca, España. Contacto: Mario Vásquez Astudillo: mvastudillo@inacap.cl 
15. Valora tus conocimientos hacia las tecnologías que utilizas para tareas académicas y di con qué frecuencia las usas:

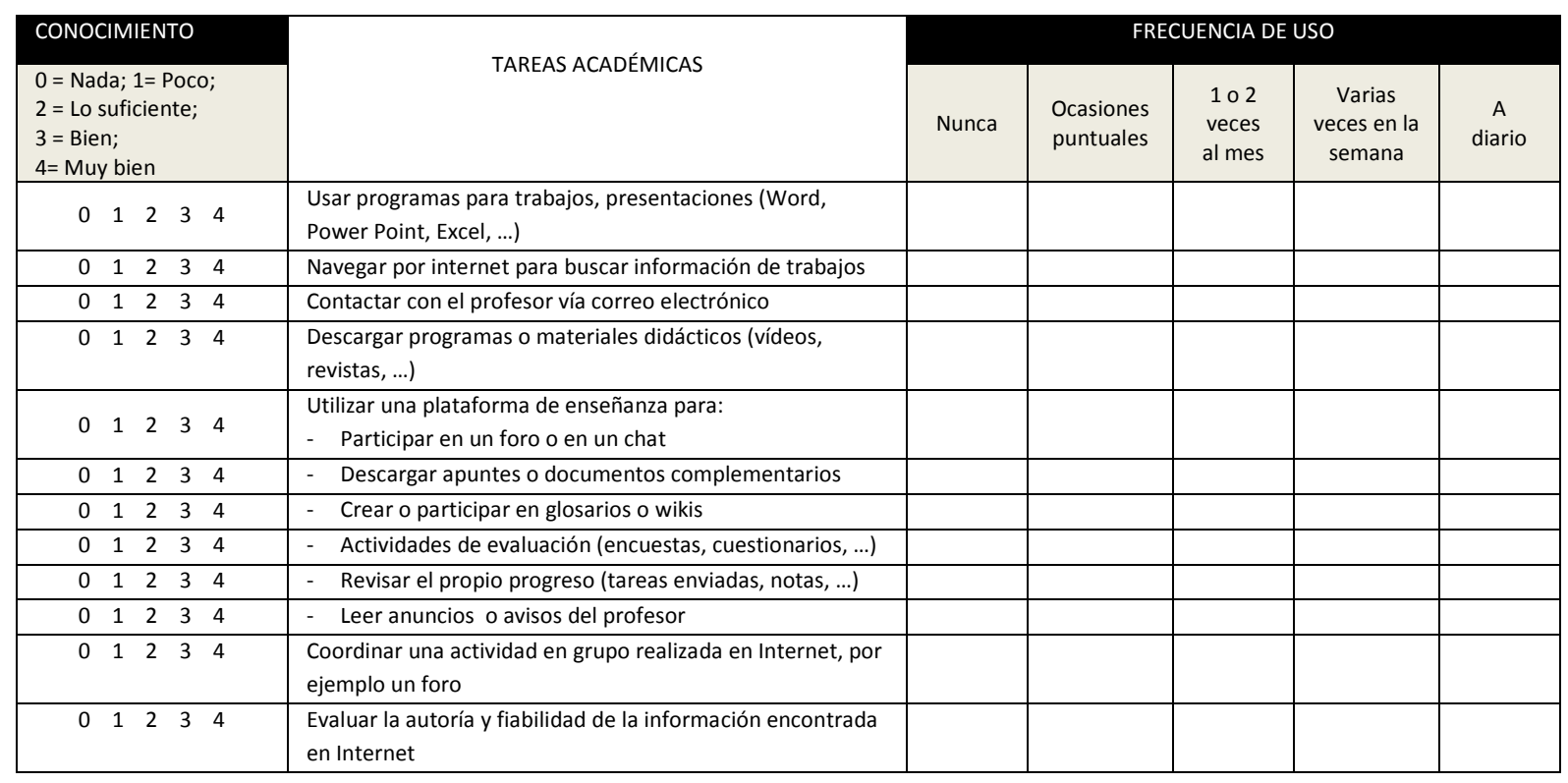

16. Indica en qué grado sabes utilizar y con qué frecuencia usas los siguientes recursos:

\begin{tabular}{|c|c|c|c|c|c|c|}
\hline CONOCIMIENTO & \multirow[b]{2}{*}{ TECNOLOGÍAS WEB 2.0} & \multicolumn{5}{|c|}{ FRECUENCIA DE USO } \\
\hline $\begin{array}{l}0=\text { Nada } ; 1=\text { Poco; } \\
2 \text { = Lo suficiente; } \\
3=\text { Bien; } \\
4=\text { Muy bien }\end{array}$ & & Nunca & $\begin{array}{l}\text { Ocasiones } \\
\text { puntuales }\end{array}$ & $\begin{array}{l}102 \\
\text { veces } \\
\text { al mes }\end{array}$ & $\begin{array}{c}\text { Varias } \\
\text { veces en la } \\
\text { semana }\end{array}$ & $\begin{array}{c}\text { A } \\
\text { diario }\end{array}$ \\
\hline $\begin{array}{lllll}0 & 1 & 2 & 3 & 4\end{array}$ & $\begin{array}{l}\text { Recursos para compartir imágenes o vídeo (Youtube, Flickr, } \\
\text { SlideShare) }\end{array}$ & & & & & \\
\hline $\begin{array}{lllll}0 & 1 & 2 & 3 & 4\end{array}$ & Recursos de edición colaborativa (Wikis, wikipedia, writely, ...) & & & & & \\
\hline $\begin{array}{lllll}0 & 1 & 2 & 3 & 4\end{array}$ & Redes sociales (Facebook, Twitter, ...) & & & & & \\
\hline $\begin{array}{lllll}0 & 1 & 2 & 3 & 4\end{array}$ & Blogs: Leer los comentarios & & & & & \\
\hline $\begin{array}{lllll}0 & 1 & 2 & 3 & 4\end{array}$ & $\begin{array}{l}\text { Blogs: Ser autor: escribir en blogs de los demás, o tener uno } \\
\text { propio }\end{array}$ & & & & & \\
\hline $\begin{array}{lllll}0 & 1 & 2 & 3 & 4\end{array}$ & Subscripciones a RSS (Bloglines, Google Reader, ...) & & & & & \\
\hline $\begin{array}{lllll}0 & 1 & 2 & 3 & 4\end{array}$ & $\begin{array}{l}\text { Herramientas de comunicación (Messenger, Skype, Google Talk, } \\
\text {...) }\end{array}$ & & & & & \\
\hline $\begin{array}{lllll}0 & 1 & 2 & 3 & 4\end{array}$ & $\begin{array}{l}\text { Entornos y juegos virtuales en red (SecondLife, EverQuest, } \\
\text { HalfLife, ...) }\end{array}$ & & & & & \\
\hline
\end{tabular}

17. ¿En qué grado crees que las tecnologías anteriores pueden ayudar a mejorar tu proceso de aprendizaje?
$\mathrm{Nad} \square$
$\mathrm{PQ} \square$
Indifer $\square$ te
Bas $\square$ nte
Mucho

18. ¿Qué ventajas encuentras en tu proceso de aprendizaje? Señala las tres más importantes.

\section{Ninguna}


Ayuda a aprovechar el tiempo

Es fácil de utilizar

Es motivador

Facilita la realización de actividades en cualquier momento y lugar

Posibilita mayor interacción con el profesor y los compañeros

Fomentan el autoaprendizaje

Otras (especificar)

19. El propósito de esta parte del cuestionario queremos conocer lo que significa para ti Internet; para ello te encontrarás una serie de adjetivos para que nos des tu opinión.

Después de leer con tranquilidad las parejas de adjetivos que se te presentan en la escala, complétala tal como se te muestra en el ejemplo. Debes contestarla sin detenerte demasiado, simplemente con la primera impresión o sentimiento que tengas. Recuerda que no hay respuestas verdaderas o falsas.

Por favor, contesta a cada pareja de adjetivos con la mayor sinceridad y sin olvidarte ninguna.

A continuación te mostramos un ejemplo sobre cómo rellenar el resto del cuestionario.

El computador es para ti:

$1=$ Extremadamente Malo

$2=$ Bastante Malo

$3=$ Ligeramente Malo

4 = Ni Malo ni Bueno; o Igualmente Malo y Bueno

$5=$ Ligeramente Bueno

$6=$ Bastante Bueno

$7=$ Extremadamente Bueno

Malo 1 _ 1 - $x_{-} \quad 7$

Bueno

Esa respuesta significa que el ordenador es para ti Bastante Bueno. 
Ahora señala, en una escala del 1 al 7, los pares de adjetivos que se presentan a continuación.

INTERNET ES PARA TI:

$\begin{array}{rllll}\text { Rápido } & 7 & ------ & 1 & \text { Lento } \\ \text { Accesible } & 7 & ------ & 1 & \text { Innacesible } \\ \text { Caro } & 1 & ------ & 7 & \text { Económico } \\ \text { Comunicativo } & 7 & ------ & 1 & \text { Reservado } \\ \text { Dinámico } & 7 & ------ & 1 & \text { Pasivo } \\ \text { Distractor } & 1 & ------- & 7 & \text { Atractivo } \\ \text { Fiable } & 7 & ------ & 1 & \text { Dudoso } \\ \text { Formativo } & 7 & ------- & 1 & \text { Deformativo } \\ \text { Seguro } & 7 & ------- & 1 & \text { Inseguro } \\ \text { Pérdida de Tiempo } & 1 & ------- & 7 & \text { Ahorro de Tiempo } \\ \text { Entretenido } & 7 & ------ & 1 & \text { Aburrido } \\ \text { Adictivo } & 1 & ------- & 7 & \text { Indiferente } \\ \text { Rígido } & 1 & ------ & 7 & \text { Flexible } \\ \text { Manejable } & 7 & ------ & 1 & \text { Avasallador } \\ \text { Ágil } & 7 & ------- & 1 & \text { Torpe } \\ \text { Necesario } & 7 & ------ & 1 & \text { Innecesario } \\ \text { Agradable } & 7 & ------ & 1 & \text { Desagradable } \\ \text { Informativo } & 7 & ------ & 1 & \text { Desinformativo } \\ \text { Ineficaz } & 1 & ------ & 7 & \text { Eficaz } \\ \text { Complicado } & 1 & ------ & 7 & \text { Simple } \\ \text { Valioso } & 7 & ------ & 1 & \text { Sin Valor }\end{array}$

Gracias por tu colaboración 
Apéndice C: Cuestionario 2

UNIVERSIDAD TECNOLOGICA DE CHILE CENTRO DE FORMACION TECNICA

Inacap

\section{Cuestionario sobre Conocimientos y Satisfacción de Estudiantes de Educación Superior hacia las Tecnologías Usadas en el Proceso de Aprendizaje $\left({ }^{*}\right)$}

Estimado/a estudiante:

El presente cuestionario tiene como objetivo conocer tu opinión acerca de algunos aspectos de la asignatura de Técnicas de la Comunicación Oral y Escrita. Te agradecemos que respondas con tu sinceridad habitual, pues sólo de esta forma podremos realizar mejoras en futuras experiencias formativas similares a la que has realizado. El cuestionario es anónimo, nadie sabrá lo que tú has contestado.

\section{ANTECEDENTES}

\begin{tabular}{|l|l|l|l|l|}
\hline 1. Sección № & & 4. Jornada & Diurna $\square$ & Vespertina $\square$ \\
\hline 2. Sede & & 5. Sexo & Hombre $\square$ & Mujer $\square$ \\
\hline 3. Año de ingreso a INACAP & & 6. Edad & & \multicolumn{2}{|c}{} \\
\cline { 1 - 3 }
\end{tabular}

Para responder las siguientes preguntas, por favor indica tu grado de desacuerdo o acuerdo con los diferentes enunciados que te ofrecemos. Marca con una $\mathbf{X}$ la alternativa que consideres correcta para cada ítem:

\begin{tabular}{|c|c|c|c|c|c|c|}
\hline & & 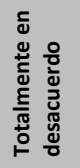 & 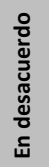 & 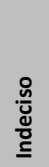 & 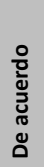 & 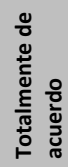 \\
\hline 7 & $\begin{array}{l}\text { Las actividades en línea individuales y grupales estaban planteadas paulatinamente según el } \\
\text { grado de dificultad }\end{array}$ & & & & & \\
\hline 8 & $\begin{array}{l}\text { La organización de las actividades realizadas en clases y planteadas por el docente me ha } \\
\text { ayudado en mi labor de aprendizaje. }\end{array}$ & & & & & \\
\hline 9 & $\begin{array}{l}\text { La organización de las actividades de aprendizaje en esta asignatura realizadas fuera de clases } \\
\text { ha facilitado mi aprendizaje }\end{array}$ & & & & & \\
\hline 10 & $\begin{array}{l}\text { Las actividades y contenidos de aprendizaje en línea y presenciales en esta asignatura estaban } \\
\text { relacionados }\end{array}$ & & & & & \\
\hline 11 & $\begin{array}{l}\text { El docente se ha preocupado porque todos participemos en las actividades realizadas fuera de } \\
\text { clases }\end{array}$ & & & & & \\
\hline 12 & Las actividades en línea fomentaron la participación de los estudiantes en la asignatura & & & & & \\
\hline 13 & Al cursar esta asignatura, el nivel de interacción con mis compañeros de grupo ha sido alto & & & & & \\
\hline 14 & $\begin{array}{l}\text { El proceso de evaluación en la asignatura durante el semestre fue coherente con las actividades } \\
\text { desarrolladas }\end{array}$ & & & & & \\
\hline 15 & $\begin{array}{l}\text { En el curso de esta asignatura, se han realizado actividades de autoevaluación suficientes para } \\
\text { verificar mi comprensión de los contenidos de la asignatura }\end{array}$ & & & & & \\
\hline 16 & El funcionamiento técnico del sitio usado es fácil de manejar & & & & & \\
\hline 17 & $\begin{array}{l}\text { Los tiempos de respuesta del sitio de Internet (espera para acceder a un vínculo, acceso a las } \\
\text { diferentes herramientas, etc.) han sido adecuados }\end{array}$ & & & & & \\
\hline 18 & El docente nos ayudó a la comprensión de las cuestiones técnicas del sitio de trabajo en línea & & & & & \\
\hline 19 & $\begin{array}{l}\text { Mis conocimientos tecnológicos previos a cursar la asignatura fueron suficientes para } \\
\text { desarrollar las actividades }\end{array}$ & & & & & \\
\hline 20 & El docente ha usado el entorno virtual como apoyo a nuestro aprendizaje & & & & & \\
\hline 21 & $\begin{array}{l}\text { Los recursos y herramientas del entorno en línea permiten mejorar el proceso de enseñanza- } \\
\text { aprendizaje }\end{array}$ & & & & & \\
\hline 22 & $\begin{array}{l}\text { Las instrucciones de las actividades de aprendizaje realizadas en la asignatura ofrecían pautas o } \\
\text { indicaciones para resolverlas }\end{array}$ & & & & & \\
\hline
\end{tabular}

\footnotetext{
*) Esta encuesta forma parte de la investigación acerca de Modelos Blended Learning en Educación Superior, Doctorado en Procesos de Formación Virtual, Universidad de Salamanca, España. Contacto: Mario Vásquez Astudillo: mvastudillo@inacap.cl
} 


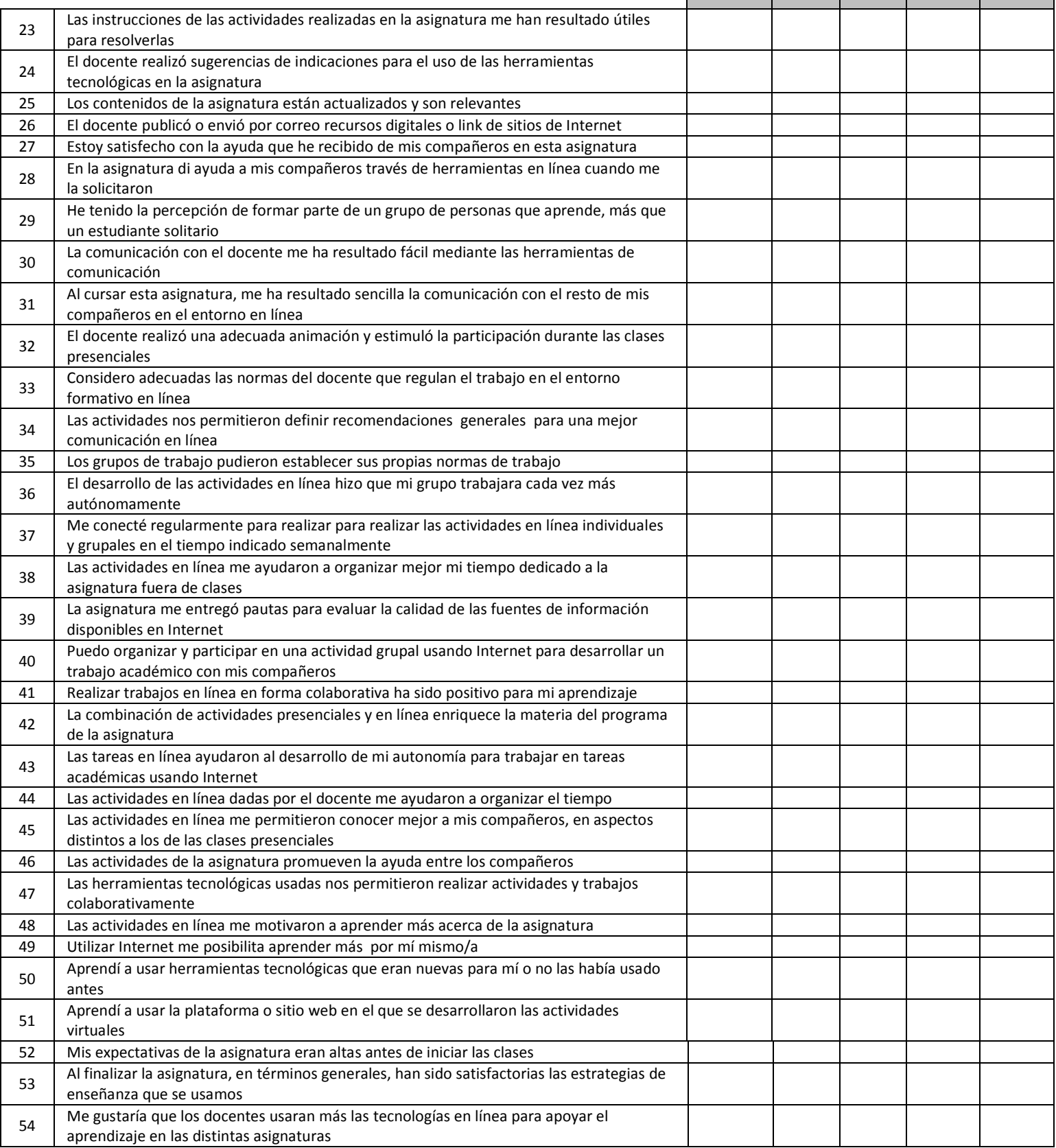


adecuados para tu formación a través de Internet?

55. ¿Qué elementos o aspectos (que no hayan aparecido anteriormente) destacarías como los más inadecuados para tu formación a través de Internet?

En las siguientes preguntas marca con una $\mathrm{X}$ tu respuesta:

56. ¿Qué porcentaje de asistencia a clases presenciales tuviste en esta asignatura?

\begin{tabular}{|l|l|l|l|l|l|l|l|l|l|}
\hline $10 \%$ & $20 \%$ & $30 \%$ & $40 \%$ & $50 \%$ & $60 \%$ & $70 \%$ & $80 \%$ & $90 \%$ & $100 \%$ \\
\hline & & & & & & & & & \\
\hline
\end{tabular}

57. ¿Qué porcentaje de las actividades en línea o virtuales participaste durante el semestre?

\begin{tabular}{|l|l|l|l|l|l|l|l|l|l|l|}
\hline $10 \%$ & $20 \%$ & $30 \%$ & $40 \%$ & $50 \%$ & $60 \%$ & $70 \%$ & $80 \%$ & $90 \%$ & $100 \%$ & No hubo \\
\hline & & & & & & & & & & \\
\hline
\end{tabular}


58. ¿Cuántas horas a la semana en promedio durante el semestre dedicaste a esta asignatura fuera del horario de clases?

\begin{tabular}{|c|c|c|c|c|c|c|c|c|c|c|}
\hline \multicolumn{10}{|c|}{ HORAS } \\
\hline 0 & 1 & 2 & 3 & 4 & 5 & 6 & 7 & 8 & 9 & 10 ó más \\
\hline & & & & & & & & & & \\
\hline
\end{tabular}

\section{Gracias por tu colaboración}


Apéndice D: Protocolo de focus group de estudiantes

\section{Aspectos generales de la asignatura:}

a. Me gustaría conocer de forma global la percepción en cuanto al desarrollo de la asignatura.

b. En términos globales cómo perciben el rendimiento de los alumnos en asignatura en la modalidad b-learning.

c. Y el grado de satisfacción en comparación con las asignaturas tradicionales.

d. ¿Qué imagen tenían de la asignatura antes del inicio de las clases? ¿Se cumplieron las expectativas?

\section{Aspectos relacionados con las actividades de aprendizaje:}

a. Comentemos acerca de las e-actividades: ventajas, desventadas, facilidades, dificultades.

b. ¿Las e-actividades y de las actividades presenciales estaban bien estructuradas? ¿Estaban articuladas?

c. ¿Facilitó la interacción entre los compañeros de la asignatura?

d. ¿Las evaluaciones eran adecuadas?

\section{Herramientas:}

a. ¿Cuáles herramientas tecnológicas usaron? ¿Sienten que aportaron al desarrollo de la asignatura?

b. ¿El docente les dio sugerencias de cómo usar las herramientas tecnológicas?

c. ¿Se sienten más motivados hacia el uso de las tecnologías y el aprendizaje en línea?

4. Comunidad, normas, reglamentos:

a. ¿Las e-actividades les permitió conocerse en aspectos distintos a los de las clases presenciales?

b. ¿En las actividades grupales pudieron establecer sus propias normas de funcionamiento?

c. ¿Las normas establecidas o sugeridas por el profesor facilitaron la organización y comunicación de los grupos?

d. ¿Lograron a lo largo del semestre cada vez mayor autonomía?

\section{Valoración global:}

a. Lo que más les gustó.

b. Sugerencias 
Lista de chequeo de categorías cubiertas en focus group a estudiantes

\begin{tabular}{|c|c|c|}
\hline Apartados & Categorías & Chequeo \\
\hline \multirow{5}{*}{$\begin{array}{l}\text { A. Actividad de } \\
\text { aprendizaje }\end{array}$} & A.1. Diseño pedagógico de las actividades en línea & \\
\hline & A.2. Diseño pedagógico de las actividades presenciales & \\
\hline & A.3. Articulación de las actividades presenciales y virtuales & \\
\hline & A.4. Interactividad pedagógica & \\
\hline & A.5. Actividades de evaluación & \\
\hline \multirow{3}{*}{ B. Herramientas } & B.1.Uso de recursos tecnológicos disponibles en línea & \\
\hline & $\begin{array}{l}\text { B.2.Sugerencias de métodos y procedimientos para el uso de } \\
\text { las herramientas tecnológicas }\end{array}$ & \\
\hline & B.3.Sugerencia y uso de recursos digitales & \\
\hline \multirow{3}{*}{ C. Comunidad } & C.1. Organización social de los alumnos & \\
\hline & C.2. Contexto de referencia & \\
\hline & C.3. Sentimiento de comunidad & \\
\hline \multirow{2}{*}{$\begin{array}{l}\text { D. Normas y } \\
\text { reglamentos }\end{array}$} & $\begin{array}{l}\text { D.1. Normas de funcionamiento establecidas por los grupos } \\
\text { de trabajo }\end{array}$ & \\
\hline & D.2 Normas de funcionamiento establecidas por el profesor & \\
\hline \multirow{2}{*}{$\begin{array}{l}\text { E. División del } \\
\text { trabajo }\end{array}$} & E.1. Roles de los alumnos y roles del profesor & \\
\hline & $\begin{array}{l}\text { E.2. Transferencia del control de la actividad del docente al } \\
\text { alumno }\end{array}$ & \\
\hline \multirow{2}{*}{$\begin{array}{l}\text { F. Valoración } \\
\text { global }\end{array}$} & F.1. Expectativas y satisfacción de la asignatura & \\
\hline & F.2. Motivación hacia las tecnologías y el aprendizaje en línea & \\
\hline
\end{tabular}


Apéndice E: Protocolo de entrevista a profesores

\section{Aspectos generales de la asignatura:}

a. Me gustaría conocer de forma global la percepción en cuanto al desarrollo de la asignatura.

b. En términos globales cómo perciben el rendimiento de los alumnos en asignatura en la modalidad b-learning.

c. Y el grado de satisfacción en comparación con las asignaturas tradicionales.

d. ¿Qué imagen tenían de la asignatura antes del inicio de las clases? ¿Se cumplieron las expectativas?

2. Aspectos relacionados con las actividades de aprendizaje:

a. Comentemos acerca de las e-actividades: ventajas, desventadas, facilidades, dificultades.

b. ¿Las e-actividades y de las actividades presenciales estaban bien estructuradas? ¿Estaban articuladas?

c. ¿Facilitó la interacción entre los alumnos de la asignatura?

\section{Herramientas:}

a. ¿Cuáles herramientas tecnológicas usaron? ¿Sienten que aportaron al desarrollo de la asignatura?

b. ¿El docente les dio sugerencias de cómo usar las herramientas tecnológicas?

c. ¿Se sienten más motivados hacia el uso de las tecnologías y el aprendizaje en línea?

\section{Comunidad, normas, reglamentos:}

a. ¿Las e-actividades les permitió conocerse en aspectos distintos a los de las clases presenciales?

b. ¿En las actividades grupales pudieron establecer sus propias normas de funcionamiento?

c. ¿Las normas establecidas o sugeridas por el profesor facilitaron la organización y comunicación de los grupos?

d. ¿Lograron a lo largo del semestre cada vez mayor autonomía?

\section{Valoración global:}

a. Lo que más les gustó.

b. Sugerencias 
Lista de chequeo de categorías cubiertas en la entrevista a profesores

\begin{tabular}{|c|c|c|}
\hline Apartados & Categorías & Chequeo \\
\hline \multirow{6}{*}{$\begin{array}{l}\text { A. Actividad de } \\
\text { aprendizaje }\end{array}$} & $\begin{array}{l}\text { A.1. Diseño pedagógico de las actividades e- } \\
\text { actividades }\end{array}$ & \\
\hline & $\begin{array}{l}\text { A.2. Diseño pedagógico de las actividades } \\
\text { presenciales }\end{array}$ & \\
\hline & $\begin{array}{l}\text { A.3. Articulación de las actividades presenciales y } \\
\text { virtuales }\end{array}$ & \\
\hline & A.4. Interactividad pedagógica & \\
\hline & A.5. Actividades de evaluación & \\
\hline & $\begin{array}{l}\text { A.5. Intencionalidad de las actividades (objetivos y } \\
\text { resultados esperados) }\end{array}$ & \\
\hline \multirow{3}{*}{ B. Herramientas } & $\begin{array}{l}\text { B.1. Finalidad del uso de recursos tecnológicos } \\
\text { disponibles en línea }\end{array}$ & \\
\hline & $\begin{array}{l}\text { B.2.Finalidad de las sugerencias de métodos y } \\
\text { procedimientos para el uso de las herramientas } \\
\text { tecnológicas }\end{array}$ & \\
\hline & B.3.Valoración de los recursos digitales sugeridos & \\
\hline \multirow{4}{*}{ C. Comunidad } & C.1. Organización social de los alumnos & \\
\hline & $\begin{array}{l}\text { C.2. Facilidades y dificultades para la comunicación en } \\
\text { línea }\end{array}$ & \\
\hline & C.3. Contexto de referencia & \\
\hline & C.4. Sentimiento de comunidad & \\
\hline \multirow{2}{*}{$\begin{array}{l}\text { D. Normas y } \\
\text { reglamentos }\end{array}$} & $\begin{array}{l}\text { D.1. Normas de funcionamiento establecidas por los } \\
\text { grupos de trabajo }\end{array}$ & \\
\hline & $\begin{array}{l}\text { D.2. Normas de funcionamiento establecidas por el } \\
\text { profesor }\end{array}$ & \\
\hline \multirow[b]{2}{*}{$\begin{array}{l}\text { E. División del } \\
\text { trabajo }\end{array}$} & E.1. Roles de los alumnos y roles del profesor & \\
\hline & $\begin{array}{l}\text { E.2. Transferencia del control de la actividad del } \\
\text { docente al alumno }\end{array}$ & \\
\hline \multirow{2}{*}{ F. Valoración global } & $\begin{array}{l}\text { F.1. Expectativas y satisfacción de la participación de } \\
\text { loa alumnos }\end{array}$ & \\
\hline & $\begin{array}{l}\text { F.2. Motivación hacia las tecnologías y la enseñanza } \\
\text { en línea }\end{array}$ & \\
\hline
\end{tabular}




\section{Apéndice F: Pauta para guiar el análisis documental}

\begin{tabular}{|c|c|c|c|c|}
\hline $\begin{array}{l}\text { Cam } \\
\text { Gru }\end{array}$ & $\begin{array}{l}: \\
:\end{array}$ & & & \\
\hline Apartado & Categorías & Descriptor & $\mathbf{N}^{\circ}$ & Comentario \\
\hline \multirow{4}{*}{$\begin{array}{l}\text { A. Actividad de } \\
\text { aprendizaje }\end{array}$} & $\begin{array}{l}\text { A.1. Diseño } \\
\text { pedagógico de las } \\
\text { actividades en línea }\end{array}$ & \multirow{4}{*}{$\begin{array}{l}\text { Tipo de actividades/tareas } \\
\text { formativas } \\
\text { Sugerencias de estrategias para la } \\
\text { realización de las actividades } \\
\text { Articulación de las actividades } \\
\text { presenciales y virtuales } \\
\text { Interactividad pedagógica potencial } \\
\text { y real } \\
\text { Utilidad y uso de las actividades de } \\
\text { evaluación } \\
\text { Número de evaluaciones y } \\
\text { ponderación }\end{array}$} & & \\
\hline & $\begin{array}{l}\text { A.2. Diseño } \\
\text { pedagógico de las } \\
\text { actividades } \\
\text { presenciales }\end{array}$ & & & \\
\hline & $\begin{array}{l}\text { A.3. Interactividad } \\
\text { pedagógica }\end{array}$ & & & \\
\hline & $\begin{array}{l}\text { A.4. Actividades de } \\
\text { evaluación }\end{array}$ & & & \\
\hline \multirow{3}{*}{$\begin{array}{l}\text { B. } \\
\text { Herramientas }\end{array}$} & C.1. Tecnológicas & $\begin{array}{l}\text { Uso de recursos tecnológicos } \\
\text { disponibles en línea } \\
\text { Interactividad tecnológica } \\
\text { potencial y real }\end{array}$ & & \\
\hline & $\begin{array}{l}\text { C. } 2 . \\
\text { Procedimentales }\end{array}$ & $\begin{array}{l}\text { Sugerencia de métodos de trabajo } \\
\text { Sugerencias de procedimientos } \\
\text { para el uso de las herramientas } \\
\text { tecnológicas }\end{array}$ & & \\
\hline & C.3. Textuales & $\begin{array}{l}\text { Artículos o recursos en Internet, } \\
\text { libros digitales o impresos usados y } \\
\text { sugeridos }\end{array}$ & & \\
\hline C. Comunidad & $\begin{array}{l}\text { D.1. Organización } \\
\text { social de los } \\
\text { alumnos } \\
\begin{array}{l}\text { D.2. Contexto de } \\
\text { referencia }\end{array}\end{array}$ & $\begin{array}{l}\text { Orientación y apoyo del docente } \\
\text { Resolución de dificultades } \\
\text { Relación de las actividades con el } \\
\text { contexto de referencia de la } \\
\text { carrera } \\
\text { Participación de los alumnos }\end{array}$ & & \\
\hline $\begin{array}{l}\text { D. Normas y } \\
\text { reglamentos }\end{array}$ & $\begin{array}{l}\text { E.1. Existencia de } \\
\text { normas y reglas }\end{array}$ & $\begin{array}{l}\text { Normas de funcionamiento } \\
\text { establecidas por los grupos de } \\
\text { trabajo } \\
\text { Normas de funcionamiento } \\
\text { establecidas por el profesor }\end{array}$ & & \\
\hline $\begin{array}{l}\text { E. División del } \\
\text { trabajo }\end{array}$ & $\begin{array}{l}\text { F.1. Roles de los } \\
\text { alumnos } \\
\text { F.1. Roles del } \\
\text { profesor }\end{array}$ & $\begin{array}{l}\text { Transferencia del control de la } \\
\text { actividad del docente al alumno }\end{array}$ & & \\
\hline $\begin{array}{l}\text { F. Otras } \\
\text { emergentes }\end{array}$ & & & & \\
\hline
\end{tabular}


Apéndice G: Planificación sugerida de las e-actividades

\begin{tabular}{|c|c|c|c|}
\hline $\begin{array}{l}\text { ETAPAS } \\
\text { G. Salmon }\end{array}$ & $\begin{array}{l}\text { No } \\
\text { semana }\end{array}$ & E-actividades & Actividades presenciales \\
\hline \multirow{3}{*}{$\begin{array}{l}1 \\
\text { Acceso y } \\
\text { motivación }\end{array}$} & 0 & $\begin{array}{l}\text { Saludo, bienvenida y } \\
\text { modalidad de } \\
\text { trabajo. }\end{array}$ & $\begin{array}{l}\text { NOTA: Todas las e-actividades el Docente las publica } \\
\text { la semana anterior a la fecha de inicio. }\end{array}$ \\
\hline & 1 & $\begin{array}{l}\text { E-actividad 1: } \\
\text { Enviar mensaje de } \\
\text { saludo. }\end{array}$ & $\begin{array}{l}\text { - Encuadre de la asignatura (en modalidad mixta, } \\
\text { - Letividades presenciales y colaborativas en línea). } \\
\text { - Informar acerca de e-actividad } 1 . \\
\text { - Informar acerca de e-actividad } 2 \text {. }\end{array}$ \\
\hline & 2 & $\begin{array}{l}\text { E-actividad 2: } \\
\text { Presentación } \\
\text { personal. }\end{array}$ & $\begin{array}{l}\text { - Hacer un balance de los mensajes de saludo, } \\
\text { asegurarse de que todos se han conectado. } \\
\text { - Informar acerca de e-actividad } 3 \text {. }\end{array}$ \\
\hline \multirow[t]{2}{*}{$\begin{array}{l}2 \\
\text { Socialización } \\
\text { en línea }\end{array}$} & 3 & $\begin{array}{l}\text { E-actividad 3: } \\
\text { Tu estilo de } \\
\text { aprendizaje. }\end{array}$ & $\begin{array}{l}\text { - Comentan acerca de las presentaciones personales } \\
\text { de la e-actividad } 2 \text { (conocer facetas de los } \\
\text { alumnos). } \\
\text { - Responder y analizar el Test de Factores Asociados } \\
\text { al Estudio } \\
\text { - Formar los grupos de trabajo, elegir un/a líder y } \\
\text { un/a secretario/a para la e-actividad } 4 \text {. } \\
\text { - Entregar una copia impresa de la e-actividad } 4 \text { al } \\
\text { líder de cada grupo. Cada grupo lee la actividad y } \\
\text { se organizan. }\end{array}$ \\
\hline & 4 & $\begin{array}{l}\text { E-actividad 4: } \\
\text { Trabajar en grupo en } \\
\text { línea. }\end{array}$ & $\begin{array}{l}\text { - Comentarios de los resultados del test estilos de } \\
\text { aprendizaje y sugerencias de estudio. } \\
\text { - Informar acerca de e-actividad } 5 \text {. }\end{array}$ \\
\hline \multirow{3}{*}{$\begin{array}{l}3 \\
\text { Intercambio } \\
\text { de } \\
\text { información }\end{array}$} & 5 & $\begin{array}{l}\text { E-actividad 5: } \\
\text { ¿A qué persona de tu } \\
\text { propia disciplina te } \\
\text { gustaría conocer? }\end{array}$ & $\begin{array}{l}\text { - Los secretarios exponen la síntesis de la e-actividad } \\
\text { 4: Trabajar en grupo en línea } \\
\text { - Realizan un listado de las recomendaciones más } \\
\text { importantes. }\end{array}$ \\
\hline & 6 & $\begin{array}{l}\text { E-actividad 6: Sitios } \\
\text { web para la } \\
\text { asignatura de TCOE }\end{array}$ & $\begin{array}{l}\text { - Comentan acerca de los personajes seleccionados } \\
\text { en la e-actividad } 5 \text {. }\end{array}$ \\
\hline & 7 & & $\begin{array}{l}\text { - Chequear el avance del trabajo grupal de la e- } \\
\text { actividad } 6\end{array}$ \\
\hline \multirow{4}{*}{$\begin{array}{c}4 \\
\text { Construcció } \\
\text { n del } \\
\text { conocimient } \\
0\end{array}$} & 8 & $\begin{array}{l}\text { E-actividad 7: } \\
\text { Comunicación virtual }\end{array}$ & $\begin{array}{l}\text { - Presentación de los sitios web seleccionados por } \\
\text { cada uno de los grupos. } \\
\text { - Ranking de los mejores sitios. }\end{array}$ \\
\hline & 9 & $\begin{array}{l}\text { E-actividad 8: Sitios } \\
\text { web de mi } \\
\text { especialidad }\end{array}$ & \\
\hline & 10 & & $\begin{array}{l}\text { - Cada grupo presentación los sitios web elegidos. } \\
\text { - Realizar ranking de los mejores sitios para TCOE. } \\
\text { - Seleccionar nuevos líderes y secretarios. } \\
\text { - Comentar de la E-actividad } 9 \text { para orientar la } \\
\text { selección de artículos. }\end{array}$ \\
\hline & 11 & $\begin{array}{l}\text { E-actividad 9: } \\
\text { Selección de } \\
\text { artículos }\end{array}$ & $\begin{array}{l}\text { - Revisar el uso del software PDF X-Change Viewer } \\
\text { para subrayar artículos PDF. }\end{array}$ \\
\hline
\end{tabular}




\begin{tabular}{|c|c|c|c|}
\hline ETAPAS & $\begin{array}{c}\text { № } \\
\text { semana }\end{array}$ & E-actividades & Actividades presenciales \\
\hline \multirow{9}{*}{$\begin{array}{c}5 \\
\text { Desarrollo }\end{array}$} & 12 & $\begin{array}{l}\text { E-actividad 10: } \\
\text { Realizar subrayado } \\
\text { estratégico de } \\
\text { artículo }\end{array}$ & $\begin{array}{l}\text { - Comentar los títulos de los artículos } \\
\text { seleccionados. } \\
\text { - Revisar elementos básicos de la confección un } \\
\text { mapa conceptual. }\end{array}$ \\
\hline & 13 & $\begin{array}{l}\text { E-actividad 11: } \\
\text { Mapa conceptual }\end{array}$ & \\
\hline & 14 & $\begin{array}{l}\text { E-actividad 12: } \\
\text { Competencias del } \\
\text { profesional del } \\
\text { futuro }\end{array}$ & \\
\hline & 15 & & $\begin{array}{l}\text { - Comentar acerca de las competencias del } \\
\text { profesional del futuro seleccionas. }\end{array}$ \\
\hline & 16 & & - Evaluación \\
\hline & 17 & & - Evaluación \\
\hline & 18 & & - Evaluación \\
\hline & 19 & & - Evaluación \\
\hline & 20 & & - Evaluación \\
\hline
\end{tabular}




\section{Contenido de las e-actividades del semestre}

\section{ASUNTO: Saludo, bienvenida y modalidad de trabajo.}

Estimados alumnos, Profesionales en Formación.

Les doy la más cordial bienvenida a INACAP y a este espacio virtual de formación profesional. Trataré de ofrecerles una orientación que les sea de utilidad para desarrollar con agilidad y desenvoltura las tareas que se proponen realizar.

\section{¿Cómo trabajaremos en esta asignatura?}

a) Esta asignatura está desarrollaremos actividades presenciales y colaborativas en línea, en una modalidad mixta. Esto significa que tendremos a la semana: cuatro horas de clases presenciales y varias horas de e-actividades o actividades virtuales, o en línea.

b) En las actividades en línea nuestras intervenciones serán asíncronas, es decir, no existe obligación de trabajar al mismo tiempo o mismo horario, a menos que se establezca el compromiso de hora y día específico. Por lo tanto cada uno de ustedes podrá ingresar al sitio de trabajo en el momento que mejor le acomode dentro de sus actividades diarias, pero es muy recomendable ingresar varias veces en la semana, especialmente al inicio de semana.

c) Por mi parte, yo ingresaré tres o cuatro veces por semana, pues mi intención es dar respuesta a sus comentarios y consultas que complementen las consultas que podamos resolver en clases.

d) Para comunicarnos contamos con este sitio, donde dejaré anuncios importantes al grupo en general acerca de las e-actividades a desarrollar.

e) Tenemos la asignatura dividida en e-actividades semanales. Les pido estar muy atentos para realizar sus intervenciones y cumplir con los plazos establecidos de antemano.

Cualquier pregunta, comentario o duda que tengan, no vacilen en exponerla, solamente envíen un mensaje, estaré atento a sus intervenciones o realicen sus consultas en clases.

Les deseo mucho éxito de antemano.

\section{Nombre del Docente}




\section{ASUNTO: E-actividad 1: Enviar mensaje de saludo}

Estimados estudiantes:

Seguramente esta será una nueva experiencia para ustedes la que entre todos haremos que sea exitosa y nos tribute muchos beneficios personales y a toda la Comunidad de Aprendizaje. Para ello, la participación oportuna de cada uno de nosotros, es indispensable.

Esta es nuestra primera e-actividad

Propósito: enviar un mensaje de saludo a todos los compañeros.

Tarea: envíe un mensaje de saludo a todos los compañeros del curso ZC0202-210 de Técnicas de la Comunicación Oral y Escrita.

Si el saludo es creativo, tanto mejor.

El mensaje debe ser breve, dos o tres líneas, o un máximo de 40 palabras.

Ingresa a

Responder: lee los mensajes de a lo menos siete compañeros.

Esta actividad es obligatoria y deberá ser finalizada el día domingo 20 de marzo a las 23:59 horas.

Queda hecha la invitación para enviar saludos, si son entretenidos y creativos, lo pasaremos bien leyéndolos.

Nombre del Docente 


\section{ASUNTO: E-actividad 2: Presentación personal}

Buen día:

Vamos a estar juntos durante todo el semestre compartiendo experiencias académicas. A veces en las instancias presenciales no tenemos la oportunidad de conocernos o que los demás conozcan algunos aspectos de nuestras vidas. Para saber algo de nuestros intereses, realizaremos la siguiente e-actividad:

Propósito: dar a conocer en línea alguna cosa sobre ti.

Tarea: ofrecer una URL (una dirección de Internet o link) que diga algo sobre ti o sobre tu vida, una de tus páginas favoritas, más que tu propia página Web. Escribe algunas líneas sobre la razón por la que la has escogido. Trata de ser breve, de ofrecer una pincelada de ti más que una historia de tu vida y trata de que el lector evite usar la barra de desplazamiento. Si quieres puedes prepararlas previamente en un procesador de texto y luego copiar y pegar.

La idea es no colocar sitios genéricos como Google, Facebook, Twiter, etc.

Responder: compartir intereses, contestar el mensaje de a lo menos cinco compañeros del curso.

Esta actividad es de carácter obligatorio y deberá ser finalizada el día domingo 27 de marzo a las 23:59 horas.

Les invito a compartir y a conocernos un poco más.

Nombre del Docente 


\section{ASUNTO: E-actividad 3: Tu estilo de aprendizaje}

Estimados estudiantes:

Todos aprendemos de manera distinta. Honey y Mumford escribieron sobre cuatro tipos de aprendizaje. Estos son:

- Los activos: tienden aprender mejor cuando trabajan con problemas y experiencias nuevas.

- Los teóricos: necesitan explorar las relaciones entre las ideas y situaciones.

- Los pragmáticos: necesitan ver enlaces obvios entre lo que están aprendiendo y los problemas y oportunidades involucradas en su trabajo.

- Los reflexivos piensan profundamente sobre los conceptos y actividades, y tienden a ofrecer respuestas meditadas.

¿Te reconoces en alguno de ellos?

Entre los integrantes del curso es muy probable que nos encontremos con todas las preferencias y estilos.

Propósito: describe tu estilo de aprendizaje y averigua el estilo de los demás.

Tarea: responde el "Cuestionario Honey-Alonso de Estilos de Aprendizaje" disponible en http://www.estilosdeaprendizaje.es/chaea/chaea.htm

Publica tus resultados en el foro de la e-actividad.

Responder: el mensaje de tres compañeros que en tu opinión ilustre cómo aparecen en el mundo en línea los diversos estilos de aprendizaje.

Esta actividad es de carácter obligatorio y deberá ser finalizada el día domingo 03 de abril a las 23:59 horas.

¡Vamos, adelante, a saber más acerca de nuestro estilo de aprendizaje!

Nombre del Docente 


\section{ASUNTO: E-actividad 4: Trabajar en grupo en línea}

Estimados estudiantes:

Las nuevas tecnologías nos facilitan el trabajo y la colaboración en red se manera asíncrona. Nuestro aprendizaje se puede incrementar de manera importante si logramos conformar verdaderos equipos.

Propósito: Investigar acerca de la mejor manera que un grupo puede trabajar en línea, compartiendo ideas y evaluándolas.

\section{Tarea:}

1. Investiguen de manera individual en Internet acerca de las recomendaciones y condiciones que permiten un adecuado trabajo de un grupo en línea.

2. Tus aportes debes dejarlos en la página de tu grupo formado durante la clase presencial. Chequea bien el grupo al cual perteneces. Usarán el "bloc de notas de Microsoft OneNote".

3. Cada participante publica las tres condiciones que considera más importantes para trabajar adecuadamente en línea en los comentarios de la E-actividad 4.

4. De común acuerdo, el grupo selecciona las cinco recomendaciones que estima son las más importante y por qué. Luego el secretario las publica colocando el título "Síntesis".

5. Roles del líder, el secretario:

El líder del grupo debe coordinar la forma de trabajo y asegurarse de que todos participen.

El secretario realiza la síntesis que será publicada y será presentada en la clase del día miércoles 12 de abril.

Responder: a los aportes de todos los integrantes del grupo para consensuar cuáles son las condiciones más importantes para trabajar en línea.

Esta actividad es de carácter obligatorio y deberá ser finalizada el día domingo 10 de abril a las 23:59 horas.

¡Les deseo un buen trabajo!

Nombre del Docente 


\section{ASUNTO: E-actividad 5: ¿A qué persona de tu propia disciplina te gustaría conocer?}

Estimados Profesionales en Formación:

En nuestras respectivas disciplinas o áreas profesionales tenemos personas que no conocemos y por alguna razón nos llaman la atención, nos han impactado y por tantos otros motivos, nos gustaría conocer.

Propósito: presentar una persona de tu disciplina que te gustaría conocer.

Tarea: nombra y entrega algunos antecedentes de una persona relacionada con tu disciplina o área profesional que te gustaría conocer.

Indica las razones por las cuales te gustaría conocerle.

Compartir: elige un personaje de tus compañeros de tu grupo, distinto al tuyo, que también te gustaría conocer.

Deja un comentario con las razones por las cuales te gustaría conocerle.

Esta actividad es de carácter obligatorio y deberá ser finalizada el día domingo 17 de abril a las 23:59 horas.

¡Adelante, aparecerán personas que son todos unos personajes!

Nombre del Docente 


\section{ASUNTO: E-actividad 6: Sitios web de mi especialidad}

Estimadas y estimados Estudiantes:

Un afectuoso saludo.

En internet existen millones de sitios, algunos buenos y otros malos, por ello a veces nos sucede que más que navegar, naufragamos por tanta información que existe. Realizaremos un trabajo colaborativo para identificar los sitios de mayor utilidad para la carrera que están estudiando.

Propósito: seleccionar sitios Web de mi especialidad

Tarea: Cada integrante del grupo

1. Elige dos sitios web distintos de utilidad para la carrera. Debe indicar la o las asignaturas para las cuales son útiles.

Para la evaluación de los sitios web completa la lista de chequeo disponible en: http://www.eduteka.org/pdfdir/ListaChequeo1.pdf

2. Publica los dos sitios con su respectiva evaluación, según la lista de chequeo. Te sugiero hacerlo en un documento en Word o Excel.

Compartir: Visita TODOS los sitios elegidos por los demás integrantes del grupo.

Entre todos los integrantes del grupo seleccionan los cinco más relevantes para la formación profesional en diferentes asignaturas.

El líder del grupo debe coordinar la forma de trabajo y asegurarse de que todos participen. El secretario realiza la síntesis que será publicada y presentada en la clase del miércoles 05 de mayo.

Esta actividad es de carácter obligatorio y tenemos hasta el domingo 10 de mayo a las 23:59 horas.

¡Bien, manos a la obra!

Revisen con calma los sitios, para que sean de icalidad!

Un abrazo

Profesor 


\section{ASUNTO: E-actividad 7: Sitios web para la asignatura de TCOE}

Estimados Profesionales en Formación:

La asignatura Técnicas de la Comunicación Oral y Escrita (TCOE) forma parte del currículum de formación profesional de tu carrera, porque una de las competencias que debe poseer un profesional es la efectiva comunicación oral y escrita.

Propósito: seleccionar sitios web útiles para la asignatura de TCOE.

Tarea: Cada integrante del grupo:

1. Selecciona tres sitios web distintos de utilidad para las competencias a desarrollar en la asignatura de TCOE. Les sugiero aquellos sitios que presenten, por ejemplo, modelos de documentos de uso frecuente en INACAP y en la empresa, a los que podrían recurrir a futuro, tanto para cumplir tareas académicas como profesionales; que aborden temas acerca de la comunicación asertiva; cómo realizar presentaciones orales; sugerencias para la redacción de informes, etc.

Les sugiero revisar el programa de la asignatura disponible en el Ambiente de Aprendizaje de la plataforma de INACAP.

Como referencia para la evaluación de fuentes electrónicas use la lista de chequeo http://www.eduteka.org/pdfdir/ListaChequeo1.pdf

Los sitios seleccionados deben cumplir con a lo menos tres de los aspectos que se señalan en la pauta antes indicada.

2. Publica los dos sitios con su respectiva evaluación (comentario de cada aspecto indicando en qué aspectos cumplen y en cuales no)

Tienes hasta el día jueves 19 de mayo para hacer tu aporte individual. A contar de ese día se descuenta un punto de la nota por día de atraso.

Responder: Visita los sitios elegidos por los demás integrantes del grupo.

Entre todos los integrantes del grupo seleccionan los tres más relevantes y de apoyo en la asignatura y a futuro.

OJO: Todas las participaciones o diálogos opinando acerca de los sitios, háganlos en el sitio de la asignatura.

El líder del grupo debe coordinar la forma de trabajo y asegurarse de que todos participen.

El secretario realiza la síntesis que será publicada.

Además será presentada en la clase del miércoles 25 de mavo.

Esta actividad es de carácter obligatorio y tenemos hasta el domingo 22 de mavo a las 23:59 horas.

¡Adelante, selecciona los sitios con calma, tu aporte será útil para todos los compañeros del curso para hoy y mañana!

Nombre del Docente 


\section{ASUNTO: E-actividad 8: Comunicación virtual}

Hola a todos:

Seguimos avanzando en esta experiencia de aprendizaje online. Este nuevo entorno de intercambio e interacción que posibilita la tecnología, se requiere tener en cuenta algunas normas básicas para la buena comunicación y el respeto a los demás.

Propósito: describir las sugerencias fundamentales para una adecuada comunicación virtual o en línea.

Tarea:

1. Lea los siguientes artículos:

- Normas de estilo en el correo electrónico: http://www.rediris.es/mail/estilo.html

- Netiqueta:

http://www.eumed.net/grumetes/netiquet.htm

- "Mírame a los ojos":

http://www.latercera.com/noticia/tendencias/sociedad/2011/01/741-336497-9-miramea-los-ojos.shtml

2. Sobre la base de la lectura de los tres artículos, responda:

¿Cuáles son las siete sugerencias fundamentales que daría para una comunicación virtual adecuada entre los compañeros del curso, con los Docentes y Directivos de INACAP?

La extensión máxima es de 200 palabras.

ATENCIÓN, tenemos nuevos líderes y secretarios.

El líder del grupo debe coordinar la forma de trabajo y asegurarse de que todos participen.

El secretario realiza la síntesis y la publica colocando el título a la "Síntesis". Además, será presentada en la clase del miércoles 1ㅇ de junio.

Responder: leer los aportes de todos los integrantes del grupo para consensuar cuáles son las siete sugerencias más importantes.

Esta actividad es de carácter obligatorio y tenemos hasta el domingo 29 de mayo a las 23:59 horas.

¡Buen trabajo virtual!

Profesor 


\section{ASUNTO: E-actividad 9: Selección de artículos \\ Estimados Profesionales en Formación: \\ Hemos realizado un interesante intercambio de ideas y hemos aprendido unos de otros, tanto en las actividades presenciales como en las virtuales. Corresponde realizar una mirada hacia atrás y hacia delante, como el dios Juno que tiene dos caras, para al mismo tiempo con una, aprender del pasado y con la otra, soñar el futuro.}

Propósito: seleccionar artículos relacionados con las competencias de un Profesional en Formación.

Tarea:

1. De manera individual, seleccionar tres artículos, disponibles en Internet, relacionados con el tema seleccionado por cada grupo en la clase presencial del día lunes 30 de mayo.

Los temas propuestos (confirma el tema de tu grupo):

- Comunicación asertiva.

- Tipos de comunicación no verbal.

- La disertación académica.

- La oratoria.

- Aprender a aprender, estrategias de estudio.

- Habilidades sociales y emocionales en la comunicación.

Características formales de los artículos:

- Extensión mínima de tres páginas.

- Que esté identificado el autor y quien lo publica (institución, revista, editorial, etc.).

- En formato PDF (Portable Document Format)

2. Publicar el listado de artículos seleccionados en el sitio de tu grupo. Para su publicación sigue el formato de referencia bibliográfica dado en el ejemplo siguiente:

VÁSQUEZ, M. (2007): Tutor virtual: desarrollo de competencias en la sociedad del conocimiento. Revista Electrónica Teoría de la Educación: Educación y Cultura en la Sociedad de la Información. Vol. 8, no2. Universidad de Salamanca. Documento en línea [Fecha de consulta: 21/11/2010] en http://www.usal.es/ teoriaeducacion/rev numero $08 \quad 02 / \mathrm{n} 8 \quad 02$ vazques.pdf

Responder: revisa los artículos seleccionados por los integrantes de tu grupo.

El líder del grupo debe coordinar la forma de trabajo y asegurarse de que todos participen. El secretario publica el listado completo de artículos seleccionados.

Esta actividad es de carácter obligatorio y tenemos hasta el domingo 05 de junio a las 23:59 horas.

Muy bien, a seleccionar artículos, cuida no quedarte con los tres primeros que encuentres. Como dice el dicho, quizás "los últimos serán los primeros".

Profesor 


\section{ASUNTO: E-actividad 10: Realizar subrayado estratégico de artículo}

Estimados Estudiantes:

Trabajaremos con uno de los artículos, puede ser uno que hayas seleccionado tú o el de algún compañero, lo importante es que cada uno elija un artículo diferente.

Propósito: realizar el subrayado estratégico de a lo menos tres páginas de un artículo.

\section{Tarea:}

1. Cada integrante del equipo selecciona y subraya un artículo diferente.

2. Subraye y destaque los conceptos clave, tanto principales como secundarios e inserta comentarios personales. Usa líneas, óvalos, recuadros, usa marcas personales al margen, inserta comentarios.

3. Recuerda que existe tres tipos de lectura:

1므 Lectura exploratoria: leemos todo el artículo para ver de qué se trata, es una lectura rápida, sin detenerse. Conviene fijarse en títulos y subtítulos, pistas que da el autor, dónde está las ideas principales, etc.

2a Lectura para ganar información: es lectura detenida en la que hacemos el subrayado y las anotaciones.

3a Lectura para estudiar: leemos sólo lo que hemos subrayado o las anotaciones.

4. Publica el artículo con el subrayado incluido respondiendo el correo de esta actividad. Para el nombre del documento usa la inicial de tu nombre y tu apellido en minúsculas (por ej. mvásquez).

IMPORTANTE: para realizar el subrayado estratégico, usa el software PDF X-Change Viewer, que permite subrayar y hacer anotaciones a documentos en PDF.

Puedes descargarlo en: http://pdf-xchange-viewer.softonic.com/descargar

Responder: revisa los artículos subrayados por los demás integrantes del equipo.

Esta actividad es de carácter obligatorio y tenemos hasta el domingo 12 de junio a las 23:59 horas.

El líder del grupo debe coordinar la forma de trabajo y asegurarse de que todos participen.

¡Adelante, buena lectura!

Profesor 


\section{ASUNTO: E-actividad 11: Mapa conceptual}

En las E-actividades 10 y 11 se seleccionó y leyó un artículo. Ahora realizaremos una síntesis visual mediante un modelo conceptual que integre todos los artículos del grupo en una sola visión integradora. Para ello usaremos el mapa conceptual.

Propósito: realizar mapa conceptual de los todos los artículos leídos en el grupo.

\section{Tarea:}

1. Organicen el trabajo para la realización del mapa conceptual digital.

2. Una sugerencia de trabajo es que cada uno realice su mapa conceptual y luego, por turno, van construyendo un mapa conceptual. Realizada esta etapa, en una sesión de estudio presencial pueden revisar y consensuar el mapa conceptual definitivo.

3. Se sugiere el uso del programa Cmap Tools: http://gratis.portalprogramas.com/CmapTools.html

Existen otros programas para la realización de mapas conceptuales, tales como:

- Mindomo

- Bubbl.us

- $\underline{\text { MindMeister }}$

Responder: a los aportes y sugerencias de todos los integrantes del equipo de trabajo.

Esta actividad es de carácter obligatorio y tenemos hasta el domingo 17 de junio a las 23:59 horas.

El líder del grupo debe coordinar la forma de trabajo y asegurarse de que todos participen. El secretario publica el mapa conceptual grupal.

¡Éxito! ¡Que les vaya muy bien organizando sus ideas!

\section{Nombre del Docente}




\section{ASUNTO: E-actividad 12: Competencias del profesional del futuro}

El filósofo y matemático Javier Echeverría señala que las nuevas tecnologías de las comunicaciones han credo un nuevo entorno, el Tercer Entorno, en el que las personas se reúnen, interactúan y colaboran.

Ese nuevo entorno ya llegó y por otro lado además nos estamos formando para un futuro que no sabemos cómo será en cuanto al uso de las tecnologías, por lo cual no se pueden enseñar tecnologías que aún no existen, pero sí podemos desarrollar las competencias para aprenderlas rápido.

Propósito: describir competencias del profesional del futuro

Tarea:

1. Definan las 10 competencias más importantes que debe tener el profesional del futuro.

2. Utilice para ello diferentes fuentes de información.

Responder: responda a los acuerdos establecidos para resolver esta tarea por parte del equipo.

El líder del grupo debe coordinar la forma de trabajo y asegurarse de que todos participen. El secretario realiza la síntesis del perfil acordado y lo publica en el sitio de la asignatura.

Esta actividad es de carácter obligatorio y tenemos hasta el domingo 19 de junio a las 23:59 horas.

¡Bien, bien, última e-actividad!

\section{Nombre del Docente}




\section{Apéndice $\mathrm{H}$ : Tablas prueba t por campus}

\begin{tabular}{ccccccccc} 
& \multicolumn{8}{c}{ ACTIVIDAD DE APRENDIZAJE } \\
\cline { 2 - 9 } & \multicolumn{2}{c}{ Campus 1 } & \multicolumn{2}{c}{ Campus 2 } & \multicolumn{2}{c}{ Campus 3 } & \multicolumn{2}{c}{ total } \\
\cline { 2 - 9 } & $\mathrm{t}$ & Valor $\mathrm{p}$ & $\mathrm{t}$ & Valor $-\mathrm{p}$ & $\mathrm{t}$ & Valor $-\mathrm{p}$ & $\mathrm{t}$ & Valor $-\mathrm{p}$ \\
\hline P20 & -1.155 & 0.253 & -1.025 & 0.308 & 3.374 & 0.001 & 1.337 & 0.001 \\
\hline P22 & -1.123 & 0.266 & 0.031 & 0.975 & 4.995 & 0.000 & 2.865 & 0.000 \\
\hline P23 & -0.435 & 0.666 & -0.823 & 0.413 & 5.006 & 0.000 & 2.635 & 0.000 \\
\hline P24 & 0.066 & 0.947 & -0.740 & 0.462 & 5.919 & 0.000 & 3.618 & 0.000 \\
\hline P25 & -0.267 & 0.790 & -0.549 & 0.585 & 6.990 & 0.000 & 4.180 & 0.000 \\
\hline P26 & -1.026 & 0.310 & -1.017 & 0.312 & 2.826 & 0.006 & 0.619 & 0.006 \\
\hline P27 & 0.061 & 0.951 & -0.989 & 0.326 & 2.503 & 0.015 & 1.165 & 0.015 \\
\hline P28 & -0.181 & 0.857 & 0.097 & 0.923 & 5.252 & 0.000 & 3.248 & 0.000 \\
\hline
\end{tabular}

HERRAMIENTAS DE APOYO

\begin{tabular}{ccccccccc} 
& \multicolumn{2}{c}{ Campus 1 } & \multicolumn{2}{c}{ Campus 2 } & \multicolumn{2}{c}{ Campus 3 } & \multicolumn{2}{c}{ total } \\
\cline { 2 - 9 } & $\mathrm{t}$ & Valor $\mathrm{p}$ & $\mathrm{t}$ & Valor $-\mathrm{p}$ & $\mathrm{t}$ & Valor $-\mathrm{p}$ & $\mathrm{t}$ & Valor $-\mathrm{p}$ \\
\hline P29 & 0.32 & 0.75 & -1.57 & 0.12 & 5.39 & 0.00 & 2.967 & 0.003 \\
\hline P30 & -1.02 & 0.31 & -0.67 & 0.51 & 5.33 & 0.00 & 2.604 & 0.010 \\
\hline P31 & 0.13 & 0.90 & 0.06 & 0.95 & 6.41 & 0.00 & 4.566 & 0.000 \\
\hline P32 & -1.39 & 0.17 & -1.61 & 0.11 & 2.45 & 0.02 & 0.437 & 0.663 \\
\hline P33 & -0.76 & 0.45 & -1.67 & 0.10 & 5.96 & 0.00 & 2.918 & 0.004 \\
\hline P34 & -2.10 & 0.04 & -0.67 & 0.50 & 4.61 & 0.00 & 2.108 & 0.036 \\
\hline P35 & -1.24 & 0.22 & -0.73 & 0.47 & 2.92 & 0.00 & 1.245 & 0.214 \\
\hline P36 & -0.87 & 0.39 & -1.08 & 0.29 & 3.15 & 0.00 & 1.285 & 0.200 \\
\hline P37 & -0.55 & 0.59 & -0.49 & 0.62 & 4.40 & 0.00 & 2.649 & 0.009 \\
\hline P38 & -0.50 & 0.62 & -1.94 & 0.06 & 2.68 & 0.01 & 0.886 & 0.377 \\
\hline P39 & 0.33 & 0.75 & -2.04 & 0.04 & 2.89 & 0.01 & 0.955 & 0.341 \\
\hline P65 & -2.02 & 0.05 & -0.41 & 0.69 & 2.04 & 0.05 & 0.722 & 0.471 \\
\hline
\end{tabular}

COMUNDAD DE APRENDIZAJE

\begin{tabular}{ccccccccc} 
& \multicolumn{2}{c}{ Campus 1 } & \multicolumn{2}{c}{ Campus 2 } & \multicolumn{2}{c}{ Campus 3 } & \multicolumn{2}{c}{ total } \\
\cline { 2 - 9 } & $\mathrm{t}$ & Valor $-\mathrm{p}$ & $\mathrm{t}$ & Valor $-\mathrm{p}$ & $\mathrm{t}$ & Valor $-\mathrm{p}$ & $\mathrm{t}$ & Valor $-\mathrm{p}$ \\
\hline P41 & -0.42 & 0.68 & -1.25 & 0.21 & 5.05 & 0.00 & 2.764 & 0.006 \\
\hline P43 & -1.08 & 0.29 & -1.05 & 0.30 & 4.52 & 0.00 & 2.272 & 0.024 \\
\hline P44 & -0.42 & 0.68 & -0.58 & 0.56 & 3.75 & 0.00 & 2.505 & 0.013 \\
\hline P45 & 0.75 & 0.46 & -0.94 & 0.35 & 2.76 & 0.01 & 1.417 & 0.158 \\
\hline
\end{tabular}


NORMAS Y REGLAMENTOS

\begin{tabular}{ccccccccc} 
& \multicolumn{2}{c}{ Campus 1 } & \multicolumn{2}{c}{ Campus 2 } & \multicolumn{2}{c}{ Campus 3 } & \multicolumn{2}{c}{ total } \\
\cline { 2 - 9 } & $\mathrm{t}$ & Valor $-\mathrm{p}$ & $\mathrm{t}$ & Valor $-\mathrm{p}$ & $\mathrm{t}$ & Valor $-\mathrm{p}$ & $\mathrm{t}$ & Valor $-\mathrm{p}$ \\
\hline P46 & -2.19 & 0.03 & -0.99 & 0.33 & 6.52 & 0.00 & 3.233 & 0.001 \\
\hline P48 & -0.07 & 0.94 & 0.98 & 0.33 & 3.97 & 0.00 & 3.402 & 0.001 \\
\hline
\end{tabular}

DIVISION DEL TRABAJO

\begin{tabular}{ccccccccc} 
& \multicolumn{2}{c}{ Campus 1 } & \multicolumn{2}{c}{ Campus 2 } & \multicolumn{2}{c}{ Campus 3 } & \multicolumn{2}{c}{ total } \\
\cline { 2 - 9 } & $\mathrm{t}$ & Valor $-\mathrm{p}$ & $\mathrm{t}$ & Valor $-\mathrm{p}$ & $\mathrm{t}$ & Valor $-\mathrm{p}$ & $\mathrm{t}$ & Valor $-\mathrm{p}$ \\
\hline P47 & -0.15 & 0.88 & -1.36 & 0.18 & 7.18 & 0.00 & 3.948 & 0.000 \\
\hline P50 & -0.66 & 0.51 & 0.21 & 0.84 & 5.67 & 0.00 & 4.065 & 0.000 \\
\hline
\end{tabular}

COMPETENCIAS INSTRUMENTALES

\begin{tabular}{ccccccccc} 
& \multicolumn{2}{c}{ Campus 1 } & \multicolumn{2}{c}{ Campus 2 } & \multicolumn{2}{c}{ Campus 3 } & \multicolumn{2}{c}{ total } \\
\cline { 2 - 9 } & $\mathrm{t}$ & Valor $-\mathrm{p}$ & $\mathrm{t}$ & Valor $-\mathrm{p}$ & $\mathrm{t}$ & Valor $-\mathrm{p}$ & $\mathrm{t}$ & Valor $-\mathrm{p}$ \\
\hline P51 & -0.51 & 0.61 & -1.17 & 0.24 & 5.90 & 0.00 & 3.343 & 0.001 \\
\hline P52 & -2.11 & 0.04 & -1.71 & 0.09 & 6.37 & 0.00 & 2.605 & 0.010 \\
\hline P53 & 0.95 & 0.35 & -0.38 & 0.71 & 3.42 & 0.00 & 2.431 & 0.016 \\
\hline P57 & -1.14 & 0.26 & 0.26 & 0.79 & 5.10 & 0.00 & 3.213 & 0.002 \\
\hline
\end{tabular}

COMPETENCIAS TECONOLOGICAS

\begin{tabular}{ccccccccc} 
& \multicolumn{2}{c}{ Campus 1 } & \multicolumn{2}{c}{ Campus 2 } & \multicolumn{2}{c}{ Campus 3 } & \multicolumn{2}{c}{ total } \\
\cline { 2 - 9 } & $\mathrm{t}$ & Valor $-\mathrm{p}$ & $\mathrm{t}$ & Valor $-\mathrm{p}$ & $\mathrm{t}$ & Valor $-\mathrm{p}$ & $\mathrm{t}$ & Valor $-\mathrm{p}$ \\
\hline $\mathrm{P} 63$ & -0.65 & 0.52 & 0.99 & 0.33 & 3.55 & 0.00 & 2.926 & 0.004 \\
\hline P64 & -2.22 & 0.03 & -0.70 & 0.49 & 4.33 & 0.00 & 2.063 & 0.040 \\
\hline
\end{tabular}

COMPETENCIAS INTERPERSONALES

\begin{tabular}{ccccccccc} 
& \multicolumn{2}{c}{ Campus 1 } & \multicolumn{2}{c}{ Campus 2 } & \multicolumn{2}{c}{ Campus 3 } & \multicolumn{2}{c}{ total } \\
\cline { 2 - 9 } & $\mathrm{t}$ & Valor $-\mathrm{p}$ & $\mathrm{t}$ & Valor $-\mathrm{p}$ & $\mathrm{t}$ & Valor $-\mathrm{p}$ & $\mathrm{t}$ & Valor - $\mathrm{p}$ \\
\hline P42 & -0.92 & 0.36 & 1.04 & 0.30 & 4.99 & 0.00 & 1.574 & 0.117 \\
\hline P60 & -1.50 & 0.14 & -1.98 & 0.05 & 2.56 & 0.01 & 2.184 & 0.030 \\
\hline P40 & -0.54 & 0.59 & -0.58 & 0.56 & 5.45 & 0.00 & 1.583 & 0.115 \\
\hline P59 & -0.73 & 0.47 & -0.28 & 0.78 & 5.03 & 0.00 & 1.410 & 0.160 \\
\hline P49 & -0.53 & 0.60 & -0.46 & 0.65 & 3.01 & 0.00 & 3.061 & 0.002 \\
\hline P56 & -1.32 & 0.19 & -0.91 & 0.37 & 2.31 & 0.02 & 3.012 & 0.003 \\
\hline
\end{tabular}

